\title{
Quinoline-triazole half-sandwich iridium(III) complexes: Synthesis, antiplasmodial activity and preliminary transfer hydrogenation studies
}

Diana Melis

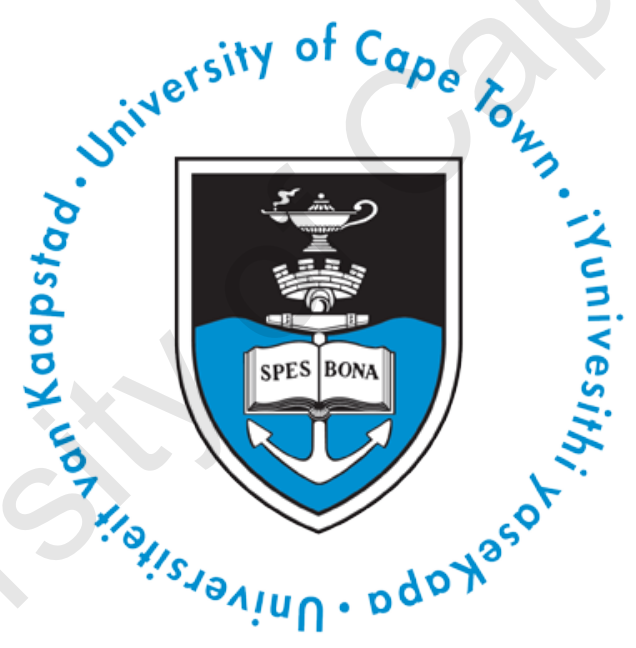

Department of Chemistry University of Cape Town

December 2019 
The copyright of this thesis vests in the author. No quotation from it or information derived from it is to be published without full acknowledgement of the source. The thesis is to be used for private study or noncommercial research purposes only.

Published by the University of Cape Town (UCT) in terms of the non-exclusive license granted to UCT by the author. 


\section{Quinoline-triazole half-sandwich iridium(III) complexes: Synthesis, antiplasmodial activity and preliminary transfer hydrogenation studies}

A dissertation submitted to the University of Cape Town in fulfilment of the requirements for the degree of Master of Science

by

Diana Melis

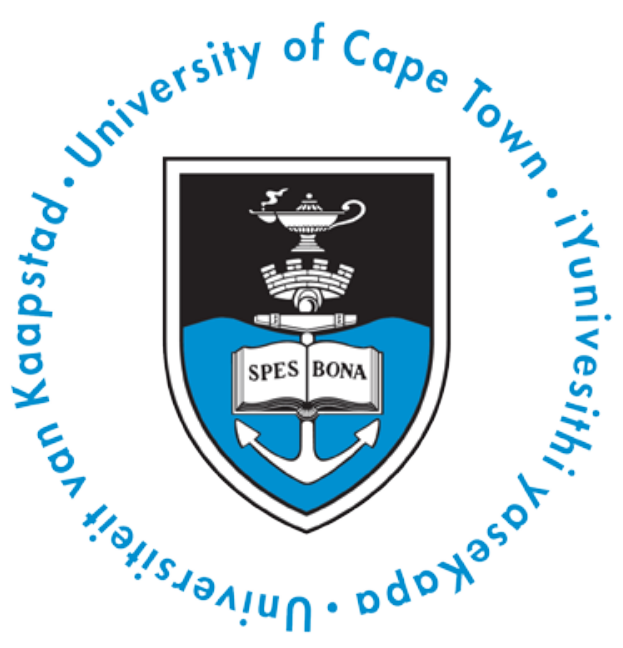

Supervisor: Associate Professor Gregory S. Smith

Department of Chemistry

University of Cape Town

Rondebosch, 7701

Cape Town

December 2019 


\section{Plagiarism Declaration}

I know the meaning of plagiarism and declare that all of the work in the document, "Quinoline-triazole half-sandwich iridium(III) complexes: Synthesis, antiplasmodial activity and preliminary transfer hydrogenation studies", is my own work and to the best of my knowledge has never been submitted for examination for any degree at any university. All sources of information are cited and fully referenced at the end of each chapter.

\footnotetext{
SIGNATURE: Signed by candidate

DATE: 5 December 2019

Diana Melis
} 


\section{Acknowledgements}

Above all, I would like to thank God for the grace and blessings He has bestowed upon me to carry out this research and complete this dissertation.

Secondly, I would like to express the deepest appreciation to my supervisor, Assoc. Prof. Gregory S. Smith, for his expertise, invaluable guidance and continued support throughout my master's degree. Thank you for all the advice, encouragement and opportunities you have given me, which have moulded me into the researcher I am today.

A special thanks also goes to the members of the Organometallic Research Group (Nadia, Nikechukwu, Shepherd, Fatima, Athi, Stephen, Taryn and Nozuko) as well as to Dr Siyabonga Ngubane, and his research students (Thato and Sinethemba). Thank you for all the support, fun, laughter and friendship both inside and outside the lab. These thanks are also extended to Dr Jill Combrinck, Mrs Sumaya Salie, Mr Virgil Verhoog and Ms Zoey Hsiao from the Department of Clinical Pharmacology for their help and guidance in the tissue culture lab. A huge thank you goes to Ms Zoey Hsiao in particular for conducting the cytotoxicity screenings and the speed-of-action assays.

I would like to acknowledge Mr Pete Roberts and Mr Marwaan Rylands for recording some of the NMR spectra and Dr Hong Su for the single-crystal X-ray diffraction studies. Further thanks are extended to Dr Chris Barnett for running the computational analyses and Dr Marietjie Stander (University of Stellenbosch) for the mass spectral analyses. Furthermore, I would like to convey my gratitude to Dr Tameryn Stringer for her guidance and friendship over the years and for proof-reading this dissertation.

Financial support was provided by the Harry Crossley Research Foundation and for this, I am truly grateful.

Finally, thank you to all my family and friends who have supported and encouraged me throughout my studies, especially my mom, dad and sister. Thank you for providing for me and for being behind me every step of the way. I also thank Mr Jason Wicks for his continued love and encouragement throughout my studies and Ms Caterina Reigl and Ms Lara Mather for being there for me whenever I needed them.

\section{Thank you all!}




\section{Conference/Symposia Contributions}

\section{June 2019 - Oral Presentation:}

Antiplasmodial activity of cyclometallated iridium(III) complexes and their potential for intracellular transfer hydrogenation.

Cape Organometallic Symposium, University of Cape Town, South Africa.

\section{July 2019 - Oral Presentation:}

Antiplasmodial activity of cyclometallated iridium(III) complexes and their potential for intracellular transfer hydrogenation.

$9^{\text {th }}$ International Symposium on Bioorganometallic Chemistry (ISBOMC), University of York, United Kingdom.

\section{September 2019 - Poster Presentation:}

Antiplasmodial activity of cyclometallated iridium(III) complexes and their potential for intracellular transfer hydrogenation.

$12^{\text {th }}$ Annual Science Postgraduate Symposium, University of Stellenbosch, South Africa.

\section{November 2019 - Poster Presentation:}

Antiplasmodial activity of cyclometallated iridium(III) complexes and their potential for intracellular transfer hydrogenation.

$1^{\text {st }}$ International Workshop on Metals in Medicine, Chimie ParisTech, PSL University, France. 


\section{Publications}

\section{Journal articles:}

- Trinuclear Ni(II), Pd(II) and Cu(II) complexes containing the 2-hydroxy-benzaldehydeferrocenyl-sulfonylhydrazone ligand: Synthesis, structural characterization and antiplasmodial evaluation.

I. Almendras, Y. Huentupil, N. Novoa, P. Roussel, D. R. Melis, G. S. Smith and R. Arancibia, Inorg. Chim. Acta, 2019, 496, 119050.

(Contribution: Ran antiplasmodial assays on the ligand and metal complexes)

- N,O-Chelating quinoline-based half-sandwich organorhodium and -iridium complexes: synthesis, antiplasmodial activity and preliminary evaluation as transfer hydrogenation catalysts for the reduction of $N A D^{+}$.

T. Stringer, D. R. Melis, and G. S. Smith, Dalton Trans., 2019, 48, 13143-13148.

(Contribution: Synthesised some of the compounds and recorded ${ }^{1} H$ NMR spectra for the transfer hydrogenation study) 


\begin{abstract}
Malaria is a devastating and pervasive infectious disease and continues to be a major global health issue, with over half the world's population being at risk of transmission. In the absence of a suitable vaccine, efforts to eradicate the disease rely heavily on clinically available drugs. Plasmodium falciparum, the deadliest species of malaria, has however become resistant to most conventional antimalarial treatments, resulting in the worldwide search for new, effective drugs. Amongst other requirements, these drugs should target resistant parasitic strains in an attempt to curb the escalation of the disease. In this regard, the incorporation of a metal into the organic framework of a biologically active compound has become an increasingly popular method of enhancing antiplasmodial activity in the drug-resistant parasite strains.

Two series of 7-chloroquinoline-1,2,3-triazole ligands, one with the direct attachment of the triazole to the quinoline and one where the two entities are separated by an aminopropyl linker, were synthesised. Coordination of selected ligands with $[\operatorname{IrCl}(\mu-\mathrm{Cl})(\mathrm{Cp} *)]_{2}$ yielded six neutral, cyclometallated and two cationic, $\mathrm{N}, \mathrm{N}$-chelated iridium complexes. Computational analysis revealed that metal coordination to the quinoline nitrogen occurs first, forming an unstable kinetic product that, upon heating over time, forms the stable, cyclometallated, thermodynamic product. All of the compounds were fully characterised using an array of spectroscopic $\left({ }^{1} \mathrm{H},{ }^{13} \mathrm{C}\left\{{ }^{1} \mathrm{H}\right\},{ }^{19} \mathrm{~F}\left\{{ }^{1} \mathrm{H}\right\},{ }^{31} \mathrm{P}\left\{{ }^{1} \mathrm{H}\right\}\right.$ NMR and FT-IR spectroscopy) and analytical (mass spectrometry and melting point analysis) techniques. Single crystal X-ray diffraction confirmed the proposed molecular structure and a pseudo-tetrahedral geometry around the metal centre for the cyclometallated and monodentate, quinoline nitrogen-coordinated complexes.
\end{abstract}

The ligand series containing the propyl chain linker displayed superior in vitro antiplasmodial activity against the chloroquine-sensitive NF54 strain of $P$. falciparum in comparison with the series having the triazole directly attached to the quinoline moiety. Upon complexation with iridium, the activity of selected ligands is significantly enhanced $\left(0.247<\mathrm{IC} \mathrm{C}_{50}(\mu \mathrm{M})<2.34\right)$, with some complexes being over one hundred times more active than their respective ligands. For most of these compounds, their antiplasmodial activity is lower in the chloroquineresistant K1 strain, however, their calculated RI values suggest that they likely only experience 
mild cross-resistance, not to the same extent of chloroquine. Selected complexes were tested against the healthy, mammalian Chinese Hamster Ovarian ( $\mathrm{CHO}$ ) cell line and were found not to be cytotoxic. They were also determined to be more selective towards the parasite than healthy cells. An "IC 50 speed assay" using the three most active complexes against the chloroquine-sensitive NF54 strain found the two neutral, cyclometallated complexes to be fast-acting compounds which reach their lowest I $C_{50}$ values within 24 hours, while the active cationic complex was determined to be slow-acting, only reaching its lowest $\mathrm{IC}_{50}$ value after 48 hours.

To gain insight into the possible mechanisms of action of these compounds, selected ligands and complexes were tested for their ability to inhibit the formation $\beta$-haematin (the synthetic form of haemozoin), since one of the mechanisms of 7-chloroquinoline-containing compounds is the inhibition of haemozoin formation. All five of the tested compounds were found to inhibit $\beta$-haematin formation to some extent but were, in general, less effective $\beta$-haematin inhibitors than chloroquine itself. Interestingly, the aminopropyl-containing cationic complex which displayed the lowest antiplasmodial activity exhibited far greater $\beta$-haematin inhibitory activity (IC $509.65 \mu \mathrm{M})$ than chloroquine (IC $5065.3 \mu \mathrm{M})$.

Finally, three of the most active complexes were evaluated for their ability to facilitate transfer hydrogenation, by reducing $\beta$-nicotinamide adenine dinucleotide $\left(\mathrm{NAD}^{+}\right)$to $\mathrm{NADH}$ in the presence of hydrogen source, sodium formate. Through preliminary qualitative and quantitative cell-free experiments, it was found that the two most active neutral, cyclometallated complexes tested may be capable of acting as transfer hydrogenation catalysts while the active, cationic complex tested did not indicate reduction of NAD ${ }^{+}$to NADH over 4 hours. 


\section{List of Abbreviations}

ACN

ACT

$A_{N}$

Ar

ART

br

$\mathrm{CDCl}_{3}$

$\mathrm{CHO}$

$\mathrm{Cp}$

Cp*

CQ

CQDP

CQR

CQS

CUAAC

d

dec.

dd

ddd

dt

DCM

DMF

DMSO

DMSO-d 6

$\mathrm{D}_{2} \mathrm{O}$

E

ESI

Et

$\mathrm{Et}_{3} \mathrm{~N}$

EtOAc

EtOH

Eq.

FQ
Acetonitrile

Artemisinin-based combination therapy

Nucleophilic addition

Aromatic

Artemisinin

Broad

Deuterated chloroform

Chinese Hamster Ovarian

Cyclopentadienyl

1,2,3,4,5-Pentamethylcylopentadienyl

Chloroquine

Chloroquine diphosphate

Chloroquine-resistant

Chloroquine-sensitive

Copper(I)-catalysed azide-alkyne cycloaddition

Doublet

Decomposed

Doublet of doublets

Doublet of doublet of doublets

Doublet of triplets

Dichloromethane

Dimethylformamide

Dimethyl sulfoxide

Deuterated DMSO

Deuterated water

Elimination

Electrospray ionisation

Ethyl

Triethylamine

Ethyl acetate

Ethanol

Equivalent(s)

Ferroquine 


\begin{tabular}{|c|c|}
\hline h & Hour(s) \\
\hline $\mathrm{Hb}$ & Haemoglobin \\
\hline HSQC & Heteronuclear single quantum coherence \\
\hline $\mathrm{Hz}$ & Hertz \\
\hline$\left\{{ }^{1} \mathrm{H}\right\}$ & Proton decoupled \\
\hline $\mathrm{IC}_{50}$ & $50 \%$ Inhibition concentration \\
\hline IR & Infrared \\
\hline $\boldsymbol{J}$ & Coupling constant \\
\hline LC & Liquid chromatography \\
\hline lit. & Literature value \\
\hline m & Multiplet (NMR) \\
\hline Me & Methyl \\
\hline $\mathrm{MeOH}$ & Methanol \\
\hline MeOD & Deuterated methanol \\
\hline $\min$ & Minute(s) \\
\hline m.p. & Melting point \\
\hline MS & Mass spectrometry \\
\hline $\mathrm{MsCl}$ & Methanesulfonyl chloride \\
\hline $\mathrm{m} / \mathrm{z}$ & Mass to charge ratio (MS) \\
\hline NAD $^{+}$ & $\beta$-nicotinamide adenine dinucleotide \\
\hline NADH & Reduced form of $\mathrm{NAD}^{+}$ \\
\hline NBT & Nitroblue tetrazolium \\
\hline NMR & Nuclear magnetic resonance \\
\hline NP-40 & Nonidet P-40 \\
\hline $\mathbf{p}$ & Pentet \\
\hline PES & Phenazine ethosulphate \\
\hline PfCRT & P. falciparum chloroquine resistance transporter \\
\hline pLDH & Parasite lactate dehydrogenase \\
\hline PT & Proton transfer \\
\hline ppm & Parts per million \\
\hline $\mathbf{q}$ & Quartet \\
\hline RBC & Red blood cell \\
\hline RI & Resistance Index \\
\hline
\end{tabular}


ROS

r.t.

S

SE

Sept.

SI

$\mathrm{S}_{\mathrm{NAr}}$

$\mathrm{S}_{\mathrm{N}} 2$

t

$t$-BuOH

td

TEA

THF

TLC

$t_{R}$

XRD

$\delta$

v
Reactive oxygen species

Room temperature

Singlet (NMR)

Standard error

Septet

Selectivity index

Nucleophilic aromatic substitution

Nucleophilic substitution

Triplet

Tert-butanol

Triplet of doublets

Triethylamine

Tetrahydrofuran

Thin layer chromatography

Retention time

X-ray diffraction

Chemical shift

Wavenumber 


\section{Table of Contents}

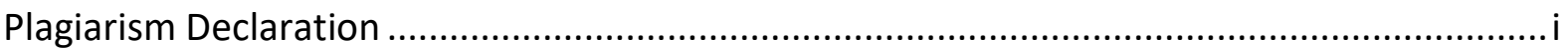

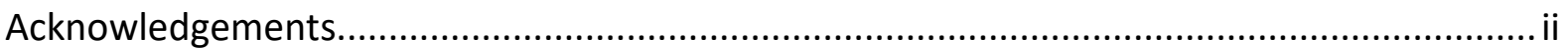

Conference/Symposia Contributions...................................................................................

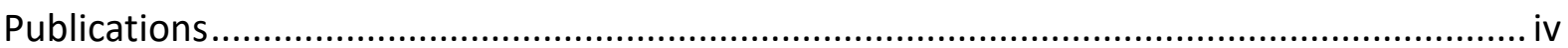

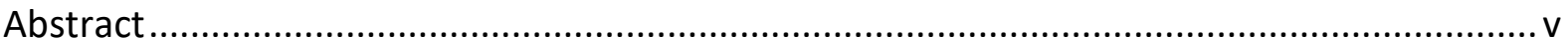

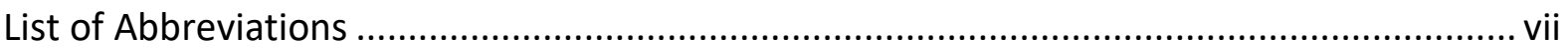

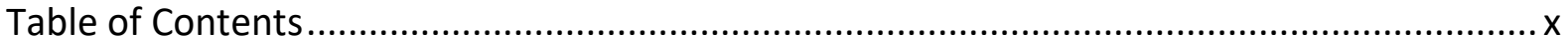

Chapter 1: Introduction and Literature Review................................................... 1

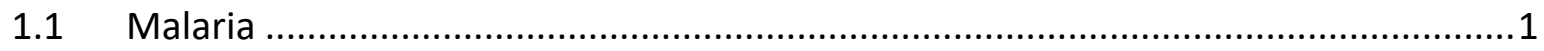

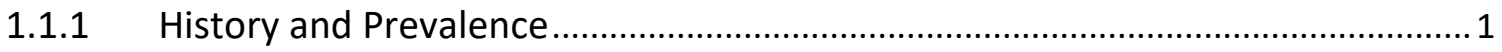

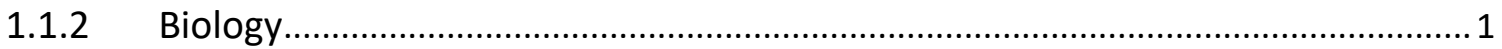

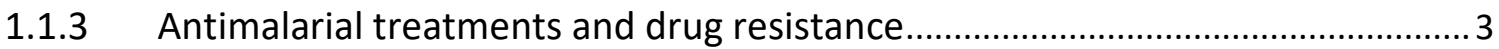

1.1.4 Chloroquine and non-chloroquine-based drugs ............................................. 4

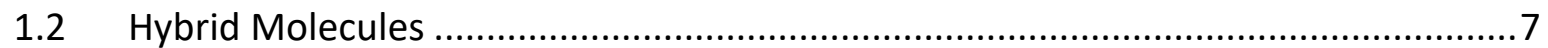

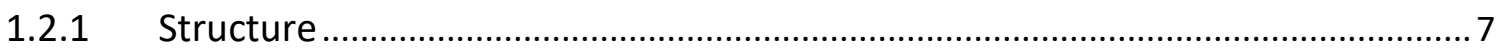

1.2.2 Aminoquinoline-triazole hybrids and their antiparasitic activity ........................ 8

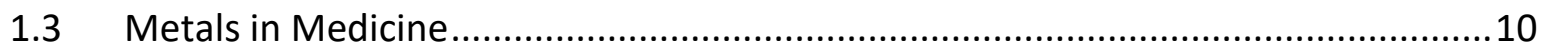

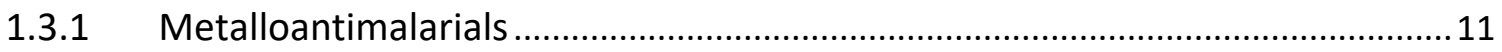

1.3.1.1 Rhodium, ruthenium and iridium complexes of CQ ............................12

1.3.1.2 Ferroquine - a potent ferrocene-CQ complex ....................................13

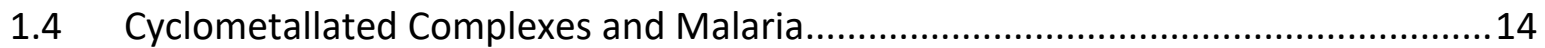

1.5 Transfer Hydrogenation Catalysis in Living Systems .........................................16

1.6 Summary and Motivation for the Current Study ..............................................19 


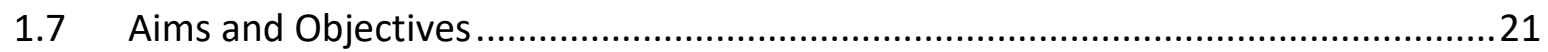

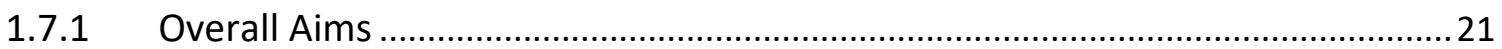

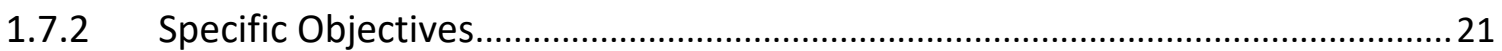

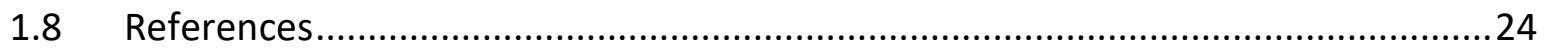

Chapter 2: Synthesis and characterisation of 7-chloroquinoline-1,2,3-triazole

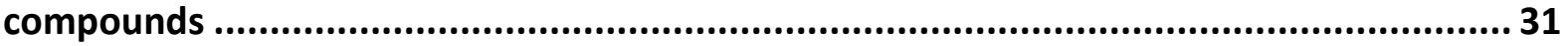

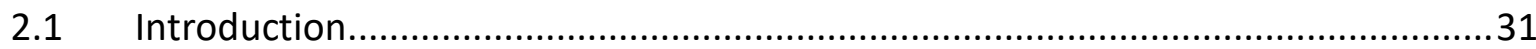

2.2 Synthesis of a series of 7-chloroquinolinotriazole derivatives ..............................34

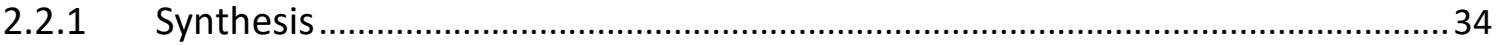

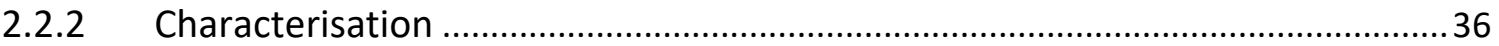

2.3 Synthesis of a series of 7-chloro-4-aminoquinolinotriazole derivatives.................42

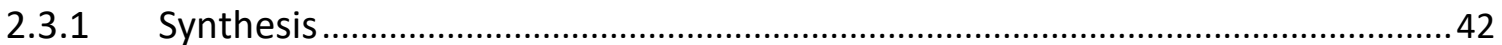

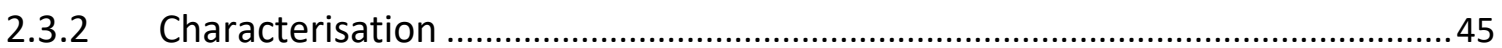

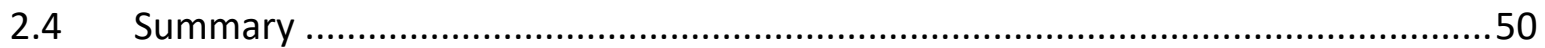

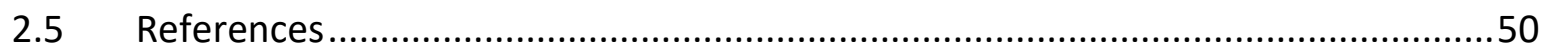

Chapter 3: Synthesis and characterisation of neutral cyclometallated and cationic $N$, $N$-chelated $\operatorname{Ir}(I I I)$ half-sandwich complexes based on 7-chloroquinoline-1,2,3-triazole

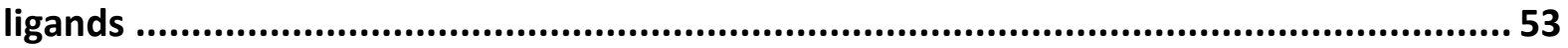

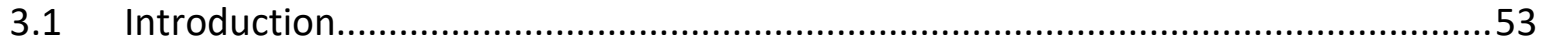

3.2 Synthesis and characterisation of half-sandwich $\operatorname{Ir}(I I I)$ complexes based on the series

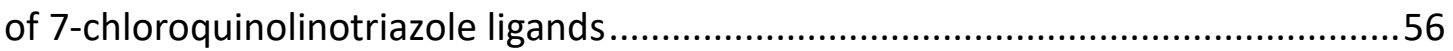

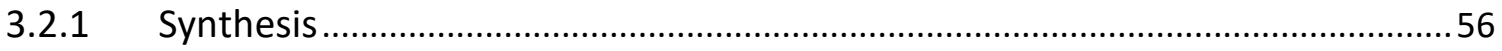

3.2.1.1 Synthesis of the neutral 7-chloroquinolinotriazole $\operatorname{Ir}($ III) complexes ...........56

3.2.1.2 Computational studies of the kinetic vs thermodynamic outcome of the $\mathrm{C}-\mathrm{H}$ activation reaction with ligand $2 \mathrm{a}$ 60 
3.2.1.3 Synthesis of the cationic 7-chloroquinolinotriazole $\operatorname{Ir}(\mathrm{III})$ complex .64

3.2.2 Characterisation .64

3.2.2.1 Characterisation of the neutral 7-chloroquinolinotriazole $\operatorname{Ir}(I I I)$ complexes....65

3.2.2.2 Characterisation of the cationic 7-chloroquinolinotriazole $\operatorname{Ir}(\mathrm{III})$ complex ......71

3.3 Synthesis and characterisation of half-sandwich $\operatorname{Ir}($ III) complexes based on the series of 7-chloro-4-aminoquinolinotriazole ligands .74

3.3.1 Synthesis .74

3.3.1.1 Attempted synthesis of the neutral 7-chloro-4-aminoquinolinotriazole Ir(III) complexes .74

3.3.1.2 Synthesis of the cationic 7-chloro-4-aminoquinolinotriazole $\operatorname{Ir}($ III) complex...77

3.3.2 Characterisation .78

3.3.2.1 Characterisation of the cationic 7-chloro-4-aminoquinolinotriazole Ir(III) complex .78

3.4 Summary .80

3.5 References .81

Chapter 4: Biological evaluation of the 7-chloroquinoline-1,2,3-triazole ligands and their respective Ir(III) half-sandwich complexes including preliminary transfer hydrogenation catalytic studies. 84

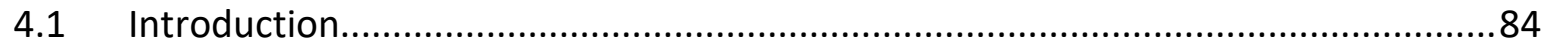

4.2 In vitro antiplasmodial evaluation against $P$. falciparum strains ...........................86

4.2.1. Antiplasmodial evaluation against the chloroquine-sensitive (CQS) NF54 strain.

4.2.2. Antiplasmodial evaluation against the chloroquine-resistant (CQR) K1 strain .91

4.3 In vitro cytotoxicity studies .92

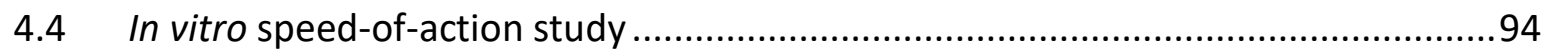

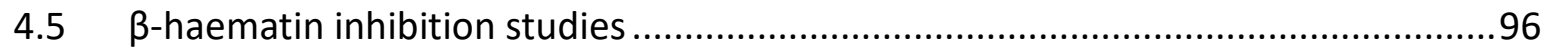


4.6.1. Qualitative ${ }^{1} \mathrm{H}$ NMR spectroscopic studies for the conversion of NAD ${ }^{+}$to NADH by complexes $7 \mathrm{a}$ and $7 \mathrm{~g}$

4.6.2. Cell-free assay to detect the conversion of $\mathrm{NAD}^{+}$to NADH by complexes 7a and $7 e$ 103

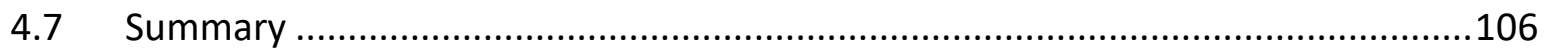

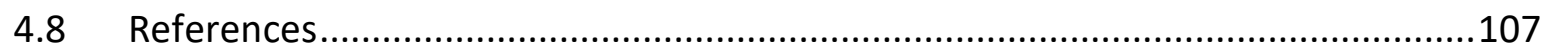

Chapter 5: Conclusions and future outlook...................................................... 110

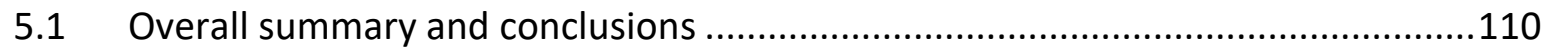

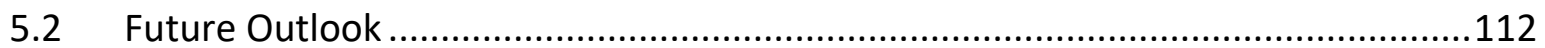

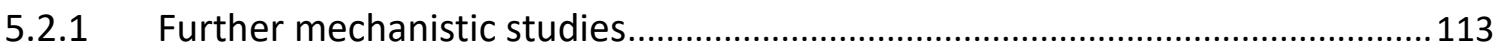

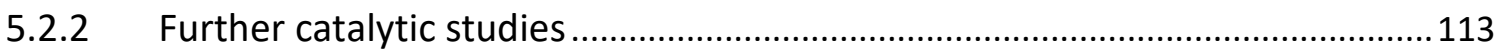

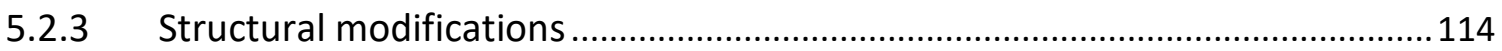

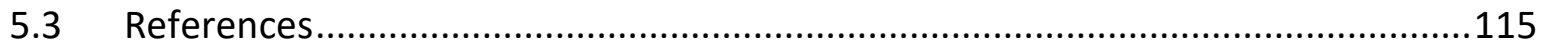

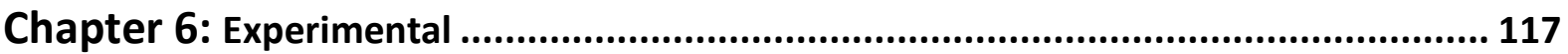

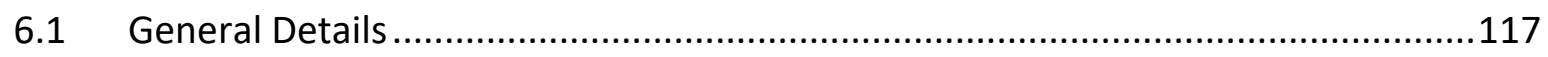

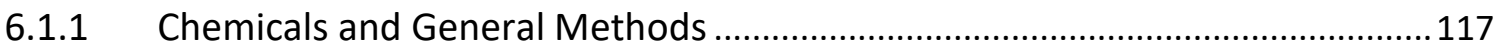

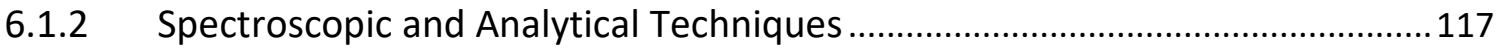

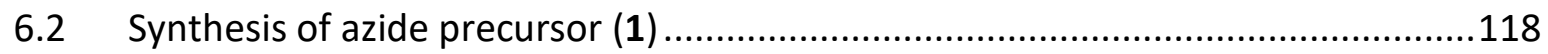

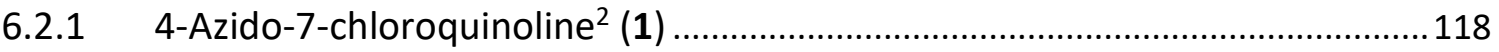

6.3 Synthesis of 7-chloro-4-(1H-1,2,3-triazol-1-yl)quinoline ligands (2a-2h) ..........119

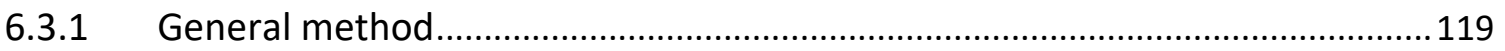

6.3.2 7-Chloro-4-(4-phenyl-1H-1,2,3-triazol-1-yl)quinoline ${ }^{3}$ (2a) ................................119

6.3.3 7-Chloro-4-(4-p-tolyl-1H-1,2,3-triazol-1-yl)quinoline ${ }^{3}$ (2b) .............................120 
6.3.4 7-Chloro-4-(4-(4-propylphenyl)-1H-1,2,3-triazol-1-yl)quinoline (2c)

6.3.5 7-Chloro-4-(4-(4-(trifluoromethyl)phenyl)-1H-1,2,3-triazol-1-yl)quinoline (2d) ...

6.3.6 7-Chloro-4-(4-(4-fluorophenyl)-1H-1,2,3-triazol-1-yl)quinoline ${ }^{3}$ (2e). 123

6.3.7 7-Chloro-4-(4-(naphthalen-2-yl)-1H-1,2,3-triazol-1-yl)quinoline (2f) . 124

6.3.8 7-Chloro-4-(4-(pyridin-2-yl)-1H-1,2,3-triazol-1-yl)quinoline (2g) 125

6.3.9 7-Chloro-4-(4-(ferrocenyl)-1H-1,2,3-triazol-1-yl)quinoline (2h) 126

6.4 Synthesis of 7-chloro-4-aminoquinoline precursors (3-5) 126

6.4.1 3-((7-Chloroquinolin-4-yl)amino)propan-1-ol ${ }^{4}$ (3) 126

6.4.2 3-((7-Chloroquinolin-4-yl)amino)propyl methanesulfonate ${ }^{4}$ (4) 127

6.4.3 N-(3-Azidopropyl)-7-chloroquinolin-4-amine ${ }^{4}(5)$ 128

6.5 Synthesis of 7-chloro- $N$-(3-(1H-1,2,3-triazol-1-yl)propyl)quinolin-4-amine ligands $(6 a-6 e)$ 129

6.5.1 General method 129

6.5.2 7-Chloro- $N$-(3-(4-phenyl-1H-1,2,3-triazol-1-yl)propyl)quinolin-4-amine ${ }^{5}$ (6a).....

6.5.3 7-Chloro-N-(3-(4-(p-tolyl)-1H-1,2,3-triazol-1-yl)propyl)quinolin-4-amine (6b) ..... 130

6.5.4 7-Chloro-N-(3-(4-(4-fluorophenyl)-1H-1,2,3-triazol-1-yl)propyl)quinolin-4amine $(6 c)$

6.5.5 7-Chloro-N-(3-(4-(pyridin-2-yl)-1H-1,2,3-triazol-1-yl)propyl)quinolin-4-amine (6d) 131

6.5.6 7-Chloro-N-(3-(4-(ferrocenyl)-1H-1,2,3-triazol-1-yl)propyl)quinolin-4-amine (6e) 132

6.6 Synthesis of cyclometallated Ir(III) half-sandwich complexes (7a-7f) 133

6.6.1 General method

6.6.2 Ir(III) triazole-phenyl complex (7a) 133 


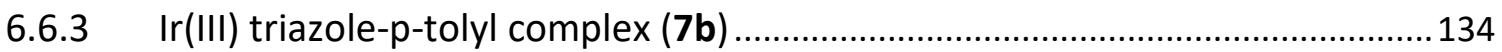

6.6.4 Ir(III) triazole-propylphenyl complex (7c) .................................................. 135

6.6.5 Ir(III) triazole-4-(trifluoromethyl)phenyl complex (7d) ....................................136

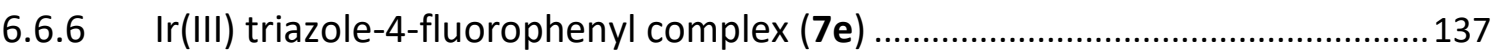

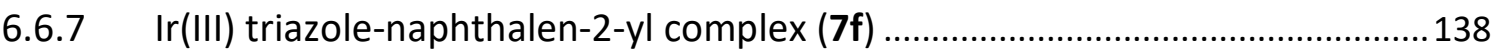

6.7 Synthesis of neutral monodentate $\operatorname{Ir}($ III) half-sandwich complex (8) ....................139

6.7.1 Ir(III) monodentate triazole-phenyl complex (8) ..............................................139

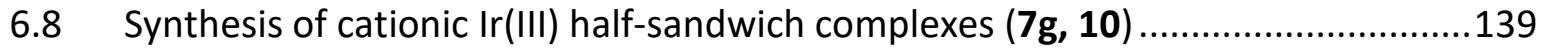

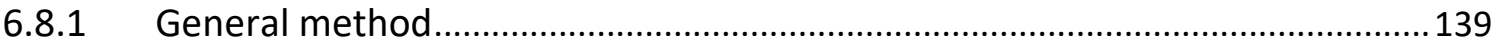

6.8.2 $\operatorname{Ir}(\mathrm{III}) \mathrm{N}, \mathrm{N}$-chelated 7-chloroquinoline-triazole complex $(\mathbf{7 g}) \ldots \ldots \ldots \ldots \ldots \ldots \ldots \ldots \ldots . . . . . . . . . . . . .140$

6.8.3 $\operatorname{Ir}(\mathrm{III}) \mathrm{N}, \mathrm{N}$-chelated 7-chloroquinoline-4-aminotriazole complex (10) ..............141

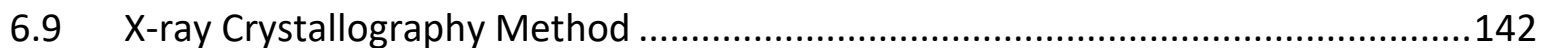

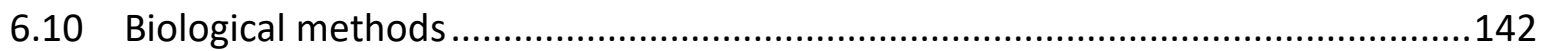

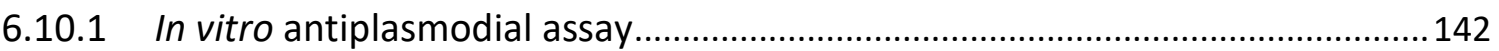

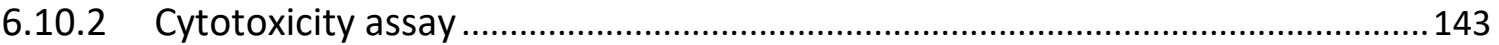

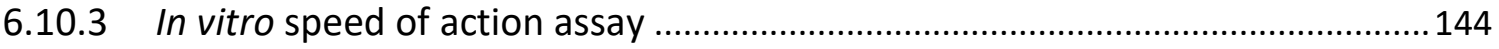

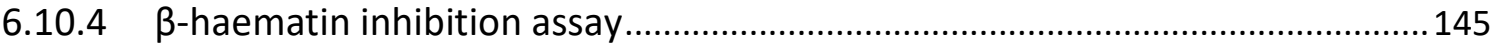

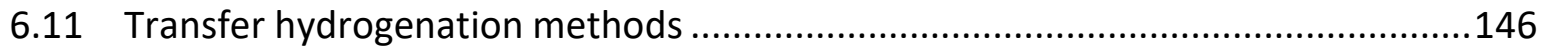

6.11.1 Method for qualitative ${ }^{1} \mathrm{H}$ NMR spectroscopy study .....................................146

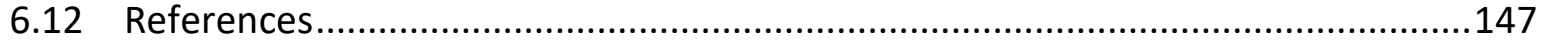




\section{Chapter 1}

\section{Introduction and Literature Review}

\section{$1.1 \quad$ Malaria}

\subsubsection{History and Prevalence}

Malaria is a life-threatening, mosquito-borne disease caused by blood parasites of the Plasmodium genus. ${ }^{1}$ Often seen as a disease of poverty, malaria has largely been neglected universally and, despite decades of research being done into its prevention and treatment, it remains one of the leading causes of mortality worldwide. According to the estimates of the World Health Organisation (WHO) in their 2018 World Malaria Report, progress towards global malaria control has stalled after an unprecedented period of success in previous years. ${ }^{2}$ In 2017, there were an estimated 219 million cases of malaria with a reported 435000 deaths, $92 \%$ of which were reported from the WHO African Region. ${ }^{2}$ With these statistics in mind, it is clear why combating this disease, which affects predominantly the poorest countries in the world, is of great importance. Malaria is one of the world's oldest diseases with ancestors of the parasite being believed to have existed half a billion years ago. ${ }^{3}$ After evolving alongside mankind throughout the years, the disease was first known to have been treated in the $1600 \mathrm{~s}$ when the native South Americans made use of the bark of the Cinchona tree to relieve the "feverish" symptoms of malaria. ${ }^{4}$ Significant progress into the treatment of malaria only took off in the $19^{\text {th }}$ century and, eventually, it was considered one of the best-studied diseases of the time in Western medicine. ${ }^{3,4}$ Western interest in the disease, however, began to decline towards the mid- $20^{\text {th }}$ century, even though the disease, on a global scale, has not. ${ }^{4}$

\subsubsection{Biology}

Malaria is a protozoan disease which is transmitted to the human host via the female Anopheles mosquito vector. ${ }^{1,5,6}$ Of the five species of Plasmodium that are infectious to humans, namely $P$. falciparum, $P$. vivax, P.ovale, $P$. malariae, and $P$. knowlesi, the species responsible for the greatest number of deaths is $P$. falciparum with this parasite accounting 
for $99.7 \%$ of the malaria cases in sub-Saharan Africa in 2017.1,2,5,6 The life cycle of $P$. falciparum is complex and involves different developmental stages in both the human and mosquito hosts. A simplified version of this life cycle can be seen in Figure 1.1.

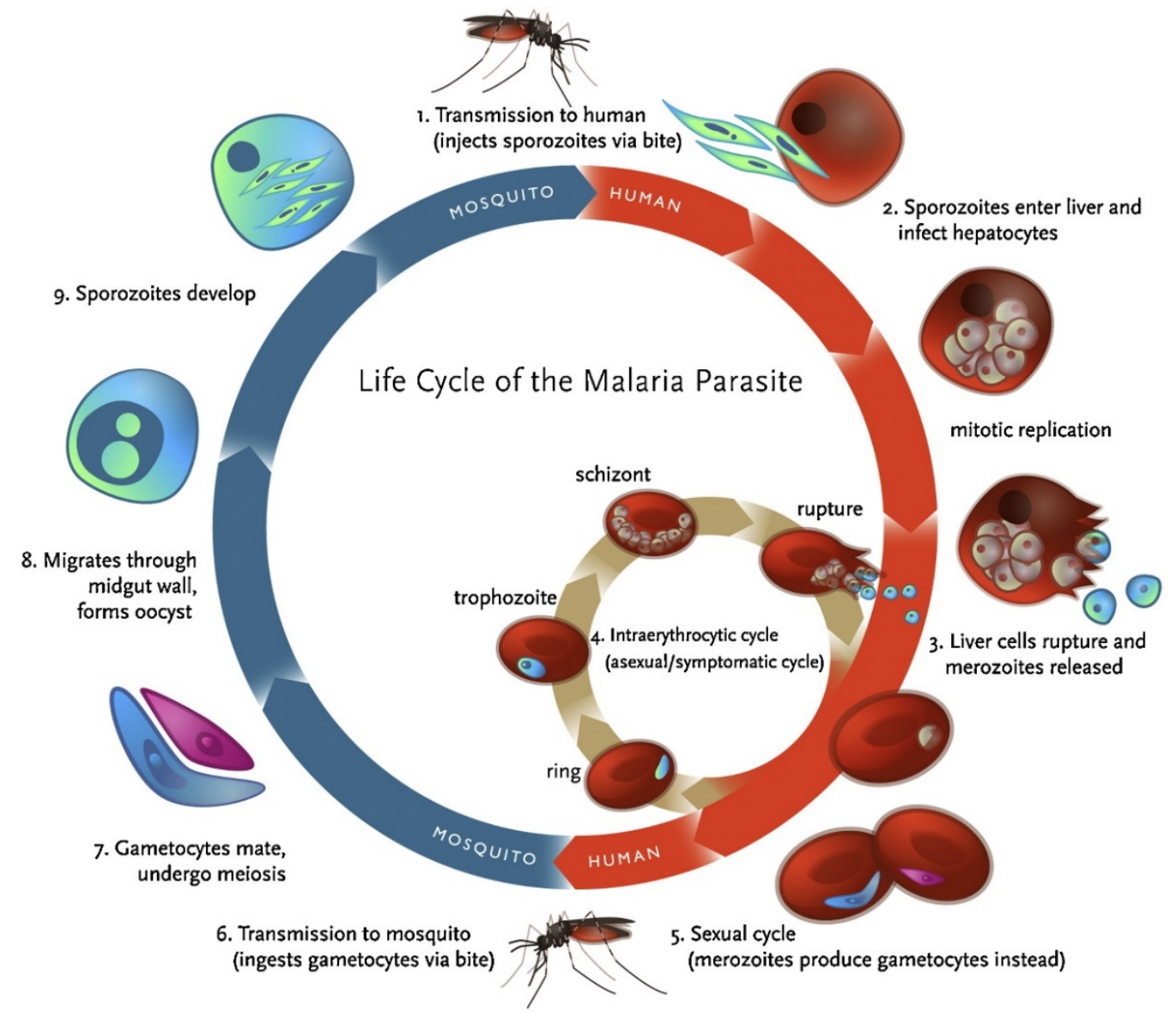

Figure 1.1: Life cycle of $P$. falciparum. ${ }^{6}$

The parasite is injected into the human host via an infected mosquito and the sporozoites then enter the liver and infect hepatocytes. ${ }^{1,6-8} \mathrm{Next}$, the pathogenic asexual blood stage takes place where the parasite leaves the liver and invades and populates the red blood cells (RBCs). This part of the cycle involves four stages, namely the merozoite, ring, trophozoite, and blood schizont stages. ${ }^{1,6-8}$ A portion of the merozoites may also be converted into gametes, which are then taken up by another mosquito in which sexual reproduction occurs. $^{1,6-8}$ Once the trophozoite stage in the RBC is reached, the parasite is able to ingest $60-80 \%$ of the host cell haemoglobin $(\mathrm{Hb})$ via phagocytosis and, thereafter, transports it into its acidic digestive vacuole. ${ }^{1,8-10}$ It is here where $\mathrm{Hb}$ degradation takes place, leaving ferriprotoporphyrin-IX, or "free" haem, as a by-product. ${ }^{1,8-11}$ Once in this "free" state, many studies have shown that this haem is toxic to the parasite as it is able to cause the generation 
of oxygen free radicals as a result of the oxidation of the haem iron centre..$^{1,8-11}$ This, among other things, causes harmful lipid peroxidation of the parasite's cell membrane and eventual cell lysis. ${ }^{1,8-10}$ To circumvent the deleterious effects of this "free" haem, the parasite has evolved a detoxification mechanism whereby the haematin is sequestered and crystallised into an insoluble, chemically inert substance known as haemozoin or malaria pigment, the structure of which can be seen in Figure 1.2.1,8-11 This haemozoin forms in the parasite's digestive vacuole and is non-toxic to the parasite, appearing as purple-black, opaque crystals under the microscope in parasite stages that are actively degrading $\mathrm{Hb}^{1,8,10}$ Because the parasite has limited capacity to synthesise amino acids, haemoglobin catabolism is thought to be necessary for parasite survival as it provides essential amino acids for growth and maturation. ${ }^{4,10}$ It is for this reason that targeting the haemoglobin metabolism pathway in the parasite has been the focus of many antimalarial drug treatments. ${ }^{4,10}$

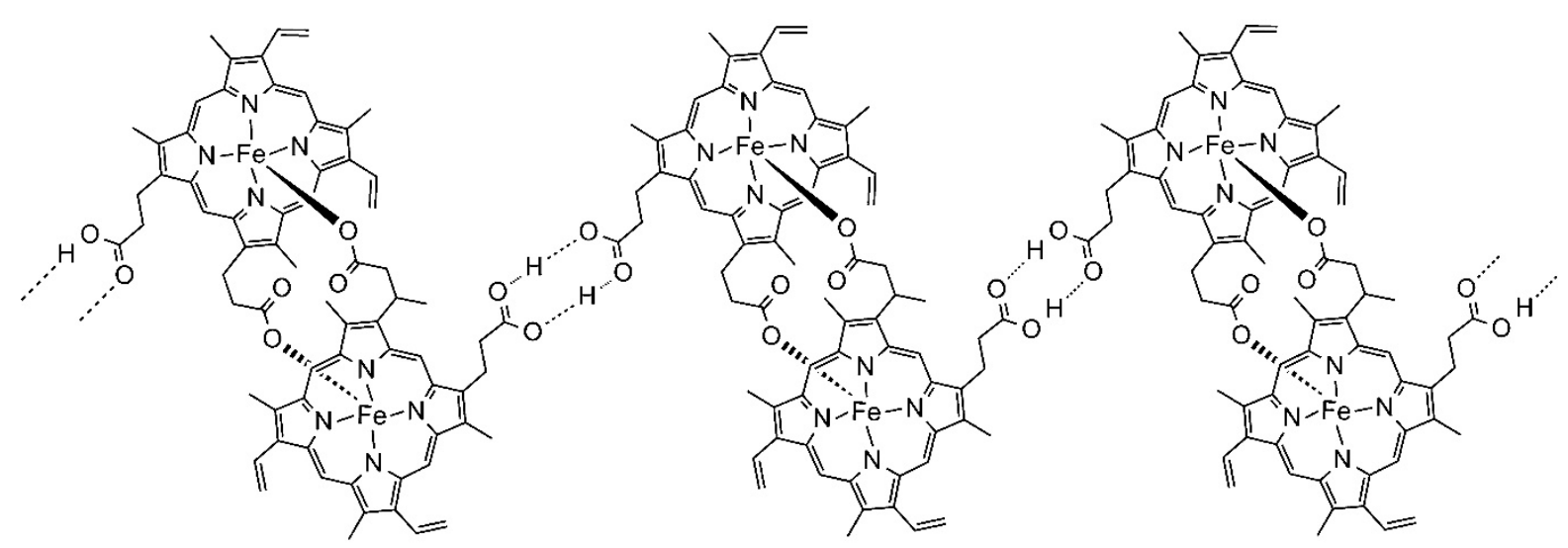

Figure 1.2: Structure of $\beta$-haematin (synthetic haemozoin). ${ }^{10}$

\subsubsection{Antimalarial treatments and drug resistance}

There are many preventative methods in place as frontline measures in the control of malaria, some examples being the use of mosquito-repellent creams and insecticide-treated mosquito nets. ${ }^{2}$ Preventative medicines may also be used when visiting areas where malaria is prevalent. $^{2}$ When prevention is no longer an option, however, there are a number of chemotherapeutic options available for people who have contracted the disease. The oldest and most well-known class of antimalarial drugs are those containing the heterocyclic aromatic quinoline moiety. ${ }^{4,12}$ The very first antimalarial agent, which forms part of this class 
of drugs, originated in the 1600s when the Countess of Chinchon was cured of malaria after being treated by the powdered bark of the Chinchona tree. ${ }^{4}$ It was only in 1820 , however, when two French chemists, Pelletier and Caventou, were able to isolate the active alkaloid ingredient, quinine, in the bark of the tree. ${ }^{4}$ The structure of quinine can be seen in Figure 1.3. Quinine has been used in antimalarial therapy ever since and is joined by other quinoline-containing compounds such as chloroquine, primaquine, amodiaquine, mefloquine and quinine in the chemotherapeutic armoury against malaria (Figure 1.3). ${ }^{4}$<smiles>C=CC1CN2CCC1C2[C@H](O)c1ccnc2ccc(OC)cc12</smiles>

Quinine<smiles>CCN(CC)CCCC(C)Nc1ccnc2cc(Cl)ccc12</smiles>

Chloroquine<smiles>COc1cc(NC(C)CCCN)c2ncccc2c1</smiles>

Primaquine<smiles>CCN(CC)Cc1cc(Nc2ccnc3cc(Cl)ccc23)ccc1O</smiles>

Amodiaquine<smiles>O[C@H](c1cc(C(F)(F)F)nc2c(C(F)(F)F)cccc12)[C@H]1CCCCN1</smiles>

Mefloquine

Figure 1.3: Examples of quinoline-containing antimalarial drugs.

\subsubsection{Chloroquine and non-chloroquine-based drugs}

One drawback with quinine is that it has side effects associated with its toxicity and also needs to be administered three times a day for seven days, thus resulting in poor compliance. ${ }^{13}$ This led to the development of the class of fully synthetic 4-aminoquinoline compounds in the 1940s, of which chloroquine (CQ) is the most popular. ${ }^{12,13}$ The reason for its popularity is because chloroquine is relatively inexpensive, non-toxic, efficacious and can be administered over three days. ${ }^{13} \mathrm{CQ}$ is also only active against the blood stages of the parasitic life cycle in which active $\mathrm{Hb}$ degradation is taking place. ${ }^{14}$ Many structure-activity relationship investigations have been conducted by various groups (Figure 1.4), focussing specifically on 


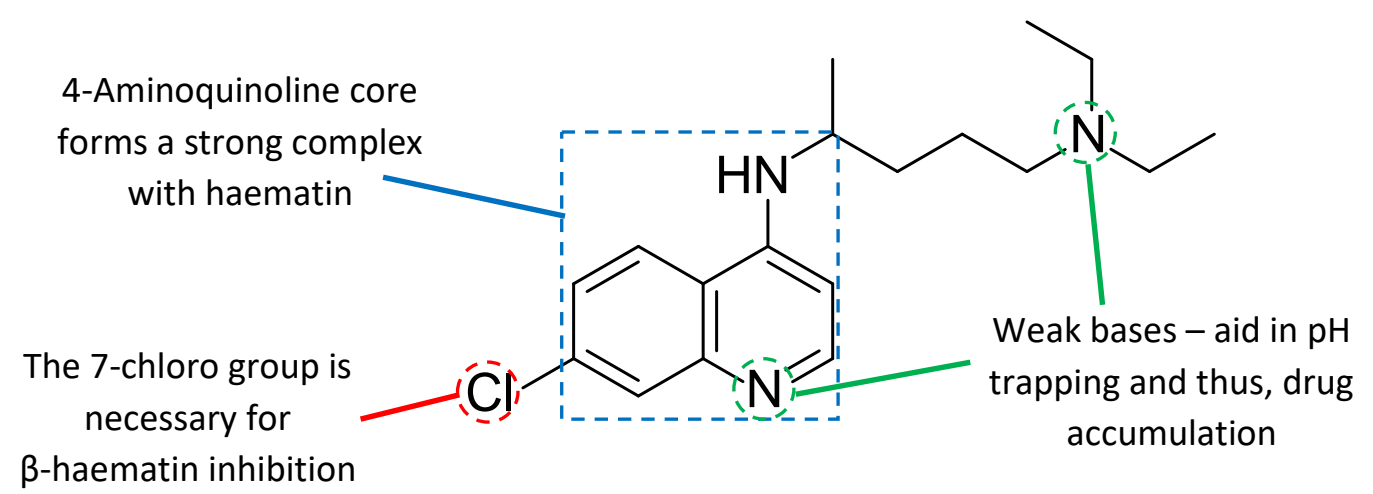

Figure 1.4: Structure-activity relationships of chloroquine. ${ }^{15}$

$\mathrm{CQ}$ and its derivatives, showing that there are numerous reasons for chloroquine's enhanced antiplasmodial activity. ${ }^{15}$ Firstly, its 4 -aminoquinoline core allows it to form a strong complex with haematin. ${ }^{15}$ Secondly, its 7 -chloro group aids in the inhibition of haemozoin formation and, lastly, the basic nitrogen atoms, both on its core and on its side chain, aid in pH trapping, thereby promoting the accumulation of the drug within the parasitic food vacuole. ${ }^{15}$ Although chloroquine has been used as an effective antimalarial agent for decades, its mechanism of action is still not completely understood, although, nowadays, it has been widely accepted that it likely involves the interruption of the formation of haemozoin, as shown in Figure

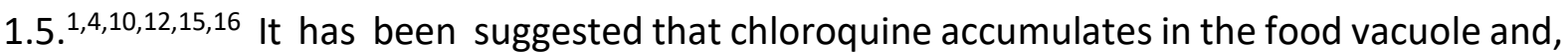
once the parasite digests the host cell $\mathrm{Hb}$, the drug is able to interact with the ferriprotoporphyrin-IX, or "free" haem, preventing its crystallisation into haemozoin. ${ }^{1,4,10,12,15,16}$ The "free" haem is then able to interact with the parasite's cell

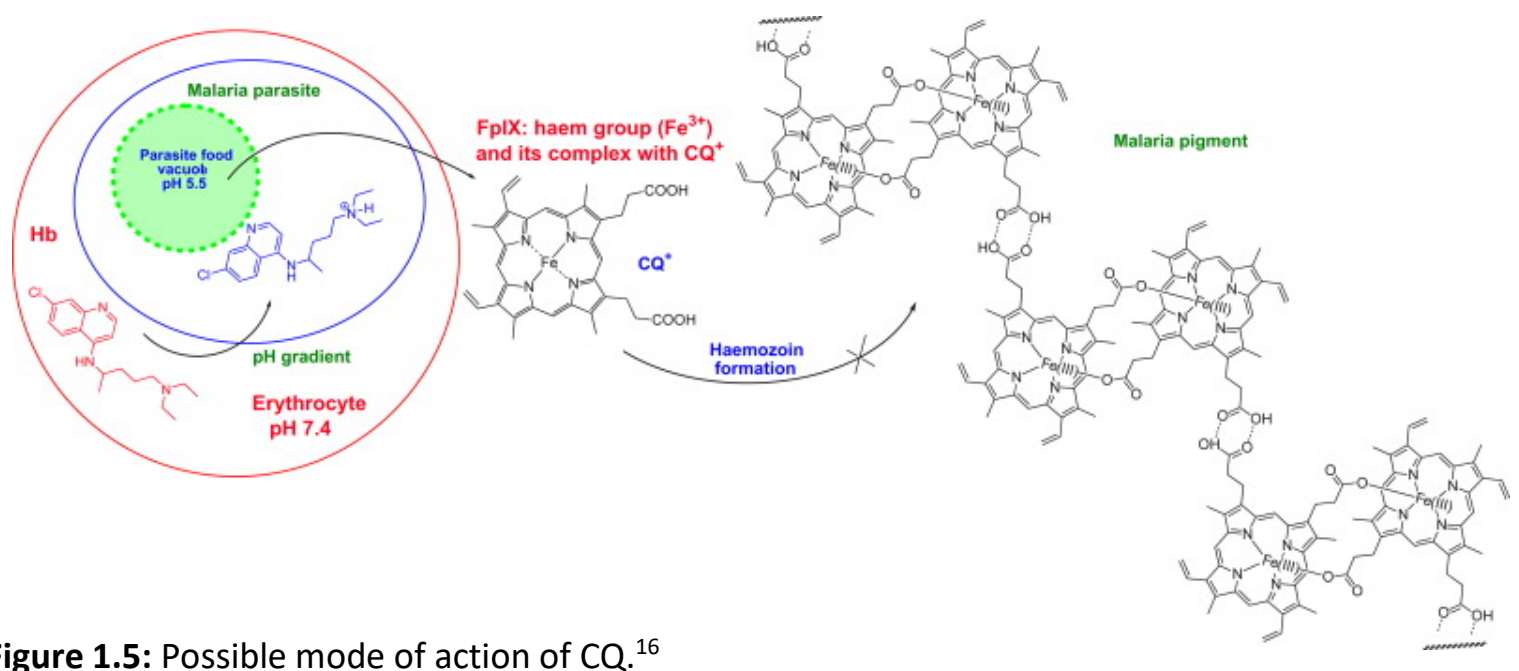

Figure 1.5: Possible mode of action of CQ. ${ }^{16}$ 
membrane, as well as cause numerous other toxic effects, eventually leading to cell death via oxidative stress or cell lysis.,10,12,16 For many years, CQ remained the vanguard antimalarial drug, however, over time, chloroquine-resistant (CQR) strains of $P$. falciparum began to emerge in Asia and South America, eventually spreading to West Africa. ${ }^{10,16,17}$ This resistance was discovered to occur through spontaneous mutations in the parasite's genetic code, particularly to a gene known as the $P$. falciparum chloroquine resistance transporter (PfCRT) gene. ${ }^{18}$ This transporter is located on the membrane of the parasitic food vacuole and, when the gene encoding for this transporter undergoes a specific mutation, it results in the efflux of quinoline and quinoline-like drugs from the acidic food vacuole. ${ }^{18-20}$ This results in a decrease in the accumulation of these drugs, rendering them practically ineffective in CQresistant $P$. falciparum strains. ${ }^{19,20}$ Owing to the proliferation of CQ-resistant parasites, CQ was virtually useless by the year 2000, with often extremely high treatment failure rates in most parts of the world. ${ }^{10,16,17,21}$ This, thus, led to the need to find alternative ways to treat malaria, with some examples being the modification of known drugs and combination therapies. ${ }^{10,17,22}$ The World Health Organisation now recommends artemisinin-based combination therapies (ACTs) as the front-line treatment for $P$. falciparum malaria. ${ }^{10,13,23,24}$ This involves the combination of artemisinin, or a derivative thereof (Figure 1.6), with a second drug that has a different mechanism of action. ${ }^{10,13,23}$ Artemisinin is a highly-effective drug which is fast-acting and capable of rapidly eliminating the malaria parasite. ${ }^{10,23}$ In combining it with another drug which targets a different mode of survival of the parasite, this combination approach aims to improve the efficacy of the treatment as well as to minimise the risk of resistance development. ${ }^{10,23}$ Although ACTs are the mainstay of recommended

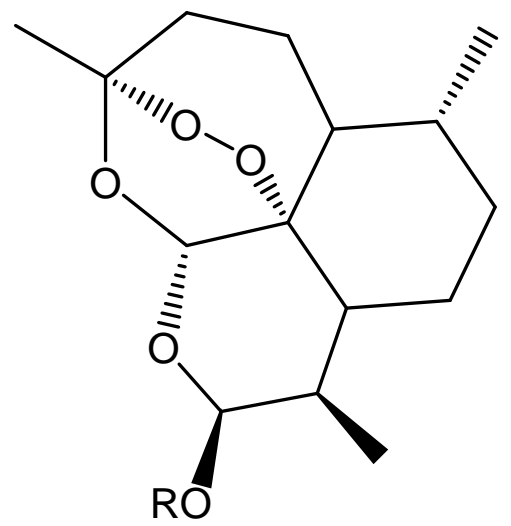

$$
\begin{array}{ll}
\mathrm{R}=\mathrm{H} & \text { Dihydroartemisinin } \\
\mathrm{R}=\mathrm{Me} & \text { Artemether } \\
\mathrm{R}=\mathrm{Et} & \text { Arteether } \\
\mathrm{R}=\mathrm{CO}\left(\mathrm{CH}_{2}\right)_{2} \mathrm{CO}_{2} \mathrm{H} & \text { Artesunate }
\end{array}
$$

Figure 1.6: The general structure of artemisinin antimalarials. 
treatment for malaria, they too could start to lose their efficacy as resistant strains of the malaria parasite have begun to emerge in Southeast Asia. ${ }^{25}$ It is, therefore, necessary to continue to develop novel antimalarial therapies in order to manage a disease of this magnitude. This brings into play the concept of pharmacophore hybridisation, an attractive strategy in the attempt to circumvent antimalarial drug resistance. ${ }^{25}$

\subsection{Hybrid Molecules}

\subsubsection{Structure}

With the unavoidable emergence of drug-resistant strains of $P$. falciparum, numerous antimalarial drug-discovery approaches are currently being pursued. Some of these strategies include the generation of optimized analogues of existing drugs, the repurposing of medicines, the evaluation and use of drug-resistance reversers and, most recently, the synthesis of hybrid molecules. ${ }^{5,26}$ The latter involves the covalent linking of two biologically active molecules, also known as pharmacophores, into one hybrid unit with a dual mode of action. $5,26,27$ In doing so, these hybrid compounds could potentially have an improved efficacy and safety, as well as be less susceptible to elicit resistance relative to the parent drugs. 5,27 There are a number of advantages of developing hybrid molecules over implementing combination therapies. ${ }^{26}$ The use of a single molecule means that the pharmacokinetics will be identical for each constituent, and it also means that there will be much less stress when it comes to things such as solubility and stability, which would be an issue in the administration of multiple agents. ${ }^{26,28}$ There is currently a number of hybrid molecules in use in the drug industry, with one such example being the effective anticancer agent, bleomycin (Figure 1.7). ${ }^{28}$ Originally isolated as an antibiotic from Streptomyces verticillus in 1966, bleomycin is a hybrid peptide-polyketide natural product used for the treatment of several malignancies. ${ }^{28,29}$ This drug has three distinct structural domains, each of which has its own different biological role: one domain for DNA binding, another for metal binding and a third containing carbohydrates, which facilitates cell penetration (Figure 1.7)..$^{28,30,31}$ As a wellstudied hybrid molecule featuring on the World Health Organisation's List of Essential Medicines, bleomycin serves as a paradigm for the synthesis of hybrid drugs. ${ }^{32}$ Since this pharmacophore hybridisation approach is a hot topic in the field of drug discovery, research 
is now being done into the development of hybrid antimalarial drugs in an attempt to circumvent the ever-increasing problem of antimalarial drug resistance.

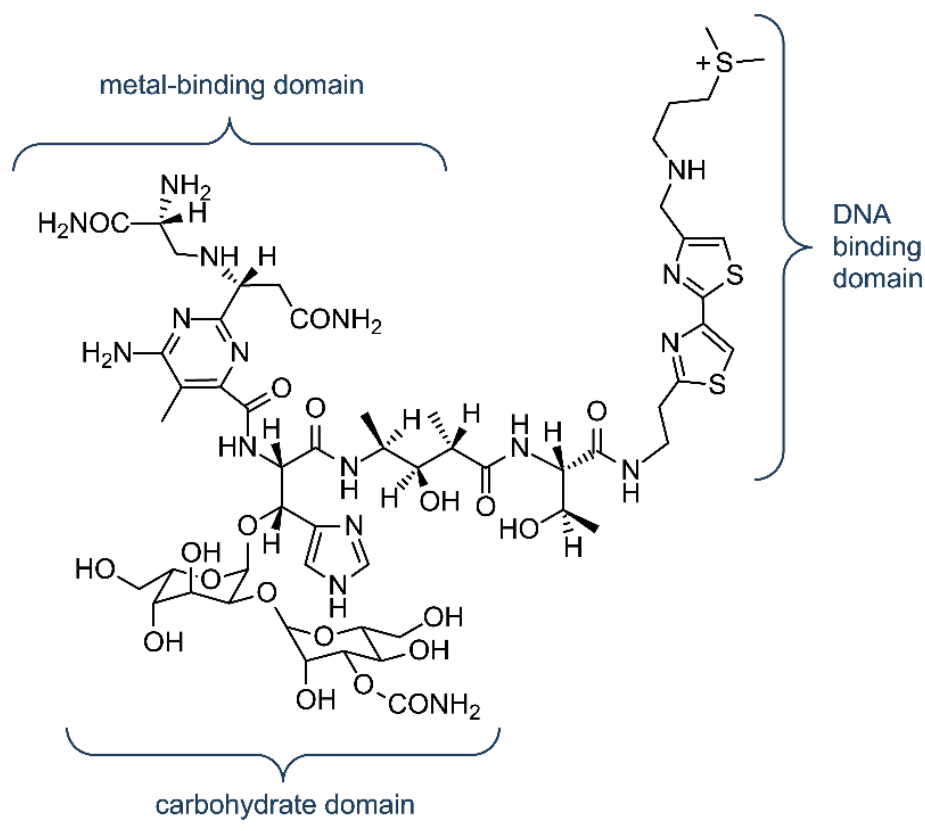

Figure 1.7: Structure of the anticancer hybrid drug, bleomycin. ${ }^{31}$

\subsubsection{Aminoquinoline-triazole hybrids and their antiparasitic activity}

Although the global diffusion of antimalarial drug resistance has spread at an alarming rate, 4-aminoquinoline derivatives, such as $C Q$, still remain the most sought out antimalarial agents for chemical modification. ${ }^{27}$ Because of its favourable biopharmaceutical properties, as well as its safety and cost effectiveness, the strategies aimed at overcoming resistance to CQ are attractive and, for this reason, the quinoline derivatives dominate the antimalarial drug pool. ${ }^{26,33}$ There are a number of recent examples of quinoline-based antimalarial drugs which employ the method of pharmacophore hybridisation, some of which can be seen in Figure $1.8 .^{26}$ These include chloroquine-triazine hybrids, ${ }^{34,35}$ chloroquine-pyramidine hybrids, ${ }^{27}$ the mefloquine-artesunate hybrid (MEFAS), ${ }^{36}$ and the organometallic chloroquineferrocene hybrid, also known as ferroquine. ${ }^{37}$ Many of these compounds have shown enhanced antimalarial activity in drug-resistant parasites compared to their respective parent drugs, with MEFAS) and ferroquine advancing further to preclinical development and Phase IIb clinical trials respectively. ${ }^{36,38}$ Moreover, the innovative hybrid salt, MEFAS, was found to be more effective than just the combination of mefloquine and artesunate as separate entities, further highlighting the need for novel hybrid drugs. ${ }^{36}$ Although there are no 


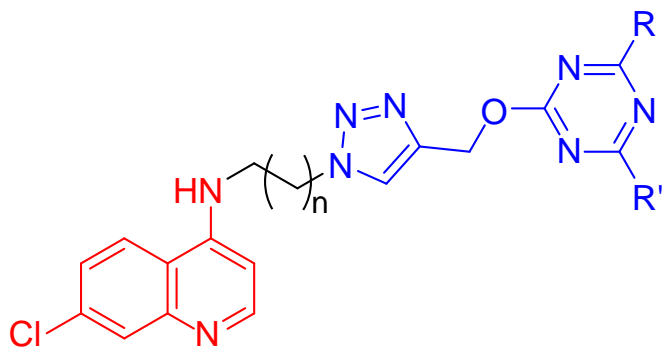

7-chloro-4-aminoquinoline:triazine hybrids

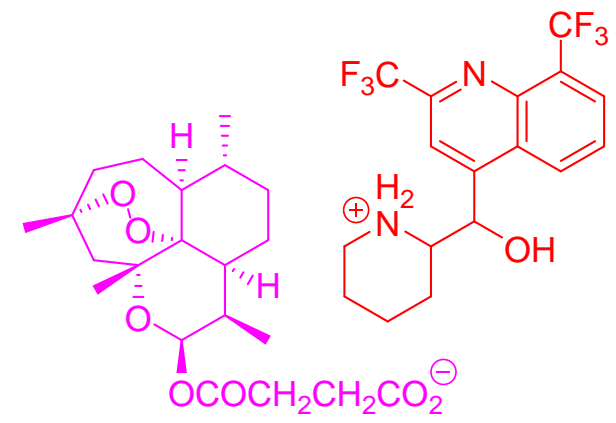

Mefloquine-artesunate hybrid (MEFAS)<smiles>[R]c1nc(C)cc(NC(C)C(C)(C)C(C)(C)C)n1</smiles>

7-chloro-4-aminoquinoline:pyrimidine hybrids

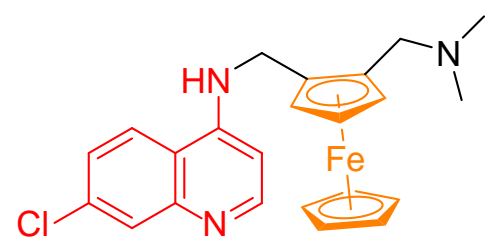

7-chloro-4-aminoquinoline:ferrocene hybrid (ferroquine)

Figure 1.8: Examples of quinoline-based hybrid antimalarial compounds. ${ }^{26}$

examples of antimalarial hybrid drugs in clinical use, it is easy to see why the 7chloroquinoline moiety would be the pharmacophore of choice in the design of such a drug. ${ }^{25}$ Another pharmacophore which is not as well-documented for antimalarial activity but which is undeniably important in medicinal chemistry is the 1,2,3-triazole entity. ${ }^{34,39-41}$ This aromatic heterocycle constitutes a five-membered ring of two carbon atoms and three nitrogen atoms and can easily be prepared using copper-catalysed click chemistry. ${ }^{34,39-41}$ Triazoles are particularly desirable pharmacophores as they are stable to acid-base hydrolysis, relatively resistant to metabolic degradation and readily associate with biological targets via hydrogen bonding. ${ }^{5,40,41}$ Although the 1,2,3-triazole entity does not exist in nature, there are a number of triazole-containing synthetic molecules which exhibit a multitude of biological activities, ranging from antifungal and antibacterial to anticancer, antituberculosis and antiHIV activities. ${ }^{39,40}$ In combining the stable triazole moiety with the antimalarial properties of the aminoquinoline skeleton, the novel class of aminoquinoline-triazole hybrid molecules could likely display enhanced antimalarial activity in an attempt to overcome the primary limitation of resistance. A 2019 review by Chu et al. details some of the recent advances in the use of 
quinoline-triazole hybrids as potential antiplasmodial and antimalarial agents. ${ }^{42} \mathrm{~A}$ few of these hybrid compounds described herein exhibited promising antiplasmodial activity, with a significant enhancement in activity shown upon the incorporation of an aminoalkyl chain linker between the triazole and quinoline entities. ${ }^{42}$ Although the quinoline-triazole hybrids were mostly found to have moderate, micromolar antiplasmodial activity, this activity could likely be improved by the incorporation of a metal into their structure, a method of antimalarial drug design which has also recently taken wind.

\subsection{Metals in Medicine}

From the days of ancient medicine to the innovative times of modern pharmacology, the use of metals in medicine has played a substantial role in the field of drug discovery. ${ }^{10,43}$ Although the use of metal-based drugs was largely abandoned in the early part of the $20^{\text {th }}$ century due to apprehension about systemic toxicity, over the past 30 years this outlook has changed with a resurgence of interest in the potential applications of metals in the design of novel therepeutics. ${ }^{43}$ The reason for this renewed interest is that research has found that transition metal compounds offer great versatility and chemical diversity not always seen in organic drugs. ${ }^{10,43-45}$ This diversity is brought about not only by the choice of the metal itself, but also by the ability to "fine-tune" the reactivity of the metal centres toward target biomolecules by altering the number and type of coordinated ligands as well as the coordination geometry of the complex. ${ }^{10,43-45}$ Transition metals in particular also have a unique binding capability and reactivity determined by their $d$ orbitals, making their complexes important in biological systems. ${ }^{10,17,43}$ There are a number of examples that prove the success of metal complexes in modern medicine. Thought to have started with Ehrlich's discovery of the arsenic-based organometallic drug, Salvarsan ${ }^{46}$ (Figure 1.9a), for the treatment of syphilis in the early 20th

(a)

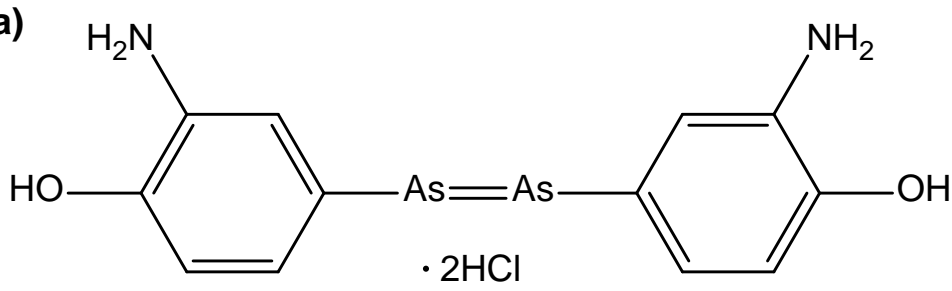

(b)

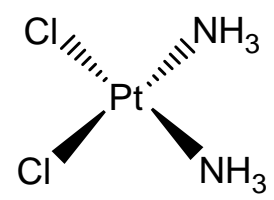

Figure 1.9: Structures of the early metal-based drugs, (a) Salvarsan ${ }^{46}$ and (b) Cisplatin. ${ }^{49}$ 
century, the field of organometallic drug design has since blossomed, with the preparation of other metal-based treatments including antiparasitic antimony complexes and gold compounds for the treatment of rheumatoid arthritis. ${ }^{47,48}$ Arguably, the most significant accidental discovery however, which fuelled interest in the field of metal-based drug design was that of the anticancer activity of the platinum-based compound, cisplatin (cis- $\left.\left[\mathrm{PtCl}_{2}\left(\mathrm{NH}_{3}\right)_{2}\right]\right)$, by Rosenberg et al. ${ }^{49}$ in the late 1960s (Figure 1.9b). ${ }^{10,43,44,47-50}$ Cisplatin and its derivatives have been used in cancer therapy ever since, however, its severe doselimiting side effects, high toxicity and the development of drug resistance largely impede its effectiveness. ${ }^{49,51}$ With the aim of overcoming these limitations, other drug-design strategies include ligand modification and the use of alternative metals to platinum, such as the Platinum Group Metals (PGMs) ruthenium, rhodium, iridium, osmium and palladium. ${ }^{52}$ These metals are of particular interest because they have a decreased toxicity but show activity comparable to platinum itself. The use of metals in anticancer drug development has thus been well explored and, with these strategies in mind, the field of metal-based antimalarial research is currently being pursued.

\subsubsection{Metalloantimalarials}

Encouraged by the success of metal-containing compounds in cancer therapy, research into the relatively unexplored field of metalloantimalarials has recently begun to emerge. ${ }^{10}$ The term "metalloantimalarials" was first coined in 2003 by Goldberg, Sharma and co-workers ${ }^{53}$, who divided these compounds into three categories, namely metal chelators, intact metal coordination complexes of known antimalarial agents, and bioorganometallic compounds. ${ }^{10,53}$ Metal compounds are particularly suitable for the treatment of parasitic diseases such as malaria because they display a marked selectivity for certain parasitic biomolecules compared to the host's biomolecules. ${ }^{43}$ With this in mind, Wasi et al. was the first to synthesise and evaluate the antimalarial activity of metal complexes of amodiaquine and primaquine - two well-known organic antimalarials. ${ }^{54}$ Some of the metals used for complexation included $\mathrm{Cr}(\mathrm{III}), \mathrm{Fe}(\mathrm{III}), \mathrm{Cu}(\mathrm{II}), \mathrm{Zn}(\mathrm{II}), \mathrm{Rh}(\mathrm{III}), \mathrm{Pd}(\mathrm{II}), \mathrm{Au}(\mathrm{II}), \mathrm{Mn}(\mathrm{II})$ and $\mathrm{Pt}(\mathrm{II})$, however, these complexes did not appear to exhibit enhanced antimalarial activity. ${ }^{54}$ It was later proposed that the complexation of transition metals with chloroquine would improve its antimalarial activity and also aid in overcoming the problem of drug resistance. 


\subsubsection{Rhodium, ruthenium and iridium complexes of $\mathrm{CQ}$}

The first organometallic complex of chloroquine to be synthesised, characterised and biologically tested was the rhodium-containing [RhCl(COD)CQ] (COD = 1,5-cyclooctadiene), reported by Sánchez-Delgado et al. in 1996.1,17,43,55,56 Figure 1.10 shows how CQ is bound to $\mathrm{Rh}$ through the unsubstituted quinoline nitrogen, which acts as a good donor site on the molecule, thus forming a 16 -electron, square planar structure. ${ }^{1,55}$ When tested for its activity against the $P$. berghei malaria species, this compound was found to display activity comparable to that of chloroquine diphosphate (CQDP). ${ }^{1,55}$ Similarly, when tested in vivo, the Rh complex showed impressive antiplasmodial activity, reducing parasitemia by $73 \%$ without any sign of acute toxicity. ${ }^{55}$

(a)

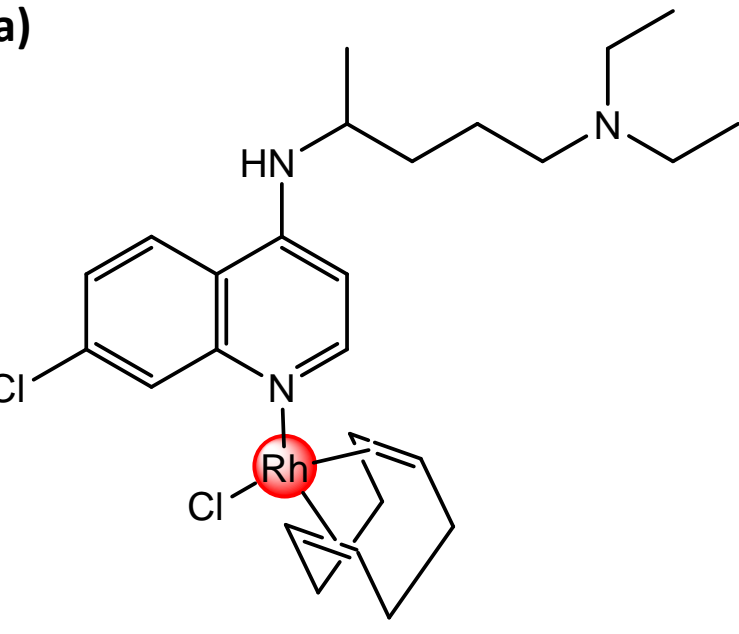

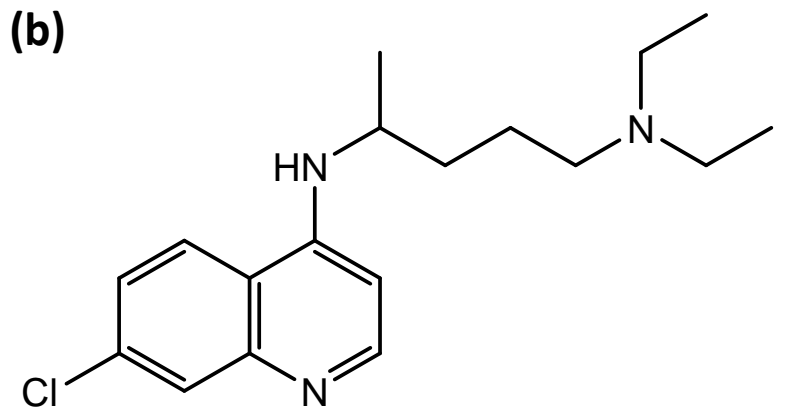

Figure 1.10: Structure of (a) the Rh-CQ complex, $\mathrm{RhCl}(\mathrm{COD}) \mathrm{CQ}$ compared to (b) chloroquine (CQ). ${ }^{55}$

Based on the promising activity displayed by this CQ-based rhodium complex, several ruthenium(II)-arene complexes of CQ were thereafter synthesised and tested against various strains of $P$. falciparum. ${ }^{1,57}$ Importantly, the activities of the complexes against the resistant parasitic strains were consistently higher than that of CQDP, demonstrating that the Ru-CQ complexes are able to interfere with the parasite's resistance mechanisms. ${ }^{1,57}$ Encouraged by the success of the aforementioned rhodium and ruthenium complexes of $C Q$, in 2007, Navarro et al. ${ }^{58}$ developed three new iridium-CQ complexes, the most active of which is shown in Figure 1.11. This complex, in which the CQ binds to the iridium through both $\mathrm{N}$ atoms in its side chain, was determined to have an $\mathrm{IC}_{50}$ value of $59 \mathrm{nM}$ against the in vitro growth of P. berghei. Again, this transition metal complex of $\mathrm{CQ}$ displayed enhanced antiplasmodial 
activity over CQ itself, which was determined to have an $\mathrm{IC}_{50}$ value of $72 \mathrm{nM}$ in the same study. ${ }^{58}$

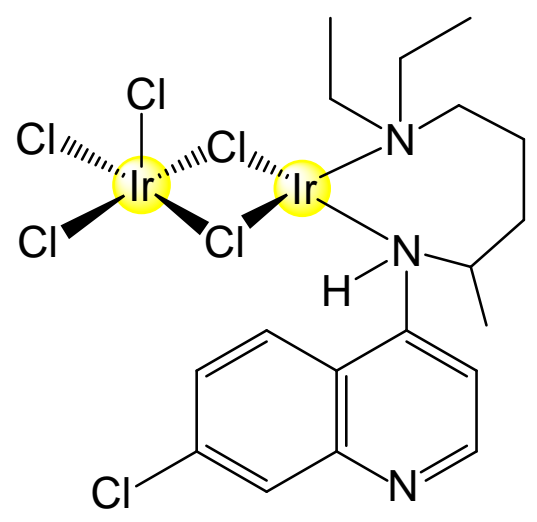

Figure 1.11: The structure of the highly active Ir-CQ complex synthesised by Navarro et al..$^{58}$

\subsubsection{Ferroquine - a potent ferrocene-CQ complex}

In continuation with the search for metal complexes which have enhanced antimalarial properties, a molecule of particular interest is the small and rigid, sandwich-like molecule, ferrocene. ${ }^{1,10,59,60}$ Ferrocene is particularly attractive because it is non-toxic, relatively stable under most conditions, highly lipophilic and easily derivatised, making it a desirable structure in biological applications and drug-development. ${ }^{1,53,59,60}$ Inspired by the impressive research done by Jaouen et al., ${ }^{61}$ who introduced ferrocene into the structures of various cancer chemotherapies, the same concept was followed for the modification of known antimalarial therapies. ${ }^{37,59}$ This was first accomplished by Biot et al. ${ }^{62}$ in 1997 by the introduction of a ferrocenyl moiety into the lateral side chain of $C Q$, thus producing ferroquine (FQ). ${ }^{1,37,56,59,60}$ The structure of $F Q$, as seen in Figure 1.12a, comprises a ferrocene molecule covalently flanked by a 4 -aminoquinoline moiety and a basic alkylamine chain. ${ }^{43,60,62}$ While FQ does retain some of the essential biological activity of $\mathrm{CQ}$, the additional ferrocene unit further enhances this activity in both the CQ-sensitive and CQ-resistant strains of $P$. falciparum. 1,10,37,60,62 In the CQ-sensitive strains, FQ was proven to be as effective as CQ, while, when tested in vitro against various CQ-resistant $P$. falciparum strains, it was found to display potency 22-times greater than that of CQ. ${ }^{37,62}$ Similarly, when tested in vivo in mice infected with various Plasmodium strains, including $P$. yoeli, $P$. berghei and $P$. vinckei vinckei, the activity of FQ was equally as respectable. ${ }^{37,62}$ It is because of this impressive activity combined 
with its ability to overcome CQ-resistance that FQ is now undergoing phase IIb clinical trials, in which the efficacy of a combination of $\mathrm{FQ}$ and artefenomel ${ }^{63}$, a novel synthetic trioxolane (Figure $1.12 \mathrm{~b}$ ), is being examined..$^{1,10,11,37,38,43}$ The activity of FQ can likely be attributed to a dual mechanism of action. ${ }^{43}$ Firstly, FQ is able to inhibit the formation of $\beta$-haematin to an even greater extent than $C Q$, and second, the generation of free radicals could possibly occur by the redox activation from ferrocene $[\mathrm{Fe}(\mathrm{II})]$ to ferrocinium $[\mathrm{Fe}(\mathrm{III})] .{ }^{43}$ Since then, many new ferrocene analogues and FQ derivatives have been synthesised and screened for antiplasmodial activity. ${ }^{1,37,43,64,65}$

(a)

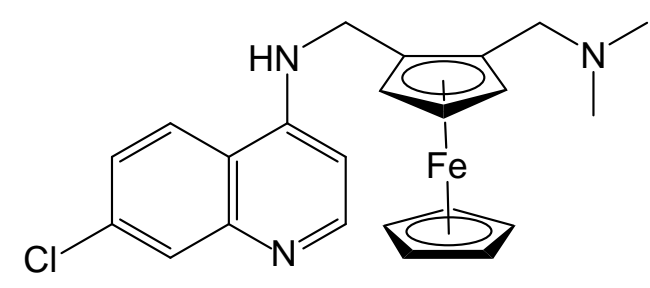

(b)

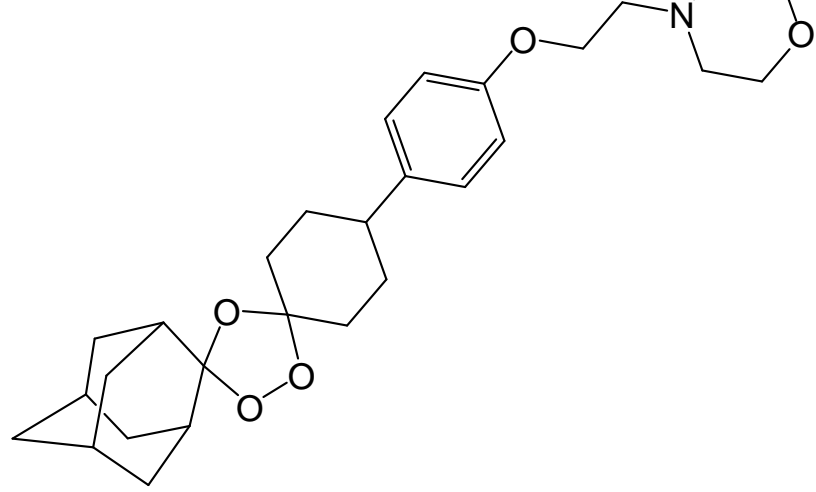

Figure 1.12: The structures of (a) ferroquine $(F Q)^{62}$ and $(b)$ artefenomel ${ }^{63}$, a combination therapy currently in phase IIb clinical trials.

\subsection{Cyclometallated Complexes and Malaria}

Cyclometallation reactions involve the transition metal-mediated activation of a $C-R$ bond, resulting in the formation of a new metal-carbon $\sigma$ bond in the form of a metallacycle. ${ }^{66,67}$ This type of intramolecular metalation reaction is one of the oldest reactions in the synthesis of organometallic complexes, having gained considerable popularity since its conception in the early 1960s. ${ }^{66-68}$ Over the past 50 years, many papers have been published involving cyclometallated complexes, making their synthesis undeniably one of the most advanced areas of current organometallic chemistry. ${ }^{66-68}$ The reason for this is because of the numerous advantages that cyclometallation has to offer. Firstly, because the reaction product is a metallacycle containing a metal bound by a chelating carboligand, it results in the strengthening of the highly susceptible $\mathrm{M}-\mathrm{C}$ bond, thereby improving the stability of the complex as a whole. ${ }^{66,69}$ This improved stability means that the complex will be protected 
against biological reduction and ligand exchange reactions, as well as making it easier to characterise. ${ }^{66,67,69}$ Secondly, the ability to alter both the anionic and the ancillary ligands means that the cytotoxicity and the pharmacokinetics of the complex can be enhanced. ${ }^{69}$ Almost all of the transition metals have been employed for cyclometallation, with some of the most successful cases incorporating the platinum group metals $\mathrm{Ru}, \mathrm{Os}, \mathrm{Rh}, \mathrm{Ir}, \mathrm{Pd} .{ }^{66}$ While there are many examples of the use of cyclometallated complexes for anticancer therapy ${ }^{70,71}$, there appears to be a paucity of examples in antimalarial research, with Smith and co-workers being among the few to have produced results in this field. ${ }^{72-75}$ Much of their research with cyclometallated complexes for malaria has focused on cyclopalladated and cycloplatinated thiosemicarbozones, with their studies into the inhibitory effects of palladium-containing thiosemicarbozones being among the first to be reported in literature. ${ }^{72-74}$ Recently, they have also investigated the antiplasmodial activity of cyclometallated ruthenium(II), rhodium(III) and iridium(III) complexes of 2 -phenylbenzimidazoles. ${ }^{75}$ These complexes exhibited promising antiplasmodial activities in both CQ-sensitive and CQ-resistant strains of P. falciparum, with some $\mathrm{IC}_{50}$ values found to be in the sub-micromolar range (Figure 1.13). ${ }^{75}$ Very little research, however, has been done into the use of quinoline-containing cyclometallated complexes for antimalarial chemotherapy, making the synthesis and evaluation of these types of compounds attractive. While the mechanism of action of cyclometallated compounds within the malaria parasite is still quite vague, one theory, as observed for metal complexes in anticancer therapy, is that of intracellular catalysis.
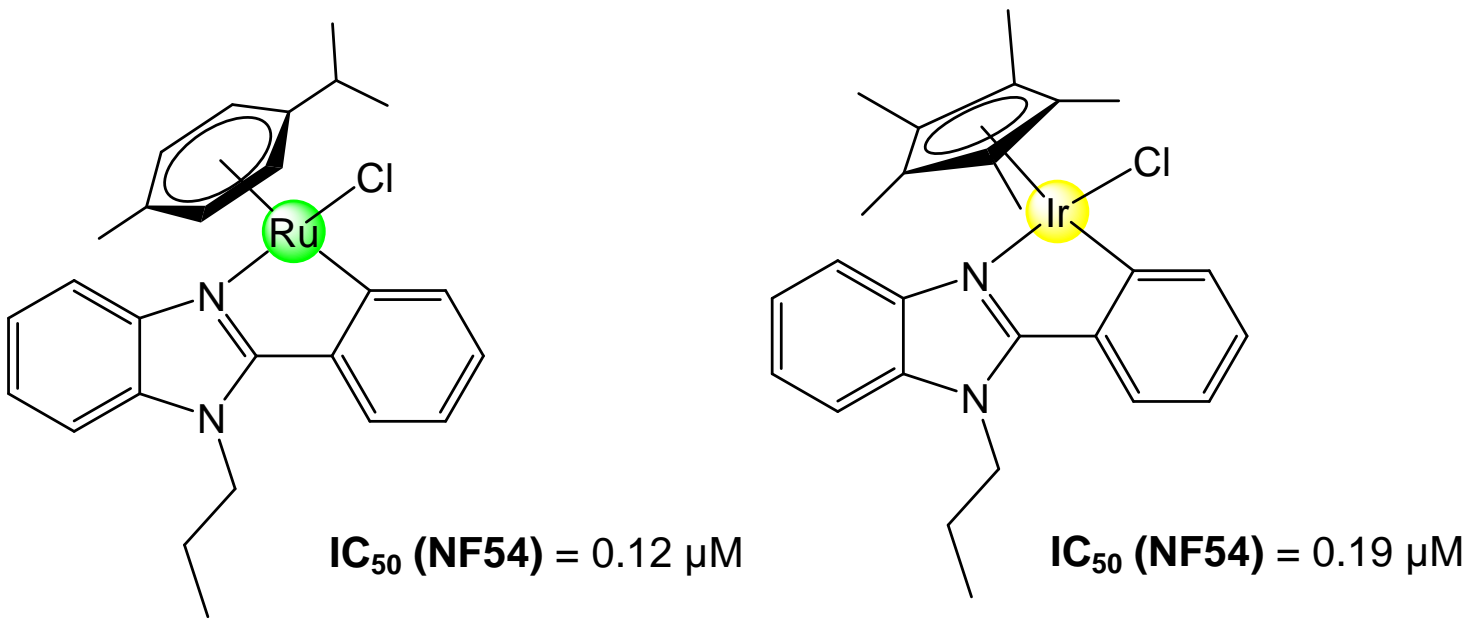

Figure 1.13: Structures of the most active 2-phenylbenzimidazole $R u(I I)$ and $\operatorname{Ir}(I I I)$ complexes synthesised by Rylands et al. ${ }^{75}$ 


\subsection{Transfer Hydrogenation Catalysis in Living Systems}

From Grubb's ruthenium carbene catalysts ${ }^{76}$ for olefin metathesis to Noyori's ruthenium arene complexes ${ }^{77}$ for the asymmetric hydrogenation of ketones, organometallic complexes have been well documented for their use as catalysts in organic chemical reactions. ${ }^{78} \mathrm{~A}$ developing frontier in the field of organometallic chemistry, however, is the use of metal complexes at the interface with biological systems. ${ }^{79,80}$ Over the past decade, the application of chemical processes within living organisms has evolved dramatically, meaning that today, many diverse and intricate synthetic molecules exist that are able to control and interfere with biological processes. ${ }^{80}$ With so many powerful chemical tools available for modulating biology, focus has now shifted towards the relatively untapped field of metal-complex catalysis within living biological systems. ${ }^{80}$ This brings into play the concept of "metallodrugs" with the idea that organometallic complexes are able to exhibit reactivities not possessed by either the metal or the organic ligands alone. ${ }^{81,82}$ The fact that these reactivities can be finetuned and adjusted as desired means that organometallic complexes are able to provide a flexible platform for the field of drug design. ${ }^{82}$ Furthermore, the use of metal complexes as catalytic drugs is attractive since this will allow the transition from exploiting predominantly stoichiometric reactions to applying catalytic processes meaning that these drugs can be administered in low, safe, non-toxic doses. ${ }^{78,80}$ The concept of transition metal catalysis within living systems was first introduced in 2006 by Streu and Meggers, ${ }^{83}$ and, in so doing, they revealed the future potential of intracellular catalysis. ${ }^{84-86}$ In their research, they found that the relatively simple half-sandwich ruthenium complex, $[C p * R u(C O D) C l]$ (Figure 1.14a, $C p^{*}=$ pentamethylcyclopentadienyl, $\mathrm{COD}=1,5$-cyclooctadiene) is capable of cleaving

(a)

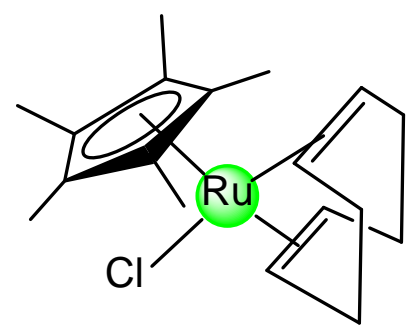

(b)

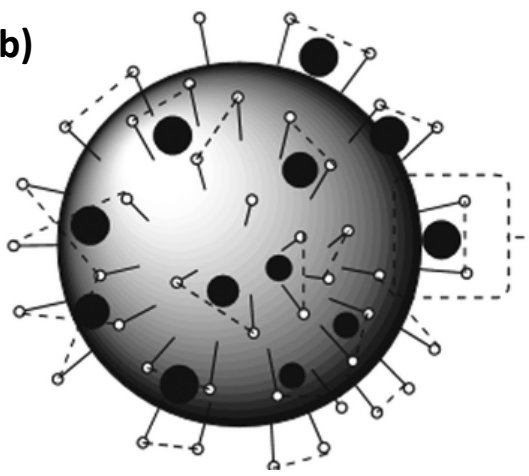

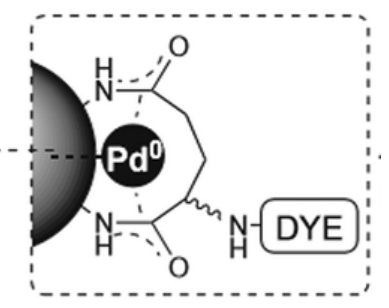

Figure 1.14: Structures of (a) $\mathrm{Cp} * \mathrm{Ru}(\mathrm{COD}) \mathrm{Cl}$ used by Streu and Meggers ${ }^{83}$ and (b) the polystyrene microspheres containing entrapped $\mathrm{Pd}$ nanoparticles designed by Yusop et al. ${ }^{87}$ 
allylcarbamates to their respective primary amines in the presence of air, water and thiols, as well as in mammalian HeLa cells. ${ }^{80,84-86}$ Following on from that, in 2011, Yusop et al. ${ }^{87}$ showed that palladium nanoparticles trapped within polystyrene microspheres are capable of entering cells and mediating various $\mathrm{Pd}^{0}$-catalysed reactions (Figure 1.14b). ${ }^{84,85}$

There are many other examples of biocompatible metal-catalysed reactions, however, one which has attracted much attention of late, particularly in the field of cancer research, is that of transfer hydrogenation catalysis. ${ }^{78,79,81,88-90}$ Transfer hydrogenation reactions make use of various precious metal catalysts for the reduction of ketones, imines and $\mathrm{C}=\mathrm{C}$ double bonds and are capable of being performed in aqueous media using sodium formate as the hydrogen source. ${ }^{81,88}$ Because these hydride transfer reductions can be done under such mild conditions, they are thus capable of being carried out with biomolecules, such as pyruvate and $\beta$-nicotinamide adenine dinucleotide $\left(\mathrm{NAD}^{+}\right) .{ }^{81}$ In the area of biocatalysis, $\mathrm{NAD}^{+}$, and its reduced form, 1,4-NADH, are abundant coenzymes required for many reactions involving enzymatic reductions. ${ }^{89}$ The ratio of $\mathrm{NAD}^{+} / \mathrm{NADH}$ has been studied extensively over the past few years and has been shown to play a role in various metabolic functions and even cell death. ${ }^{91}$ It is for this reason that these coenzymes have become promising drug targets in the treatment of diseases such as cancer and, because NADH is too expensive to be used in stoichiometric amounts, there is current interest in the in situ regeneration of this coenzyme under biologically relevant conditions. ${ }^{91}$ The reduction of $\mathrm{NAD}^{+}$to regenerate $\mathrm{NADH}$ via metal complex catalysis can be seen in Figure $1.15 .^{89}$

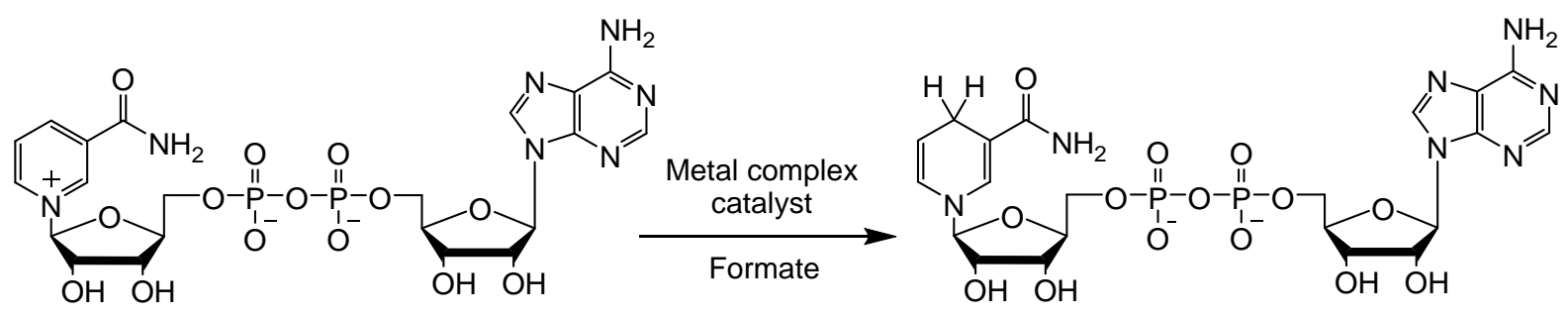

NAD $^{+}$

NADH

Figure 1.15: Reduction of $\mathrm{NAD}^{+}$to $\mathrm{NADH}$ via metal complex catalysis, using sodium formate as the hydrogen source. ${ }^{89}$

Steckhan et al. ${ }^{92}$ developed the first series of transfer hydrogenation catalysts in 1991 that were capable of utilising high concentrations of sodium formate to regenerate NADH in aqueous media at $\mathrm{pH} 7$ and $37{ }^{\circ} \mathrm{C} .86,90$ Since then, many organo-Ru(II), $-\mathrm{Rh}(\mathrm{III})$ and $-\mathrm{Ir}(\mathrm{III})$ 
complexes have likewise been found to be able to catalyse hydride transfer reactions under biologically relevant conditions. ${ }^{78,86,88,90}$ Ruthenium(II)-arene complexes were shown to form hydride complexes in aqueous solution with formate as the hydrogen source while rhodium(III) and iridium(III) pentamethylcyclopentadienyl (Cp*) complexes are capable of catalysing the regioselective reduction of $\mathrm{NAD}^{+}$to $\mathrm{NADH}$, again in the presence of formate. ${ }^{78,80,88,89,92-94}$ Sadler and co-workers found that lung cancer cells (A594) are remarkably tolerant to formate, even at millimolar concentrations, leading the same group to suggest that transfer hydrogenation catalysis could possibly be achieved within cancer cells. ${ }^{78,88,89}$ They investigated many metal complexes as potential intracellular hydride transfer catalysts, one of which being the iridium-arene complex, $\left[\left(\eta^{5}-\mathrm{C}_{5} \mathrm{Me}_{4} \mathrm{C}_{6} \mathrm{H}_{5}\right) \operatorname{Ir}(\text { phen })\left(\mathrm{H}_{2} \mathrm{O}\right)\right]^{2+}$ (Figure 1.16a), which was shown to affect the NAD ${ }^{+} / \mathrm{NADH}$ ratio within human $\mathrm{A} 2780$ ovarian cancer cell lines, thereby possibly affecting the function of $\mathrm{NADH}$-dependant redox enzymes. ${ }^{80,93}$ Another success story in this regard is the series of $\mathrm{Ru}(\mathrm{II})$ sulfonamido ethyleneamine complexes (Figure 1.16b) which, when co-administered with sodium formate, showed impressive activity towards human ovarian cancer cells by reducing the intracellular $\mathrm{NAD}^{+}$levels. ${ }^{78,80}$ Combined with its ability to initiate catalysis, sodium formate at non-toxic concentrations has therefore been shown to enhance and potentiate the anticancer activity of metal complexes. ${ }^{78,88}$ Although no metal-based catalytic drugs have advanced through to clinical trials, catalytic reactions have successfully been achieved in cancer cells, showing the potential for the design of safe, metal-based drugs.
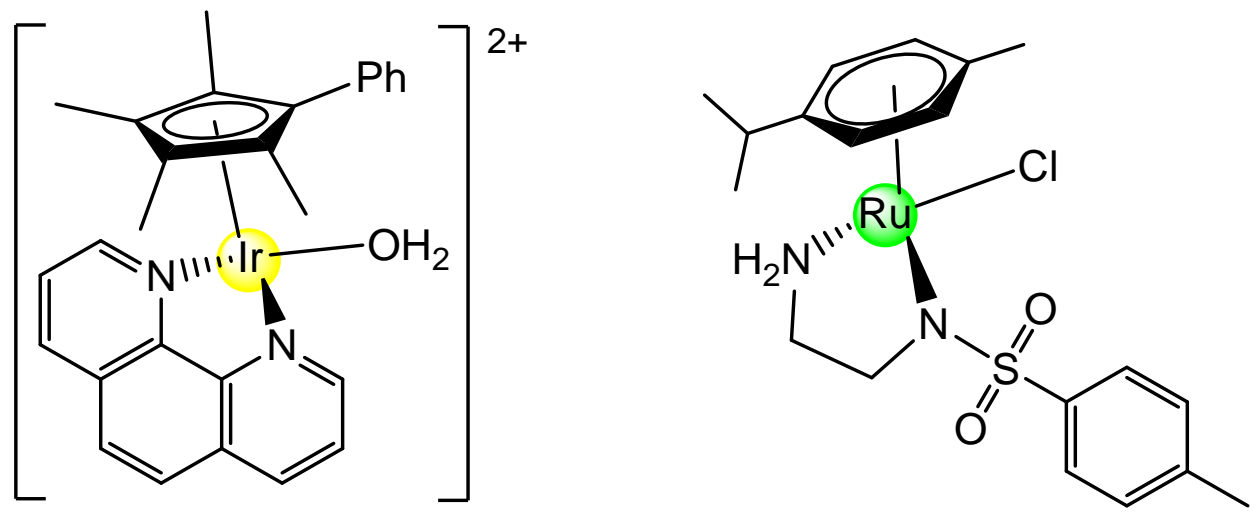

Figure 1.16: Complexes capable of intracellular transfer hydrogenation catalysis; (a) $\left[\left(\eta^{5}-\mathrm{C}_{5} \mathrm{Me}_{4} \mathrm{C}_{6} \mathrm{H}_{5}\right) \operatorname{Ir} \text { (phen) }\left(\mathrm{H}_{2} \mathrm{O}\right)\right]^{2+}$ by Betanzos-Lara et al. ${ }^{93}$ and (b) an example of a $\mathrm{Ru}(\mathrm{II})$ sulfonamido ethyleneamine complex synthesised by Soldevila-Barreda et al. ${ }^{78}$ 
In terms of the use of transfer hydrogenation catalysts which could have an effect on the viability of the malaria parasite, $P$. falciparum, little to no research has been conducted. This was until 2019 when Stringer et al. ${ }^{95}$ showed that a quinoline-based half-sandwich iridium complex tested in vitro at a concentration of $1000 \mathrm{ng} / \mathrm{mL}$ against the CQR $\mathrm{K} 1$ strain of P. falciparum displays a significant stepwise decrease in parasite viability with increasing concentrations of sodium formate. ${ }^{95}$ Although only a preliminary study, this result makes the idea of testing metal complexes for their hydride transfer capabilities within the malaria parasite an exciting and worthwhile endeavour.

\subsection{Summary and Motivation for the Current Study}

Malaria is one of the most prevalent parasitic diseases in the world, however, efforts to eradicate the disease are hindered by the spread of drug-resistant parasitic strains. This means that research into finding novel, alternative therapies has become a priority. Pharmacophore hybridisation has recently become a way of developing new drugs by the combination of two antimalarial pharmacophores into one molecule, thereby producing molecules which have enhanced activity and reduced ability to elicit resistance relative to the parent drugs. Currently, a number of antimalarial hybrids being researched have focused on the drug CQ because of its excellent antimalarial activity as well as its low toxicity and costeffectiveness. It is for this reason that the 7-chloroquinoline entity of CQ will be employed, along with the highly stable triazole structure, for the synthesis of the hybrid ligands in this study. Various aromatic groups possessing electron-withdrawing or -donating functionalities will be included in the structure of these ligands, one of which will incorporate the ferrocenyl moiety, as used in the structure of ferroquine. Furthermore, because of the significant enhancement in activity shown upon the incorporation of an aminoalkyl chain linker between the triazole and quinoline entities in literature, one series of compounds will contain an aminopropyl linker while one will not.

In addition to hybridisation as an effective strategy in the design of novel antimalarials, the incorporation of a metal into the structure of the molecule has shown great success, particularly in the development of anticancer drugs. The reason for this is that metal compounds offer great chemical diversity not always seen in organic drugs and the reactivity 
of the metal centres can be "fine-tuned" to target certain biomolecules. Because of this, this study focusses on the coordination of the organic ligands to an iridium centre to produce neutral, cyclometallated and cationic, $N, N$-chelated half-sandwich $\operatorname{Ir}(I I I)$ complexes. This will be done in order to improve the antiplasmodial activity of the compounds further, as well as to examine the effect of metal coordination on parasitic cross resistance.

The complexes will be tested for their ability to catalyse the hydride transfer reduction of $\mathrm{NAD}^{+}$to $\mathrm{NADH}$ with sodium formate as the hydrogen source. This type of reaction has been performed within cancer cells, with $\operatorname{Ir}(\mathrm{III}) \mathrm{Cp}^{*}$ complexes in particular showing very good catalytic ability. Transfer hydrogenation has, however, not until very recently been investigated within the malaria parasite, $P$. falciparum, although the success of these types of compounds as catalytic anticancer agents gives sufficient motivation for their use in this respect in this study. Figure 1.17 shows the rationale for the general structure of the complexes to be synthesised.

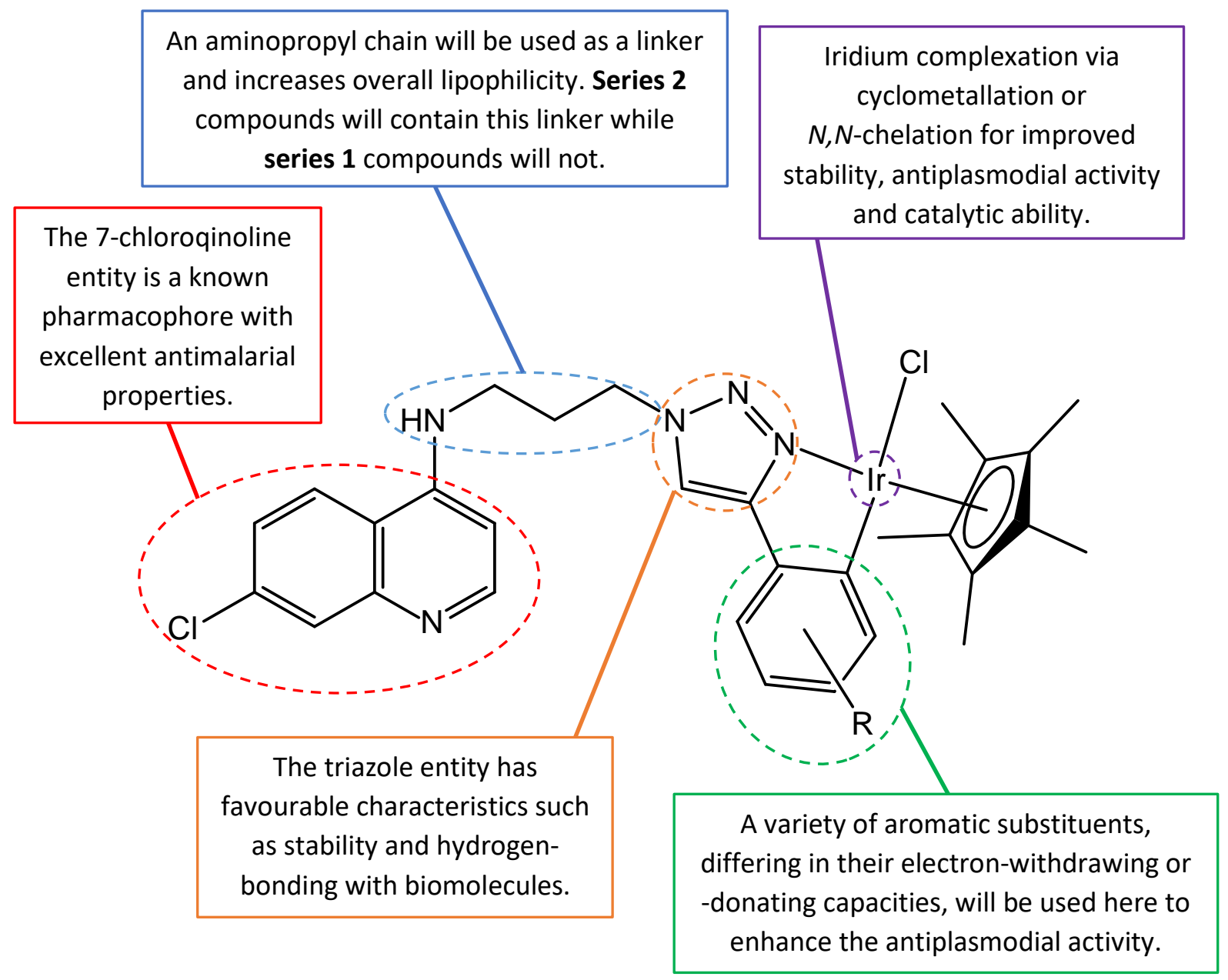

Figure 1.17: Generalised structure of the $\operatorname{Ir}($ III) half-sandwich complexes to be synthesised in this study, along with the structure-activity relationships of its constituents. 


\subsection{Aims and Objectives}

\subsubsection{Overall Aims}

The overall aims of this study were:

1) To synthesise and characterise various 7-chloroquinoline-1,2,3-triazole ligands and their corresponding neutral and cationic half-sandwich iridium(III) complexes.

2) To evaluate the in vitro antiplasmodial activity of these ligands and complexes.

3) To investigate possible mechanisms of action of these complexes.

4) To elucidate the ability of the complexes to catalyse the hydride transfer reduction of $\mathrm{NAD}^{+}$to $\mathrm{NADH}$ using sodium formate in a cell-free environment.

\subsubsection{Specific Objectives}

The specific objectives of this study were:

1) To synthesise a series of 7-chloroquinoline-1,2,3-triazole ligands containing various aromatic side groups. (Figure 1.18)<smiles>[R]c1cn(-c2ccnc3cc(Cl)ccc23)nn1</smiles>

Series 1

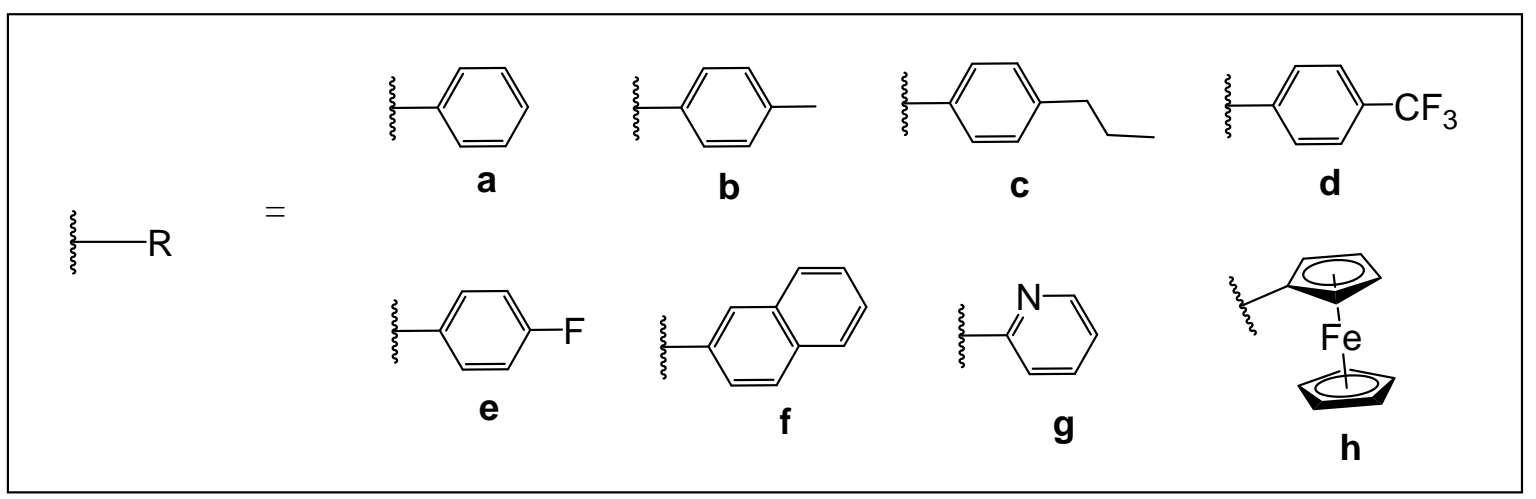

Figure 1.18: General structure of the series of 7-chloroquinoline-1,2,3-triazole ligands synthesised in this study. 
2) To synthesise a second, smaller series of 7-chloro-4-aminoquinoline-1,2,3-triazole ligands containing various aromatic side groups (Figure 1.19).<smiles>[R]c1cn(CCCNc2ccnc3cc(Cl)ccc23)nn1</smiles>

Series 2

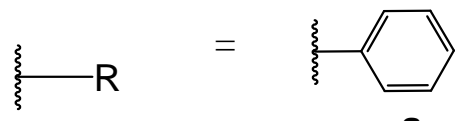

a

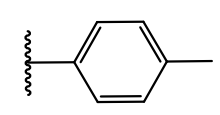

b

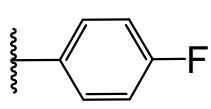

C

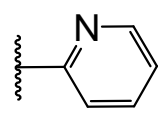

d

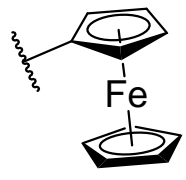

e

Figure 1.19: General structure of the series of 7-chloro-4-aminoquinoline-1,2,3-triazole ligands synthesised in this study.

3) To synthesise two series of cyclometallated Ir(III) complexes using the quinoline-triazole ligands described previously (Figure 1.20).

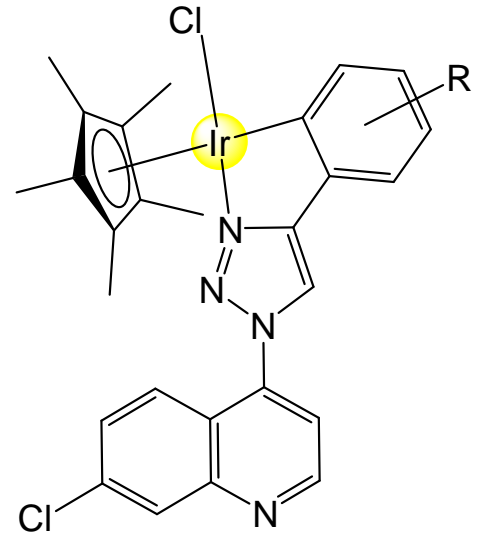

Series 1

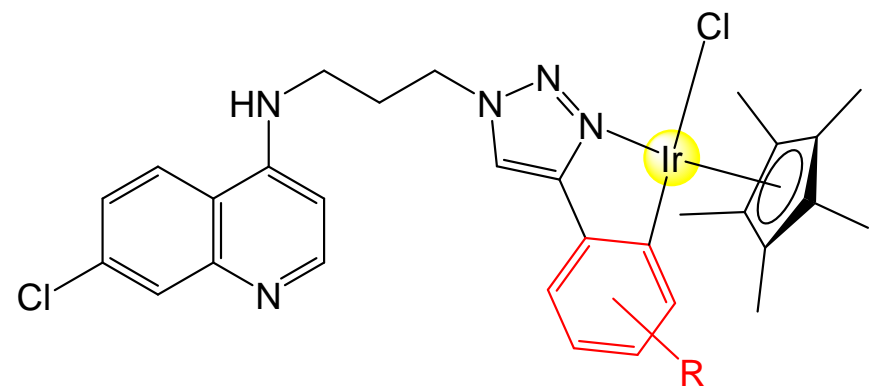

Series 2

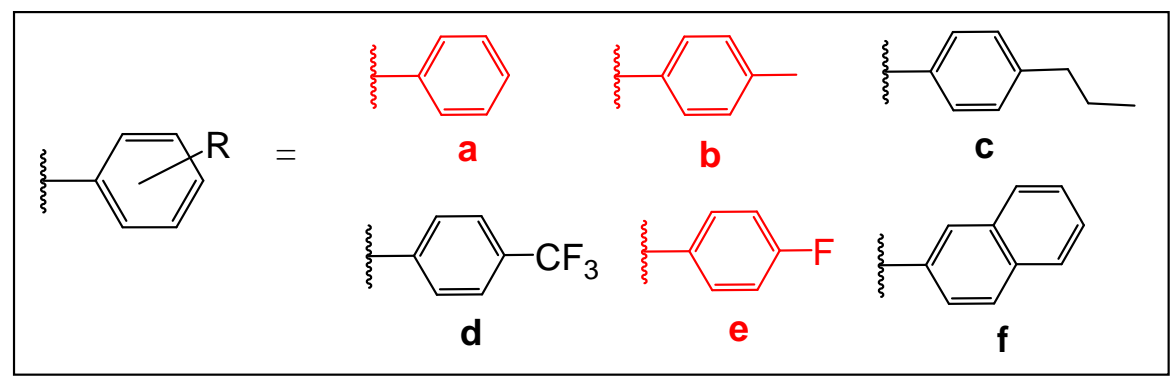

Figure 1.20: General structures of the two series of cyclometallated $\operatorname{Ir}(I I I)$ complexes. (Only the aromatic groups in red were used for series 2). 
4) To synthesise two $N, N$-chelated cationic $\operatorname{Ir}(I I I)$ quinoline-triazole complexes. (Figure 1.21)

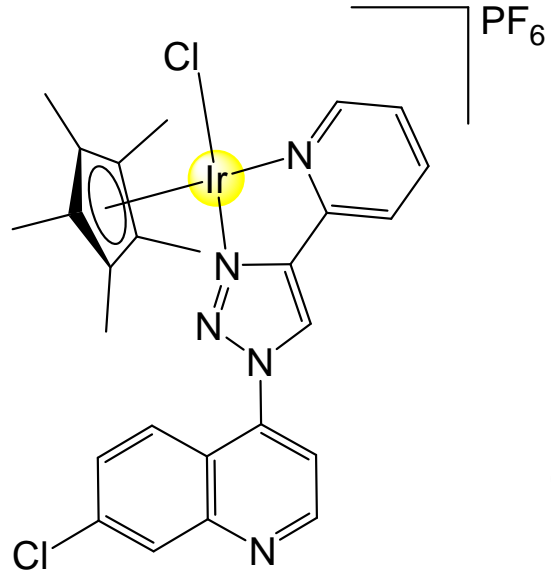

Series 1

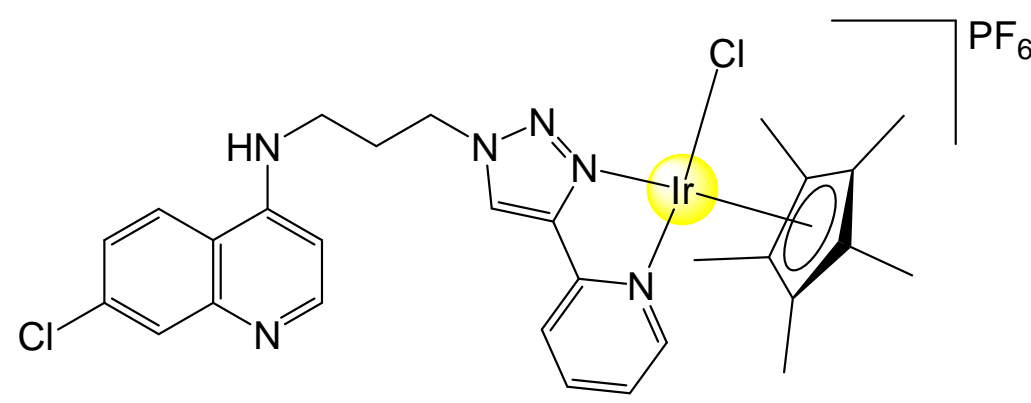

Series 2

Figure 1.21: General structures of the two $N, N$-chelated cationic $\operatorname{Ir}(I I I)$ quinoline-triazole complexes synthesised in this study.

5) To characterise all of the compounds synthesised using Nuclear Magnetic Resonance spectroscopy (NMR), Fourier Transform - Infrared spectroscopy (FT-IR), High Performance Liquid Chromatography (HPLC), Electrospray Ionisation Mass Spectroscopy (ESI-MS) and melting point analysis. Single crystal X-ray diffraction (XRD) analysis was used to provide further insight into the structure of some of the isolated complexes.

6) To investigate the in vitro antiplasmodial activity of all compounds against the CQS NF54 strain of $P$. falciparum. The most active compounds were further tested against the CQR $\mathrm{K} 1$ strain of $P$. falciparum. The most active compounds against both parasitic strains were tested for cytotoxicity against the Chinese Hamster Ovarian (CHO) cell line.

7) To carry out mechanistic studies on some of the active compounds, including speed-ofaction assays and tests for the inhibition of synthetic haemozoin ( $\beta$-haematin) formation using an NP-40 detergent-mediated assay.

8) Finally, to elucidate the ability of some of the $\operatorname{Ir}(I I I)$ complexes to catalyse the hydride transfer reduction of $\mathrm{NAD}^{+}$to $\mathrm{NADH}$ using sodium formate in a cell-free environment. 


\subsection{References}

1 M. Navarro, W. Castro and C. Biot, Organometallics, 2012, 31, 5715-5727.

$2 \quad$ World Health Organization, World Malaria Report 2018, Geneva, 2018.

3 S. M. Rich, F. H. Leendertz, G. Xu, M. LeBreton, C. F. Djoko, M. N. Aminake, E. E. Takang, J. L. D. Diffo, B. L. Pike, B. M. Rosenthal, P. Formenty, C. Boesch, F. J. Ayala and N. D. Wolfe, Proc. Natl. Acad. Sci., 2009, 106, 14902-14907.

4 R. Banerjee and D. E. Goldberg, In Antimalarial Chemotherapy: Mechanisms of Action, Resistance, and New Directions in Drug Discovery, Humana Press Inc, Totowa, NJ, 1st edn., 2001.

5 S. Vandekerckhove and M. D'Hooghe, Bioorg. Med. Chem., 2015, 23, 5098-5119.

$6 \quad$ N. Vale, L. Aguiar and P. Gomes, Front. Pharmacol., 2014, 5, 275.

7 L. H. Miller, D. I. Baruch, K. Marsh and O. K. Doumbo, Nature, 2002, 415, 673-679.

8 C. Biot, W. Castro, C. Y. Botté and M. Navarro, Dalton Trans., 2012, 41, 6335-6349.

9 P. L. Olliaro and D. E. Goldberg, Parasitol. Today, 1995, 11, 294-297.

10 P. F. Salas, C. Herrmann and C. Orvig, Chem. Rev., 2013, 113, 3450-3492.

11 Y. C. Ong and G. Gasser, Drug Discov. Today Technol. (in press), DOI:10.1016/j.ddtec.2019.06.001.

12 M. Foley and L. Tilley, Clin. Pharmacol. Ther., 1998, 79, 55-87.

13 R. G. Ridley, Nature, 2002, 415, 686-693.

14 V. V. Kouznetsov and A. Gómez-Barrio, Eur. J. Med. Chem., 2009, 44, 3091-3113.

15 T. J. Egan, R. Hunter, C. H. Kaschula, H. M. Marques, A. Misplon and J. Walden, J. Med. Chem., 2000, 43, 283-291.

16 V. V. Kouznetsov and A. Gómez-Barrio, Eur. J. Med. Chem., 2009, 44, 3091-3113.

17 M. Navarro, W. Castro, M. Madamet, R. Amalvict, N. Benoit and B. Pradines, Malar. J., $2014,13,1-8$ 
P. G. Bray, R. E. Martin, L. Tilley, S. A. Ward, K. Kirk and D. A. Fidock, Mol. Microbiol., 2005, 56, 323-333.

A. Ecker, A. M. Lehane, J. Clain and D. A. Fidock, Trends Parasitol., 2012, 28, 504-514.

21 World Health Organization, Global Report on Antimalarial Drug Efficacy and Drug Resistance: 2000-2010, Geneva, 2010.

22 T. Hirao and T. Moriuchi, Eds., Advances in Bioorganometallic Chemistry, Elsevier, 1st edn., 2019.

23 World Health Organisation, Guidelines for the Treatment of Malaria, Geneva, 2006.

24 N. Baartzes, T. Stringer and G. S. Smith, in Advances in Bioorganometallic Chemistry, eds. T. Hirao and T. Moriuchi, Elsevier, 2019, pp. 193-213.

25 E. M. Guantai, K. Ncokazi, T. J. Egan, J. Gut, P. J. Rosenthal, P. J. Smith and K. Chibale, Bioorg. Med. Chem., 2010, 18, 8243-8256.

26 G. M. Fisher, R. P. Tanpure, A. Douchez, K. T. Andrews and S. A. Poulsen, Chem. Biol. Drug Des., 2014, 84, 462-472.

27 S. Manohar, U. C. Rajesh, S. I. Khan, B. L. Tekwani and D. S. Rawat, ACS Med. Chem. Lett., 2012, 3, 555-559.

28 B. Meunier, Acc. Chem. Res., 2008, 41, 69-77.

29 Y. Zou, N. E. Fahmi, C. Vialas, G. M. Miller and S. M. Hecht, J. Am. Chem. Soc., 2002, $124,9476-9488$.

30 E. A. Sausville, R. W. Stein, J. Peisach and S. B. Horwitz, Biochemistry, 1978, 17, 27462754.

31 Nucleic-acid Drug Interactions, https://www.atdbio.com/content/16/Nucleic-aciddrug-interactions\#Bleomycin, (accessed 5 February 2018).

32 World Health Organization, WHO Model List of Essential Medicines, 2017.

33 N. Boechat, M. D. L. G. Ferreira, L. C. S. Pinheiro, A. M. L. Jesus, M. M. M. Leite, C. C. S. 
Júnior, A. C. C. Aguiar, I. M. De Andrade and A. U. Krettli, Chem. Biol. Drug Des., 2014, 84, 325-332.

34 S. Manohar, S. I. Khan and D. S. Rawat, Chem. Biol. Drug Des., 2011, 78, 124-136.

35 S. Manohar, S. I. Khan and D. S. Rawat, Bioorg. Med. Chem. Lett., 2010, 20, 322-325.

36 F. D. P. Varotti, A. C. C. Botelho, A. A. Andrade, R. C. De Paula, E. M. S. Fagundes, A. Valverde, L. M. U. Mayer, J. S. Mendonça, M. V. N. De Souza, N. Boechat and A. U. Krettli, Antimicrob. Agents Chemother., 2008, 52, 3868-3874.

37 C. Biot, F. Nosten, L. Fraisse, D. Ter-Minassian, J. Khalife and D. Dive, Parasite, 2011, 18, 207-214.

38 To Evaluate the Efficacy of a Single Dose Regimen of Ferroquine and Artefenomel in Adults and Children With Uncomplicated Plasmodium Falciparum Malaria (FALCI), https://clinicaltrials.gov/ct2/show/NCT02497612, (accessed 20 October 2019).

39 S. G. Agalave, S. R. Maujan and V. S. Pore, Chem. Asian J., 2011, 6, 2696-2718.

40 A. H. Kategaonkar, P. V. Shinde, A. H. Kategaonkar, S. K. Pasale, B. B. Shingate and M. S. Shingare, Eur. J. Med. Chem., 2010, 45, 3142-3146.

41 E. Tesfaselassie, Antimalarial Drug Discovery using Triazoles to Overcome Chloroquine Resistance, Portland, OR, 2000.

42 X. M. Chu, C. Wang, W. L. Wang, L. L. Liang, W. Liu, K. K. Gong and K. L. Sun, Eur. J. Med. Chem., 2019, 166, 206-223.

43 M. Navarro, C. Gabbiani, L. Messori and D. Gambino, Drug Discov. Today, 2010, 15, 1070-1078.

44 N. P. E. Barry and P. J. Sadler, ACS Nano, 2013, 7, 5654-5659.

45 G. Gasser and N. Metzler-Nolte, Curr. Opin. Chem. Biol., 2012, 16, 84-91.

46 P. Ehrlich and A. Bertheim, Ber. Dtsch. Chem. Ges., 1912, 45, 756-766.

47 S. P. Fricker, Dalton Trans., 2007, 4903.

48 B. C. S. Allardyce and P. J. Dyson, Platin. Met. Rev., 2001, 45, 62-69. 
50 L. Ronconi and P. J. Sadler, Coord. Chem. Rev., 2007, 251, 1633-1648.

51 M. A. Jakupec, M. Galanski, V. B. Arion, C. G. Hartinger and B. K. Keppler, Dalton Trans., 2008, 2, 183-194.

52 T. Gianferrara, I. Bratsos and E. Alessio, Dalton Trans., 2009, 37, 7588-7598.

53 S. E. Harpstrite, A. A. Beatty, S. D. Collins, A. Oksman, D. E. Goldberg and V. Sharma, Inorg. Chem., 2003, 42, 2294-2300.

54 N. Wasi, H. B. Singh, A. Gajanana and A. N. Raichowdhary, Inorg. Chim. Acta, 1987, 135, 133-137.

55 R. A. Sánchez-Delgado, M. Navarro, H. Pérez and J. A. Urbina, J. Med. Chem., 1996, 39, 5204-5209.

56 P. R. F. Marcelino, M. B. Moreira, T. M. Lacerda and S. S. da Silva, Biomedical Applications of Metals, eds. M. Rai, A. P. Ingle and S. Medici, Springer International Publishing, Cham, 2018, pp. 167-194.

57 C.S. Rajapakse; A. Martínez; B. Naoulou; A.A. Jarzecki; L. Suárez; C. Deregnaucourt; V. Sinou; J. Schrével; E. Musi; G. Ambrosini; G.K. Schwartz; R.A. Sánchez-Delgado, Inorg. Chem., 2009, 48, 1122-1131.

58 M. Navarro, S. Pekerar and H. A. Pérez, Polyhedron, 2007, 26, 2420-2424.

59 F. Dubar, J. Khalife, J. Brocard, D. Dive and C. Biot, Molecules, 2008, 13, 2900-2907.

60 A. Kondratskyi, K. Kondratska, F. Vanden Abeele, D. Gordienko, C. Dubois, R. A. Toillon, C. Slomianny, S. Lemière, P. Delcourt, E. Dewailly, R. Skryma, C. Biot and N. Prevarskaya, Sci. Rep., 2017, 7, 1-15.

61 A. Vessieres, G. Jaouen, M. Gruselle, J. L. Rossignol, M. Savignac, S. Top and S. Greenfield, J. Steroid Biochem., 1988, 30, 301-306.

62 C. Biot, G. Glorian, L. A. Maciejewski, J. S. Brocard, O. Domarle, G. Blampain, P. Millet, A. J. Georges, H. Abessolo, D. Dive and J. Lebibi, J. Med. Chem., 1997, 40, 3715-3718. 
S. A. Charman, S. Arbe-Barnes, I. C. Bathurst, R. Brun, M. Campbell, W. N. Charman, F. C. K. Chiu, J. Chollet, J. C. Craft, D. J. Creek, Y. Dong, H. Matile, M. Maurer, J. Morizzi, T. Nguyen, P. Papastogiannidis, C. Scheurer, D. M. Shackleford, K. Sriraghavan, L. Stingelin, Y. Tang, H. Urwyler, X. Wang, K. L. White, S. Wittlin, L. Zhou and J. L. Vennerstrom, Proc. Natl. Acad. Sci., 2011, 108, 4400-4405.

64 T. Stringer, L. Wiesner and G. S. Smith, Eur. J. Med. Chem., 2019, 179, 78-83.

65 N. Baartzes, T. Stringer, R. Seldon, D. F. Warner, D. Taylor, S. Wittlin, K. Chibale and G. S. Smith, Eur. J. Med. Chem., 2019, 180, 121-133.

66 M. Albrecht, Chem. Rev., 2010, 110, 576-623.

67 J. P. Djukic, J. B. Sortais, L. Barloy and M. Pfeffer, Eur. J. Inorg. Chem., 2009, 7, 817-853.

68 A. D. Ryabov, Chem. Rev., 1990, 90, 403-424.

69 N. Cutillas, G. S. Yellol, C. De Haro, C. Vicente, V. Rodríguez and J. Ruiz, Coord. Chem. Rev., 2013, 257, 2784-2797.

70 Z. Liu, A. Habtemariam, A. M. Pizarro, S. A. Fletcher, A. Kisova, O. Vrana, L. Salassa, P. C. A. Bruijnincx, G. J. Clarkson, V. Brabec and P. J. Sadler, J. Med. Chem., 2011, 54, 30113026.

71 G. S. Yellol, A. Donaire, J. G. Yellol, V. Vasylyeva, C. Janiak and J. Ruiz, Chem. Commun., 2013, 49, 11533-11535.

72 P. Chellan, S. Nasser, L. Vivas, K. Chibale and G. S. Smith, J. Organomet. Chem., 2010, 695, 2225-2232.

73 P. Chellan, K. M. Land, A. Shokar, A. Au, S. H. An, C. M. Clavel, P. J. Dyson, C. de Kock, P. J. Smith, K. Chibale and G. S. Smith, Organometallics, 2012, 31, 5791-5799.

74 M. Adams, C. de Kock, P. J. Smith, K. Chibale and G. S. Smith, J. Organomet. Chem., 2013, 736, 19-26.

75 L. Rylands, A. Welsh, K. Maepa, T. Stringer, D. Taylor, K. Chibale and G. S. Smith, Eur. J. Med. Chem., 2019, 161, 11-21.

76 P. Schwab, R. H. Grubbs and J. W. Ziller, J. Am. Chem. Soc., 1996, 118, 100-110. 
77 S. Hashiguchi, A. Fujii, K.-J. Haack, K. Matsumura, T. Ikariya and R. Noyori, Angew. Chem. Int. Ed. Engl., 1997, 36, 288-290.

78 J. J. Soldevila-Barreda, I. Romero-Canelón, A. Habtemariam and P. J. Sadler, Nat. Commun., 2015, 6, 6582.

79 A. H. Ngo, M. Ibañez and L. H. Do, ACS Catal., 2016, 6, 2637-2641.

80 P. K. Sasmal, C. N. Streu and E. Meggers, Chem. Commun., 2013, 49, 1581-1587.

81 J. J. Soldevila-Barreda and P. J. Sadler, Curr. Opin. Chem. Biol., 2015, 25, 172-183.

82 S. J. Dougan, A. Habtemariam, S. E. McHale, S. Parsons and P. J. Sadler, Proc. Natl. Acad. Sci., 2008, 105, 11628-11633.

83 C. Streu and E. Meggers, Angew. Chem. Int. Ed., 2006, 45, 5645-5648.

84 Y. Bai, J. Chen and S. C. Zimmerman, Chem. Soc. Rev., 2018, 47, 1811-1821.

85 J. L. M. Miguel Martínez-Calvo, Coord. Chem. Rev., 2018, 359C, 57-79.

86 A. H. Ngo, S. Bose and L. H. Do, Chem. Eur. J., 2018, 24, 10584-10594.

87 R. M. Yusop, A. Unciti-Broceta, E. M. V. Johansson, R. M. Sánchez-Martín and M. Bradley, Nat. Chem., 2011, 3, 239-243.

88 J. J. Soldevila-Barreda, A. Habtemariam, I. Romero-Canelón and P. J. Sadler, J. Inorg. Biochem., 2015, 153, 322-333.

89 Y. K. Yan, M. Melchart, A. Habtemariam, A. F. A. Peacock and P. J. Sadler, J. Biol. Inorg. Chem., 2006, 11, 483-488.

90 J. J. Soldevila-Barreda and N. Metzler-Nolte, Chem. Rev., 2019, 119, 829-869.

91 J. J. Soldevila-Barreda, P. C. A. Bruijnincx, A. Habtemariam, G. J. Clarkson, R. J. Deeth and P. J. Sadler, Organometallics, 2012, 31, 5958-5967.

92 E. Steckhan, S. Herrmann, R. Ruppert, E. Dietz, M. Frede and E. Spika, Organometallics, $1991,10,1568-1577$.

93 S. Betanzos-Lara, Z. Liu, A. Habtemariam, A. M. Pizarro, B. Qamar and P. J. Sadler, Angew. Chem. Int. Ed., 2012, 51, 3897-3900. 
94 H. C. Lo, C. Leiva, O. Buriez, J. B. Kerr, M. M. Olmstead and R. H. Fish, Inorg. Chem., $2001,40,6705-6716$.

95 T. Stringer, D. R. Melis and G. S. Smith, Dalton Trans., 2019, 48, 13143-13148. 


\section{Chapter 2}

\section{Synthesis and characterisation of 7-chloroquinoline-1,2,3-triazole}

\section{compounds}

\subsection{Introduction}

Malaria is the biggest killer of humans globally, with the deadliest species of the parasite, Plasmodium falciparum, having shown an ability to evade all prescribed treatments, most recently artemisinin-based combination therapies (ACTs). ${ }^{1-3}$ Focus therefore needs to be given to improving the activity of known pharmacophores within drug-resistant strains of the parasite. As mentioned in Chapter 1, an important chemical entity found in many antimalarial drugs, such as chloroquine and amodiaquine, is the highly successful 7-chloroquinoline pharmacophore. ${ }^{4-8}$ The success of many 7-chloroquinoline-based antimalarial drugs was founded not only on great clinical efficacy, but also on factors such as good host safety and cost effectiveness. ${ }^{9-11}$ Since chloroquine (CQ) was the mainstay of chemotherapy against malaria for much of the last 50 years, structural modification of this drug, particularly at the aminoalkyl side chain, with another bioactive entity could bring about the hybrid-drug therapy that is desperately needed to stem the tide of drug resistance. ${ }^{9,11-13}$ In this regard, a few excellent reviews on the use of hybrid drugs for malaria have been published over the last decade. ${ }^{13-16}$

A good bioactive candidate for use in combination with 7-chloroquinoline is the 1,2,3-triazole group, and several 1,2,3-triazole derivatives have been reported as effective antimalarial agents against both $C Q$-sensitive and CQ-resistant $P$. falciparum strains. ${ }^{17}$ The importance of triazolic compounds in medicinal chemistry is irrefutable. This is underscored by the ability of the five-membered ring to undergo hydrogen bonding, therefore making it perfect in binding biological targets such as those within the malaria parasite. ${ }^{18-20}$ Several groups have reported the synthesis and antiplasmodial evaluation of 1,2,3-triazole-based quinoline compounds and some of the most active compounds of these studies are shown in Figure 2.1. ${ }^{6,21-23}$ Of these hybrid compounds, some have the quinoline directly attached to the triazole, while in others, the two entities are separated by a linear aminoalkyl chain linker. Guantai et al. synthesised 


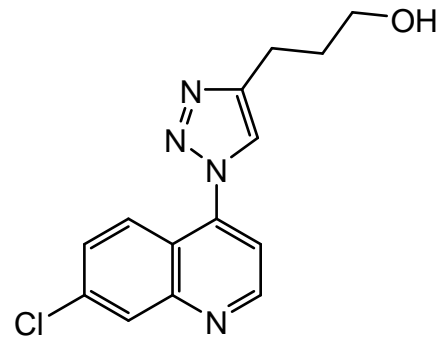

Pereira et al. ${ }^{6}$ $\left(9.6 \mu \mathrm{M}^{\mathrm{W} 2}\right)$

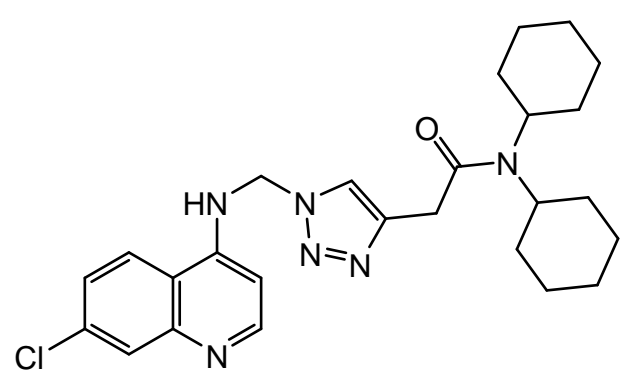

Joshi et al. ${ }^{21}$
$\left(0.35 \mu \mathrm{M}^{\mathrm{D} 10}\right)$

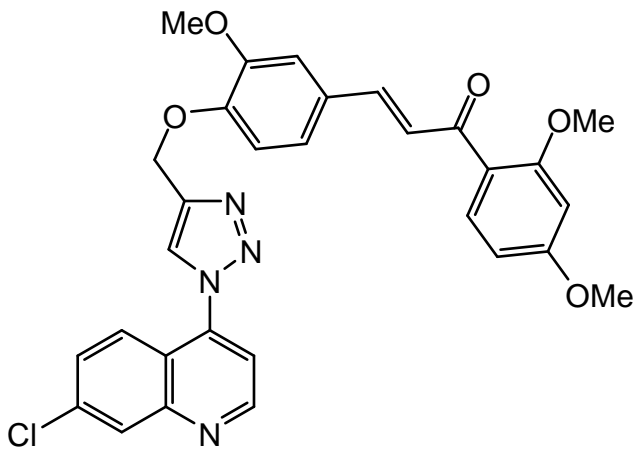

Guantai et al. ${ }^{23}$ $\left(0.04 \mu \mathrm{M}^{\mathrm{D} 10}, 0.07 \mu \mathrm{M}^{\mathrm{Dd} 2}\right.$, $0.09 \mu \mathrm{M}^{\mathrm{W} 2}$ )<smiles>Cc1cccc(C)c1Nc1nc(COc2nc(COc3cn(CCCNc4ccnc5cc(Cl)ccc45)nn3)nc(N(C)C)n2)nc2ccc(Cl)cc12</smiles>

Manohar et al. 22 $\left(0.73 \mu \mathrm{M}^{\mathrm{W} 2}, 0.58 \mu \mathrm{M}^{\mathrm{D} 6}\right)$

Figure 2.1. Selected examples of active quinoline-triazole compounds against various strains of P. falciparum, reported in literature. ${ }^{6,21-23}$

highly-active, directly-attached quinoline-triazole compounds with sub-micromolar $I_{50}$ values against all three of the tested $P$. falciparum strains (D10, Dd2 and W2). ${ }^{23}$ Similarly, Pereira et al. also synthesised a series of directly-attached quinoline-triazole compounds with some having low micromolar activity, but found that having a linker between the triazole and quinoline entities is crucial for the antimalarial activity and that there is a direct correlation between this activity and the length of the alkyl linker. ${ }^{6}$ It is for this reason that many of the known quinoline-triazole hybrid compounds bear a one- to three-carbon spacer, such as the compounds synthesised by Joshi et al. ${ }^{21}$ and Manohar et al. ${ }^{22}$ (Figure 2.1), both of which exhibited good, micromolar activity against both sensitive and resistant strains.

Owing to the success of the aforementioned 7-chloroquinoline-triazole hybrids as antimalarial agents, particularly in the resistant $P$. falciparum strains, this chapter will focus 
on the synthesis of various 7-chloroquinoline-1,2,3-triazole compounds, both new and previously-synthesised. Figure 2.2 shows the structure-function relationship of the compounds reported in this chapter. Encouraged by the results obtained by Guantai et al. for the direct attachment of the 7-chloroquinoline pharmacophore to the triazole entity, a similar synthetic route for the first series of 7-chloroquinolinotriazole compounds was followed. ${ }^{23}$ An aminopropyl chain linker was included in the scaffold of the second series of 7-chloro-4aminoquinolinotriazole compounds because of the reported improved antimalarial activity exhibited when incorporating a linear aminoalkyl chain between the two bioactive groups. ${ }^{6,17}$ Furthermore, various aromatic moieties bearing side-groups ranging from electronwithdrawing to electron-donating in nature were attached to position-4 on the triazole in order to delineate possible structure-activity relationships.

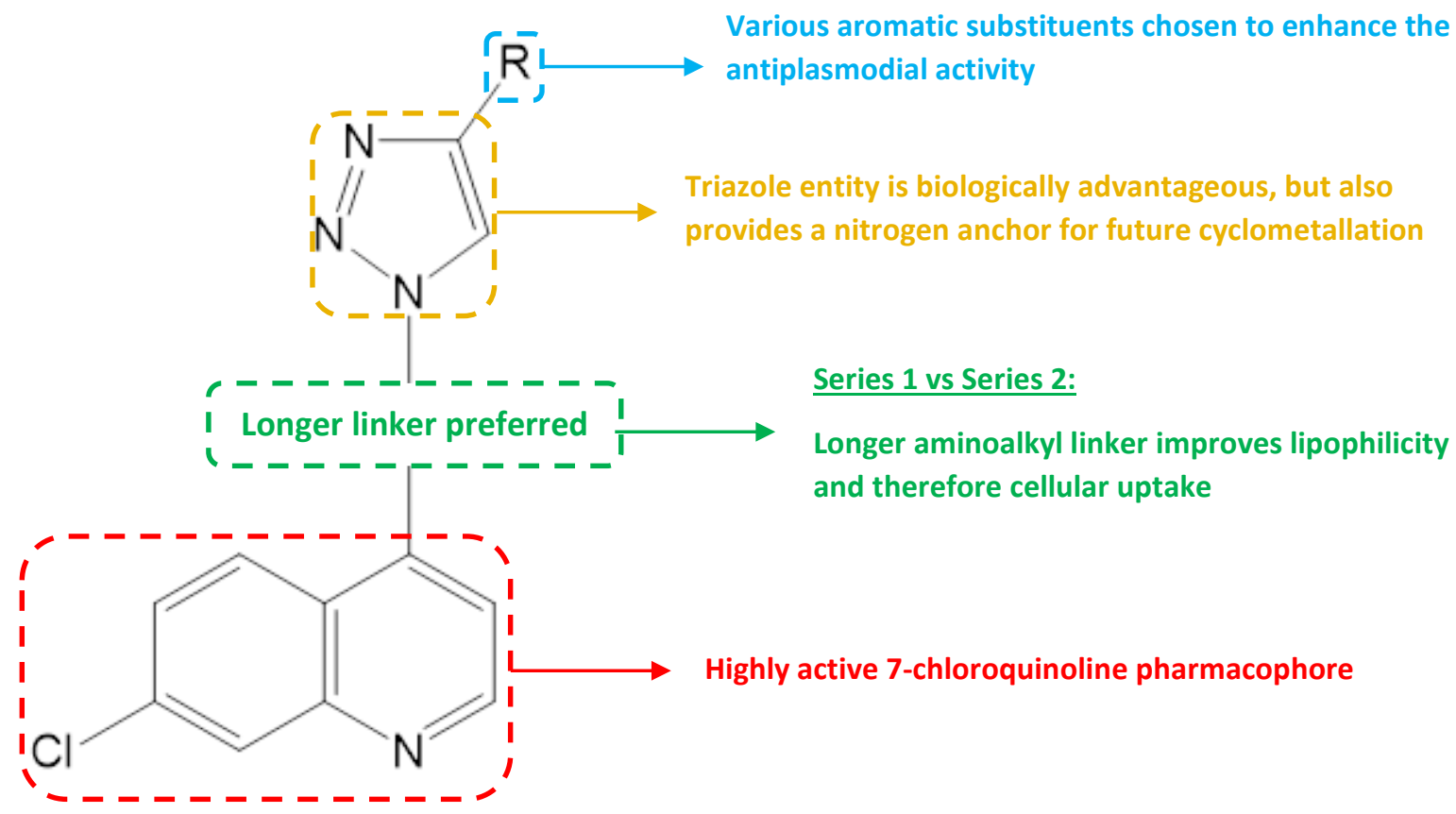

Figure 2.2. The structure-function relationship of the quinoline-triazole ligands to be reported in this chapter. 


\subsection{Synthesis of a series of 7-chloroquinolinotriazole derivatives}

\subsubsection{Synthesis}

The synthesis of the series of 7-chloroquinoline-1,2,3-triazole derivatives ( $2 a-h)$ required two synthetic steps, as outlined in Scheme 2.1 .<smiles>Cc1ccc(Cl)c2ccc(Cl)cc12</smiles>

$\mathrm{Cl}^{\prime}$

a

e
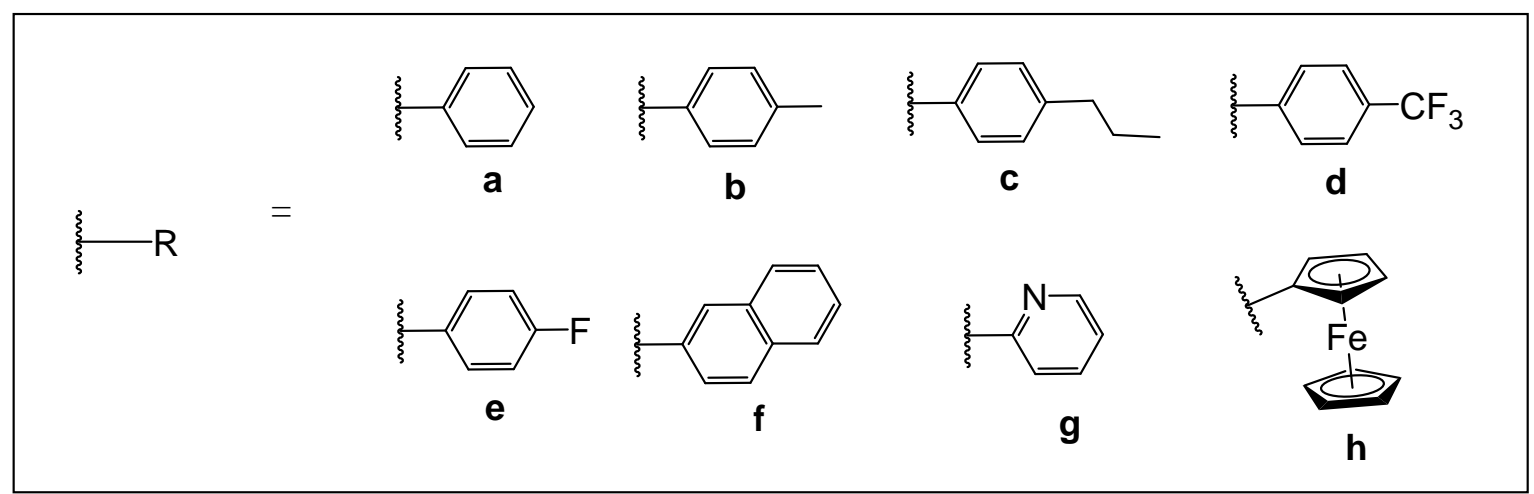<smiles>Nc1ccnc2cc(Cl)ccc12</smiles>

1 (ii)<smiles>[R]c1cn(-c2ccnc3cc(Cl)ccc23)nn1</smiles>

$2 a-h$

Scheme 2.1. Synthesis of the 7-chloroquinolinotriazole derivatives. Reagents and conditions: (i) $\mathrm{NaN}_{3}, \mathrm{DMF}, 65{ }^{\circ} \mathrm{C}, 5 \mathrm{~h}$; (ii) Aromatic alkyne, $t$-BuOH or DCM/ $\mathrm{H}_{2} \mathrm{O}(1: 1), \mathrm{CuSO}_{4} .5 \mathrm{H}_{2} \mathrm{O}$, sodium ascorbate, $30^{\circ} \mathrm{C}, 2-72 \mathrm{~h}$.

The first step involved the synthesis of 4-azido-7-chloroquinoline, 1, from 4,7-dichloroquinoline and excess sodium azide via a nucleophilic aromatic substitution reaction $\left(S_{N} A r\right) \cdot{ }^{23}$ In this type of reaction, the addition of a nucleophile to an aromatic ring displaces the desired leaving group, the mechanism of which is shown in Figure $2.3 .{ }^{24}$ The highly nucleophilic azide anion attacks the quinoline at the carbon bearing the chloride-group at position-4 (numbering shown in Figure 2.3). This chloride, as opposed to the one at position-7 on the quinoline, is the favoured leaving group. This is a consequence of the position of the quinoline nitrogen, which acts like an electron sink and can accept a lone pair of electrons, thereby allowing the attack by the nucleophilic azide at carbon-4. Subsequent elimination of the chloride results in the desired quinoline-azide compound. This azide 
precursor, 1, was isolated as pale-yellow, needle-like crystals in a good yield (70\%). This compound is soluble in a range of polar and non-polar solvents, as well as alcoholic solvents.

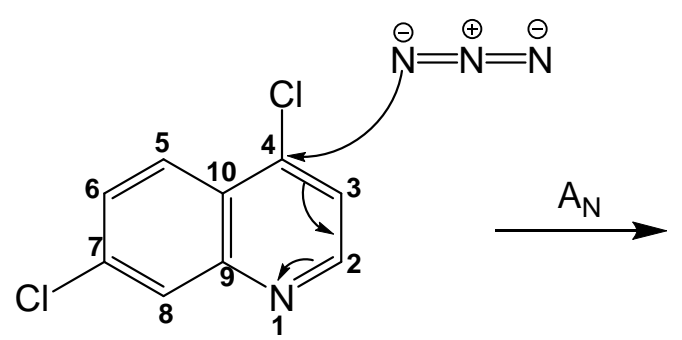

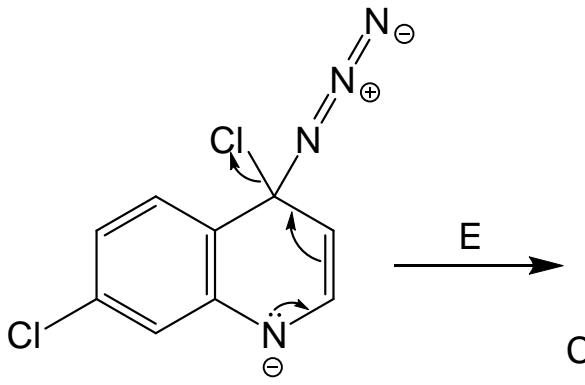<smiles>Nc1ccnc2cc(Cl)ccc12</smiles>

1

Figure 2.3. Proposed mechanism of the nucleophilic aromatic substitution $\left(S_{N} A r\right)$ reaction to afford azide compound $1 .^{24}$

The second step involved reacting the 4-azido-7-chloroquinoline, 1, with various aromatic alkynes via a "click" reaction following the methodology of Sharpless and co-workers ${ }^{25,26}$ for the $\mathrm{Cu}(\mathrm{I})$-catalysed azide-alkyne 1,3-dipolar cycloaddition (CuAAC) reaction. This method is commonly used for the synthesis of 1,2,3-triazole hybrid compounds and has become the benchmark of 'click chemistry'. The reason for this is because the reaction is very reliable, biocompatible and high-yielding, with the copper(I) salts being reported to accelerate the reaction 10 million-fold. ${ }^{25,26}$ This copper catalyst is prepared in situ using sodium ascorbate to reduce $\mathrm{Cu}(\mathrm{II})$ to $\mathrm{Cu}(\mathrm{I})$. The catalytic mechanism subsequently proposed by Sharpless and Fokin et al. ${ }^{27}$ suggests a $\sigma$-bound copper acetylide bearing a $\pi$-bound copper forms from the terminal alkyne, which then coordinates to the terminal azide (Figure 2.4). This results in the formation of an unusual 6-membered copper metallacycle, with the second copper atom acting as a stabilising donor ligand. This is the point at which cyclisation and subsequent protonation occurs, resulting in the triazole product and regeneration of the catalyst which can be used for further catalytic cycles. For the synthesis of 7-chloroquinolinotriazole compounds, $\mathbf{2 a - h}$, the various aromatic alkynes were chosen according to the electronwithdrawing or -donating effect of the respective side-group. This was done to be able to draw conclusions on which type of functional group results in better overall antiplasmodial activity. Following a literature method $^{9}$, the reactions were carried out in a mixture of DCM or $t$-butanol and water, in the presence of $\mathrm{CuSO}_{4} .5 \mathrm{H}_{2} \mathrm{O}$ and sodium ascorbate. $t$-Butanol was used in the cases where the reactions proceeded for longer than $24 \mathrm{~h}$ as the DCM was 

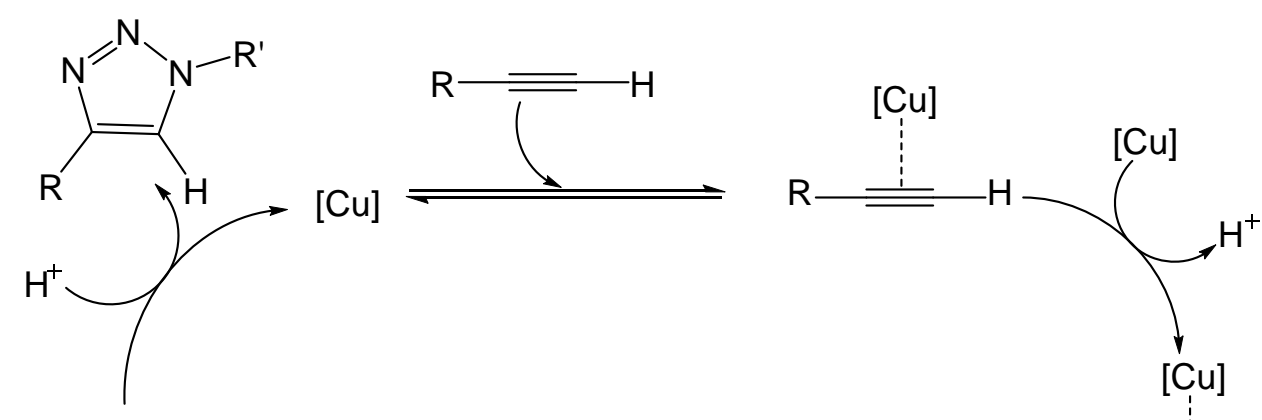<smiles>[R]c1nnn([R])c1[AlH2]</smiles><smiles>[R]C#CC(C)C(C)N[R]</smiles>
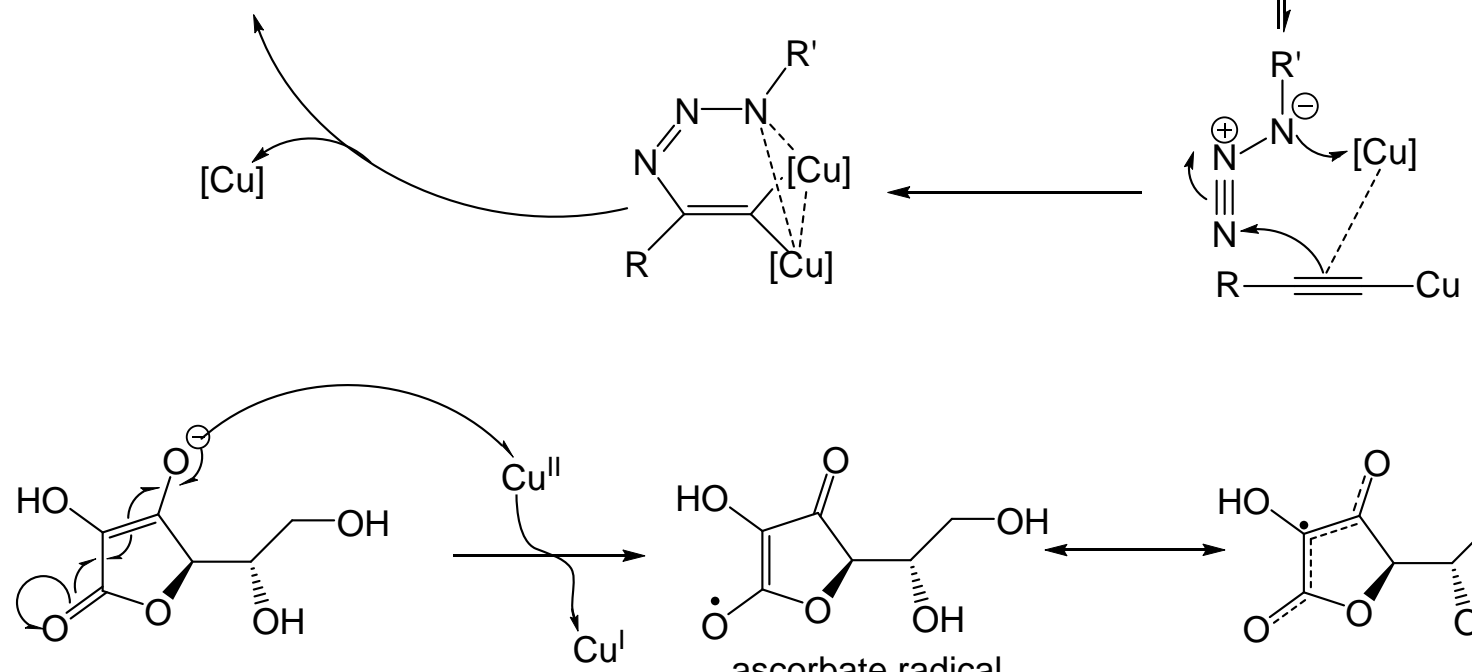<smiles>O=C1O[C@H]([C@@H](O)CO)C(=O)C1O</smiles>

Figure 2.4. Proposed catalytic cycle for the CuAAC reaction to afford compounds $\mathbf{2 a - h}{ }^{27}$

evaporating at $30^{\circ} \mathrm{C}$ over time. In general, the synthesis of the ligands proceeded easily and quickly. The exceptions to this were the syntheses of ligand 2 c (23\%) and the pyridylcontaining ligand, $\mathbf{2 g}$, which was a sluggish reaction, taking $72 \mathrm{~h}$ to react and yielding only $43 \%$ product. The other reactions reached completion within $24 \mathrm{~h}$, resulting in white and paleyellow solids with moderate to good yields of $62-83 \%$. All compounds were stable at room temperature and when exposed to air.

\subsubsection{Characterisation}

The 4-azido-7-chloroquinoline, 1, and 7-chloroquinolinotriazole derivatives, 2a-h, were characterised using various spectroscopic and analytical techniques. These included ${ }^{1} \mathrm{H}$, ${ }^{13} \mathrm{C}\left\{{ }^{1} \mathrm{H}\right\},{ }^{19} \mathrm{~F}\left\{{ }^{1} \mathrm{H}\right\}$ (compounds $\mathbf{2 d}$ and $\mathbf{2 e}$ ), ${ }^{1} \mathrm{H}-{ }^{1} \mathrm{H}$ correlation spectroscopy (COSY) and 
heteronuclear single quantum coherence (HSQC) nuclear magnetic resonance (NMR) spectroscopy, as well as infrared (IR) spectroscopy, liquid chromatography coupled with mass spectrometry (LCMS), electrospray ionisation-mass spectrometry (ESI-MS) and melting point analysis.

\section{NMR Spectroscopy}

Analysis of the ${ }^{1} \mathrm{H}$ NMR spectrum of compound 1 and comparison of it to the spectrum of the 4,7-dichloroquinoline starting material confirms the synthesis of the desired azide compound (Figure 2.5). Although the number, multiplicity and integrations of the peaks remain the same for both the starting material and compound 1, noticeable shifts in certain peaks attest to the synthesis of the desired azide product. The most notable peak shift is the upfield shift in the signal for the proton at position-3 from $\delta_{H} 7.49 \mathrm{ppm}$ to $\delta_{H} 7.13 \mathrm{ppm}$. The reason for this is because the azide has a weaker electron-withdrawing effect compared to the chloride, thus the proton adjacent to the azide group will be more shielded. The product of the click reaction between the 4 -azido-7-chloroquinoline, $\mathbf{1}$, and phenylacetylene is ligand $\mathbf{2 a}$ and its respective

(a)
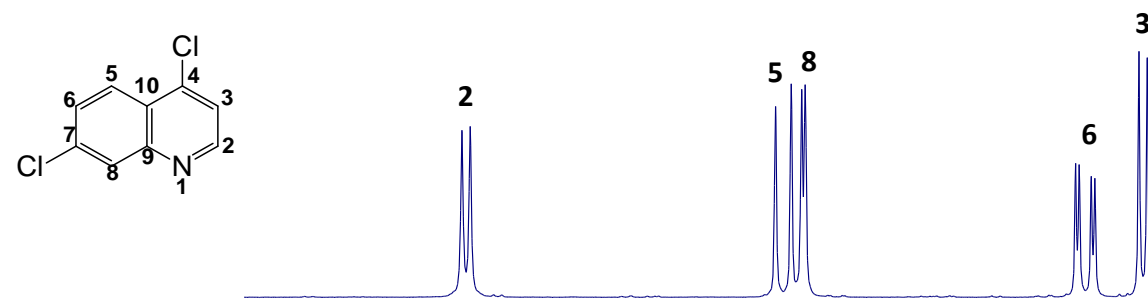

3

(b)

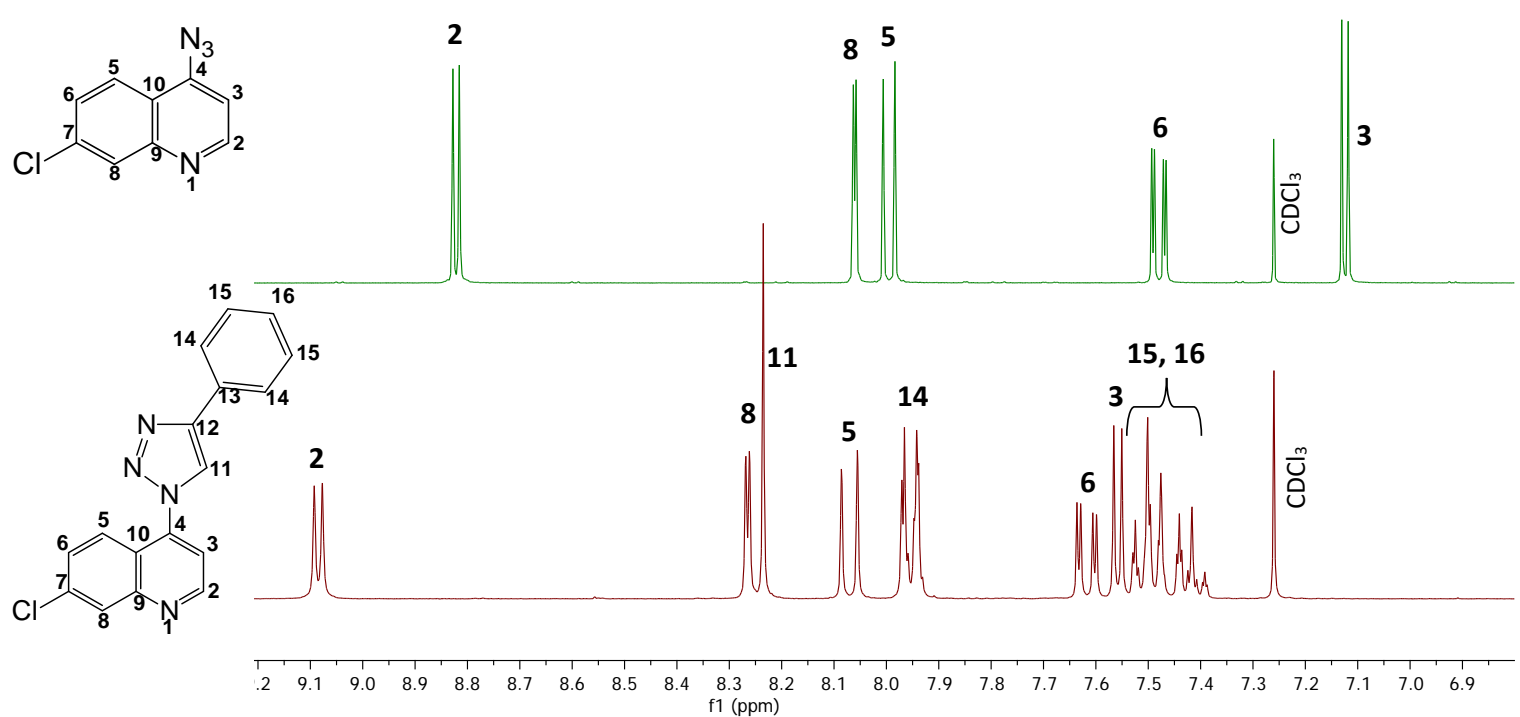

Figure 2.5: Stacked ${ }^{1} \mathrm{H}$ NMR spectra showing the aromatic regions of (a) 4,7-dichloroquinoline, (b) azide precursor $\mathbf{1}$ and (c) ligand $\mathbf{2 a}$ in $\mathrm{CDCl}_{3}$. 
${ }^{1} \mathrm{H}$ NMR spectrum (spectrum (c) in Figure 2.5) attests to its correct synthesis. Evidence for the success of the click reaction is indicated, most notably, by the presence of the triazole proton signal, $\mathrm{H}-11$, which is present as a singlet integrating for one proton at $\delta_{H} 8.24 \mathrm{ppm}$. The doublet for $\mathrm{H}-3$ on the quinoline entity of $2 \mathrm{a}$ is present more downfield compared to the starting material, $\mathbf{1}$, since the triazole has a much greater electron-withdrawing effect compared to the azide functionality. The final indicator for the synthesis of the desired 7-chloroquinolinotriazole compound is the presence of the phenyl proton signals, which exist as multiplets in their different characteristic aromatic regions. Analysis of the ${ }^{1} \mathrm{H}$ NMR spectra of the rest of this series of 7-chloroquinolinotriazole compounds (i.e. $\mathbf{2} \mathbf{b}-\mathbf{h}$ ) confirms that all nine desired compounds have been synthesised. Figure 2.6 shows the ${ }^{1} \mathrm{H}$ NMR spectra for three other representative compounds of this series. Again, the diagnostic triazole proton signal provides the best evidence for successful 7-chloroquinolinotriazole formation, with the characteristic singlet present between $\delta_{H} 7.89$ (ligand $\mathbf{2 h}$ ) and 8.68 ppm (ligand $\mathbf{2 g}$ ). The much lower chemical shift of the triazole proton resonance for compound $\mathbf{2 h}$ compared to the rest is likely due to the ferrocene entity being much less electron-withdrawing compared to the

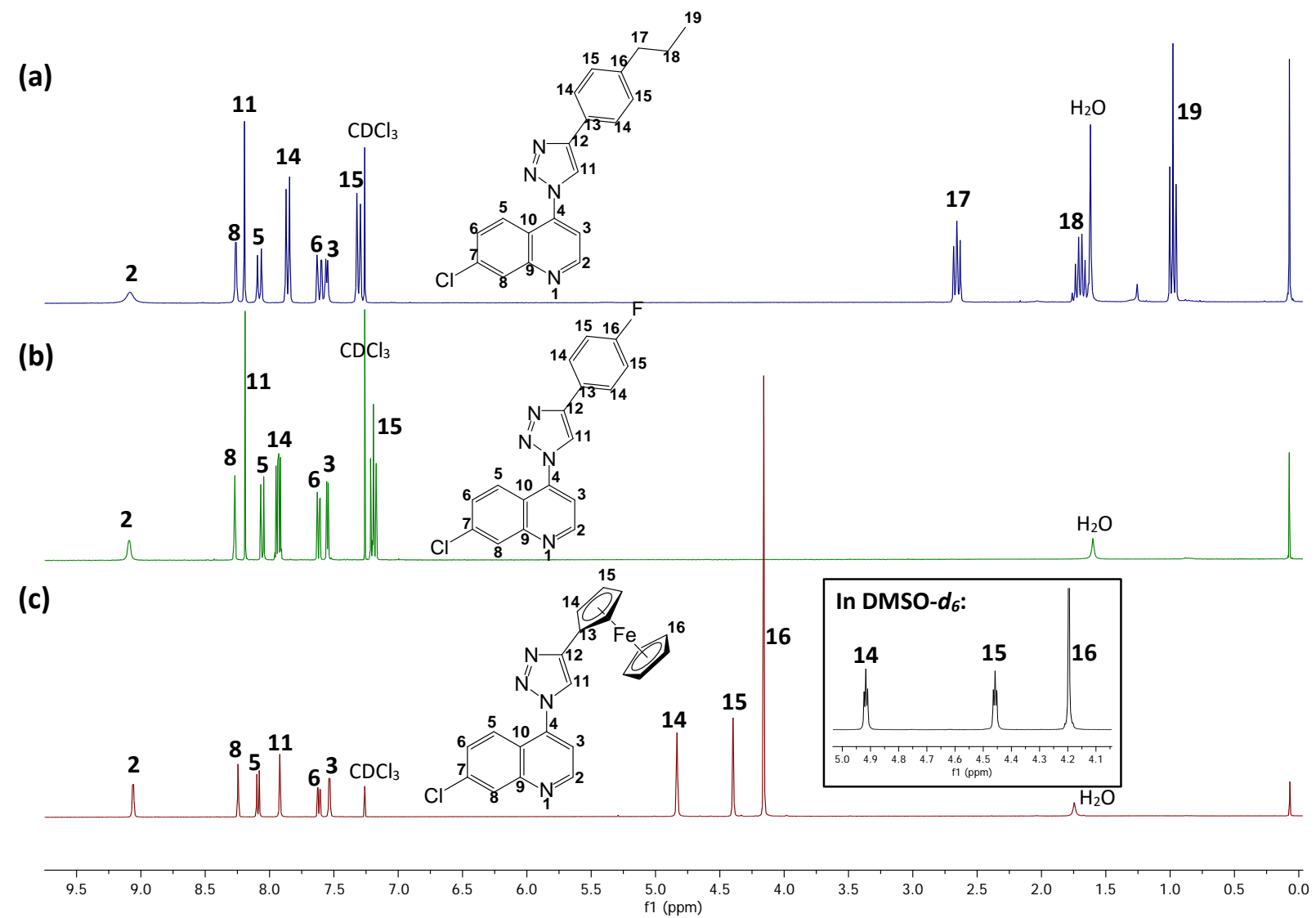

Figure 2.6: Stacked ${ }^{1} \mathrm{H}$ NMR spectra of 7-chloroquinolinotriazole ligands: (a) $2 c$, (b) $2 e$ and (c) $2 h$ in $\mathrm{CDCl}_{3}$. The inset picture shows the ferrrocenyl signals for $\mathbf{2 h}$ in DMSO- $d_{6}$. 
other phenyl groups, causing the triazole proton to be more shielded. In some spectra, the doublet signal for $\mathrm{H}-2$ is broadened, however, it still integrates for one proton as expected. Several other characteristic signals can also be seen in the spectra for the representative ligands in Figure 2.6. For $\mathbf{2 c}$, the expected triplets and sextet are observed in the aliphatic region for the propyl chain, each integrating for two protons. In the spectrum of $\mathbf{2 e}$, there are no aliphatic signals but the proton signals for the aromatic protons, $\mathrm{H}-14$ and $\mathrm{H}-15$, are present as multiplets, as expected, due to coupling with the NMR-active fluorine atom. Lastly, in the spectrum of the ferrocenyl-ligand, $\mathbf{2} \mathbf{h}$, the characteristic signals for the ferrocenyl moiety are present between $\delta_{H} 4.16$ and $4.83 \mathrm{ppm}$. In $\mathrm{CDCl}_{3}$, the large singlet at $\delta_{H} 4.16 \mathrm{ppm}$ represents the 5 protons of the lower unsubstituted $\mathrm{Cp}$ ring, while the resonances for $\mathrm{H}-14$ and $\mathrm{H}-15$ on the upper monosubstituted $\mathrm{Cp}$ ring are present as broadened signals, integrating for 2 protons each. It is surprising that these signals are not triplets as expected, however, when ${ }^{1} \mathrm{H}$ NMR spectroscopy was performed with the same compound in DMSO- $d_{6}$, these signals do indeed present as pseudotriplets. The ferrocenyl region of this ${ }^{1} \mathrm{H}$ NMR spectrum can be seen in the inset picture in Figure 2.6.

${ }^{13} \mathrm{C}\left\{{ }^{1} \mathrm{H}\right\}$ NMR spectroscopy was used to characterise further the 4-azido-7-chloroquinoline, $\mathbf{1}$, and compounds $\mathbf{2 a - h}$ and the resulting spectra, again, confirm the synthesis of the desired compounds. Signals pertaining to the triazole carbons for ligands $\mathbf{2 a - h}$ are present in the range of $\delta_{c} 120.75 \mathrm{ppm}$ (compound $\mathbf{2 b}$ ) to $\delta_{\mathrm{C}} 129.01 \mathrm{ppm}$ (compound $\mathbf{2 h}$ ). These triazole carbon chemical shifts are in the expected region of $\sim 120 \mathrm{ppm}$ as described for 1,2,3-triazoles in literature. ${ }^{28}$ Since the ${ }^{13} \mathrm{C}\left\{{ }^{1} \mathrm{H}\right\}$ NMR spectra of $\mathbf{2} \mathbf{d}$ and $\mathbf{2 e}$ are not ${ }^{19} \mathrm{~F}$ decoupled, $\mathrm{C}-\mathrm{F}$ coupling is seen for the carbons closest to the fluorine atoms (Figure 2.7). Coupling constants for ${ }^{1} J_{C-F}$, ${ }^{2} J_{C-F}$ and ${ }^{3} J_{C-F}$ are observed for both compounds and were found to be $272.1 \mathrm{~Hz}, 32.7 \mathrm{~Hz}$ and 3.6 $\mathrm{Hz}$ respectively for $\mathbf{2 d}$ and $248.7 \mathrm{~Hz}, 21.9 \mathrm{~Hz}$ and $8.2 \mathrm{~Hz}$ respectively for compound $\mathbf{2 e}$. The ${ }^{13} \mathrm{C}\left\{{ }^{1} \mathrm{H}\right\}$ NMR spectrum for compound $\mathbf{2 d}$ (Figure 2.7a) shows that each of these carbons which experience $\mathrm{C}-\mathrm{F}$ coupling appear as quartets due to coupling to the three fluorine atoms of the $\mathrm{CF}_{3}$ group. On the other hand, for compound $\mathbf{2 e}$, which only has one fluorine atom in its structure, the carbons which experience $\mathrm{C}-\mathrm{F}$ coupling are present as doublets (Figure 2.7b). Compounds $\mathbf{2} \mathbf{d}$ and $\mathbf{2 e}$ were also analysed using ${ }^{19} \mathrm{~F}\left\{{ }^{1} \mathrm{H}\right\}$ NMR spectroscopy, with a single 
(a)

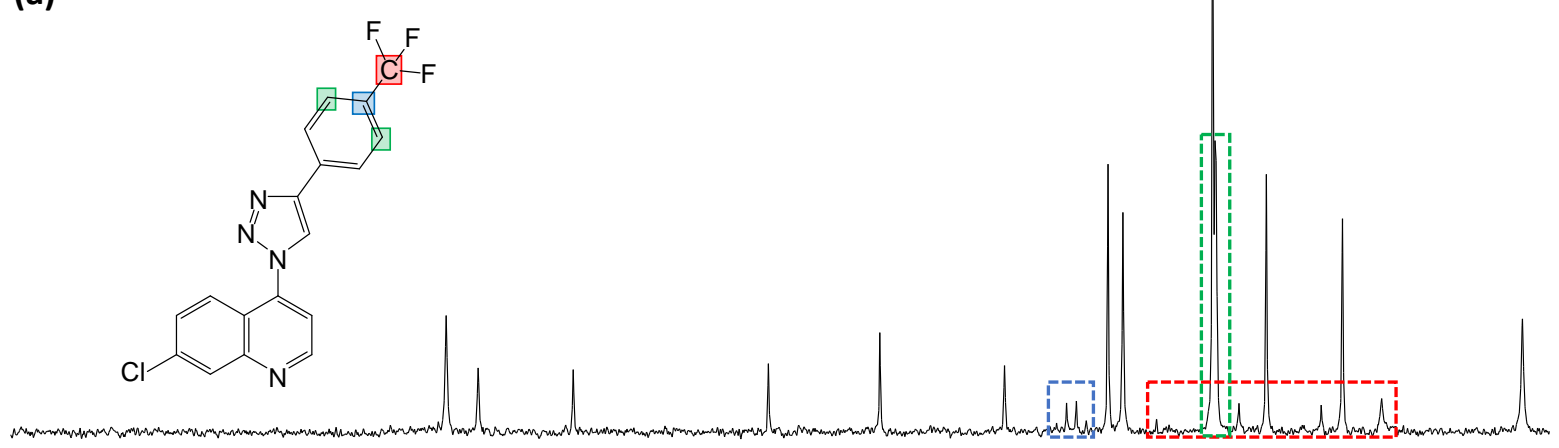

(b)

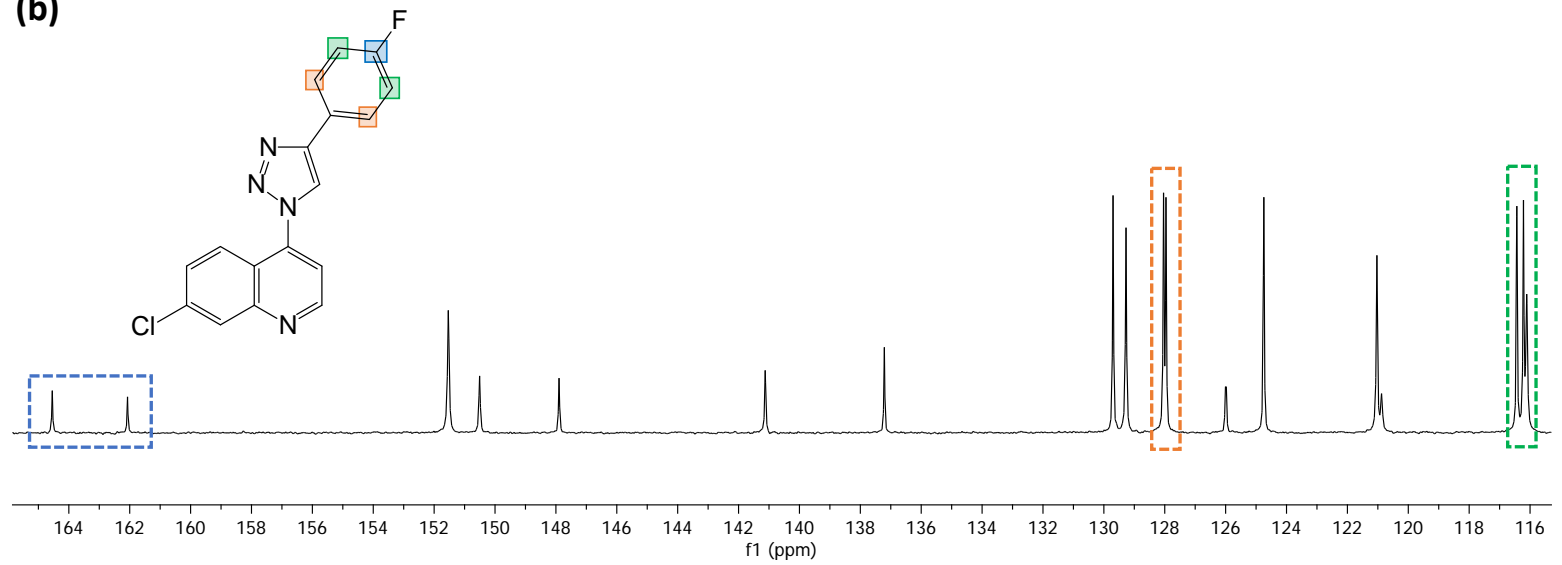

Figure 2.7: ${ }^{13} \mathrm{C}\left\{{ }^{1} \mathrm{H}\right\}$ NMR spectra of (a) $\mathbf{2} \mathbf{d}$ and (b) $2 \mathrm{e}$ in $\mathrm{CDCl}_{3}$, highlighting key carbon regions which display C-F coupling.

resonance being observed at $\delta_{\mathrm{F}}-62.7$ and $-112.2 \mathrm{ppm}$ respectively, indicating the presence of only one type of fluorinated compound for each. Another compound which shows coupling in its respective ${ }^{13} \mathrm{C}\left\{{ }^{1} \mathrm{H}\right\}$ NMR spectrum is the ferrocenyl compound, $\mathbf{2} \mathbf{h}$. The carbons of the ferrocene moiety, both on the upper and lower $\mathrm{Cp}$ rings, appear as multiplets due to C-C coupling with the neighbouring aromatic protons on each ring, as shown in Figure 2.8.

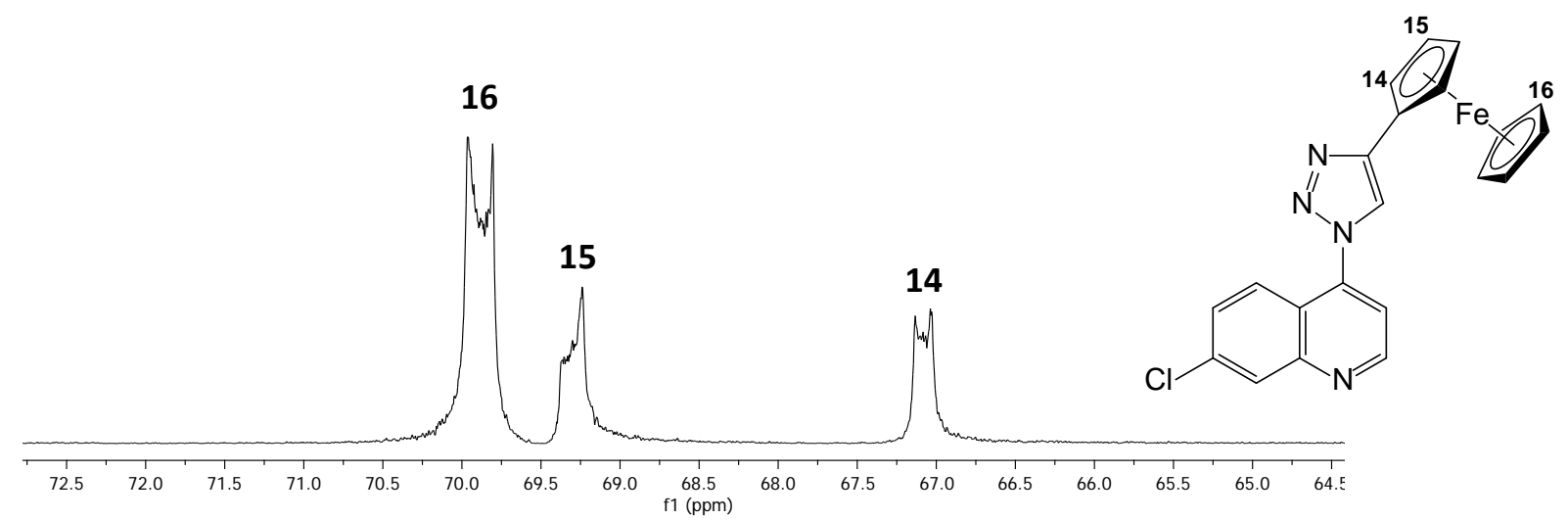

Figure 2.8: ${ }^{13} \mathrm{C}\left\{{ }^{1} \mathrm{H}\right\}$ NMR spectrum of the ferrocenyl carbon region of $\mathbf{2 h}$, showing the multiplets as a result of C-C coupling. 


\section{Infrared (IR) Spectroscopy}

Infrared spectroscopy is a technique used to identify the various infrared-active groups of a molecule based on the vibrations of the atoms within these groups. The infrared spectra recorded for the 4-azido-7-chloroquinoline compound, $\mathbf{1}$, as well as for all the 7-chloroquinolinotriazole compounds, $\mathbf{2 a - h}$, attest to the composition of the compounds and are in accordance with literature data. Figure 2.9 shows the overlapping IR spectra of the starting material, 4,7-dichloroquinoline, as well as azide compound $\mathbf{1}$ and 7-chloroquinolinotriazole compound, $\mathbf{2 a}$. The infrared spectra of $\mathbf{2 a - h}$ are all quite similar, therefore, the spectrum of $\mathbf{2 a}$ serves as a representative spectrum for all nine 7-chloroquinolinotriazole compounds. This characterisation technique proved useful in determining the successful formation of the triazole entity from the azide and alkyne starting materials. In the infrared spectrum of 1 , a strong $v(\mathrm{~N}=\mathrm{N}=\mathrm{N})$ signal for the azide functional group, which was not present in the spectrum of 4,7-dichloroquinoline, can be seen at $2119 \mathrm{~cm}^{-1}$, indicating the desired azide compound had indeed been formed. Infrared spectroscopy was also useful in revealing the presence or absence of the reactant, $\mathrm{NaN}_{3}$ in the product mixture before purification. Since $\mathrm{NaN}_{3}$ can be explosive in the presence of

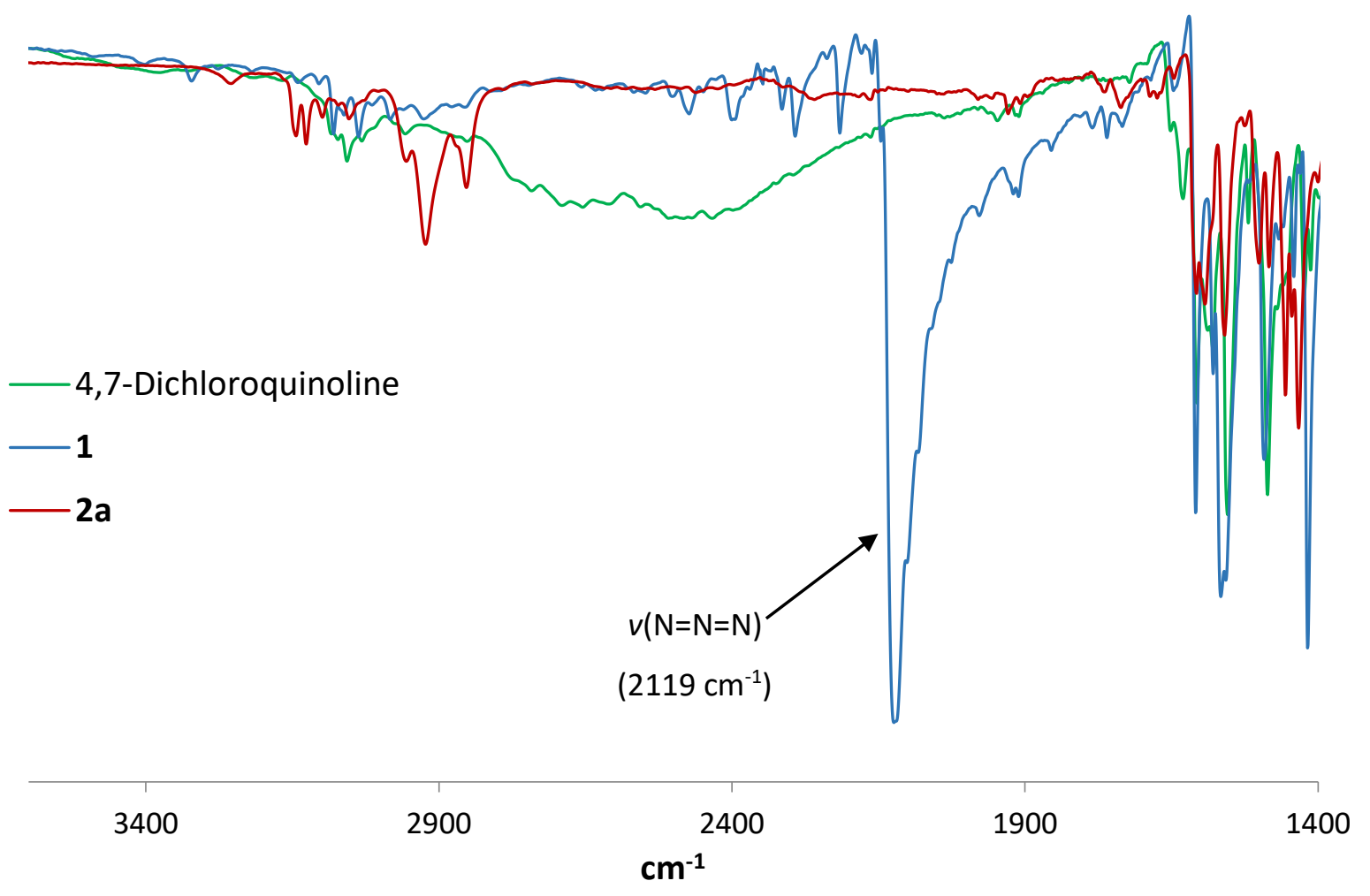

Figure 2.9: Stacked IR spectra of 4,7-dichloroquinoline (green), 4-azido-7-chloroquinoline 1 (blue) and 7-chloroquinolinotriazole compound $\mathbf{2 a}$ (red). 
halogenated solvents, it was imperative to ensure its complete removal before the next synthetic step. If $\mathrm{NaN}_{3}$ was still present, more than one azide absorption band would be visible in the $2120-2160 \mathrm{~cm}^{-1}$ frequency range. As seen in Figure 2.9, this was not the case since only one strong $v(\mathrm{~N}=\mathrm{N}=\mathrm{N})$ signal is observed. Although this azide absorption band does have a few shoulders, these are at lower wavenumbers and likely due to other functional group vibrations. In the infrared spectrum of the representative 7-chloroquinolinotriazole compound, $\mathbf{2 a}$, the absence of the characteristic azide absorption band indicates that all the 4-azido-7-chloroquinoline, 1, had been reacted with the alkyne to form the desired triazolic compound.

\section{Mass spectrometry (LCMS and ESI-MS)}

Eight of the 7-chloroquinolinotriazole compounds, 2a-g, were evaluated using LCMS, to ascertain both their purity and to confirm their molecular weight. The purity of all eight compounds was determined to be above $95 \%$. In terms of the mass spectral data, these compounds were all ionised as the protonated molecular ion, $[\mathrm{M}+\mathrm{H}]^{+}$, confirming that the desired compounds were synthesised. The ferrocenyl compound $\mathbf{2} \mathbf{h}$ was analysed using high resolution ESI-MS, yielding a peak at $\mathrm{m} / \mathrm{z}$ 414.0333, corresponding to the calculated mass of 414.0335 for the molecular ion $\left([\mathrm{M}]^{+}\right)$.

\subsection{Synthesis of a series of 7-chloro-4-aminoquinolinotriazole derivatives}

Literature has shown that the inclusion of an alkyl chain between the aminoquinoline and the triazole moieties of similar compounds improves the antiplasmodial activity of the compound as a whole., ${ }^{9,17}$ This therefore led to the synthesis of a series of 7-chloro-4aminoquinolinotriazole compounds containing a propyl chain linker within their scaffolds.

\subsubsection{Synthesis}

The synthesis of the 7-chloro-4-aminoquinolinotriazole compounds (6a-e) involved four synthetic steps, as outlined in Scheme 2.2. The first step is a nucleophilic aromatic substitution $\left(S_{N} A r\right)$ of the chloride at position 4 on 4,7-dichloroquinoline with 3-aminopropanol to form the alcohol precursor compound, 3. This compound was synthesised following a literature 
method ${ }^{7}$ and the mechanism of this reaction is the same as that seen in Figure $2.3^{24}$, with the 3-aminopropanol being the nucleophile instead of the azide. The completion of the reaction was determined by TLC analysis, producing a beige solid in an excellent yield of $98 \%$.<smiles>Clc1ccc2c(Cl)ccnc2c1</smiles>

(i)<smiles>OCCCNc1ccnc2cc(Cl)ccc12</smiles>

3 (ii)<smiles>COCCCNc1ccnc2cc(Cl)ccc12</smiles>

4

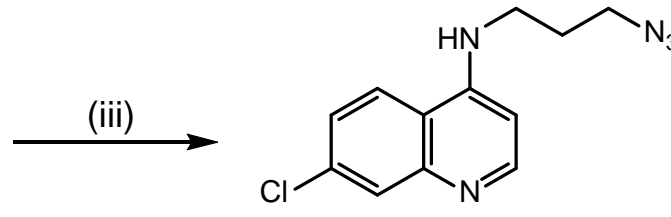

5

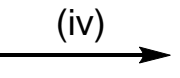<smiles>[R]c1cn(CCCNc2ccnc3cc(Cl)ccc23)nn1</smiles>

6a-e

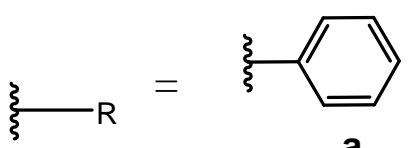

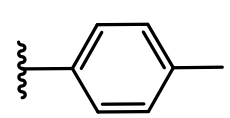

b

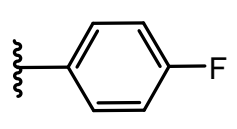

c

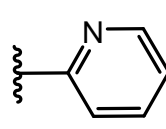

d

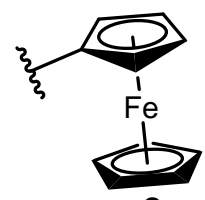

e

Scheme 2.2. Synthesis of the 7-chloro-4-aminoquinolinotriazole derivatives. Reagents and conditions: (i) 3-Aminopropanol, $80^{\circ} \mathrm{C}, 1 \mathrm{~h}$, then $130^{\circ} \mathrm{C}, 17 \mathrm{~h}$, neat; (ii) Methanesulfonyl chloride, Et ${ }_{3} \mathrm{~N}, \mathrm{THF}, 0{ }^{\circ} \mathrm{C}$ $\rightarrow$ r.t., $5 \mathrm{~h}$; (iii) $\mathrm{NaN}_{3^{\prime}}$ DMF, $65{ }^{\circ} \mathrm{C}, 15 \mathrm{~h}$; (iv) Aromatic alkyne, $t$-BuOH/ $\mathrm{H}_{2} \mathrm{O}(1: 1), \mathrm{CuSO}_{4} \cdot 5 \mathrm{H}_{2} \mathrm{O}, \mathrm{Na}$ ascorbate, $40{ }^{\circ} \mathrm{C}, 24-48 \mathrm{~h}$.

The second step, using the same literature method, involved converting the terminal alcohol of $\mathbf{3}$ to a better leaving group before the introduction of the azide. ${ }^{7}$ At first, thionyl chloride was used as a chlorinating agent, however, this was discontinued as the use of this reagent resulted in very poor yields ( $20 \%)$. Another literature method was used, thereafter, in which the alcohol group was converted to a methanesulfonate (mesylate) group using methanesulfonyl chloride and triethylamine. ${ }^{29}$ The formation of this mesylate precursor compound, 4, is believed to proceed via the mechanism shown in Figure $2.10 .^{30}$ The methanesulfonyl chloride first undergoes an $\mathrm{E}_{1} \mathrm{CB}$ elimination (unimolecular elimination via the conjugate base) whereby the non-nucleophilic base, triethylamine, abstracts a proton from the methyl group to form a carbanion, which then generates the highly reactive sulfene intermediate. Attack by the alcohol on this intermediate, followed by a rapid proton transfer, 
results in the formation of the desired mesylate product. This desired product, $\mathbf{4}$, was isolated as a beige solid in a moderate yield of $43 \%$. Although this yield is lower than expected, it is double that of the chloride-containing product produced when following the method using thionyl chloride as the reagent. The reason for this is likely due to the fact that the mesylate is a much better leaving group than the chloride as the sulfonate ions are capable of stabilising the negative charge via resonance. ${ }^{30}$

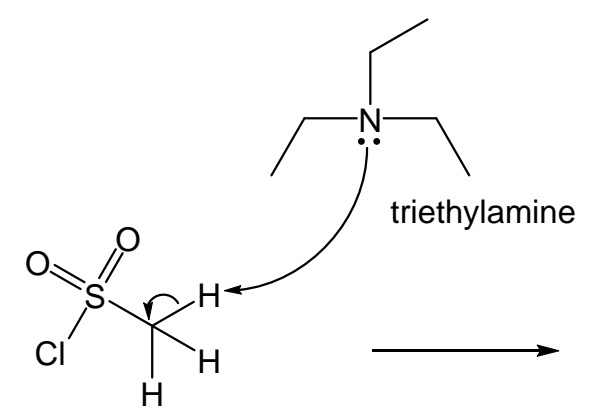

methanesulfonyl

chloride<smiles>O=S1(=O)[C@H]2CCC[C@@H]1[C@H](O)[C@H]2O</smiles><smiles>O=S(=O)(Cl)CO</smiles>

sulfene

$\mathrm{Cl}^{\prime}$<smiles>C1CCCCC1</smiles><smiles>OCCCNc1ccnc2cc(Cl)ccc12</smiles>

3<smiles>CS(=O)(=O)COCCCNc1ccnc2cc(Cl)ccc12</smiles>

4

Figure 2.10: Proposed mechanism for the conversion of an alcohol (3) to a mesylate (4). ${ }^{30}$

The third step involved the formation of the azide precursor compound $\mathbf{5}$ from mesylate compound 4 following an $S_{N} 2$ substitution reaction, the mechanism of which is shown in Figure $2.11 .^{31}$ In this reaction, the nucleophilic azide group from $\mathrm{NaN}_{3}$ attacks the carbon adjacent to the OMs leaving group, forming a transition state in which the carbon under nucleophilic attack is pentacoordinate. The mesylate leaving group is then eliminated from the opposite side of the nucleophilic attack, resulting in the formation of the desired azide 
compound, 5. The reaction conditions for this reaction were the same as those in the synthesis of $\mathbf{1}$, producing the azide intermediate $\mathbf{5}$ as a fluffy, white powder in a moderate yield of $45 \%$.<smiles>N#CCCCCCNc1ccnc2cc(Cl)ccc12</smiles>

4<smiles>N#CCCNc1ccnc2cc(Cl)ccc12</smiles>

5

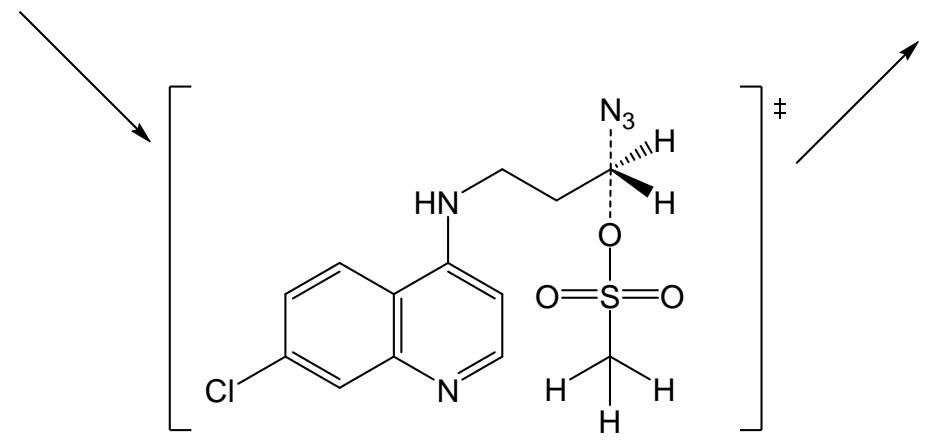

Figure 2.11: Proposed mechanism for the $S_{\mathrm{N}} 2$ reaction to form compound $5{ }^{31}$

The final step in the synthesis of the 7-chloro-4-aminoquinolinotriazole compounds, 6a-e, was the reaction of the azide precursor, 5, with five different aromatic alkynes following the copper-catalysed "click" reaction. These particular alkynes were chosen based on the good antiplasmodial activities (vide infra, chapter 4, section 4.2) of the 7-chloroquinolinotriazole Ir(III) complexes containing these R-groups. The catalytic mechanism follows the same CuAAC cycle as that seen for the 7-chloroquinolinotriazole compounds, 2 a-h (Figure 2.4). ${ }^{27}$ The yields for these five 7-chloro-4-aminoquinolinotriazole compounds, 6a-e, were moderate, ranging between $55 \%(6 \mathrm{~d})$ and $70 \%(6 \mathrm{e})$. All compounds are also stable at room temperature and when exposed to air.

\subsubsection{Characterisation}

All of the precursor compounds, 3-5, and 7-chloro-4-aminoquinolinotriazole compounds, 6a-e, were characterised by various spectroscopic and analytical techniques. These included ${ }^{1} \mathrm{H},{ }^{13} \mathrm{C}\left\{{ }^{1} \mathrm{H}\right\},{ }^{19} \mathrm{~F}\left\{{ }^{1} \mathrm{H}\right\}$ (compound $6 \mathrm{c}$ ), ${ }^{1} \mathrm{H}-{ }^{1} \mathrm{H}$ correlation spectroscopy (COSY) and heteronuclear single quantum coherence (HSQC) nuclear magnetic resonance (NMR) spectroscopy, as well 
as infrared (IR) spectroscopy, liquid chromatography coupled with mass spectrometry (LCMS), electrospray ionisation-mass spectrometry (ESI-MS) and melting point analysis.

\section{NMR Spectroscopy}

The NMR spectra were recorded in DMSO- $d_{6}$ for all the precursor compounds, 3-5, and 7-chloro-4-aminoquinolinotriazole compounds, 6a-e. Figure 2.12 shows the ${ }^{1} \mathrm{H}$ NMR spectra of the precursor compounds 3-5 and analysis of these spectra confirmed the synthesis of the proposed compounds. In all three spectra, the aromatic regions are almost identical as the functional group conversions have occurred at the terminal end of the propyl chain a distance away from the quinoline ring-system. These functional group conversions, going from alcohol to mesylate and finally to azide, can be observed using ${ }^{1} \mathrm{H}$ NMR spectroscopy. Starting with the spectrum of the alcohol precursor compound, 3 (Figure 2.12a), the substitution of the 3-aminopropanol with the chloride at position-4 of the 4,7-dichloroquinoline starting material

(a)

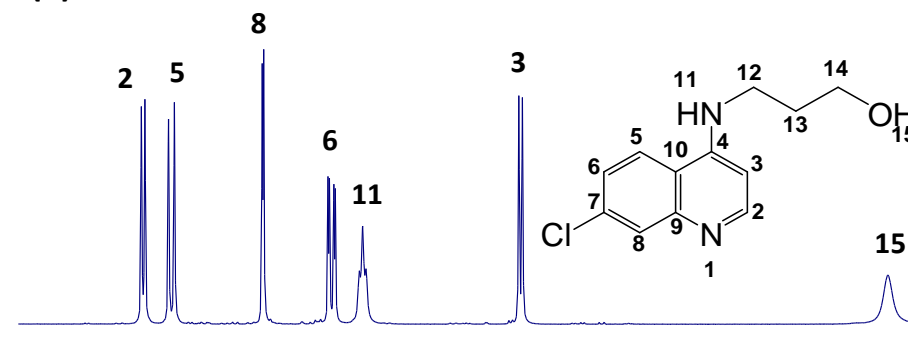

(b)
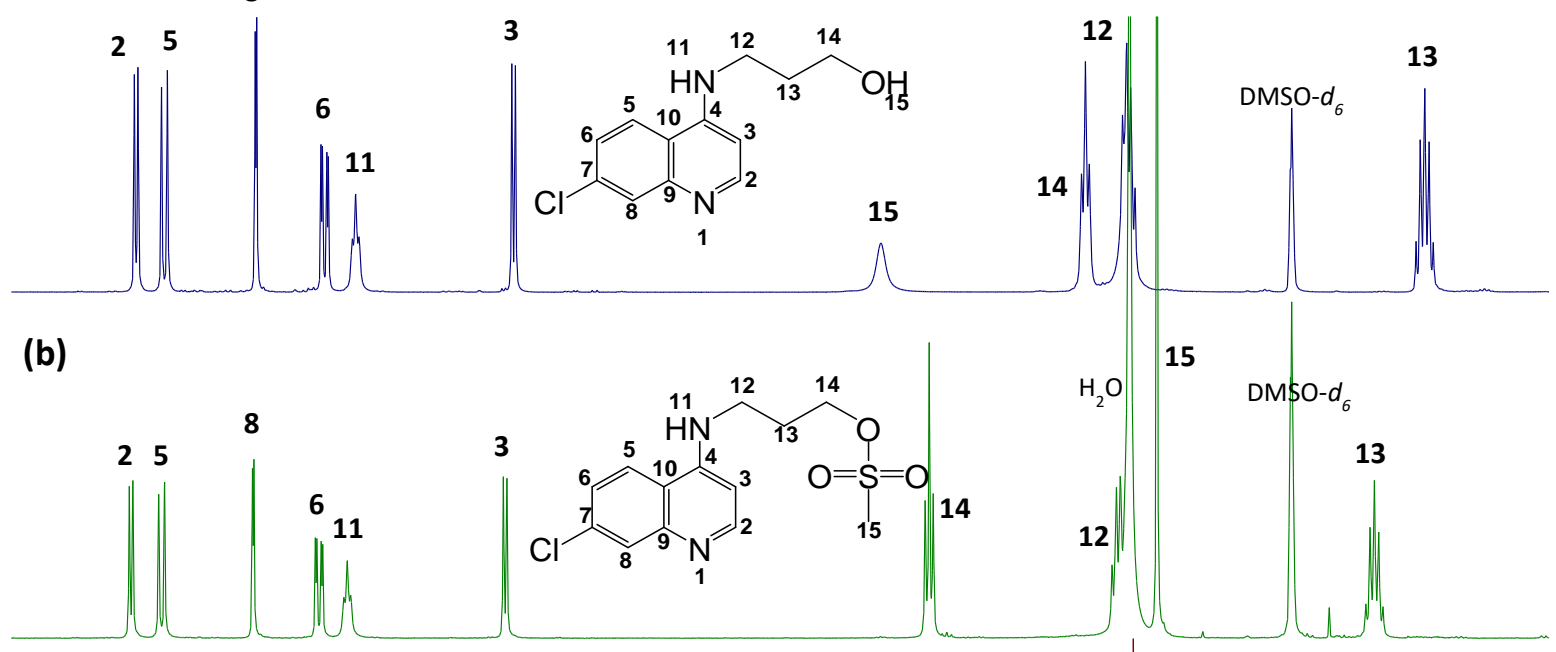

(c)

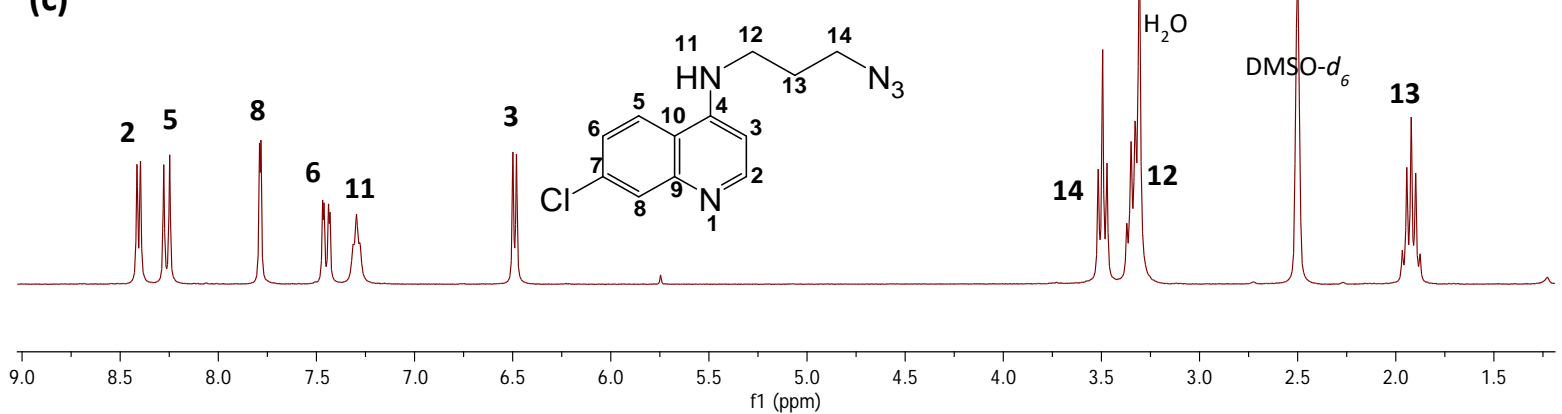

Figure 2.12. ${ }^{1} \mathrm{H}$ NMR spectra of precursor compounds, (a) 3, (b) 4 and (c) 5 in DMSO- $d_{6}$. 
was confirmed by the presence of several diagnostic signals. These signals include the three distinct resonances of the aliphatic propyl protons $(\mathrm{H}-12, \mathrm{H}-13$ and $\mathrm{H}-14)$, the triplet for the secondary amine proton $(\mathrm{H}-11)$ and the proton of the alcohol group $(\mathrm{H}-15)$. It is this alcohol proton, which is present as a broad signal at $\delta_{H} 4.57 \mathrm{ppm}$, that is absent in the spectrum of the subsequent compound, $\mathbf{4}$, since the alcohol is converted to a mesylate. The spectrum of 4 (Figure 2.12b) instead shows a singlet integrating for 3 protons at $\delta_{H} 3.18 \mathrm{ppm}$ corresponding to the methyl group on the mesylate, thereby confirming the successful substitution by the methanesulfonyl entity. Since this mesylate is more electron-withdrawing than the previous alcohol group, the triplet corresponding to the adjacent protons on the propyl chain (i.e. $\mathrm{H}-14$ on Figure $2.12 \mathrm{~b}$ ) is shifted more downfield compared to the same signal in the spectrum of $\mathbf{3}$. In converting the mesylate to the subsequent azide compound, 5, the methyl protons from the previous mesylate group are now absent in the ${ }^{1} \mathrm{H}$ NMR spectrum of 5 (Figure 2.12c). The same propyl proton signal, $\mathrm{H}-14$, which had shifted downfield previously is now present upfield again as the azide functionality is less electron-withdrawing than the methanesulfonate group.

The reaction of the azide intermediate, $\mathbf{5}$, with five different aromatic alkynes produced five 7-chloro-4-aminoquinolinotriazole compounds, 6a-e, the structures of which can be confirmed from their respective ${ }^{1} \mathrm{H}$ NMR spectra. Figure 2.13 shows the ${ }^{1} \mathrm{H}$ NMR spectra for three representative compounds of this series. In all three spectra, the triazole proton signal (found between $\delta_{H} 8.20-8.67 \mathrm{ppm}$ ) is the first indicator of successful triazole formation from the preceding azide compound. In the ${ }^{1} \mathrm{H}$ NMR spectrum of the compound bearing the unsubstituted phenyl group, 6a (Figure 2.13a), additional aromatic signals corresponding to the protons of the new phenyl group also testify to the correct synthesis of the desired compound. This is likewise true in the spectrum of the fluorophenyl-containing compound, 6c, which shows two distinct signals for the aromatic protons ( $\mathrm{H}-18$ and $\mathrm{H}-19$ in Figure 2.13b). These signals, however, are present as multiplets due to the coupling of the aromatic protons to the NMR-active fluorine atom. This coupling is confirmed by the presence of doublets for carbons neighbouring the fluoride in the respective ${ }^{13} \mathrm{C}\left\{{ }^{1} \mathrm{H}\right\}$ NMR spectrum and the ${ }^{19} \mathrm{~F}\left\{{ }^{1} \mathrm{H}\right\}$ NMR spectrum shows the presence of only one singlet at $-114.24 \mathrm{ppm}$. The signal for $\mathrm{H}-12$ is completely hidden under the water signal of the ${ }^{1} \mathrm{H}$ NMR spectrum for compound $\mathbf{6 c}$ 
(a)

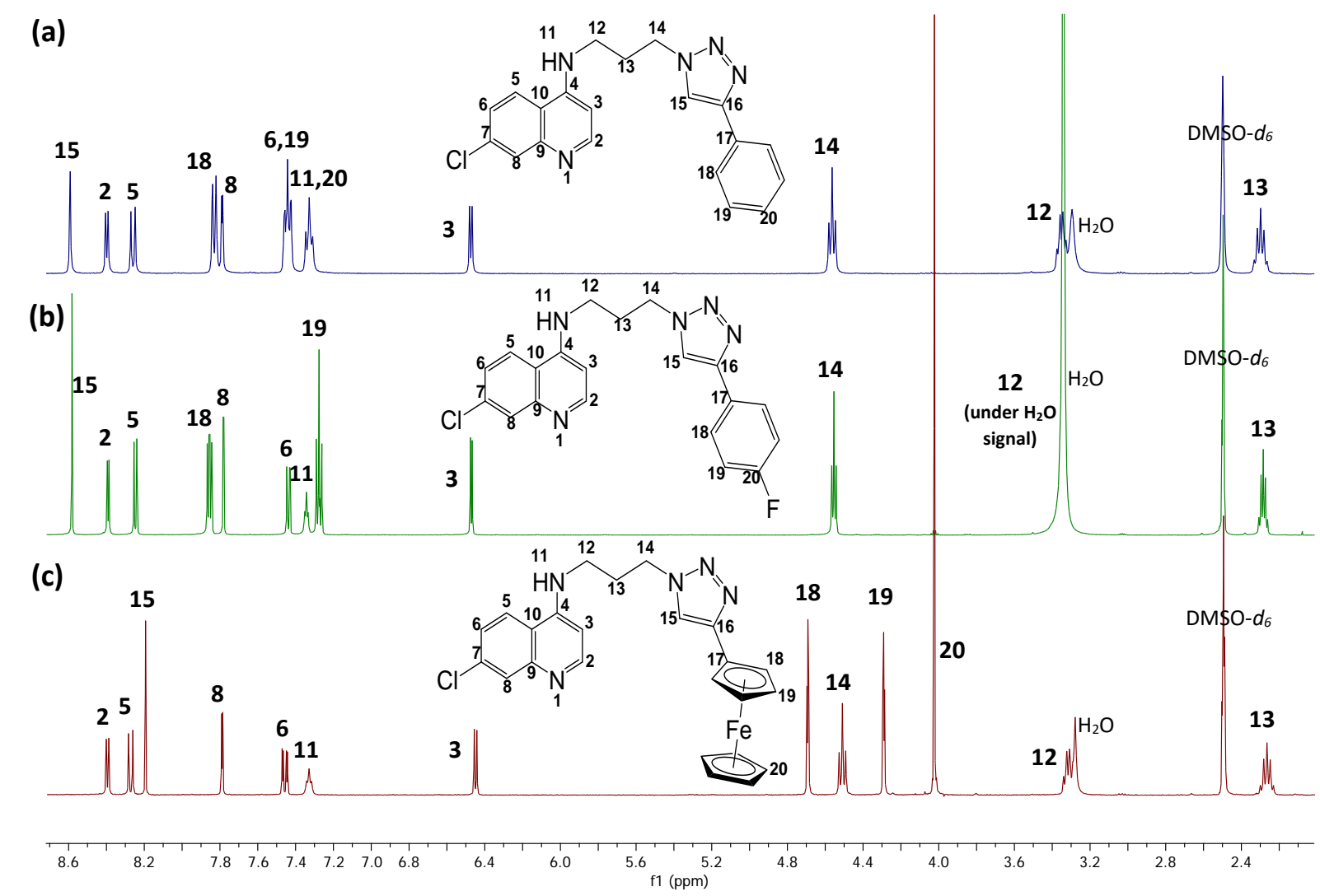

Figure 2.13. Stacked ${ }^{1} \mathrm{H}$ NMR spectra of the representative 7-chloro-4-aminoquinolinotriazole compounds, (a) 6a, (b) $6 \mathrm{c}$ and (c) 6e in DMSO- $d_{6}$.

and this is confirmed by the cross peak observed at this chemical shift using 2D NMR spectroscopic methods such as HSQC and COSY. Figure $2.13 \mathrm{c}$ shows the ${ }^{1} \mathrm{H}$ NMR spectrum for the ferrocenyl-containing 7-chloro-4-aminoquinolinotriazole compound, 6e. As with the 7-chloroquinolinotriazole ferrocenyl compound $\mathbf{2} \mathbf{h}$, the triazole proton resonance of $\mathbf{6 e}$ is present more upfield compared to that of the other ligands of this series since the ferrocene is less electron-withdrawing than the phenyl substituents. The protons of the ferrocene are observed as triplets at $\delta_{H} 4.30$ and 4.70 ppm for the upper monosubstituted $\mathrm{Cp}$ ring and as a large singlet at $\delta_{H} 4.03$ for the five protons of the lower unsubstituted $\mathrm{Cp}$ ring. The successful synthesis of the desired compounds of this series was further corroborated using ${ }^{13} \mathrm{C}\left\{{ }^{1} \mathrm{H}\right\} \mathrm{NMR}$ spectroscopy, in which the expected number of signals in the spectrum of each compound was observed. 


\section{Infrared (IR) Spectroscopy}

Further evidence for the synthesis of the desired precursor compounds, 3-5, and 7-chloro-4aminoquinolinotriazole compounds, 6a-e, was provided using infrared spectroscopy. The presence of the broad $v(\mathrm{O}-\mathrm{H})$ signal for the alcohol group of 3 , the subsequent absence of this alcohol absorbance band for 4 and the presence of the azide $v(\mathrm{~N}=\mathrm{N}=\mathrm{N})$ absorbance band for 5 were all within the expected spectral regions, providing further evidence for the correct functional group conversions for these compounds (Figure 2.14). The infrared spectra of the 7-chloro-4-aminoquinolinotriazole compounds, 6a-e, look very similar to those of the 7-chloroquinolinotriazole compounds, $\mathbf{2 a - h}$. The only noticeable difference in the spectra of 6a-h is the presence of the secondary amine $v(\mathrm{~N}-\mathrm{H})$ signal, visible in the expected between 3296 and $3337 \mathrm{~cm}^{-1}$.

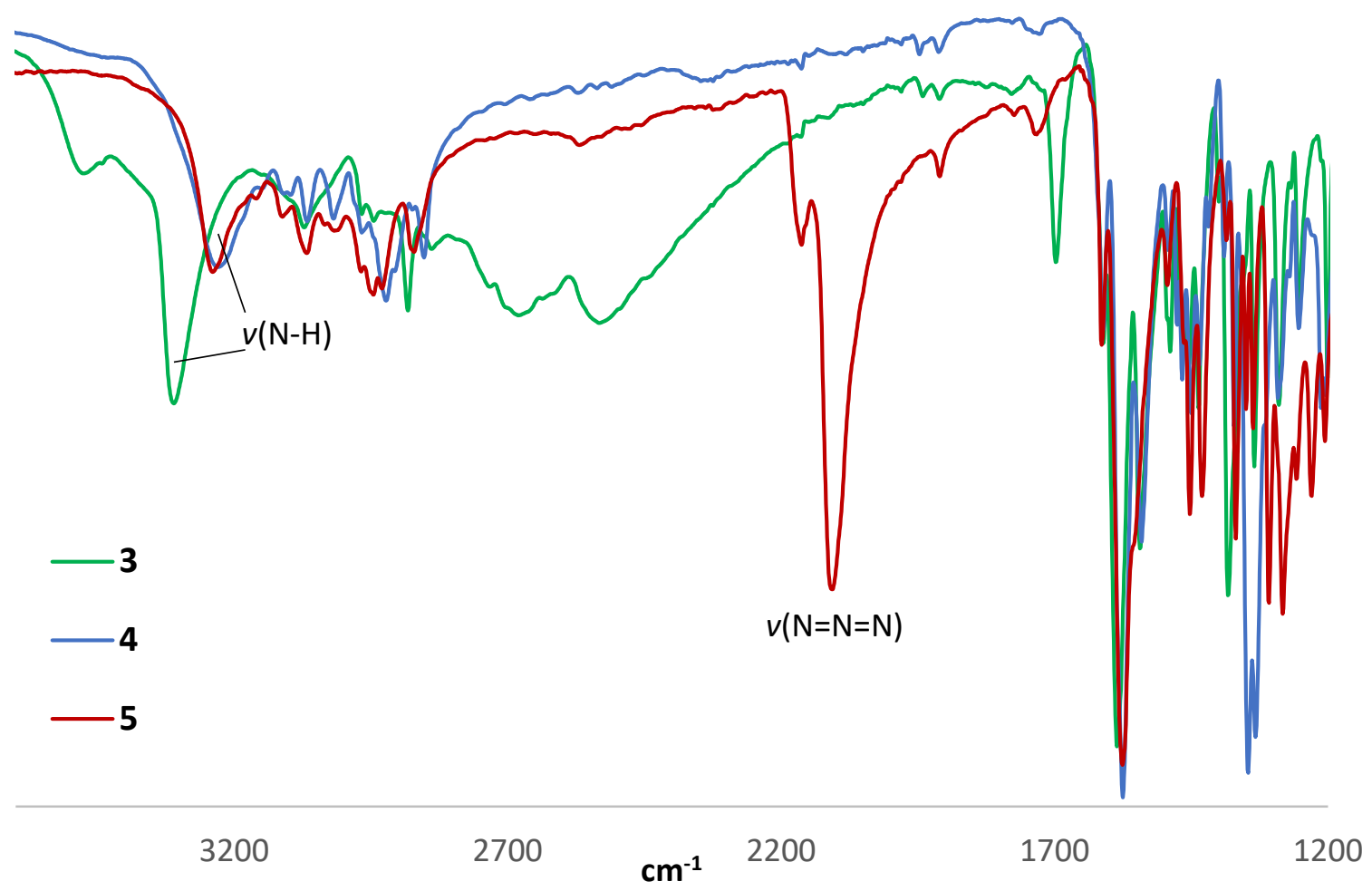

Figure 2.14: Stacked IR spectra of precursor compounds 3 (green), 4 (blue) and 5 (red).

\section{Mass spectrometry (LCMS and ESI-MS)}

The percentage purity of the series of 7-chloro-4-aminoquinolinotriazole compounds, 6a-e, was evaluated using liquid chromatography coupled with mass spectrometry and all were determined to be greater than $98 \%$ pure. The mass spectra of 6a-e show that all five 
compounds were all ionised as the protonated molecular ion, $[\mathrm{M}+\mathrm{H}]^{+}$, confirming that the desired compounds were synthesised. The ferrocenyl compound 6e was analysed using high resolution ESI-MS, yielding a base peak at $\mathrm{m} / \mathrm{z}$ 472.0997, corresponding to the calculated mass of 472.0986 for the molecular ion $\left([\mathrm{M}]^{+}\right)$.

\subsection{Summary}

A series of 7-chloroquinolinotriazole compounds (2a-h), with the direct attachment of the triazole entity onto the quinoline system, was successfully synthesised and isolated in moderate to good yields. A second, smaller, series of 7-chloro-4-aminoquinolinotriazole compounds (6a-e), each bearing a propyl chain linker between the triazole and quinoline entities, was subsequently synthesised. Click chemistry was used to synthesise both series of compounds and was proven to be a quick and easy way to synthesise triazole compounds in relatively good yields. Both series of compounds were fully characterised using various spectroscopic and analytical techniques and all compounds were stable at room temperature. ${ }^{1} \mathrm{H},{ }^{13} \mathrm{C}\left\{{ }^{1} \mathrm{H}\right\},{ }^{19} \mathrm{~F}\left\{{ }^{1} \mathrm{H}\right\}$ NMR spectroscopy, infrared spectroscopy, LCMS and mass spectrometry were predominantly used to elucidate the structures of the products correctly. 2D NMR experiments, such as COSY and HSQC, were used to assign proton and carbon resonances and correlations correctly for all the triazole compounds (2a-h and 6a-e).

\subsection{References}

$1 \quad$ World Health Organization, World Malaria Report 2017, Geneva, 2017.

2 A. M. Dondorp, F. Nosten, P. Yi, D. Das, A. P. Phyo, J. Tarning, K. M. Lwin, F. Ariey, W. Hanpithakpong, S. J. Lee, P. Ringwald, K. Silamut, M. Imwong, K. Chotivanich, P. Lim, T. Herdman, S. S. An, S. Yeung, P. Singhasivanon, N. P. J. Day, N. Lindegardh, D. Socheat and N. J. White, N. Engl. J. Med., 2009, 361, 455-467.

3 A. Robert, O. Dechy-Cabaret, J. Cazelles and B. Meunier, Acc. Chem. Res., 2002, 35, 167-174.

4 K. Yearick, K. Ekoue-Kovi, D. P. Iwaniuk, J. K. Natarajan, J. Alumasa, A. C. De Dios, P. D. Roepe and C. Wolf, J. Med. Chem., 2008, 51, 1995-1998. 

Nascimento, F. M. Dos Santos, R. K. Da Rocha, J. C. D. Lopes and A. B. De Oliveira, Eur. J. Med. Chem., 2014, 73, 295-309.

P. M. Njogu, J. Gut, P. J. Rosenthal and K. Chibale, ACS Med. Chem. Lett., 2013, 4, 637641.

8 S. Vandekerckhove and M. D’Hooghe, Bioorg. Med. Chem., 2015, 23, 5098-5119.

9 N. Boechat, M. D. L. G. Ferreira, L. C. S. Pinheiro, A. M. L. Jesus, M. M. M. Leite, C. C. S. Júnior, A. C. C. Aguiar, I. M. De Andrade and A. U. Krettli, Chem. Biol. Drug Des., 2014, 84, 325-332.

10 World Health Organization, WHO Model List of Essential Medicines, 2017.

11 V. R. Solomon, W. Haq, K. Srivastava, S. K. Puri and S. B. Katti, J. Med. Chem., 2007, 50, 394-398.

12 B. Meunier, Acc. Chem. Res., 2008, 41, 69-77.

13 V. V. Kouznetsov and A. Gómez-Barrio, Eur. J. Med. Chem., 2009, 44, 3091-3113.

14 J. Walsh and A. Bell, Curr. Pharm. Des., 2009, 15, 2970-2985.

15 S. S. Chauhan, M. Sharma and P. M. S. Chauhan, Drug News Perspect., 2010, 23, 632646.

16 M. Mushtaque and Shahjahan, Eur. J. Med. Chem., 2015, 90, 280-295.

17 X. M. Chu, C. Wang, W. L. Wang, L. L. Liang, W. Liu, K. K. Gong and K. L. Sun, Eur. J. Med. Chem., 2019, 166, 206-223.

18 B. Schulze and U. S. Schubert, Chem. Soc. Rev., 2014, 43, 2522-2571.

19 V. D. Bock, H. Hiemstra and J. H. Van Maarseveen, Eur. J. Org. Chem., 2006, 51-68.

20 S. G. Agalave, S. R. Maujan and V. S. Pore, Chem. Asian J., 2011, 6, 2696-2718.

21 M. C. Joshi, K. J. Wicht, D. Taylor, R. Hunter, P. J. Smith and T. J. Egan, Eur. J. Med. Chem., 2013, 69, 338-347.

22 S. Manohar, S. I. Khan and D. S. Rawat, Chem. Biol. Drug Des., 2011, 78, 124-136. 
23 E. M. Guantai, K. Ncokazi, T. J. Egan, J. Gut, P. J. Rosenthal, P. J. Smith and K. Chibale, Bioorg. Med. Chem., 2010, 18, 8243-8256.

24 P. Sykes, A Guidebook to Mechanism in Organic Chemistry, Pearson Education Limited, Essex, England, 6th edn., 1986.

25 F. Himo, T. Lovell, R. Hilgraf, V. V. Rostovtsev, L. Noodleman, K. B. Sharpless and V. V. Fokin, J. Am. Chem. Soc., 2005, 127, 210-216.

26 V. V. Rostovtsev, L. G. Green, V. V. Fokin and K. B. Sharpless, Angew. Chem. Int. Ed., 2002, 41, 2596-2599.

27 B. T. Worrell, J. A. Malik and V. V. Fokin, Science, 2013, 340, 457-460.

28 X. Creary, A. Anderson, C. Brophy, F. Crowell and Z. Funk, J. Org. Chem., 2012, 77, 87568761.

29 K. Starčević, D. Pešić, A. Toplak, G. Landek, S. Alihodžić, E. Herreros, S. Ferrer, R. Spaventi and M. Perić, Eur. J. Med. Chem., 2012, 49, 365-378.

30 M. S. Singh, Advanced Organic Chemistry: Reactions And Mechanisms, Dorling Kindersley Pvt. Ltd., Dheli, India, $2^{\text {nd }}$ edn., 2004.

31 J. Clayden, N. Greeves and S. Warren, Organic Chemistry, Oxford University Press Inc., New York, United States, $2^{\text {nd }}$ edn., 2001. 


\section{Chapter 3}

\section{Synthesis and characterisation of neutral cyclometallated and cationic $N, N$-chelated $\operatorname{Ir}(I I I)$ half-sandwich complexes based on 7-chloroquinoline-1,2,3-triazole ligands}

\subsection{Introduction}

The success of metal-containing compounds in cancer treatment, namely cisplatin and its analogues $^{1}$, sparked a prolific increase in interest towards the use of metal complexes in medicinal chemistry. Over the past decade, the burgeoning field of bioorganometallic chemistry has provided effective and promising therapeutic alternatives to purely organic drugs. $^{2-5}$ It has been well established that the incorporation of a metal onto the scaffold of a particular pharmacophore significantly enhances its biological activity through the unique chemical versatility provided by the metal complex as a whole. ${ }^{6-8}$ In this regard, great success has been achieved in the synthesis of organometallic antimalarial agents, with particular focus being given to the modification of the chloroquine pharmacophore by the incorporation of a metal moiety. ${ }^{9-11}$ This is exemplified by the organometallic compound ferroquine, the ferrocenyl analogue of chloroquine. ${ }^{12,13}$ In combination with its impressive antimalarial activity, its marked ability to overcome chloroquine-resistance has resulted in the further testing of this compound in clinical trials, along with the trioxolane, artefenomel. ${ }^{13-15}$

While the inclusion of the ferrocene moiety into the lateral side chain of the drug chloroquine proved an effective method of improving antimalarial drug activity, there is a myriad of other ways in which a similar result may be achieved. Other drug design approaches include the use of Platinum Group Metals (PGMs), while generally avoiding the use of platinum itself due to its high toxicity and negative side-effects. ${ }^{2,16}$ Complexes incorporating ruthenium, rhodium, osmium, palladium and iridium are particularly attractive as they have similar activity to platinum-based complexes while being safer and more biofriendly. ${ }^{17}$ Using these transition metals, a number of coordination complexes of the quinoline moiety have been synthesised, examples of which are shown in Figure 3.1.11,18,19 $\mathrm{Li}$ et al. synthesised a series of ruthenium 


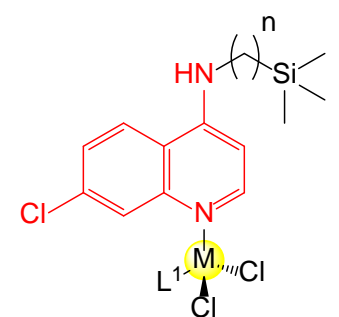

3.1 ( $\mathrm{n}=1, \mathrm{M}=\mathrm{Ru}, \mathrm{L}_{1}=$ benzene)

$3.2\left(n=1, M=R u, L_{1}=p\right.$-cymene)

$3.3\left(n=1, M=R h, L_{1}=C p^{*}\right)$

3.4 ( $n=3, M=R u, L_{1}=$ benzene)

3.5 ( $\mathrm{n}=3, \mathrm{M}=\mathrm{Ru}, \mathrm{L}_{1}=p$-cymene)

$3.6\left(n=3, M=R h, L_{1}=C p^{\star}\right)$

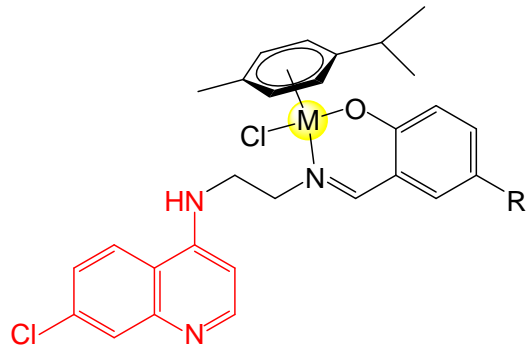

$3.7(M=R u, R=H)$

$3.8(M=R u, R=F)$

$3.9(\mathrm{M}=\mathrm{Ru}, \mathrm{R}=\mathrm{Cl})$

$3.10(\mathrm{M}=\mathrm{Ru}, \mathrm{R}=\mathrm{Br})$

$3.11(M=R u, R=I)$

$3.12\left(\mathrm{M}=\mathrm{Ru}, \mathrm{R}=\mathrm{NO}^{2}\right)$

$3.13(M=R u, R=O M e)$

$3.14(M=R u, R=t-B u)$

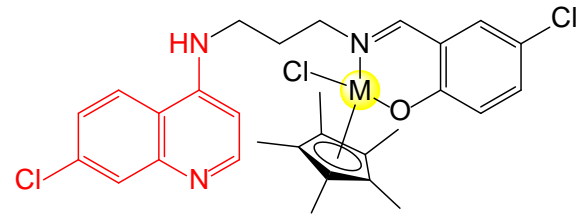

$3.15(M=O s, R=H)$

$3.16(\mathrm{M}=\mathrm{Os}, \mathrm{R}=\mathrm{F})$

$3.17(\mathrm{M}=\mathrm{Os}, \mathrm{R}=\mathrm{Cl})$

$3.18(M=O s, R=I)$

$3.19(M=O s, R=O M e)$

$3.20(\mathrm{M}=\mathrm{Ir})$

$3.21(M=R h)$

Figure 3.1. Transition metal complexes of the aminoquinoline moiety. ${ }^{11,18,19}$

and rhodium half-sandwich aminoquinoline complexes, all of which contained an organosilane moiety in their lateral side chain (Figure 3.1, 3.1-3.6). ${ }^{18}$ When tested against the chloroquine-sensitive (CQS) NF54 and chloroquine-resistant (CQR) Dd2 strains of $P$. falciparum, all the complexes were found to have $\mathrm{IC}_{50}$ values in the nanomolar range, with selected complexes even displaying an antiplasmodial activity of less than $100 \mathrm{nM}$. In derivatising the aminoquinoline with a salicylaldimine moiety, Ekengard et al. was able to create ligands with multiple possible sites of metal-coordination. ${ }^{11}$ Their $\mathrm{N}, \mathrm{O}$-chelating salicylaldimine ruthenium and osmium complexes (Figure 3.1, 3.7-3.19) displayed good antiplasmodial activity in the nanomolar range $\left(\mathrm{IC}_{50}<0.73 \mu \mathrm{M}\right)$ when tested against the CQS strain, NF54. ${ }^{11}$ Similar good activity in the same $P$. falciparum strain was observed with the $\mathrm{N}, \mathrm{O}$-chelating salicylaldimine iridium and rhodium complexes synthesised by Stringer et al. ${ }^{19}$ (Figure 3.1, 3.20-3.21). Unfortunately, both series of aminoquinoline salicylaldimine complexes displayed cross-resistance in the CQR strain, indicated by the loss in antiplasmodial activity at the tested concentrations. ${ }^{11,19}$

For many years, a popular method of metal coordination to an organic scaffold has been via cyclometallation - the formation of a new metal-carbon $\sigma$ bond in the form of a metallacycle. ${ }^{20} \mathrm{~A}$ number of biologically active cyclometallated complexes have been synthesised, with their activity likely enhanced by the strong $\mathrm{M}-\mathrm{C}$ bond formed, which may prevent biological reduction and ligand exchange reactions. ${ }^{21-23}$ To date, not much research has been done into the use of cyclometallated complexes as antiplasmodial agents. 
Cyclometallation, however, may provide a beneficial stabilising effect on the metal complex within the malaria parasite. Rylands et al. showed this to be the case with their recent investigation into the antiplasmodial activity of cyclometallated ruthenium(II), rhodium(III) and iridium(III) half-sandwich complexes of 2-phenylbenzimidazoles (Figure 3.2). ${ }^{24}$ Antiplasmodial activity assays revealed the cyclometallated complexes to have superior activity in comparison to their respective organic ligands against both sensitive and resistant parasite strains, with $\mathrm{IC}_{50}$ values in the low to sub-micromolar range $(0.12-5.17 \mathrm{mM}) .^{24}$

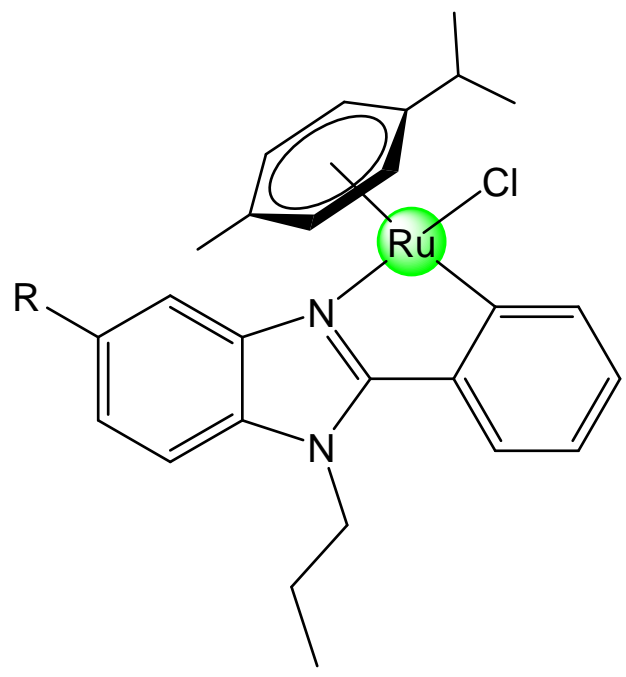

$\mathbf{R}=\mathrm{H}, \mathrm{Cl}, \mathrm{CH}_{3}, \mathrm{CF}_{3}$

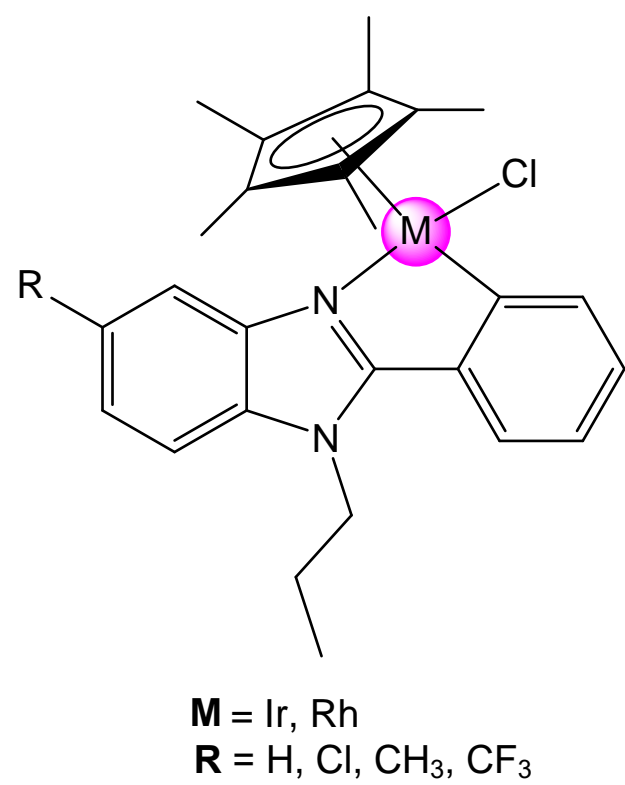

Figure 3.2. $R$ (III), $R$ h(III) and $\operatorname{Ir}(I I I)$ cyclometallated complexes of 2-phenylbenzimidazoles synthesised by Rylands et al. ${ }^{24}$

In this chapter, the synthesis and characterisation of novel neutral, cyclometallated and cationic, $N, N$-chelated half-sandwich $\operatorname{Ir}(I I I)$ complexes of 7-chloroquinoline-1,2,3-triazoles is described. This follows the well-documented concept of incorporating a metal into the scaffold of a known pharmacophore in the hope of improving its biological activity, particularly in parasite resistant strains. ${ }^{9-11}$ Iridium was selected as the metal of choice for these complexes because, in addition to its efficacy, it is generally regarded as safe and biofriendly. The negatively charged pentamethylcyclopentadienyl $\left(\mathrm{Cp} \mathrm{p}^{*}\right)$ ligand was chosen as a good stabilising ligand for $\operatorname{Ir}(\mathrm{III}) .{ }^{25} \mathrm{~A}$ variety of spectroscopic and analytical techniques were used to elucidate and confirm the structures of the proposed complexes. 
3.2 Synthesis and characterisation of half-sandwich $\operatorname{Ir}(I I I)$ complexes based on the series of 7-chloroquinolinotriazole ligands

\section{2.1 Synthesis}

\subsubsection{Synthesis of the neutral 7-chloroquinolinotriazole Ir(III) complexes}

The synthesis of the neutral cyclometallated iridium pentamethylcyclopentadienyl ( $\mathrm{Cp}$ *) 7-chloroquinolinotriazole complexes (7a-f) was achieved via sodium acetate-mediated C-H activation (Scheme 3.1).
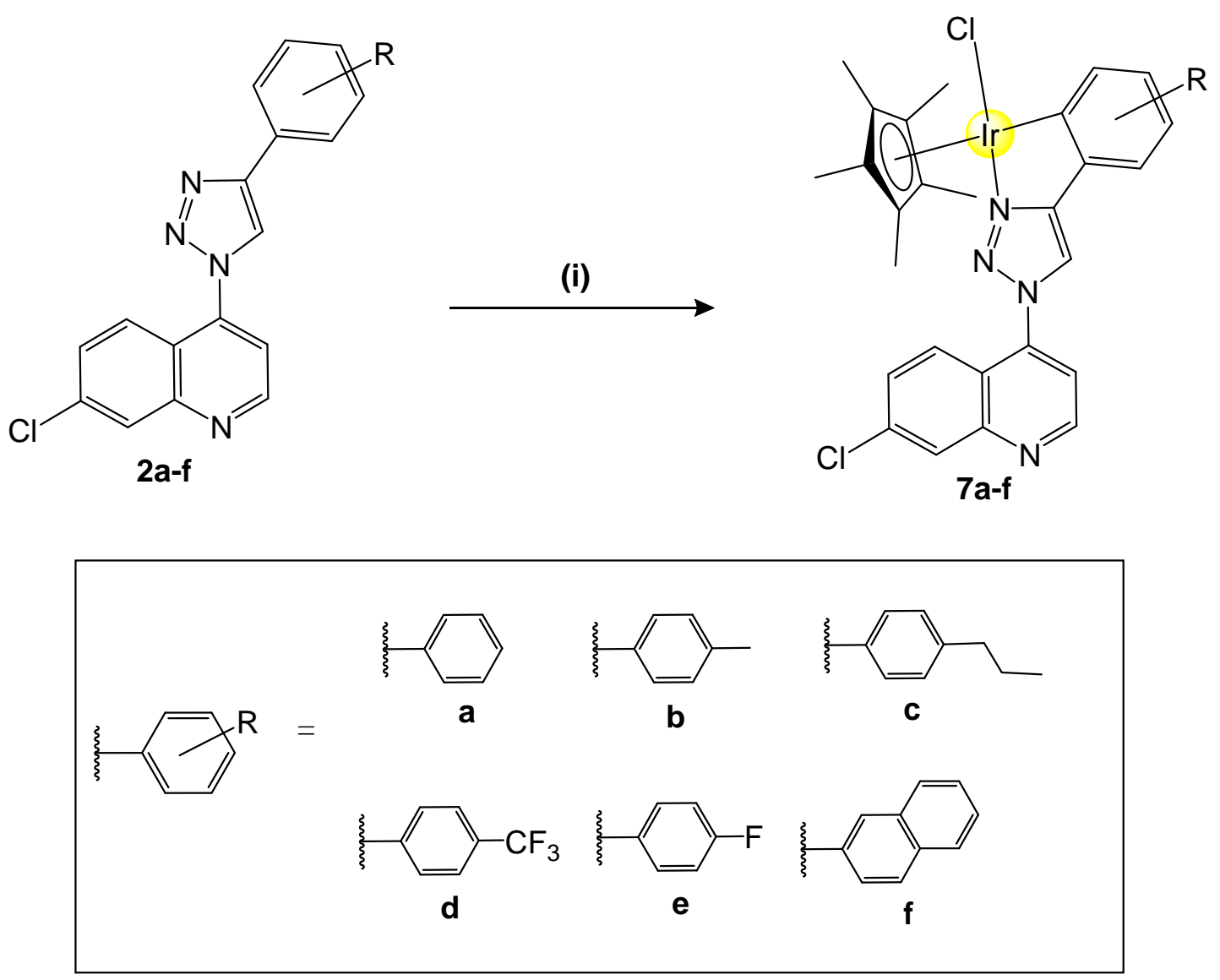

Scheme 3.1. Synthesis of the neutral cyclometallated $\operatorname{Ir}(I I I)$ 7-chloroquinolinotriazole complexes (7a-f). Reagents and conditions: (i) $[\mid r C p *(\mu-\mathrm{Cl}) \mathrm{Cl}]_{2}$ (0.7 eq.), $\mathrm{NaOAc}\left(2\right.$ eq.), ACN, $65{ }^{\circ} \mathrm{C}(72$ h), r.t. (72 h).

Although complexes 7a-f are new, their synthesis was conducted following a modified literature method. ${ }^{26}$ This literature method was used because it involved a similar triazolephenyl system for cyclometallation via $\mathrm{C}-\mathrm{H}$ activation. The synthesis required dissolving the respective 7-chloroquinolinotriazole ligand (2a-f), 2 equivalents of $\mathrm{NaOAC}$ and 0.7 equivalents 
of the pentamethylcyclopentadienyliridium(III) dimer in dry acetonitrile. This reaction mixture was then heated to $65{ }^{\circ} \mathrm{C}$ for $72 \mathrm{~h}$, after which it was stirred for another $72 \mathrm{~h}$ at room temperature, allowing the respective complex (7a-f) to precipitate as a yellow solid. The pentamethylcyclopentadienyliridium(III) dimer was synthesised previously and used without further purification. ${ }^{27}$ The dimer was used in slight excess ( 0.7 equivalents instead of 0.5 equivalents) because this encouraged more of the ligand to react to form the respective complex, thereby, slightly improving the complex yields overall. This excess dimer remained in solution when the complex precipitate was removed via vacuum filtration. The synthesis of the neutral Ir(III) 7-chloroquinolinotriazole complexes (7a-f) was generally sluggish, taking 6 days to react and resulting in only the partial consumption of the ligands, as determined via TLC analysis. It is for this reason that the yields for the cyclometallated $\operatorname{Ir}(\mathrm{III})$ complexes were inconsistent, with the highest being $85 \%$ (7c) and the lowest being $10 \%$ (7f).

The synthesis of cyclometallated complexes is generally achieved via intramolecular $\mathrm{C}-\mathrm{H}$ activation in the presence of a suitable base, such as NaOAc. Although the exact mechanism of this process and the role of the acetate has not yet been determined, several key intermediates have been identified through theoretical and experimental studies conducted by Davies and co-workers (Figure 3.3). ${ }^{28-30}$ Based on their proposed mechanism for the cyclometallation of amines, imines and oxazolines using various metal dimers ${ }^{28}$, the suggested mechanism for the synthesis of the cyclometallated Ir(III) 7-chloroquinolinotriazole complexes (7a-f) is shown in Figure 3.3. Studies show that one of the possible roles of the acetate is to promote the cyclometallation of the ligand with $[\mid r C p *(\mu-C l) C l]_{2}$ by helping to facilitate the break-up of the dimer and the exchange of one of the chloride ligands. ${ }^{28}$ This can occur either before or after the ligand associates, as seen by intermediates I and II on the way to form intermediate III in Figure 3.3. Next, for $\mathrm{C}-\mathrm{H}$ activation to occur, a vacant site is needed and, thus, the loss of an anion from intermediate III is necessary. It had previously been suggested that $\mathrm{C}-\mathrm{H}$ activation may occur through one of two possible mechanisms, the first being via oxidative addition of the aryl $\mathrm{C}-\mathrm{H}$ bond, followed by reductive elimination, as depicted by intermediate $\mathbf{I V}^{1}$ in Figure $3.3 .{ }^{28}$ The alternative route would be by the electrophilic attack of the metal on the arene, via the Wheland intermediate $\mathbf{I V}^{2}$, followed by the loss of a proton. ${ }^{28}$ 


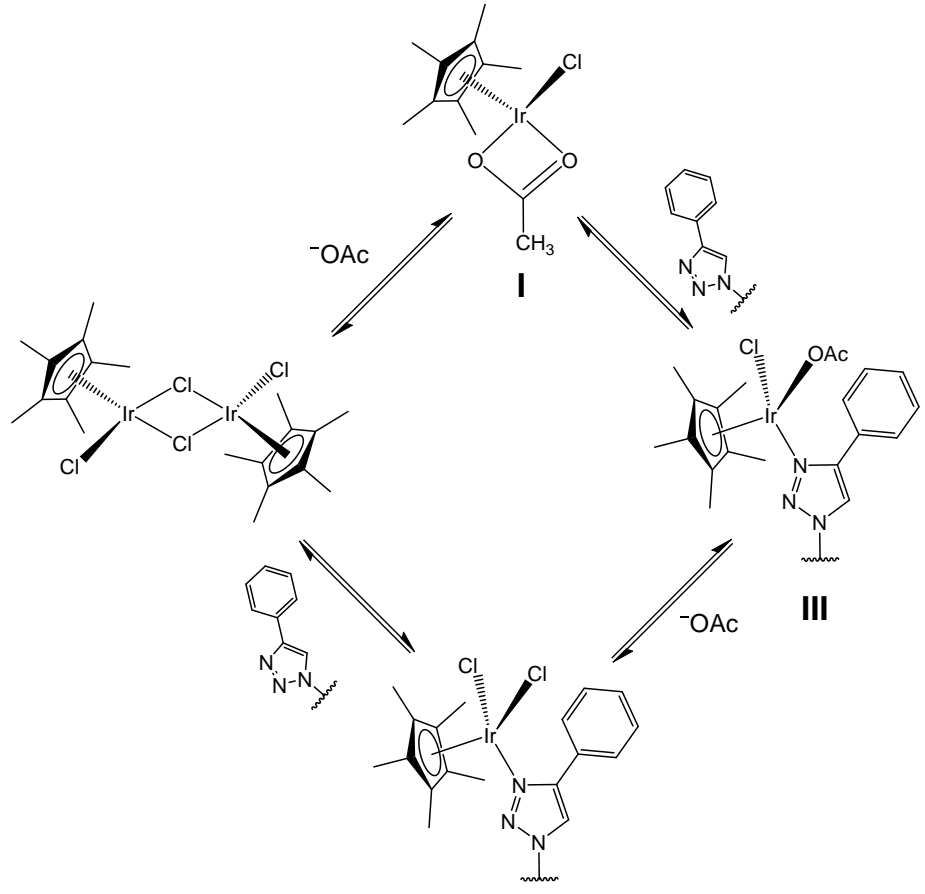

II
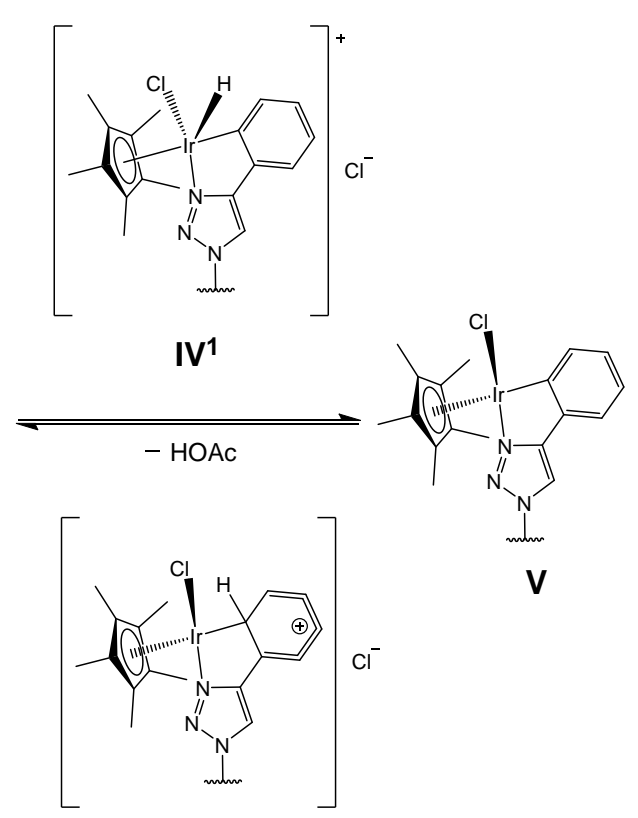

$\mathrm{IV}^{2}$

Figure 3.3. Proposed mechanism for the synthesis of the cyclometallated $\operatorname{Ir}($ III) 7-chloroquinolinotriazole complexes (7a-f). ${ }^{28}$

In order to gain better insight into the structure of the transition state in these cyclometallation reactions, Davies et al. conducted a different study in which computational methods were used to investigate the cyclometallation of dimethylbenzylamine with $\left[\mathrm{Pd}(\mathrm{OAc})_{2}\right] .{ }^{29}$ Through density functional theory (DFT) calculations, their results suggested the existence of a six-membered transition state through which an acetate-assisted hydrogentransfer process occurs. ${ }^{29}$ This was found to be the most accessible route towards the formation of the final cyclometallate, however, it was discovered to proceed via an agostic $\mathrm{C}-\mathrm{H}$ intermediate complex rather than the previously-suggested Wheland intermediate. ${ }^{28,29}$ In this process, the acetate plays a key role in acting as an intramolecular base for deprotonation, as well as possibly stabilising the agostic intermediate through hydrogen bonding. Based on this literature, a proposed transition state for the cyclometallated complexes in this chapter is illustrated in Figure 3.4. The reason why the proton-transfer via a six-membered transition state is more accessible than a previously-suggested fourmembered transition state is because it allows the acetate to be orientated in a manner appropriate for it to act as an intramolecular base. ${ }^{29}$ This allows deprotonation to occur with minimal distortion to the system, meaning that the reaction pathway can proceed via a low- 
energy transition state, as suggested by Davies et al. in a further study using $\left\{\mathrm{Cp}^{*} \mid \mathrm{r}\right\}$ complexes. ${ }^{30}$ It also means that $\mathrm{C}-\mathrm{H}$ activation is able to occur at the ortho-position on the arene, as the pendant acetate arm is in close proximity to the ortho-proton, thereby putting it in a position to facilitate the proton-transfer.
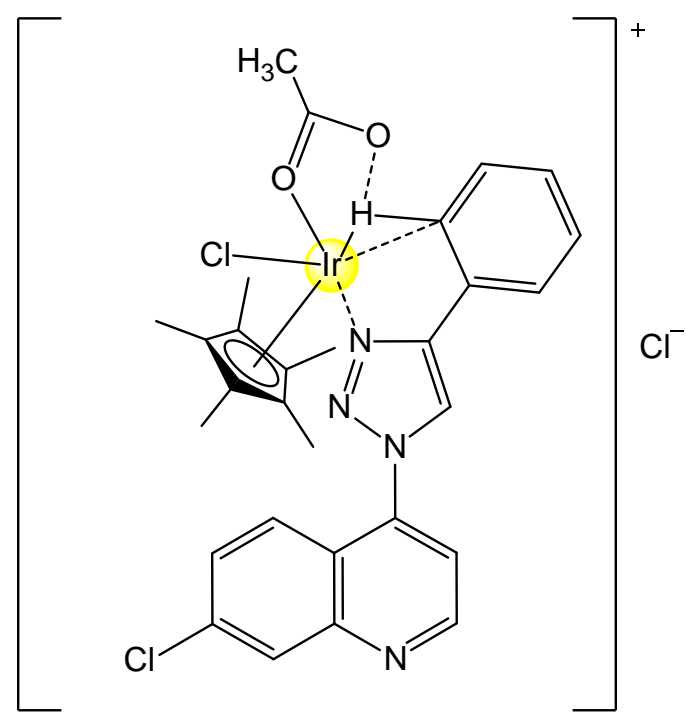

Figure 3.4. Proposed 6-membered transition state of the $\mathrm{C}-\mathrm{H}$ activation mechanism, resulting in the formation of the cyclometallated complexes (7a-f)..$^{29}$

Since the discovery made by the Davies group in 2003 that harsh reaction conditions and a strong base are not needed to activate the $\mathrm{C}-\mathrm{H}$ bond, cyclometallation reactions under mild reaction conditions have become increasingly popular. ${ }^{28}$ Their reported method was one of the first for the cyclometallation of nitrogen donor ligands using metals such as Ir, Rh and Ru, with the $\mathrm{C}-\mathrm{H}$ activation reaction occurring at room temperature and promoted by the mild base, sodium acetate. ${ }^{28}$ It was, therefore, surprising when the synthesis of the cyclometallated $\operatorname{Ir}(\mathrm{III})$ complexes described in this chapter did not follow the mild conditions prescribed for reactions of this kind. Instead, these complexes were only able to be synthesised when heated in acetonitrile at over $65^{\circ} \mathrm{C}$ and when the reactants were stirred together for almost a week. It was discovered that, when attempting this reaction at room temperature, a bright yellow precipitate was formed about one minute after adding the solvent to the reactants. Upon isolation and characterisation of this yellow precipitate, it was determined that the metal was not coordinated to the third nitrogen of the triazole as desired, but rather coordinated to the more basic quinoline nitrogen in a monodentate manner, as shown by complex 8 in Scheme 3.2. This bright yellow precipitate observed for 
<smiles>Clc1ccc2c(-n3cc(-c4ccccc4)nn3)ccnc2c1</smiles>

$2 \mathbf{a}$<smiles></smiles>

Scheme 3.2. Synthesis of the neutral monodentate $\operatorname{Ir}(I I I)$ 7-chloroquinolinotriazole complex, 8. Reagents and conditions: (i) $[\operatorname{IrCp} *(\mu-\mathrm{Cl}) \mathrm{Cl}]_{2}(0.7$ eq.), $\mathrm{NaOAc}(2$ eq.), $\mathrm{ACN}$, r.t., $\sim 1$ min.

the monodentate complex was formed first in the synthesis of all six cyclometallated complexes (7a-f), however, only the monodentate complex $\mathbf{8}$, synthesised using ligand $\mathbf{2 a}$, was properly isolated and fully characterised. It was also discovered that, upon heating the monodentate complexes in acetonitrile to a temperature of $65^{\circ} \mathrm{C}$ and above, the bright yellow precipitate gradually went back into solution over a period of three days and, when cooled, another yellow precipitate formed. This precipitate was that of the desired cyclometallated $\operatorname{Ir}($ III) complexes, 7a-f, in each case. This observation gave rise to the idea that kinetic versus thermodynamic control could be taking place in this reaction, with the monodentate complex being the fastest-formed kinetic product while more energy is required to form the cyclometallated, thermodynamic product.

\subsubsection{Computational studies of the kinetic vs thermodynamic outcome of the $\mathrm{C}-\mathrm{H}$ activation} reaction with ligand $2 a$

Various computational simulations were performed to investigate this hypothesis. Two methods were used, namely optimisation to find a stationary point and a relaxed geometry scan to scan the Ir-N bond length. The ORCA software (v 4.1.1) $)^{31}$ was used and dispersioncorrected DFT was chosen as the level of theory ${ }^{32}$, specifically the BLYP-D3 method with def2SVP as a basis and def2-ECP as an effective core potential. Optimisations were carried out; 
frequencies and molecular orbitals were calculated, and scans were carried out with the same level of theory. The labelled pathway for these studies is shown in Figure 3.5, detailing the reaction process from the iridium metal dimer, I, through the plausible intermediates and ending with the characterised compounds, IV and $\mathbf{V}$.

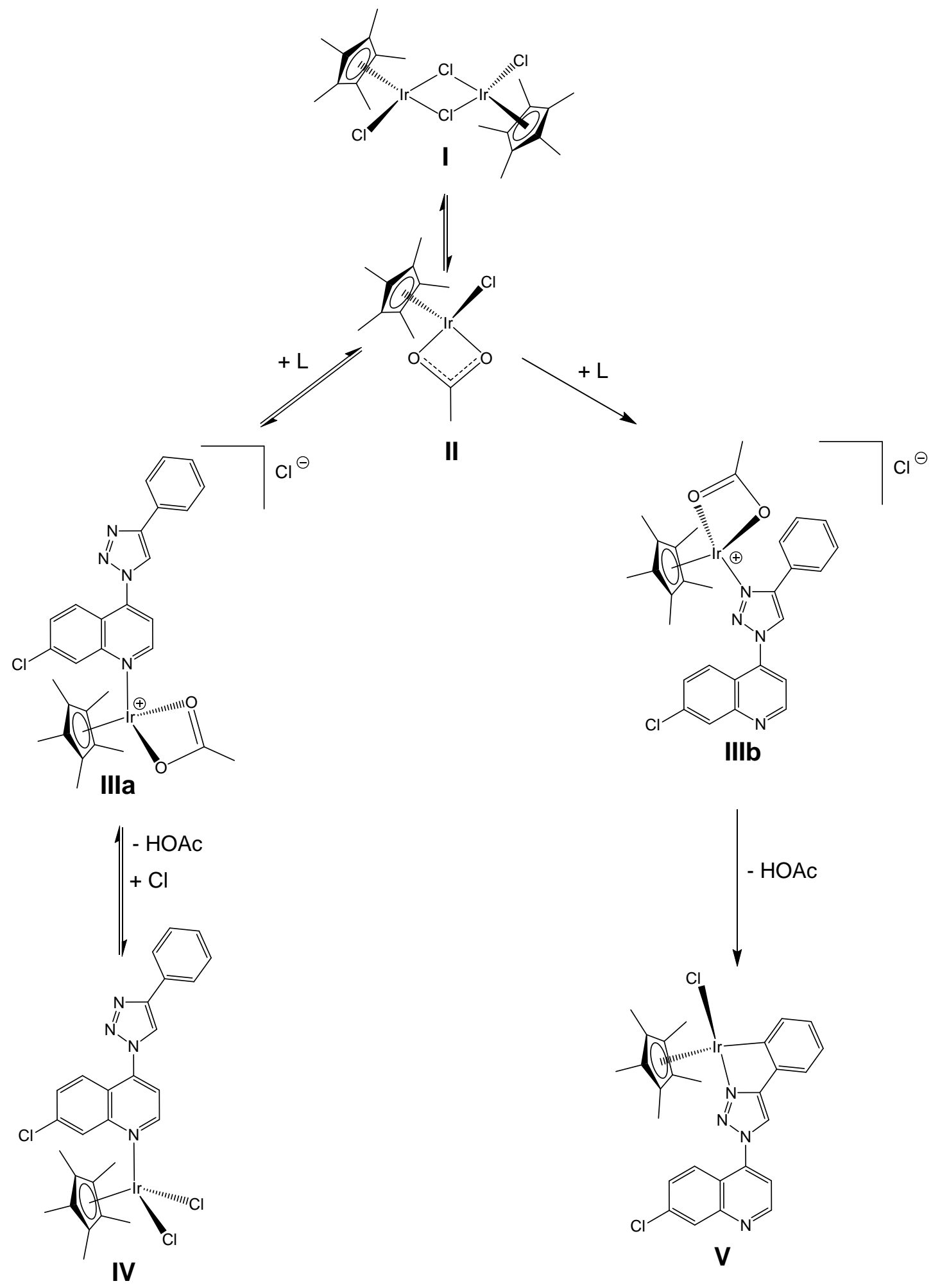

Figure 3.5. Labelled pathway for the reaction process from the $\operatorname{Ir} \mathrm{Cp}^{*}$ dimer to the final complexes. 
Firstly, an optimisation of the cations of IIla and IIIb, the plausible intermediates on the way to the final compounds, was carried out. The energy calculated for these molecules can be directly compared as these molecules contain the same atoms but in a different arrangement. A chloride anion is removed at this stage to provide a vacant site for potential cyclometallation. The results of this study found that intermediate IIIb, with the Ir coordinated to the triazole nitrogen, is lower in energy than the quinoline-coordinated-Ir intermediate IIla by $4 \times 10^{-4}$ hartrees or $2 \mathrm{kcal} / \mathrm{mol}$. While a small change, this shows that intermediate IIIb is already more stable than intermediate IIla.

The reaction to form product IV or $\mathbf{V}$ from intermediate II and the ligand, $\mathbf{L}$, was then investigated. The energy barrier between the reactants and the products is estimated by creating a neutral complex of II with the ligand, as shown in Figure 3.6. A scan is carried out where the Ir-N bond is then pulled from a short bond length to several Angström away. This process, although modelled as the inverse of the ligand binding, represents how the ligand binds to II. A small energy barrier which can be overcome at standard state temperature $\left(25^{\circ} \mathrm{C}\right)$ would be considered to lead to a kinetic product, while a larger energy barrier which leads to a lower energy product would be considered the thermodynamic route. Figure 3.6 shows the outcome of the two simulations performed, one with the ligand bound to the metal at the quinoline nitrogen and one with the ligand binding at the triazole nitrogen. Figure 3.6a shows the energy diagram for the former, illustrating that the outcome for the coordination of the metal to the quinoline nitrogen is a small energy barrier. When the distance between the Ir and quinoline nitrogen is $6.0 \AA$, the resulting complex structure is relatively low in energy. As the distance thereafter decreases, the energy increases until it eventually reaches an energy barrier of over $5.4 \mathrm{kcal} / \mathrm{mol}$. At this energy, the bond forms, resulting in a higher energy complex. This energy barrier can be overcome at standard state temperature, which explains why the monodentate complex $\mathbf{8}$ formed relatively quickly at room temperature and suggests a kinetic product. The outcome for the latter, the coordination of the metal to the triazole nitrogen, is shown in the energy diagram in Figure 3.6b. In this case, the energy barrier for the formation of the Ir-N bond is very high, with no minimum observed thus far. When the distance between the $\mathrm{Ir}$ and triazole nitrogen is $5.2 \AA$, the resulting complex structure is low in energy, however, as the distance decreases, the energy increases until it eventually reaches an energy barrier of nearly $12 \mathrm{kcal} / \mathrm{mol}$. The higher predicted energy required to form 
the cyclometallated complex $7 \mathrm{a}$ explains the need for the high temperature required to synthesise this product. These calculations support the hypothesis that the complex $7 \mathbf{a}$ is a thermodynamic product while complex $\mathbf{8}$ is a kinetic product.
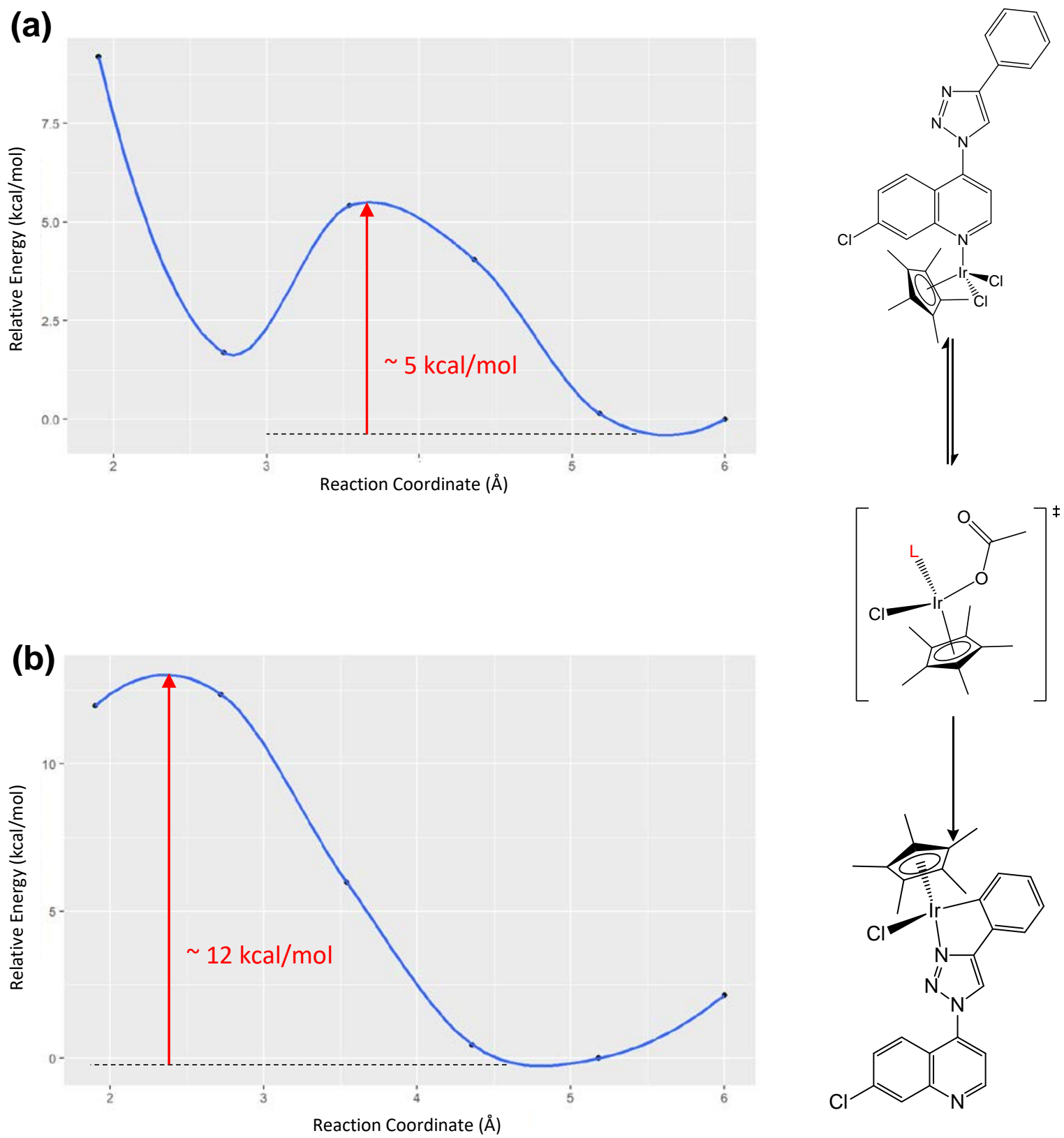

Figure 3.6. Energy diagrams of the two outcomes of metal coordination to the ligand at either (a) the quinoline nitrogen or (b) the triazole nitrogen. 


\subsubsection{Synthesis of the cationic 7-chloroquinolinotriazole Ir(III) complex}

The synthesis of the cationic $N, N$-chelated half-sandwich iridium(III) 7-chloroquinolinotriazole complex $(\mathbf{7 g})$ was achieved via a bridge-splitting reaction of the iridium dimer and coordination of the ligand $\mathbf{2} \mathbf{g}$, as shown in Scheme 3.3. In this entropically-driven reaction, the ligand coordinates to the metal via the triazole and pyridyl nitrogen atoms, forming a stable five-membered ring. A salt metathesis using hexafluorophosphate was then carried out to replace the chloride counterion and to allow for the precipitation of the cationic complex from the solution.

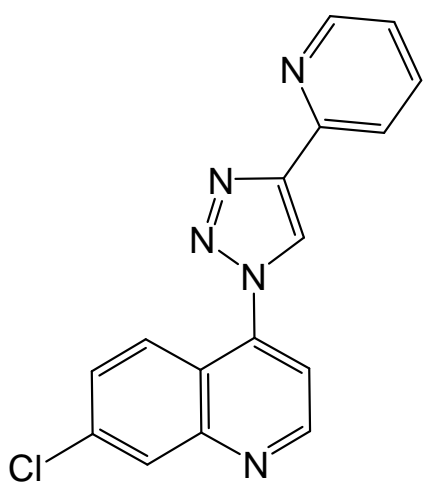

$2 \mathrm{~g}$

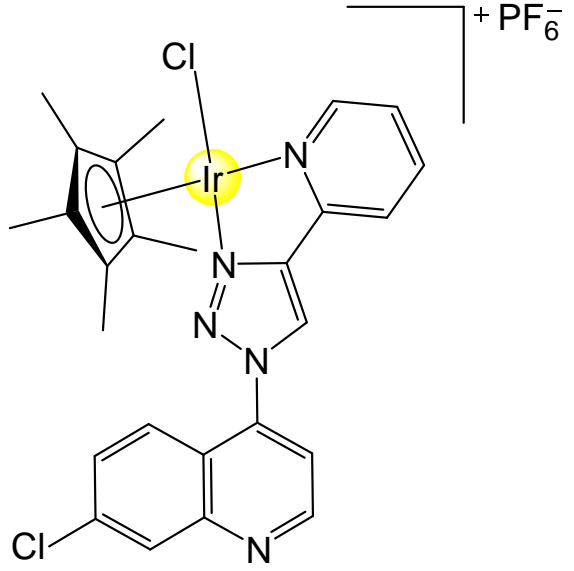

$7 \mathrm{~g}$

Scheme 3.3. Synthesis of the $N, N$-chelated $\operatorname{Ir}(I I I)$ 7-chloroquinolinotriazole cationic complex (7g). Reagents and conditions: (i) $[\mathrm{IrCp} *(\mu-\mathrm{Cl}) \mathrm{Cl}]_{2}$ (0.5 eq.), $\mathrm{NH}_{4} \mathrm{PF}_{6}$ (4 eq.) DCM/EtOH, r.t., 22 h.

The cationic $\mathrm{N}, \mathrm{N}$-chelated half-sandwich iridium(III) 7-chloroquinolinotriazole complex $(\mathbf{7 g})$ was isolated as a pale yellow powder in a good yield of $79 \%$. It is soluble in a wide range of solvents and sparingly soluble in water.

\subsubsection{Characterisation}

The neutral cyclometallated Ir(III) complexes (7a-f), neutral monodentate Ir(III) complex (8) and cationic $\mathrm{Ir}(\mathrm{III})$ complex ( $\mathbf{7 g}$ ) were characterised using various spectroscopic and analytical techniques. These included ${ }^{1} \mathrm{H},{ }^{13} \mathrm{C}\left\{{ }^{1} \mathrm{H}\right\},{ }^{19} \mathrm{~F}\left\{{ }^{1} \mathrm{H}\right\}$ (compounds $\mathbf{7 d}$ and $\mathbf{7 e}$ ), ${ }^{31} \mathrm{P}\left\{{ }^{1} \mathrm{H}\right\}$ (compound 7g), ${ }^{1} \mathrm{H}-{ }^{1} \mathrm{H}$ correlation spectroscopy (COSY) and heteronuclear single quantum coherence (HSQC) nuclear magnetic resonance (NMR) spectroscopy, as well as infrared (IR) spectroscopy, electrospray ionisation mass spectrometry (ESI-MS), single-crystal X-ray diffraction (XRD) (complexes $7 \mathbf{a}$ and 8 ) and melting point analysis. 


\subsubsection{Characterisation of the neutral 7-chloroquinolinotriazole Ir(III) complexes}

\section{NMR Spectroscopy}

Analysis of the ${ }^{1} \mathrm{H}$ NMR spectra of the neutral cyclometallated iridium pentamethylcyclopentadienyl 7-chloroquinolinotriazole complexes (7a-f) confirmed the successful coordination of the respective ligands to the metal centre. Figure 3.7 shows the ${ }^{1} \mathrm{H}$ NMR spectra of cyclometallated complex 7a and monodentate complex $\mathbf{8}$, as well as the spectrum of their respective ligand, 2 a. In spectrum (b) in Figure 3.7, evidence for coordination to the metal is first provided by the presence of a singlet at $1.81 \mathrm{ppm}$, which integrates for 15 protons and corresponds to the protons on the $\mathrm{Cp}^{*}$ ligand. Further evidence is the absence of a proton signal at the ipso-carbon of $\mathrm{C}-\mathrm{H}$ activation relative to the ${ }^{1} \mathrm{H}$ NMR

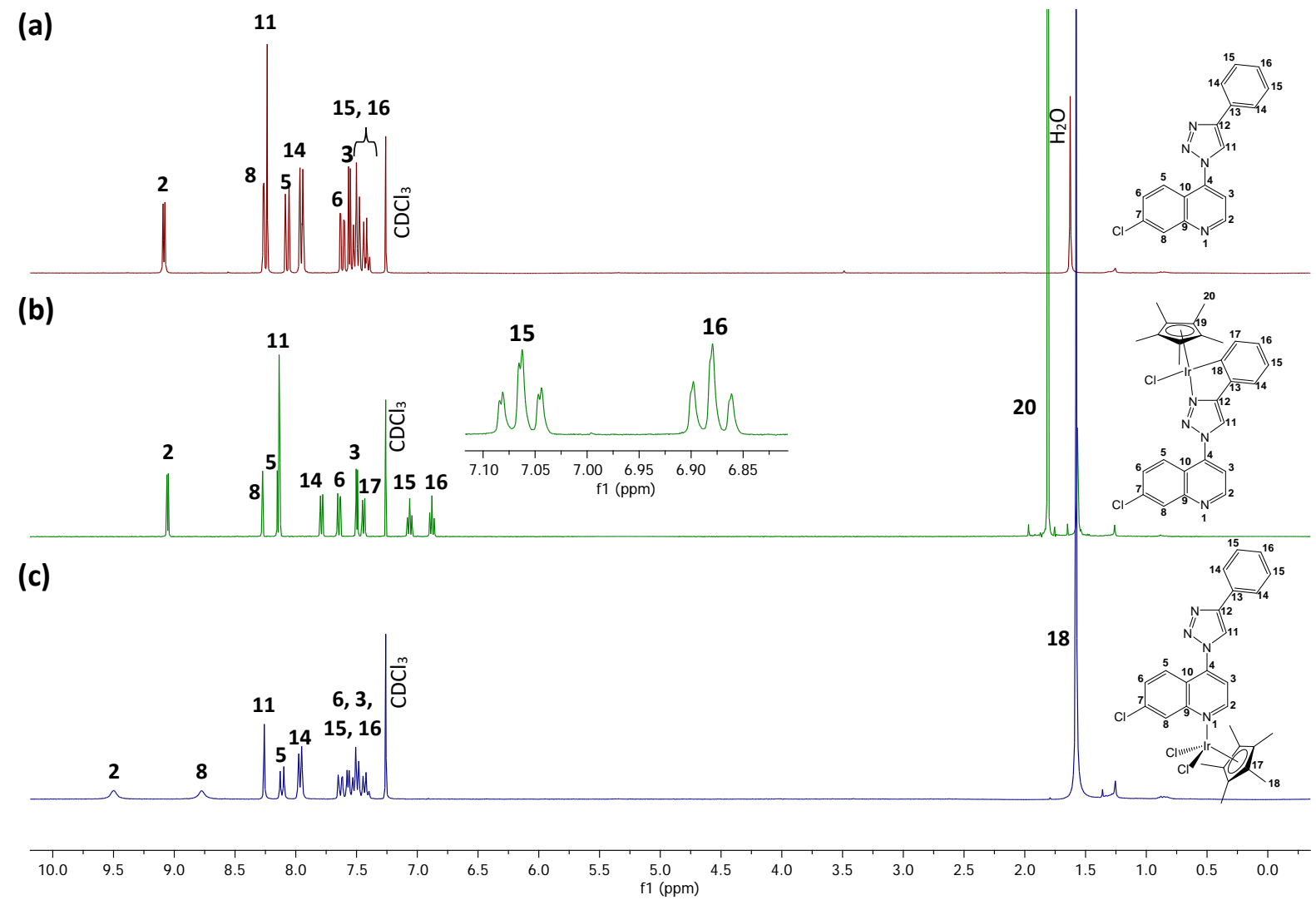

Figure 3.7. Stacked ${ }^{1} \mathrm{H}$ NMR spectra of (a) 7-chloroquinolinotriazole ligand, $2 \mathrm{a}$, (b) neutral cyclometallated Ir(III) 7-chloroquinolinotriazole complex, 7a, and (c) neutral monodentate Ir(III) 7-chloroquinolinotriazole complex, 8 , in $\mathrm{CDCl}_{3}$.

spectrum of the respective ligand starting material (Figure 3.7a). It can additionally be seen that, where protons 15 and 16 are present as a multiplet in the ${ }^{1} \mathrm{H}$ NMR spectrum of the 
ligand, these proton signals become distinct triplets-of-doublets upon metal coordination. These two triplets-of-doublets are visible in the inset section of the respective spectrum in Figure 3.7b. This occurrence is likely due to the effect of cyclometallation, which "locks" the phenyl ring in place thereby preventing its free rotation and causes protons 15 and 16 to resonate in different environments. This is in contrast to the spectrum of the monodentate Ir(III) complex, 8, which is shown in Figure 3.7c. The spectrum of this complex is almost identical to that of the ligand, however, the presence of a singlet at $1.58 \mathrm{ppm}$, which integrates for 15 protons corresponding to the $\mathrm{Cp}^{*}$ ligand is evidence for metal coordination. In addition to this, the downfield shift and broadening of proton signals 2 and 8 indicates that metal coordination is most likely to the quinoline nitrogen as these are the protons which are closest to the site of coordination. The broadening of these signals is possibly due to longrange coupling to the $\mathrm{Cp}^{*}$ moiety, which is in the vicinity of the protons in question.

Figure 3.8 shows two more representative ${ }^{1} \mathrm{H}$ NMR spectra of complexes $7 \mathrm{c}$ and $7 \mathrm{e}$ in the series of neutral cyclometallated Ir(III) 7-chloroquinolinotriazole complexes. As with the spectrum of complex $7 \mathrm{a}$, the presence of a singlet at $1.81 \mathrm{ppm}$ integrating for 15 protons is

(a)

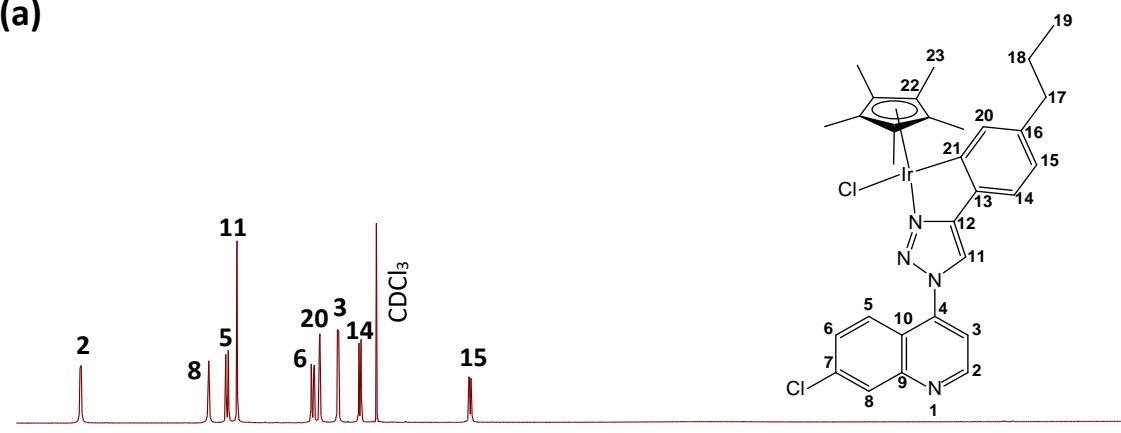

(b)

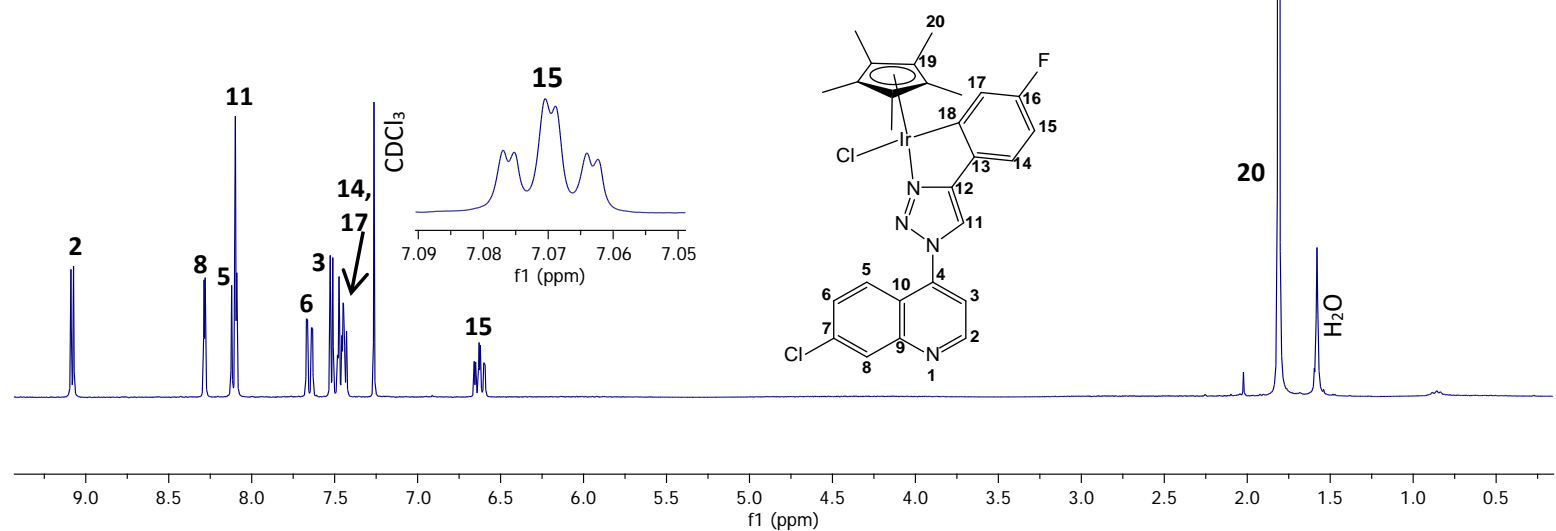

Figure 3.8. Stacked ${ }^{1} \mathrm{H}$ NMR spectra of neutral cyclometallated $\operatorname{Ir}(\mathrm{III})$ 7-chloroquinolinotriazole complexes, (a) $7 \mathrm{c}$ and (b) $7 \mathrm{e}$ in $\mathrm{CDCl}_{3}$. 
assigned to the $\mathrm{Cp}^{*}$ ligand in $7 \mathrm{c}$ and $7 \mathrm{e}$. Furthermore, the absence of one aromatic proton relative to the 7-chloroquinolinotriazole starting material also supports cyclometallation via $\mathrm{C}-\mathrm{H}$ activation. In the spectrum of complex 7c (Figure 3.8a), two distinct multiplets are observed at 2.48 and $2.59 \mathrm{ppm}$. These two multiplets correspond to the methylene protons closest to the phenyl ring and HSQC spectroscopy further confirms that the two proton signals are assigned to one carbon peak. The change from a triplet before complexation to two distinct signals is a result of the chirality induced by the stereogenic metal centre, causing these protons to become diastereotopic and thus non-equivalent. Additionally, coordination of the ligand to the metal for complex 7e was further confirmed by the presence of the signal for proton 15 integrating for one proton in its respective ${ }^{1} \mathrm{H}$ NMR spectrum. The same resonance in the ${ }^{1} \mathrm{H}$ NMR spectrum of the ligand integrated for two protons, because of the symmetry of the 1,4-disubstituted phenyl ring. This symmetry is, however, removed upon cyclometallation and the signal exists as a multiplet, visible in the enlarged section of spectrum (b) in Figure 3.8, due to coupling of the proton to the NMR-active fluorine atom.

${ }^{13} \mathrm{C}\left\{{ }^{1} \mathrm{H}\right\}$ NMR spectroscopy was also used to confirm that complexation had been successful. The two carbon resonances for the quaternary and methyl carbons of the pentamethylcyclopentadienyl ( $\mathrm{Cp}^{*}$ ) ligand are observed at around 9.2 and $89 \mathrm{ppm}$ respectively. 2D NMR techniques such as HSQC and COSY, were used to confirm the carbon assignments made. Compounds $\mathbf{7 d}$ and $\mathbf{7 e}$ were also analysed using ${ }^{19} \mathrm{~F}\left\{{ }^{1} \mathrm{H}\right\}$ NMR spectroscopy, with a single resonance being observed at $\delta_{F}-62.13$ and $-112.2 \mathrm{ppm}$ respectively, indicating the presence of only one type of fluorinated compound for each.

\section{Infrared Spectroscopy}

The infrared spectra of the cyclometallated complexes 7a-f are almost identical to those of their respective ligands, displaying analogous absorbance bands at similar wavenumbers. The IR spectrum of cyclometallated complex $\mathbf{7 a}$ and its corresponding ligand $\mathbf{2} \mathbf{a}$ can be seen in Figure 3.9. In these two spectra, the quinoline $v(\mathrm{C}=\mathrm{N})$ absorption band is present at $1560 \mathrm{~cm}^{-1}$, slightly lower than the expected region for the $\mathrm{C}=\mathrm{N}$ functional group due to the electron-withdrawing effect of the highly conjugated quinoline-triazole-phenyl system. In the IR spectrum of monodentate complex 8 (Figure 3.9), the $v(\mathrm{C}=\mathrm{N})_{\text {quinoline }}$ absorption band has shifted to a higher wavenumber of $1593 \mathrm{~cm}^{-1}$. This shift to a higher wavenumber corroborates 


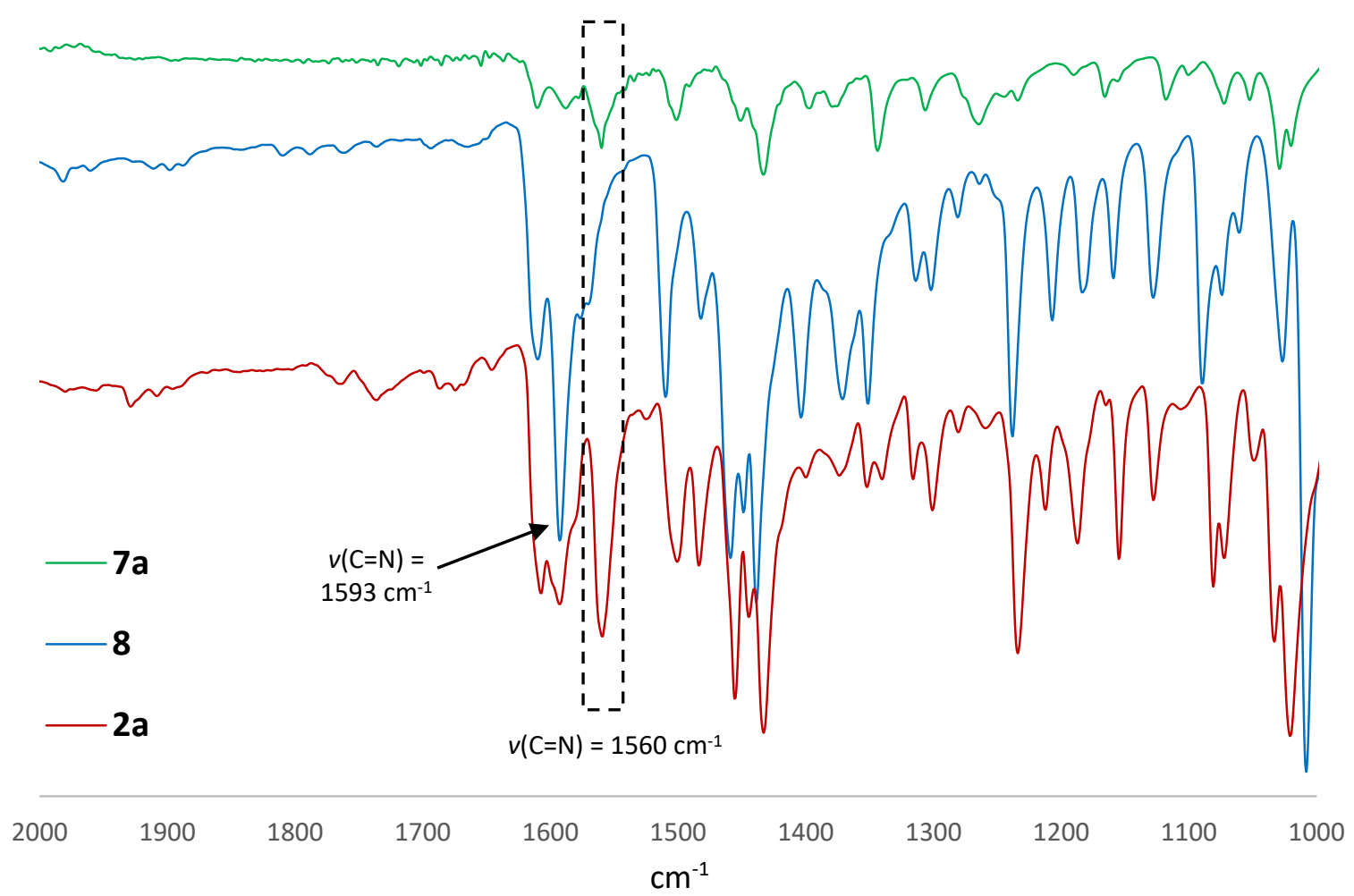

Figure 3.9. Stacked IR spectra of ligand $2 \mathrm{a}$ and neutral $\operatorname{Ir}(\mathrm{III})$ complexes $7 \mathbf{7 a}$ and $\mathbf{8}$. The shift of the quinoline $v(\mathrm{C}=\mathrm{N})$ absorption band is highlighted.

the downfield shift of the aromatic quinoline $\mathrm{C}=\mathrm{N}$ proton signal in the respective ${ }^{1} \mathrm{H}$ NMR spectrum (Figure $3.7 \mathrm{c}$ ). This is due to a significant degree of $\pi$-electron donation from the lone-pair of electrons on the quinoline nitrogen atom of the ligand to the vacant $d$-orbitals on the metal centre. Absorbance band shifts of this kind have been reported for similar complexes in literature. ${ }^{18,33}$

\section{High Resolution Mass Spectrometry}

High resolution electrospray lonisation mass spectrometry (ESI-MS) was used to further confirm the structural integrity of the neutral Ir(III) 7-chloroquinolinotriazole complexes 7a-f and 8. In general, the mass spectrum of the complexes recorded in DCM show base peaks which correspond to the molecular ion with the loss of a chloride ion, $[\mathrm{M}-\mathrm{Cl}]^{+}$. On the other hand, those complexes in which the mass spectra were recorded in DMSO yielded $[\mathrm{M}-\mathrm{Cl}+\mathrm{DMSO}]^{+}$fragments corresponding to the molecular ion which has had the chloride ion replaced by a DMSO molecule. 


\section{Single Crystal X-Ray Diffraction (XRD)}

The molecular structures of the $\operatorname{Ir}(\mathrm{III})$ cyclometallated complex 7a and the $\operatorname{Ir}(\mathrm{III})$ monodentate complex 8 were elucidated by single crystal X-ray diffraction (Figure 3.10). Single crystals of complexes $7 \mathbf{a}$ and $\mathbf{8}$ were grown by the slow diffusion of diethyl ether into a concentrated dichloromethane solution.

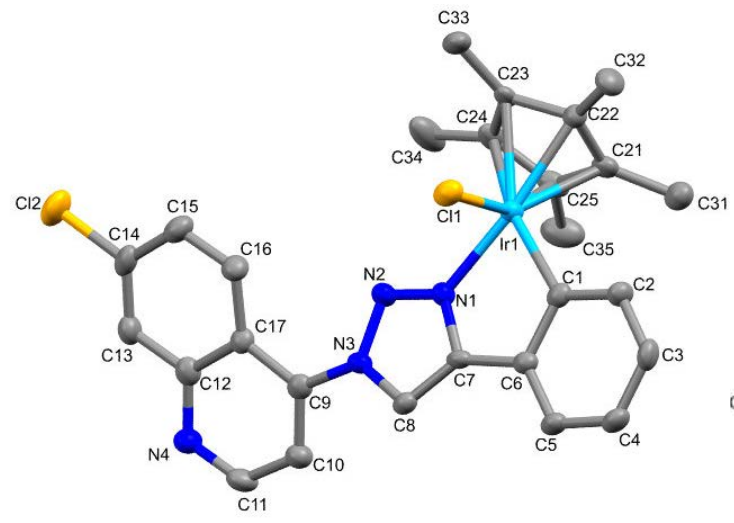

(a)

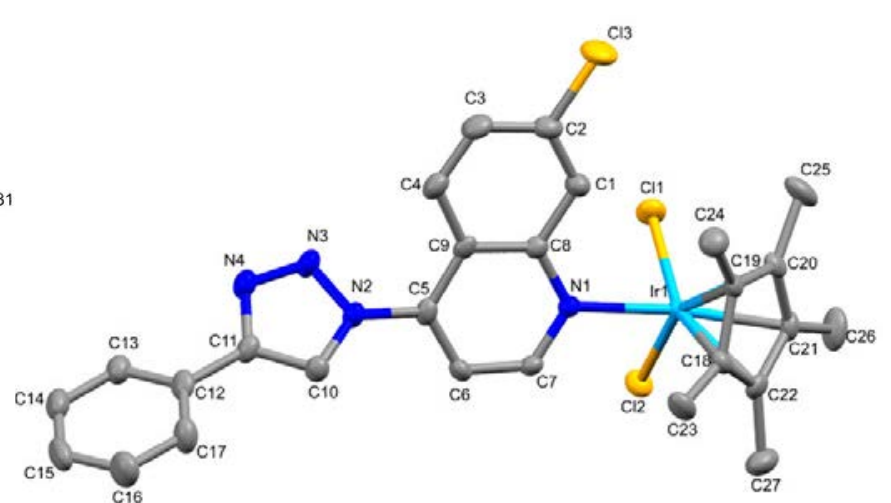

(b)

Figure 3.10. X-ray crystallographic ORTEP diagrams of neutral $\operatorname{Ir}(I I I) \mathrm{Cp}^{*}$ 7-chloroquinolinotriazole complexes a) 7 a (cyclometallate) and b) 8 (monodentate), where thermal ellipsoids are drawn at $40 \%$ and $50 \%$ probability level respectively.

From the ORTEP diagrams of complexes $\mathbf{7 a}$ and $\mathbf{8}$, it can be seen that both $\operatorname{Ir}(\mathrm{III})$ complexes adopt the well-documented "three-legged piano-stool" structure where the pentamethylcyclopentadienyl $\left(\mathrm{C} \mathrm{p}^{*}\right)$ ligand forms the seat of the piano-stool while the three "legs" are formed from the chloride and 7-chloroquinolinotriazole chelating ligand (complex 7a), or two chlorides and the monodentate 7-chloroquinolinotriazole ligand (complex 8). The piano-stool structure is also commonly observed in many other iridium, rhodium and ruthenium half-sandwich complexes reported in literature. ${ }^{24,25,34}$ Table 3.1 summarises the crystal data and refinement parameters for both complexes. Complex 7 a crystallizes in a P2 $1 / c$ space group with a monoclinic system while complex $\mathbf{8}$ crystallises in a Pbca space group with an orthorhombic system. A total of 4 and 8 molecules per unit cell were observed for complexes $7 \mathrm{a}$ and $\mathbf{8}$ respectively. Selected bond distances and angles for both complexes are listed in Table 3.2. This data suggests that the geometry around the metal centre is pseudotetrahedral as the bond angles around the metal centre range between 77.58 and $88.39^{\circ}$ for 
Table 3.1. Crystallographic data and refinement parameters for complexes $7 a$ and 8.

\begin{tabular}{|c|c|c|}
\hline & Complex 7a & Complex 8 \\
\hline Chemical formula & $\mathrm{C}_{27} \mathrm{H}_{25} \mathrm{Cl}_{2} \mathrm{IrN} \mathrm{N}_{4}$ & $\mathrm{C}_{27} \mathrm{H}_{26} \mathrm{Cl}_{3} \mathrm{IrN} \mathrm{N}_{4}$ \\
\hline Formula weight & 668.63 & 705.09 \\
\hline Crystal system & monoclinic & orthorhombic \\
\hline Space group & $\mathrm{P} 2_{1} / \mathrm{c}$ (No. 14) & Pbca (No. 61) \\
\hline \multirow[t]{2}{*}{ a, b, c ( $(\AA)$} & 12.6578(13), 7.9469(9), & 7.9369(5), 22.7369(14), \\
\hline & $24.600(3)$ & $28.4099(16)$ \\
\hline$\alpha, \beta, \gamma\left({ }^{\circ}\right)$ & $90,97.192(3), 90$ & - \\
\hline$V\left(\AA^{3}\right)$ & $2455.1(5)$ & $5126.9(5)$ \\
\hline $\mathbf{Z}$ & 4 & 8 \\
\hline $\mathrm{D}\left(\mathrm{g} \cdot \mathrm{cm}^{-3}\right)$ & 1.809 & 1.827 \\
\hline$\mu\left(\mathrm{mm}^{-1}\right)$ & 5.680 & 5.546 \\
\hline$F(000)$ & 1304 & 2752 \\
\hline Crystal size (mm) & $0.03 \times 0.07 \times 0.09$ & $0.07 \times 0.08 \times 0.09$ \\
\hline $\mathbf{T}(\mathrm{K})$ & 173 & 173 \\
\hline Scan range $\left({ }^{\circ}\right)$ & $1.7<\theta<28.4$ & $1.4<\theta<28.4$ \\
\hline Unique reflections & 6162 & 6441 \\
\hline $\mathbf{R}_{\text {int }}$ & 0.110 & 0.121 \\
\hline Reflections used & 4783 & 4775 \\
\hline \multicolumn{3}{|l|}{$[1>2 \sigma(I)]$} \\
\hline $\mathbf{R}$ indices (all data) & R 0.0314, wR2 0.0682, S 1.01 & R 0.0266, wR2 0.0546, S 1.01 \\
\hline Goodness-of-fit & 1.01 & 1.01 \\
\hline $\operatorname{Max}, \operatorname{Min} \Delta \rho\left(\mathrm{e} \AA^{-3}\right)$ & $-1.14,0.70$ & $-0.63,0.51$ \\
\hline
\end{tabular}

both complexes. These angles are too low for both a tetrahedral $\left(109.5^{\circ}\right)$ or square planar $\left(90.0^{\circ}\right)$ geometry. For complex $7 \mathrm{a}$, the new 5 -membered ring formed by cyclometallation is not entirely planar as expected with a torsion angle of $4.6^{\circ}$, while the quinoline moiety and the triazole-phenyl ring system of this complex are also not co-planar, with a torsion angle of $32.5^{\circ}$. In the case of the monodentate complex, 8 , the quinoline moiety and the triazole- 
phenyl ring system are similarly not co-planar, but rotated $47.8^{\circ}$ from each other. Also, without the rigidity afforded by cyclometallation, the torsion angle between the triazole and phenyl rings is $22.8^{\circ}$, much larger than the $4.6^{\circ}$ for the same angle of the cyclometallated complex.

Table 3.2: Selected bond lengths and angles for $\operatorname{Ir}(I I I)$ complexes $\mathbf{7 a}$ and 8.

\begin{tabular}{|c|c|c|c|}
\hline \multicolumn{2}{|c|}{ Complex 7a } & \multicolumn{2}{|c|}{ Complex 8} \\
\hline \multicolumn{4}{|c|}{ Bond lengths (Å) } \\
\hline $\mathbf{I r}_{1}-\mathbf{N}_{1}$ & $2.071(3)$ & $\mathbf{I r}_{1}-\mathbf{N}_{1}$ & $2.159(3)$ \\
\hline $\mathrm{Ir}_{1}-\mathrm{Cl}_{1}$ & $2.3986(12)$ & $\mathrm{Ir}_{1}-\mathrm{Cl}_{1}$ & $2.4167(12)$ \\
\hline$I r_{1}-C_{1}$ & $2.062(4)$ & $\mathrm{Ir}_{1}-\mathrm{Cl}_{2}$ & $2.3952(9)$ \\
\hline $\mathrm{Ir}_{1}-\mathrm{C}_{21}$ & $2.166(4)$ & $\mathrm{Ir}_{1}-\mathrm{C}_{18}$ & $2.154(4)$ \\
\hline$I r_{1}-C_{22}$ & $2.153(4)$ & $\operatorname{Ir}_{1}-\mathrm{C}_{19}$ & $2.177(4)$ \\
\hline $\mathrm{Ir}_{1}-\mathrm{C}_{23}$ & $2.242(4)$ & $\mathrm{Ir}_{1}-\mathrm{C}_{20}$ & $2.156(3)$ \\
\hline$I r_{1}-C_{24}$ & $2.242(4)$ & $\operatorname{Ir}_{1}-\mathrm{C}_{21}$ & $2.133(4)$ \\
\hline $\operatorname{Ir}_{1}-\mathrm{C}_{25}$ & $2.149(4)$ & $\operatorname{Ir}_{1}-\mathrm{C}_{22}$ & $2.156(4)$ \\
\hline \multicolumn{4}{|c|}{ Bond angles $\left({ }^{\circ}\right)$} \\
\hline $\mathrm{Cl}_{1}-\mathrm{Ir}_{1}-\mathrm{N}_{1}$ & $88.39(9)$ & $\mathrm{Cl}_{1}-\mathrm{Ir}_{1}-\mathrm{N}_{1}$ & $87.76(8)$ \\
\hline$N_{1}-I r_{1}-C_{1}$ & $77.58(14)$ & $\mathrm{Cl}_{2}-\mathrm{Ir}_{1}-\mathrm{N}_{1}$ & $87.29(9)$ \\
\hline $\mathrm{Cl}_{1}-\mathrm{Ir}_{1}-\mathrm{C}_{1}$ & $85.84(11)$ & $\mathrm{Cl}_{1}-\mathrm{Ir}_{1}-\mathrm{Cl}_{2}$ & $85.34(3)$ \\
\hline \multicolumn{4}{|c|}{ Torsion angles $\left({ }^{\circ}\right)$} \\
\hline$N_{1}-C_{7}-C_{6}-C_{1}$ & $4.6(5)$ & $\mathrm{N}_{4}-\mathrm{C}_{11}-\mathrm{C}_{12}-\mathrm{C}_{13}$ & $47.8(5)$ \\
\hline $\mathrm{C}_{17}-\mathrm{C}_{9}-\mathrm{N}_{3}-\mathrm{N}_{2}$ & $-32.2(5)$ & $\mathrm{N}_{4}-\mathrm{N}_{2}-\mathrm{C}_{5}-\mathrm{C}_{9}$ & $22.8(6)$ \\
\hline
\end{tabular}

\subsubsection{Characterisation of the cationic 7-chloroquinolinotriazole Ir(III) complex}

\section{NMR Spectroscopy}

Analysis of the ${ }^{1} \mathrm{H}$ NMR spectrum of the cationic $\mathrm{N}, \mathrm{N}$-coordinated $\operatorname{Ir}(\mathrm{III})$ complex, $\mathbf{7 g}$, confirmed the coordination of the metal to the respective ligand, $\mathbf{2 g}$. Figure 3.11 shows the ${ }^{1} \mathrm{H}$ NMR spectrum of the cationic $\operatorname{Ir}(\mathrm{III})$ complex $7 \mathrm{~g}$ and that of its respective organic ligand, $\mathbf{2 g}$. The first indicator of successful metal-coordination is provided by the presence of a singlet at $1.76 \mathrm{ppm}$, which integrates for 15 protons and corresponds to the protons of the $\mathrm{Cp}^{*}$ ligand. Further evidence is the general downfield shift in all the aromatic signals of complex 
(a)

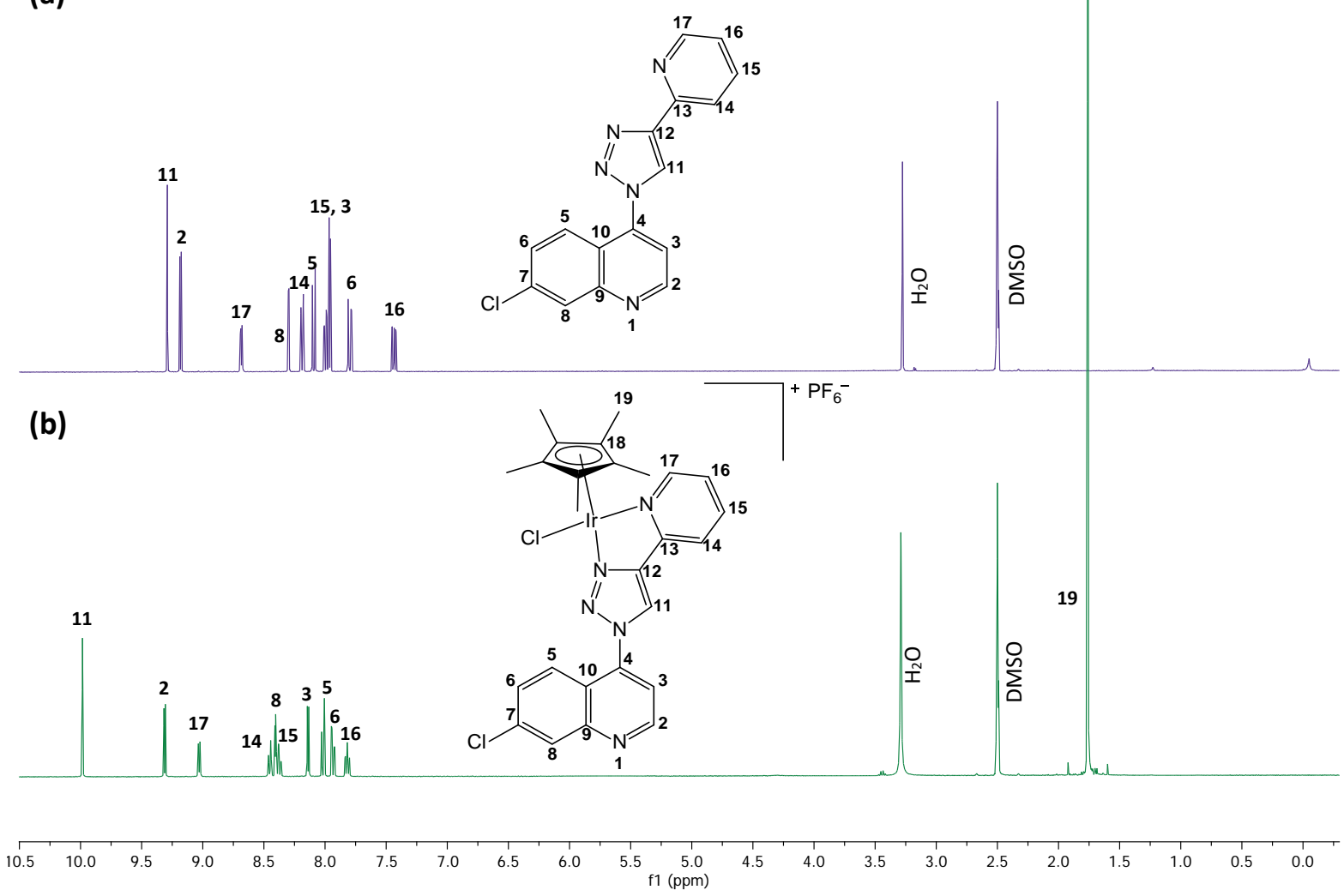

Figure 3.11. Stacked ${ }^{1} \mathrm{H}$ NMR spectra of (a) 7-chloroquinolinotriazole ligand, $\mathbf{2 g}$ and (b) cationic $\mathrm{N}, \mathrm{N}$-coordinated $\operatorname{Ir}(\mathrm{III})$ 7-chloroquinolinotriazole complex, $7 \mathrm{~g}$ in DMSO- $d_{6}$.

$7 \mathrm{~g}$ compared to the same signals of the free ligand, $2 \mathrm{~g}$. This downfield shift in the aromatic protons of the complex, particularly for protons 17 and 11, is expected for cationic complexes and is likely as a result of the metal centre being electron-deficient. This, again, confirms that the metal has coordinated to the triazole and pyridyl nitrogen atoms.

${ }^{13} \mathrm{C}\left\{{ }^{1} \mathrm{H}\right\}$ NMR spectroscopy was also used to confirm that coordination of the $\operatorname{Ir}(\mathrm{III})$ functionality had been successful. The two carbon resonances for the quaternary and methyl carbons of the pentamethylcyclopentadienyl ( $\left.C p^{*}\right)$ ligand are present at around 8.3 and 89 ppm. 2D NMR techniques such as HSQC and COSY, were used to confirm the carbon assignments. The presence of the $\mathrm{PF}_{6}$-anion was confirmed using ${ }^{31} \mathrm{P}\left\{{ }^{1} \mathrm{H}\right\} N M R$ spectroscopy, which resulted in a septet at $-144.17 \mathrm{ppm}(J=711.2 \mathrm{~Hz})$. This also confirmed that only one type of $\mathrm{PF}_{6}$-containing compound existed and that no excess $\mathrm{NH}_{4} \mathrm{PF}_{6}$ was present in the product mixture. 


\section{Infrared Spectroscopy}

In addition to NMR spectroscopy, infrared spectroscopy was used to verify further the $\mathrm{N}, \mathrm{N}$-coordination of the $\operatorname{Ir}(\mathrm{III})$ centre to ligand $\mathbf{2 g}$ (Figure 3.12). A shift in the pyridyl $v(\mathrm{C}=\mathrm{N}$ ) absorption band is characteristic of complexation, as is the presence of a broad $v(P-F)$ absorbance band, characteristic of the $\mathrm{PF}_{6}$-counterion. In the IR spectrum of complex $\mathbf{7 g}$, the $v(\mathrm{C}=\mathrm{N})_{\text {pyridyl }}$ stretching frequency is present at $1630 \mathrm{~cm}^{-1}$, which is at a higher wavenumber than that of the ligand, observed at $1605 \mathrm{~cm}^{-1}$. This is likely due to the decreased backdonation of electrons into the empty anti-bonding $\left(\pi^{*}\right)$ orbitals of the ligand as a result of the metal-centre being electron-deficient. This decreased synergic effect therefore causes a weakening of the $\mathrm{Ir}-\mathrm{N}$ bond and strengthening the $\mathrm{C}=\mathrm{N}$ bond, forcing the $v(\mathrm{C}=\mathrm{N})_{\text {pyridyl }}$ absorbance band to shift to a higher frequency. The shift of the $v(C=N)$ absorbance band in pyridiyl moieties to higher wavenumbers upon complexation has been observed in other pyridine complexes ${ }^{35,36}$ and thus confirms metal coordination to the pyridyl nitrogen. Finally, at a lower frequency range of $950-800 \mathrm{~cm}^{-1}$ in the IR spectrum of complex $7 \mathrm{~g}$ (Figure 3.12), a broad, strong band at $825 \mathrm{~cm}^{-1}$ is observed, which is caused by the stretching vibrations of

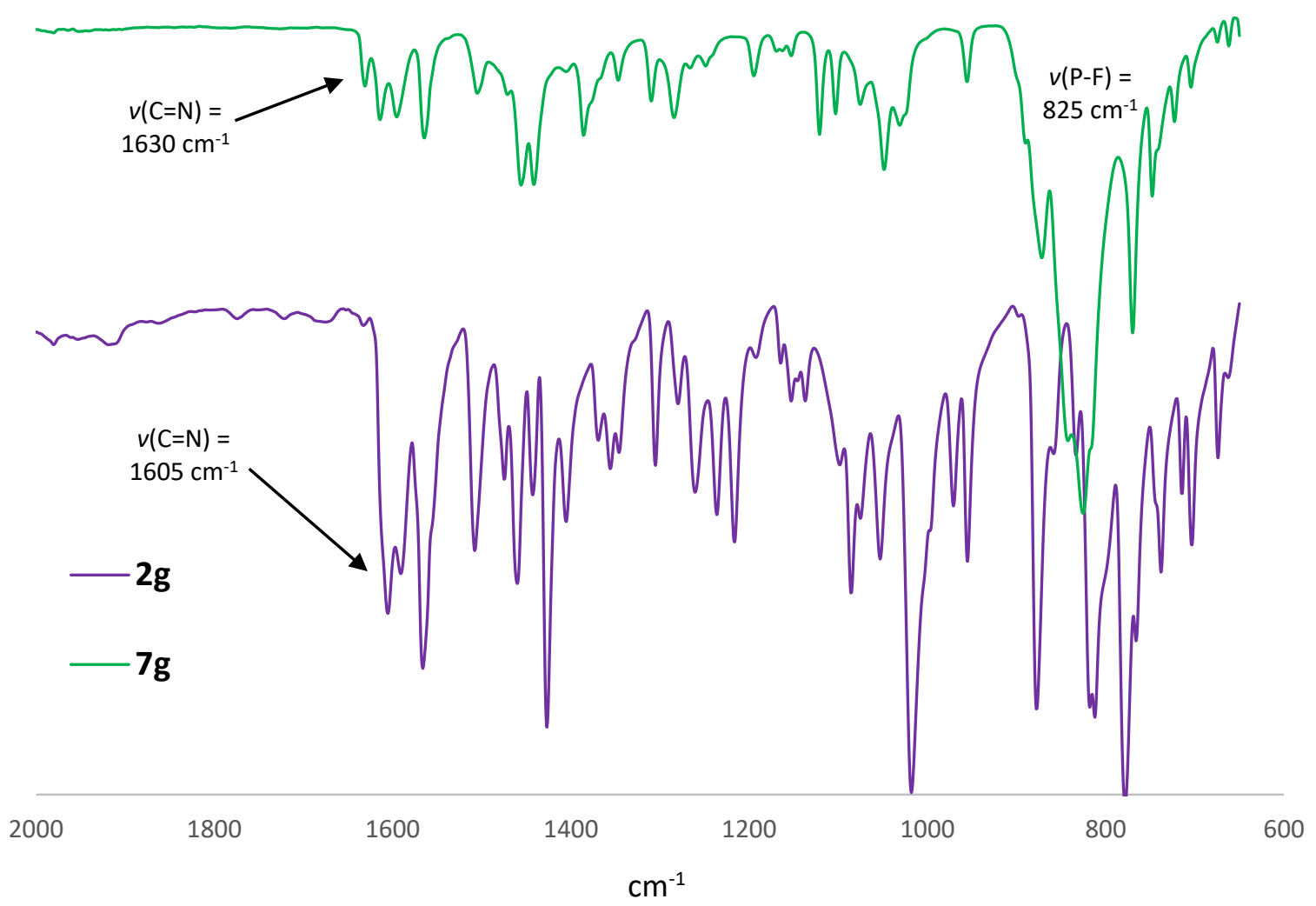

Figure 3.12. Stacked IR spectra of ligand $\mathbf{2 g}$ and cationic $\operatorname{Ir}(I I I)$ complex $\mathbf{7 g}$. 
the $\mathrm{PF}_{6}$ anion. This is further proof that a cationic complex with a $\mathrm{PF}_{6}$-counterion has been synthesised.

\section{High Resolution Mass Spectrometry}

High resolution electrospray lonisation mass spectrometry (ESI-MS) was used to confirm the synthesis of the desired cationic Ir(III) complex. The mass spectrum of the complex shows a peak which corresponds to the molecular ion without the $\mathrm{PF}_{6}$-ion, $\left[\mathrm{M}-\mathrm{PF}_{6}\right]^{+}$. This $m / z$ value of 670.1107 corresponds to the calculated value of 670.1116 .

\subsection{Synthesis and characterisation of half-sandwich $\operatorname{Ir}($ III) complexes based on} the series of 7-chloro-4-aminoquinolinotriazole ligands

\subsubsection{Synthesis}

\subsubsection{Attempted synthesis of the neutral 7-chloro-4-aminoquinolinotriazole Ir(III) complexes}

The synthesis of the neutral cyclometallated 7-chloro-4-aminoquinolinotriazole $\operatorname{Ir}(\mathrm{III})$ complexes 9a-c from ligands 6a-c (Scheme 3.4) was attempted a multiple times using various reaction conditions and solvents, as detailed below. No evidence of a cyclometallated product was found in each case, therefore, the synthesis of desired complexes 9a-c was unsuccessful.<smiles>[R]c1ccc(-c2cn(CCCNc3ccnc4cc(Cl)ccc34)nn2)cc1</smiles>

6a-c

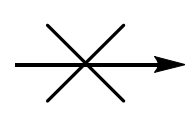

$\mathrm{Cl}$<smiles>[SiH3]</smiles><smiles>C1CC2CCCC2C1</smiles>

9a-c

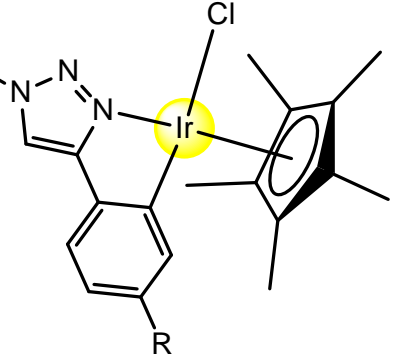

R-groups: $\mathbf{a}:-\mathrm{H} ; \mathbf{b}:-\mathrm{CH}_{3}$; $\mathbf{c}:-\mathrm{F}$

Scheme 3.4. Attempted synthesis of the neutral cyclometallated $\operatorname{Ir}($ III) 7-chloro-4aminoquinolinotriazole complexes $9 a-c$ from ligands $6 a-c$.

The details of the different cyclometallation attempts using ligand $\mathbf{6 a}$, including the reaction conditions and results, can be seen in Table 3.3. Only the attempts using ligand $\mathbf{6 a}$ to 
synthesise complex $9 \mathbf{a}$ will be discussed as all reactions using ligands $\mathbf{6 b}$ or $\mathbf{6 c}$ showed similar unsuccessful results.

Table 3.3. Details of the different reaction attempts to synthesise complex 9a from ligand 6 a.

\begin{tabular}{|c|c|c|c|c|}
\hline \multirow{2}{*}{ Attempt } & \multicolumn{3}{|c|}{ Reaction Conditions } & \multirow{2}{*}{ Result } \\
\cline { 2 - 4 } & Solvent & Temperature & Total time & \\
\hline 1 & $\mathrm{ACN}$ & $65^{\circ} \mathrm{C}(72 \mathrm{~h})$ & $5 \mathrm{~d}$ & $\begin{array}{c}\text { Solution became dark } \\
\text { black }\end{array}$ \\
\hline 2 & $\begin{array}{c}\mathrm{DCM} / \mathrm{MeOH} \\
(1: 1)\end{array}$ & r.t. & $2 \mathrm{~d}$ & Yellow precipitate forms \\
\hline 3 & $\begin{array}{c}\mathrm{DCM} / \mathrm{MeOH} \\
(4: 1)\end{array}$ & r.t. & $6 \mathrm{~d}$ & Yellow precipitate forms \\
\hline 4 & $\begin{array}{c}\mathrm{DCM} / \mathrm{EtOH} \\
(1: 1)\end{array}$ & $\begin{array}{c}40^{\circ} \mathrm{C}(48 \mathrm{~h}), \\
\text { then r.t. }(48 \mathrm{~h})\end{array}$ & $4 \mathrm{~d}$ & Orange precipitate forms \\
\hline 5 & $\mathrm{THF}$ & $50^{\circ} \mathrm{C}(24 \mathrm{~h})$ & $1 \mathrm{~d}$ & Dark red liquid product \\
\hline
\end{tabular}

The ${ }^{1} \mathrm{H}$ NMR spectra of the products of some of the reaction attempts in Table 3.3 can be seen in Figure 3.13. The first attempt involved using the same reaction conditions used for the synthesis of cyclometallated complexes 7a-f. This involved heating the ligand, NaOAc and iridium $\mathrm{Cp}$ * dimer in $\mathrm{ACN}$ at $65{ }^{\circ} \mathrm{C}$ for $72 \mathrm{~h}$ and, thereafter, stirring the reaction mixture at room temperature for a further $72 \mathrm{~h}$. After heating for $72 \mathrm{~h}$, however, the reaction mixture turned dark black and was thus assumed to have decomposed at the high reaction temperature. The next attempt, therefore, involved stirring the reactants at room temperature for 2 days in a 1:1 mixture of $\mathrm{DCM}$ and $\mathrm{MeOH}$, since the ligand was insoluble in room temperature $A C N$ and pure DCM. The ${ }^{1} \mathrm{H}$ NMR spectrum of the resulting product of this reaction is shown in Figure 3.13d, in which no evidence for successful cyclometallation is observed. Instead, many of the signals correspond to those of the unreacted ligand, but could also be as a result of metal coordination to the quinoline nitrogen. This, however, could not be confirmed as there are multiple signals in the aliphatic region where the $\mathrm{Cp}^{*}$ proton resonances are usually found, as well as many other new signals which are not present in the spectrum of the ligand. The ${ }^{1} \mathrm{H}$ NMR spectrum of the product of attempt 3 (Figure 3.13c) shows similar, unsuccessful results. The difference with this attempt was that the ratio of DCM to $\mathrm{MeOH}$ used was increased to $4: 1$ and the reaction was left to stir for 6 days at room temperature. In addition to using a different mixture of solvents (i.e. DCM/EtOH), it was also then decided that gentle heat should be used next to encourage the reactants to react, which 


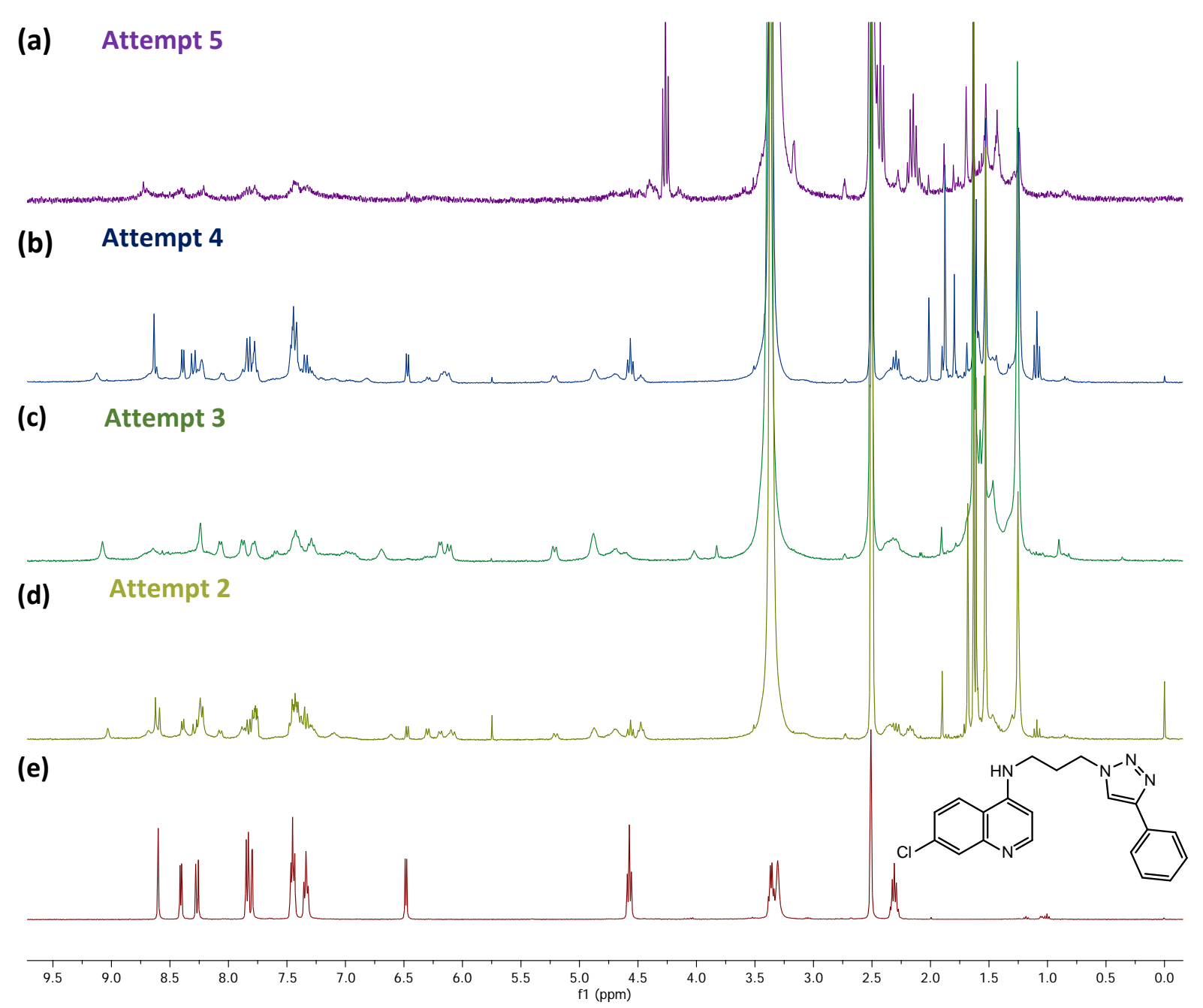

Figure 3.13. Stacked ${ }^{1} \mathrm{H}$ NMR spectra of various cyclometallation reaction attempts, namely (a) attempt 5, (b) attempt 4, (c) attempt 3 and (d) attempt 2, as well as (e) 7-chloro-4aminoquinolinotriazole ligand, $6 \mathrm{a}$, in DMSO- $d_{6}$.

is what was done in attempt 4. Although the reaction mixture did not turn black at this heat, the ${ }^{1} \mathrm{H}$ NMR spectrum of the resulting precipitate shows, again, no clear evidence that the cyclometallation reaction was successful (Figure $3.13 \mathrm{~b}$ ). In the final attempt, namely attempt 5, a completely different solvent and set of reaction conditions were used. After heating the reactants in THF at $50{ }^{\circ} \mathrm{C}$ for $24 \mathrm{~h}$, the solution turned from pale orange to dark red. Although TLC analysis showed the presence of the ligand in the reaction mixture after this time, the reaction was stopped as the mixture had turned dark red. The ${ }^{1} \mathrm{H}$ NMR spectrum of the resulting dark liquid shows that the heat had likely caused the reactants to decompose, as the signals are very broad with no distinct characteristic peaks observed (Figure 3.13a). 
Since none of the attempts to synthesise the cyclometallated $\operatorname{Ir}(I I I)$ complexes 9a-c showed any success, it was decided not to continue pursuing this strategy.

\subsubsection{Synthesis of the cationic 7-chloro-4-aminoquinolinotriazole Ir(III) complex}

The synthesis of the cationic $N, N$-chelated iridium(III) half-sandwich 7-chloro-4aminoquinolinotriazole complex (10) was achieved, as with cationic complex $\mathbf{7 g}$, via a bridgesplitting reaction of the iridium dimer and coordination of the ligand $\mathbf{6 d}$ (Scheme 3.5). In this entropically-driven reaction, the ligand coordinates to the metal via the triazole and pyridyl nitrogen atoms, forming a stable five-membered ring. A salt metathesis was carried out thereafter using hexafluorophosphate, which was done to replace the chloride counterion and allow for the easy precipitation of the complex.

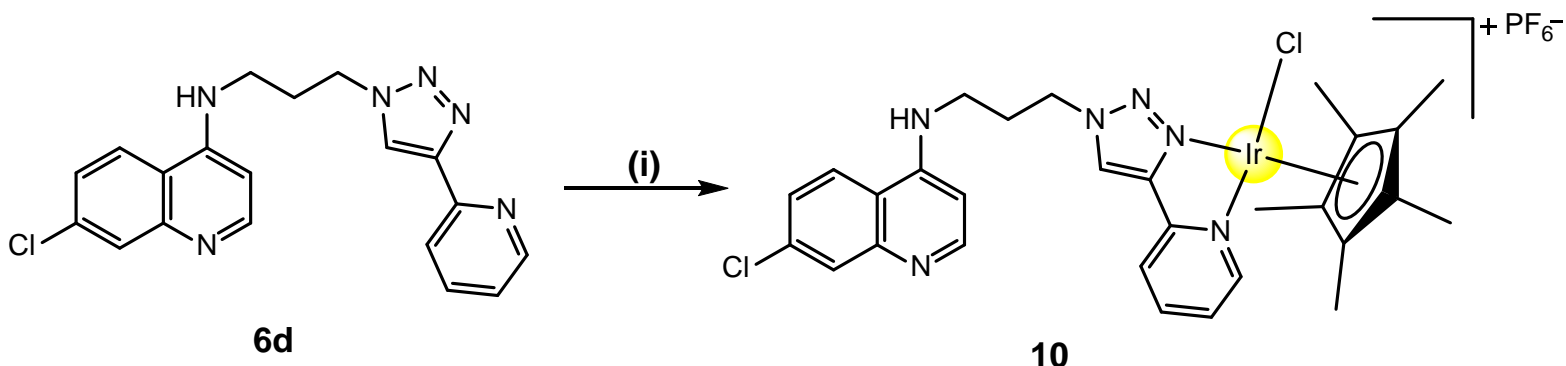

Scheme 3.5. Synthesis of the cationic $N, N$-chelated $\operatorname{Ir}(I I I)$ 7-chloro-4-aminoquinolinotriazole complex (10). Reagents and conditions: (i) $[\mid r C p *(\mu-C l) C l]_{2}\left(0.5\right.$ eq.), $\mathrm{NH}_{4} \mathrm{PF}_{6}$ (2 eq.) DCM/EtOH, r.t., 22 h.

The cationic $\mathrm{N}, \mathrm{N}$-chelated iridium(III) 7-chloroquinolinotriazole complex (10) was isolated as a pale yellow powder in a poor yield of $25 \%$. Since TLC analysis showed that all of the ligand had been consumed during the reaction, the likely reason for this low yield is because the precipitate was very sticky and clumped together. This made filtration and collection very difficult as the precipitate stuck to the bottom of the reaction vessel. Although a variety of solvents (i.e. $\mathrm{MeOH}, \mathrm{EtOH}$, pentane, $\mathrm{Et}_{2} \mathrm{O}$ ) were used to try to isolate the complex the precipitate remained sticky, with the highest yield being achieved when filtered and washed with cold EtOH. 


\subsubsection{Characterisation}

The $N, N$-chelated iridium(III) $\mathrm{Cp}^{*}$ 7-chloro-4-aminoquinolinotriazole cationic complex (10) was characterised using various spectroscopic and analytical techniques. These included ${ }^{1} \mathrm{H}$, ${ }^{13} \mathrm{C}\left\{{ }^{1} \mathrm{H}\right\},{ }^{19} \mathrm{~F}\left\{{ }^{1} \mathrm{H}\right\},{ }^{31} \mathrm{P}\left\{{ }^{1} \mathrm{H}\right\},{ }^{1} \mathrm{H}-{ }^{1} \mathrm{H}$ correlation spectroscopy (COSY) and heteronuclear single quantum coherence (HSQC) nuclear magnetic resonance (NMR) spectroscopy, as well as infrared (IR) spectroscopy, electrospray ionisation-mass spectrometry (ESI-MS) and melting point analysis.

\subsubsection{Characterisation of the cationic 7-chloro-4-aminoquinolinotriazole Ir(III) complex}

\section{NMR Spectroscopy}

The ${ }^{1} \mathrm{H}$ NMR spectrum of the $N, N$-chelated cationic $\operatorname{Ir}(I I I)$ complex, 10 , as well as its respective 7-chloro-4-aminoquinolinotriazole ligand, $\mathbf{6 d}$, is shown in Figure 3.14. Coordination of the $\operatorname{Ir}(\mathrm{III}) \mathrm{Cp}^{*}$ moiety is, again, firstly proven by the presence of a singlet for 15 protons at

(a)<smiles>Clc1ccc2c(NCCCn3cc(-c4ccccn4)nn3)ccnc2c1</smiles>
15

|

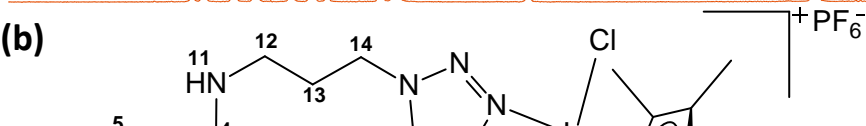

(b)

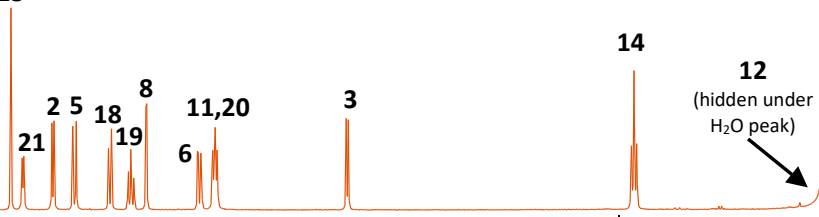<smiles>ClC1=CC2CCCC(C1)C2</smiles>

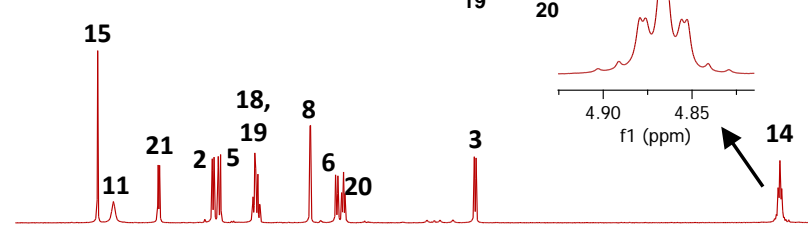

15

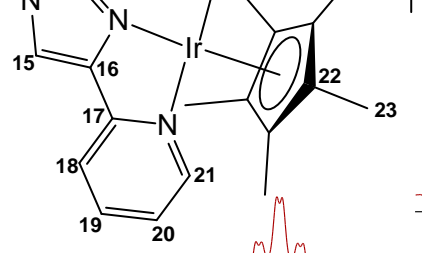

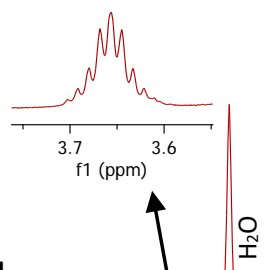

ion

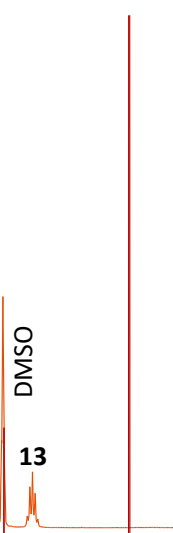


$1.68 \mathrm{ppm}$, which corresponds to the protons of the $\mathrm{Cp}^{*}$ ligand (Figure 3.14b). Secondly, as seen with cationic complex $\mathbf{7 g}$, the general downfield shift of all the aromatic signals of complex $\mathbf{1 0}$ compared to its respective ligand $\mathbf{6 d}$ (Figure 3.14a) is further evidence for the cationic complex formation. This is as a result of the cationic complex being electron-deficient compared to the ligand. Lastly, the splitting of the methylene protons of the propyl chain linker into distinct multiplets compared to the same protons on the ligand is the final proof that metal coordination has occurred. This splitting is observed for all three of the propyl proton signals for complex 10, namely protons 12,13 and 14 , with some of the signals enlarged in Figure 3.14b. As discussed previously, this phenomenon is as a result of the chirality induced by the stereogenic metal centre, causing these protons to become diastereotopic and thus non-equivalent.

In addition to the above ${ }^{1} \mathrm{H} N M R$ data, the data obtained from the ${ }^{13} \mathrm{C}\left\{{ }^{1} \mathrm{H}\right\},{ }^{19} \mathrm{~F}\left\{{ }^{1} \mathrm{H}\right\}$ and ${ }^{31} \mathrm{P}\left\{{ }^{1} \mathrm{H}\right\}$ NMR spectra of this complex is also in agreement with the proposed cationic $\operatorname{Ir}(\mathrm{III})$ complex structure. ${ }^{31} \mathrm{P}\left\{{ }^{1} \mathrm{H}\right\}$ NMR spectroscopy, which shows a septet at $-144.18 \mathrm{ppm}(J=711.2 \mathrm{~Hz})$, was used to confirm the presence of the $\mathrm{PF}_{6}$ anion. This also affirmed the existence of only one type of $\mathrm{PF}_{6}$-containing compound and that no excess $\mathrm{NH}_{4} \mathrm{PF}_{6}$ was present in the product mixture.

\section{Infrared Spectroscopy}

Infrared spectroscopy was used to verify further the $N, N$-coordination of the $\operatorname{Ir}(I I I)$ centre to ligand $6 \mathrm{~d}$ (Figure 3.15). A shift in the pyridyl $v(C=N)$ absorption band from $1580 \mathrm{~cm}^{-1}$ in the IR spectrum of the ligand (6d) to a higher wavenumber of $1615 \mathrm{~cm}^{-1}$ in the spectrum of complex (10) is observed. This is as a result of the decreased synergic effect with cationic complexes, as discussed previously, and is therefore evidence for metal coordination to the pyridyl nitrogen. A broad, strong band at $825 \mathrm{~cm}^{-1}$ is also observed in the IR spectrum of complex 10 . This is as a result of the $v(\mathrm{P}-\mathrm{F})$ stretching vibrations of the $\mathrm{PF}_{6}$ anion and is evidence for the synthesis of a cationic complex with a $\mathrm{PF}_{6}$ counterion. 


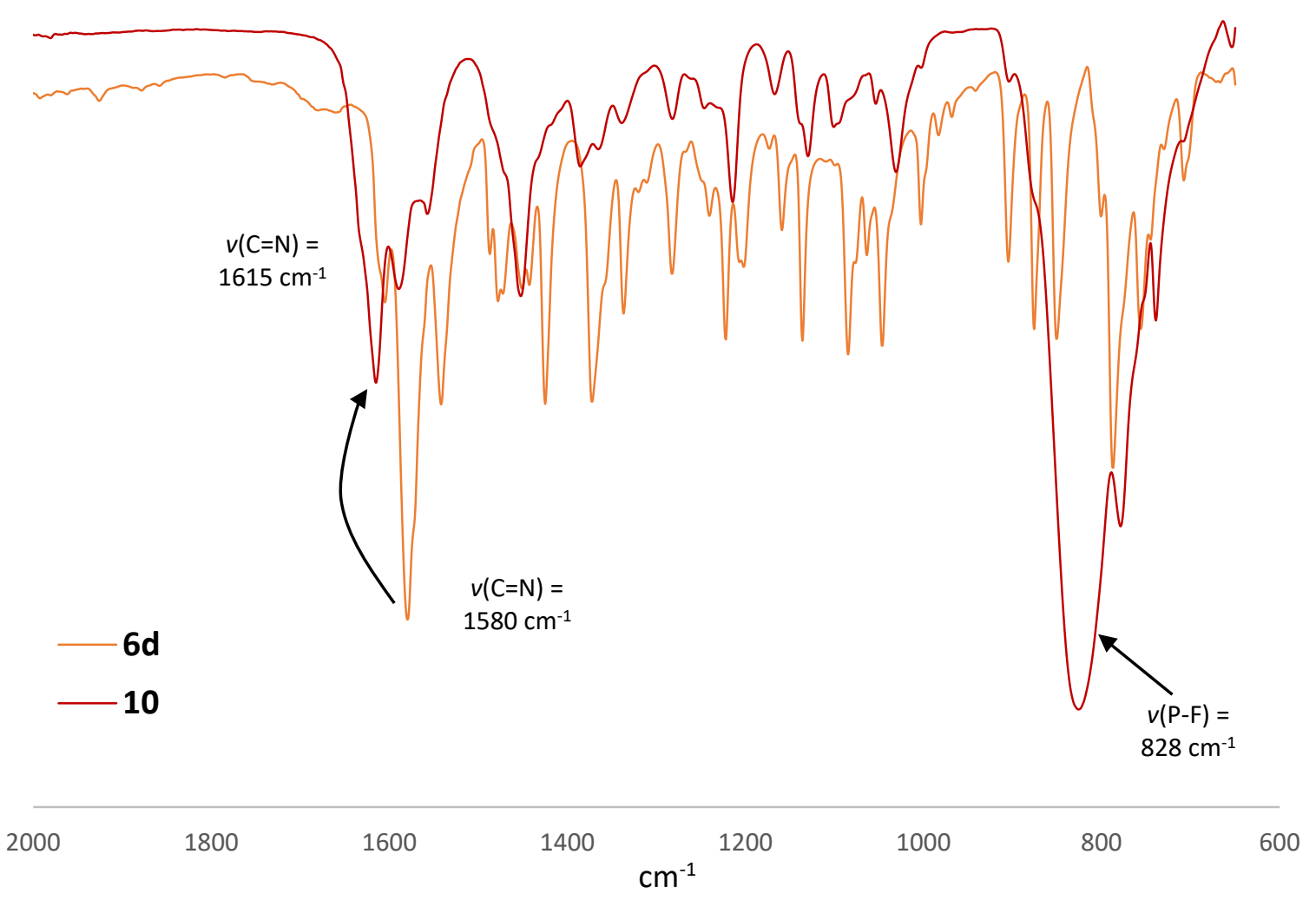

Figure 3.15. Stacked IR spectra of ligand $6 \mathrm{~d}$ and cationic $N, N$-coordinated $\operatorname{Ir}(\mathrm{III})$ 7-chloro-4aminoquinolinotriazole complex, 10.

\section{High Resolution Mass Spectrometry}

High resolution electrospray ionisation mass spectrometry (ESI-MS) was used to confirm the structural integrity of the cationic $\operatorname{Ir}(I I I)$ complex 10 . The mass spectrum of the complex shows a peak which corresponds to the molecular ion without the $\mathrm{PF}_{6}$-ion, $\left[\mathrm{M}-\mathrm{PF}_{6}\right]^{+}$. This $\mathrm{m} / z$ value of 727.166 corresponded to the calculated value of 727.170 .

\subsection{Summary}

A series of new $\operatorname{Ir}($ III) complexes based on a 7-chloroquinolinotriazole scaffold were synthesised successfully. This series consists of six neutral cyclometallated Ir(III) complexes (7a-f), one neutral monodentate $\operatorname{Ir}(\mathrm{III})$ complex (8) and one cationic $N, N$-chelated $\operatorname{Ir}(\mathrm{III})$ complex $(\mathbf{7 g})$. The complexes were synthesised in poor to very good yields $(10-85 \%)$, with the inconsistency in the yields a result of the sluggish nature of the cyclometallation reaction. Computational analysis revealed the monodentate $\operatorname{Ir}(\mathrm{III})$ complex, $\mathbf{8}$, to be the fastest-formed kinetic product while more heat and time is required to form the more stable, 
thermodynamic cyclometallated products, 7a-f. The synthesis of a second series of novel cyclometallated $\operatorname{Ir}(\mathrm{III})$ 7-chloro-4-aminoquinolinotriazole complexes (9a-c) was attempted, however, this was unsuccessful likely due to the inability of the respective ligands to undergo $\mathrm{C}-\mathrm{H}$ activation under the tested conditions. On the other hand, the cationic $\mathrm{N}, \mathrm{N}$-chelated $\operatorname{Ir}(\mathrm{III})$ 7-chloro-4-aminoquinolinotriazole complex (10) of this series was successfully synthesised. All complexes were fully characterised using NMR $\left({ }^{1} \mathrm{H},{ }^{13} \mathrm{C}\left\{{ }^{1} \mathrm{H}\right\},{ }^{19} \mathrm{~F}\left\{{ }^{1} \mathrm{H}\right\},{ }^{11} \mathrm{P}\left\{{ }^{1} \mathrm{H}\right\}, \mathrm{COSY}, \mathrm{HSQC}\right)$ spectroscopy, as well as infrared spectroscopy and high resolution ESI-mass spectrometry. Single crystals of complexes $\mathbf{7 a}$ and $\mathbf{8}$ were analysed by X-ray diffraction, which proved the bidentate and monodentate coordination modes of the ligand to the metal respectively. The spectroscopic and analytical data therefore validate and attest to the integrity of the proposed structures of the complexes $(\mathbf{7 a - g}, \mathbf{8}, \mathbf{1 0})$.

\subsection{References}

1 B. Rosenberg, Cancer, 1985, 55, 2303-2316.

2 C. G. Hartinger and P. J. Dyson, Chem. Soc. Rev., 2009, 38, 391-401.

3 R. H. Fish and G. Jaouen, Organometallics, 2003, 22, 2166-2177.

4 T. Hirao and T. Moriuchi, Eds., Advances in Bioorganometallic Chemistry, Elsevier, 1st edn., 2019.

5 C. S. Allardyce and P. J. Dyson, in Bioorganometallic Chemistry. Topics in Organometallic Chemistry., Springer, Berlin, Heidelberg, Volume 17., 2006, pp. 177210.

6 M. Navarro, C. Gabbiani, L. Messori and D. Gambino, Drug Discov. Today, 2010, 15, 1070-1078.

$7 \quad$ N. P. E. Barry and P. J. Sadler, ACS Nano, 2013, 7, 5654-5659.

8 G. Gasser and N. Metzler-Nolte, Curr. Opin. Chem. Biol., 2012, 16, 84-91.

9 M. Navarro, W. Castro, M. Madamet, R. Amalvict, N. Benoit and B. Pradines, Malar. J., $2014,13,1-8$.

10 M. Navarro, W. Castro and C. Biot, Organometallics, 2012, 31, 5715-5727. 
11 E. Ekengard, L. Glans, I. Cassells, T. Fogeron, P. Govender, T. Stringer, P. Chellan, G. C. Lisensky, W. H. Hersh, I. Doverbratt, S. Lidin, C. de Kock, P. J. Smith, G. S. Smith and E. Nordlander, Dalton Trans., 2015, 44, 19314-19329.

12 C. Biot, G. Glorian, L. A. Maciejewski, J. S. Brocard, O. Domarle, G. Blampain, P. Millet, A. J. Georges, H. Abessolo, D. Dive and J. Lebibi, J. Med. Chem., 1997, 40, 3715-3718.

13 C. Biot, F. Nosten, L. Fraisse, D. Ter-Minassian, J. Khalife and D. Dive, Parasite, 2011, 18, 207-214.

14 F. Dubar, J. Khalife, J. Brocard, D. Dive and C. Biot, Molecules, 2008, 13, 2900-2907.

15 To Evaluate the Efficacy of a Single Dose Regimen of Ferroquine and Artefenomel in Adults and Children With Uncomplicated Plasmodium Falciparum Malaria (FALCI), https://clinicaltrials.gov/ct2/show/NCT02497612, (accessed 20 October 2019).

16 M. A. Jakupec, M. Galanski, V. B. Arion, C. G. Hartinger and B. K. Keppler, Dalton Trans., 2008, 2, 183-194.

17 T. Gianferrara, I. Bratsos and E. Alessio, Dalton Trans., 2009, 37, 7588-7598.

18 A. Agents, Y. Li, C. De Kock, P. J. Smith, H. Guzgay, D. T. Hendricks, K. Naran, V. Mizrahi, D. F. Warner, K. Chibale and G. S. Smith, Organometallics, 2013, 32, 141-150.

19 T. Stringer, D. R. Melis and G. S. Smith, Dalton Trans., 2019, 48, 13143-13148.

20 M. Albrecht, Chem. Rev., 2010, 110, 576-623.

21 J. P. Djukic, J. B. Sortais, L. Barloy and M. Pfeffer, Eur. J. Inorg. Chem., 2009, 7, 817853.

22 N. Cutillas, G. S. Yellol, C. de Haro, C. Vicente, V. Rodríguez and J. Ruiz, Coord. Chem. Rev., 2013, 257, 2784-2797.

23 G. S. Yellol, A. Donaire, J. G. Yellol, V. Vasylyeva, C. Janiak and J. Ruiz, Chem. Commun., $2013,49,11533-11535$.

24 L. Rylands, A. Welsh, K. Maepa, T. Stringer, D. Taylor, K. Chibale and G. S. Smith, Eur. J. Med. Chem., 2019, 161, 11-21.

25 Z. Liu, A. Habtemariam, A. M. Pizarro, S. A. Fletcher, A. Kisova, O. Vrana, L. Salassa, P. C. A. Bruijnincx, G. J. Clarkson, V. Brabec and P. J. Sadler, J. Med. Chem., 2011, 54, 
3011-3026.

26 R. Maity, S. Hohloch, C. Su and M. Van Der Meer, Chem.: Eur. J., 2014, 20, 9952-9961.

27 J. W. Kang, K. Moseley and P. M. Maitiis, J. Am. Chem. Soc., 1969, 91, 5970-5977.

28 D. L. Davies, O. Al-duaij, J. Fawcett, M. Giardiello, S. T. Hilton and D. R. Russell, Dalton Trans., 2003, 2, 4132-4138.

29 D. L. Davies, S. M. A. Donald and S. A. Macgregor, J. Am. Chem. Soc., 2005, 127, 1375413755.

30 D. L. Davies, S. M. A. Donald, O. Al-duaij and S. A. Macgregor, J. Am. Chem. Soc., 2006, $128,4210-4211$.

31 F. Neese, Wiley Interdiscip. Rev. Comput. Mol. Sci., 2018, 8, e1327.

32 M. Steinmetz and S. Grimme, ChemistryOpen, 2013, 2, 115-124.

33 Y. Li, C. De Kock, P. J. Smith, K. Chibale and G. S. Smith, Organometallics, 2014, 33, 4345-4348.

34 Q. Du, L. Guo, M. Tian, X. Ge, Y. Yang, X. Jian, Z. Xu, Z. Tian and Z. Liu, Organometallics, $2018,37,2880-2889$.

35 G. Gupta, S. Gloria, S. L. Nongbri, B. Therrien and K. M. Rao, J. Organomet. Chem., 2011, 696, 2014-2022.

36 R. Payne, P. Govender, B. Therrien, C. M. Clavel, P. J. Dyson and G. S. Smith, J. Organomet. Chem., 2013, 729, 20-27. 


\section{Chapter 4}

\section{Biological evaluation of the 7-chloroquinoline-1,2,3-triazole ligands and their respective Ir(III) half-sandwich complexes including preliminary transfer hydrogenation catalytic studies}

\subsection{Introduction}

Antimalarial drug resistance has emerged as one of the greatest challenges in the push towards malaria eradication worldwide. This increased resistance is largely the result of specific gene and protein mutations within the parasite, such as in the case of the Plasmodium falciparum CQ-resistance transporter (PfCRT) protein. ${ }^{1-3}$ Mutations in this protein are thought to cause the efflux of the antimalarial drug, chloroquine, from the digestive vacuole, therefore leading to a decreased accumulation of the drug in CQ-resistant $P$. falciparum strains. ${ }^{1-3}$ This thus highlights the urgent need for novel chemotherapies which have improved efficacy against resistant strains of the parasite. Over the past decade, the derivatisation of existing antimalarial drugs with transition metals has been explored in an attempt to combat the issue of resistance. ${ }^{4}$ This strategy is exemplified by ferroquine, the metal-based derivative of chloroquine which displays potent antimalarial activity in CQ-resistant strains. ${ }^{5-7}$ Owing to its increased lipophilicity afforded by the ferrocene moiety, it is able to accumulate to a greater extent within the digestive vacuole of parasite resistant strains than chloroquine itself. ${ }^{6,7}$

While the improved activity observed upon metal complexation could be attributed to enhanced lipophilicity, as seen with ferroquine, the exact mechanism of action of many metalbased compounds within the malaria parasite is still relatively unknown. Knowledge of the mechanism of action of an effective drug is crucial as it can be used as a tool in the drugdesign process in order to enhance biological activity while avoiding the emergence of parasitic resistance. ${ }^{8}$ To this effect, the mechanism of action of metal-chloroquine derivatives has been explored and their potent activity is largely attributed to the inhibition of haemozoin formation by the parasite. ${ }^{8-10}$ While it is uncertain how the mechanism of these types of drugs operates within the parasite, it is well established that chloroquine itself complexes to 
haematin in solution, thereby inhibiting the formation of $\beta$-haematin, the synthetic form of haemozoin used in cell-free experiments. ${ }^{11,12}$ Interaction studies of haematin with various metal-chloroquine complexes has also shown that this mechanism holds in the presence of a metal, with the metal-chloroquine derivatives often interacting with haematin in a manner analogous to chloroquine. ${ }^{13,14}$

Although diverse in structure, many of the metal-based antimalarial drug candidates synthesised to date share a common characteristic - they are all stoichiometric agents which react only once with their targets. ${ }^{15}$ While many have shown success in this regard, this concept is limited by the often high doses of the metallodrug required to produce the desired effect, consequently resulting in significant toxicity and side-effects. ${ }^{15}$ As an alternative strategy, the use of metallodrugs capable of performing catalytic reactions within biological systems is becoming increasingly popular. ${ }^{16-18}$ In particular, great interest has been directed towards the use of metal-based catalytic compounds capable of interfering with the $\mathrm{NAD}^{+} / \mathrm{NADH}$ transfer hydrogenation reactions within cancer cells as a novel mechanism of action. ${ }^{19-21}$ Examples of these types of intracellular catalytic complexes are shown in Figure 4.1. Iridium(III)-pyridine complexes have been shown to use $\mathrm{NADH}$ as a hydrogen source to target cancer cells, while hydride transfer by ruthenium(II)-arene complexes to $\mathrm{NAD}^{+}$from formate have also been demonstrated, with both types of reactions exhibiting significant efficacy in the overall enhancement of anticancer activity. ${ }^{20,22}$ Intracellular transfer hydrogenation reactions have therefore been thoroughly studied in terms of anticancer applications, however, very little research has been done into the use of transfer hydrogenation catalysts in antimalarial therapy.
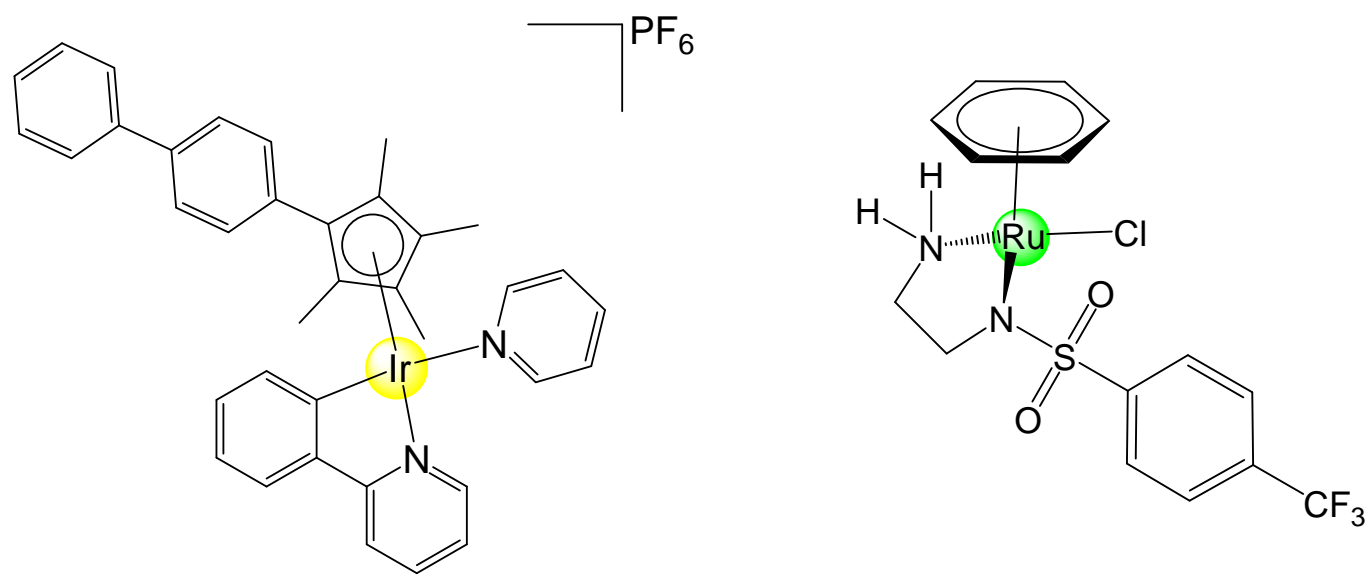

Figure 4.1: Examples of iridium(III)-pyridine and ruthenium(II)-arene complexes capable of catalysing intracellular transfer hydrogenation reactions in cancer cells. ${ }^{20,22}$ 
This chapter is concerned with the biological activity of the 7-chloroquinoline-1,2,3-triazole ligands (2a-h and 6a-e) and their respective $\operatorname{Ir}(I I I)$ half-sandwich complexes (7a-g, 8 and 10). All synthesised compounds were tested for their antiplasmodial activity against the chloroquine-sensitive (CQS) NF54 strain of $P$. falciparum and the most active compounds of these were further tested against a chloroquine-resistant (CQR) K1 strain of $P$. falciparum. This was done to ascertain whether the compounds retain their activity in the resistant strain, a characteristic which is vital for overcoming antimalarial drug resistance. Selected complexes were also tested against the healthy, mammalian Chinese Hamster Ovarian ( $\mathrm{CHO}$ ) cell line to determine complex cytotoxicity and selectivity, and speed-of action assays were conducted to establish how quickly selected complexes act within the parasite. To gain insight into the possible mechanisms of action of these compounds, a $\beta$-haematin inhibition assay, as well as catalytic transfer hydrogenation experiments were carried out. The transfer hydrogenation experiments were conducted in a cell-free environment, with the future goal being to test the most active complexes for their catalytic ability within the malaria parasite.

\subsection{In vitro antiplasmodial evaluation against $P$. falciparum strains}

\subsubsection{Antiplasmodial evaluation against the chloroquine-sensitive (CQS) NF54 strain}

The 7-chloroquinoline-1,2,3-triazole ligands $2 \mathrm{a}-\mathrm{h}$ and $6 \mathrm{a}-\mathrm{e}$, as well as the $\operatorname{Ir}(\mathrm{III})$ half-sandwich complexes 7a-g, $\mathbf{8}$ and $\mathbf{1 0}$ were evaluated for their antiplasmodial activity in vitro against the NF54 CQS strain of $P$. falciparum. The parasite lactate dehydrogenase (pLDH) assay, developed by Makler et al., was used to perform a full dose-response experiment on all the synthesised compounds to determine their $\mathrm{IC}_{50}$ values. ${ }^{23} \mathrm{An} \mathrm{IC}_{50}$ value is defined as the concentration of a drug at which $50 \%$ of the parasite growth is inhibited. The results for the ligands are summarised in Table 4.1 and those of the metal complexes in Table 4.2.

The antiplasmodial activity results in Table 4.1 show that ligands $\mathbf{2 a - h}$, with the triazole directly attached to the quinoline, exhibited low antiplasmodial activity. Of these, ligand $\mathbf{2 c}$ bearing the propyl functionality was found to be the most active, with an $\mathrm{IC}_{50}$ value of 9.87 $\mu \mathrm{M}$, followed closely by the ferrocenyl ligand, $\mathbf{2} \mathbf{h}$, with an $\mathrm{IC}_{50}$ value of $12.3 \mu \mathrm{M}$. The lipophilic nature of the propyl and ferrocenyl moieties is likely the reason for their enhanced 
Table 4.1: In vitro antiplasmodial activity of 7-chloroquinolinotriazole ligands 2a-h and 4-amino-7chloroquinolinotriazole ligands 6a-e against the chloroquine-sensitive NF54 strain of $P$. falciparum.

\begin{tabular}{|c|c|c|c|}
\hline Compound & R-substituent & Structure & $I C_{50}(\mu \mathrm{M}) \pm$ SE NF54 \\
\hline $2 a$ & $\mathrm{H}$ & & $22.73 \pm 3.48$ \\
\hline $2 b$ & $\mathrm{CH}_{3}$ & & $19.88 \pm 3.46$ \\
\hline 2c & $\left(\mathrm{CH}_{2}\right)_{2} \mathrm{CH}_{3}$ & & $9.87 \pm 0.57$ \\
\hline $2 d$ & $\mathrm{CF}_{3}$ & & $22.30 \pm 4.43$ \\
\hline $2 e$ & $F$ & & $18.28 \pm 0.65$ \\
\hline $2 f$ & & & $27.87 \pm 2.24$ \\
\hline $2 \mathrm{~g}$ & & & $28.02 \pm 1.37$ \\
\hline $2 h$ & Fc & & $12.30 \pm 2.56$ \\
\hline $6 a$ & $\mathrm{H}$ & & $0.190 \pm 0.063$ \\
\hline $6 b$ & $\mathrm{CH}_{3}$ & & $0.324 \pm 0.057$ \\
\hline $6 c$ & $F$ & & $0.200 \pm 0.003$ \\
\hline $6 d$ & $\mathrm{~N}^{\prime \prime}$ & & $1.35 \pm 0.37$ \\
\hline $6 e$ & Fc & & $10.71 \pm 0.38$ \\
\hline CQDP & - & & $0.0106 \pm 0.0023$ \\
\hline
\end{tabular}

activity, although there is no discernible trend in antiplasmodial activity with any of the other ligands from this series. On the other hand, when the quinoline and triazole moieties are separated by an aminopropyl linker, as in the case of ligands $6 a-e$, the antiplasmodial activity increases significantly, with some even displaying over a 100 -fold increase in activity. The $\mathrm{IC}_{50}$ values of the ligands containing an aminopropyl linker (6a-e) and the analogous ligands of the series without a linker $(\mathbf{2} a, \mathbf{2} b, \mathbf{2} \mathbf{e}, \mathbf{2} \mathbf{g}$ and $\mathbf{2} \mathbf{h})$ are displayed pictorially in Figure 4.2. The graph demonstrates a clear trend in the $\mathrm{IC}_{50}$ values between the two series, indicating that the presence of an aminopropyl chain is crucial for antiplasmodial activity, a trend which is 
confirmed by similar compounds in literature. ${ }^{24}$ Interestingly, not only is the lipophilic propyl linker important for antiplasmodial activity, but the positioning of the propyl chain, as well as the presence of the secondary amine also plays a key role in enhancing the activity of the compound. This is indicated by the fact that the $\mathrm{IC}_{50}$ value of ligand $2 \mathrm{c}(9.87 \mu \mathrm{M})$ is fifty times higher than that of ligand $6 a(0.190 \mu \mathrm{M})$, with the difference between the two compounds being the placement of the propyl functionality within the scaffold of the compound. This result therefore indicates that having the propyl group as a linker between two separate moieties is advantageous, as is the presence of the secondary amine, which aids in the formation of a strong complex with haematin within the digestive vacuole of the parasite. ${ }^{25}$

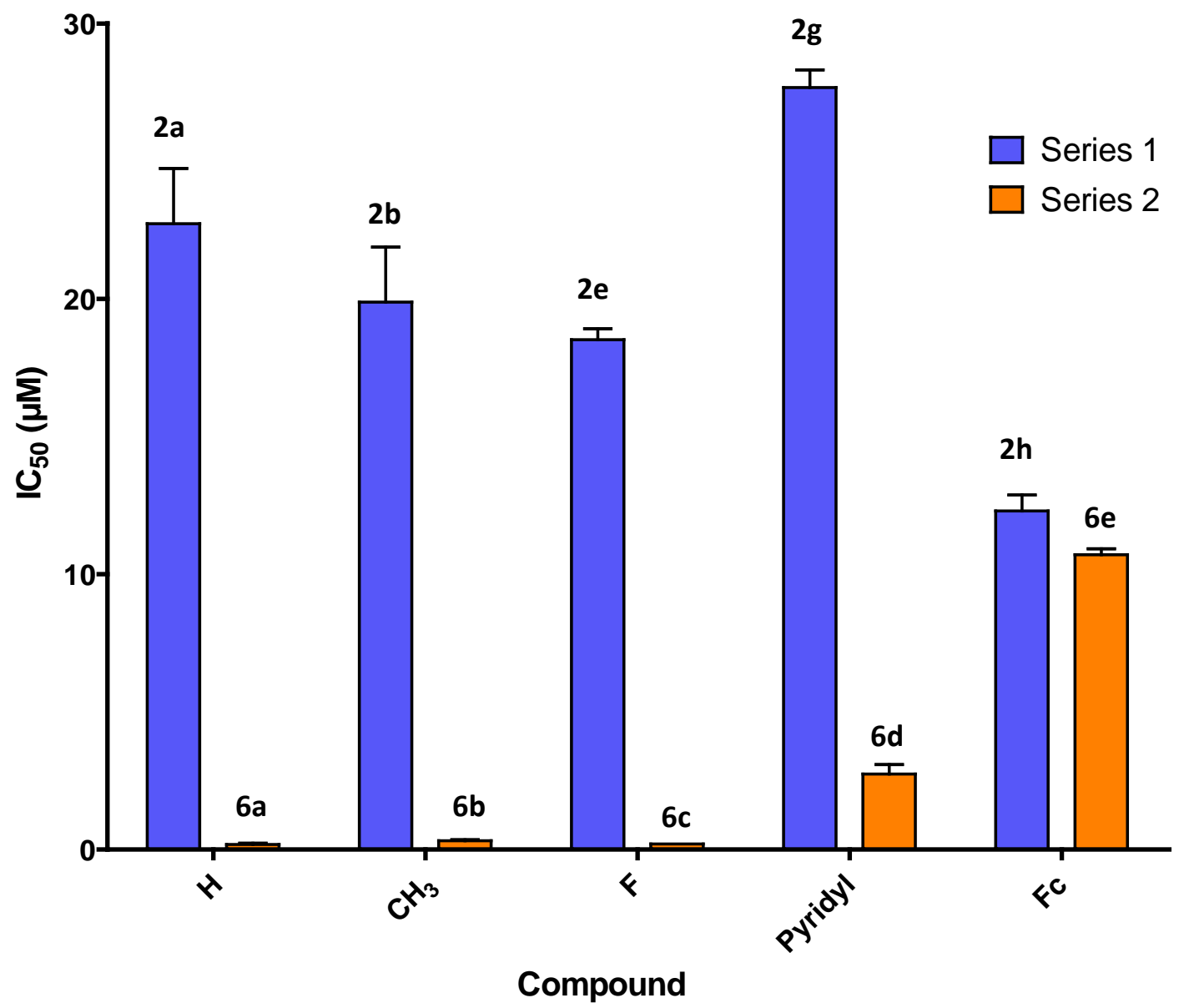

Figure 4.2. Graph depicting the $I C_{50}$ values of analogous ligands from series $1(\mathbf{2 a}, \mathbf{2 b}, \mathbf{2 e}, \mathbf{2 g}, \mathbf{2 h})$ and series 2 (6a-e).

The activity of selected ligands is significantly enhanced upon metal complexation with iridium, with some complexes being over one hundred times more active than their respective ligands, as shown in Table 4.2. This suggests that the metal entity could play a role 
in reducing parasite viability, which may be linked to an increase to the overall lipophilicity of the compound or to the interaction of the metal centre with target compounds, although the mechanism for this is still unknown. The most active complex of all the $\operatorname{Ir}(\mathrm{III})$ complexes synthesised is the cationic, $\mathrm{N}, \mathrm{N}$-chelated complex $\mathbf{7 g}$, with a submicromolar $\mathrm{IC}_{50}$ value of $0.247 \mu \mathrm{M}$. The reason for this is likely due to the solubility of this complex, which went readily into the water-based medium used for the assay while the neutral, cyclometallated complexes formed a precipitate when in the same medium. The neutral cyclometallated complex solutions were therefore sonicated to improve solubility before being used in the assay, resulting in low micromolar $\mathrm{IC}_{50}$ values for all six complexes (7a-f). Of the neutral cyclometallated complexes, complex $7 \mathrm{a}$ displayed the best activity $(0.688 \mu \mathrm{M})$, followed by 7e $(0.993 \mu \mathrm{M})$ and $7 \mathrm{~b}(1.02 \mu \mathrm{M})$. This shows that introducing more hydrophobic side groups to metal complexes does not necessarily confer greater antiplasmodial activity, since the unsubstituted complex, $7 a$, was the most active of the neutral series. Surprisingly, although ligand $\mathbf{2 c}$ displayed the lowest $\mathrm{IC}_{50}$ value of all synthesised ligands, its activity is not retained upon complexation. This likely means that a precise balance of lipophilicity is required to ensure cellular uptake by the parasite. The antiplasmodial activity of complex $\mathbf{8}$, in which the ligand is coordinated in a monodentate fashion to the iridium via the quinoline nitrogen, was also determined. This complex was found to have poor activity, with an $\mathrm{IC}_{50}$ value of $48.4 \mu \mathrm{M}$, indicating that the mode of metal coordination has a large impact on parasite viability. This also validates the effort put into synthesising the cyclometallated complexes of this series because, although their synthesis takes much more time and energy than the monodentate, quinoline nitrogen-coordinated complex, the antiplasmodial results confirm that cyclometallation vastly improves the antiplasmodial activity of the complex. The final complex to be tested for its antiplasmodial activity against the CQS NF54 strain was the second series $\mathrm{N}, \mathrm{N}$-chelated complex, 10. Interestingly, this complex does not follow the same trend as that seen for the cationic complex $\mathbf{7 g}$ of the first series, where antiplasmodial activity is greatly enhanced upon metal coordination. In this case, the $\mathrm{IC}_{50}$ value of the complex could not be determined accurately at the tested concentration and was thus said to be greater than $11.5 \mu \mathrm{M}$. This could be a result of the compound becoming too hydrophobic upon complexation, since the ligand already contains a hydrophobic propyl linker. Further tests should be done to confirm this theory. 
Table 4.2: In vitro antiplasmodial activity of $\operatorname{Ir}(I I I)$ half-sandwich complexes $\mathbf{7 a - g}, \mathbf{8}$ and $\mathbf{1 0}$ against the chloroquine-sensitive NF54 strain of $P$. falciparum.

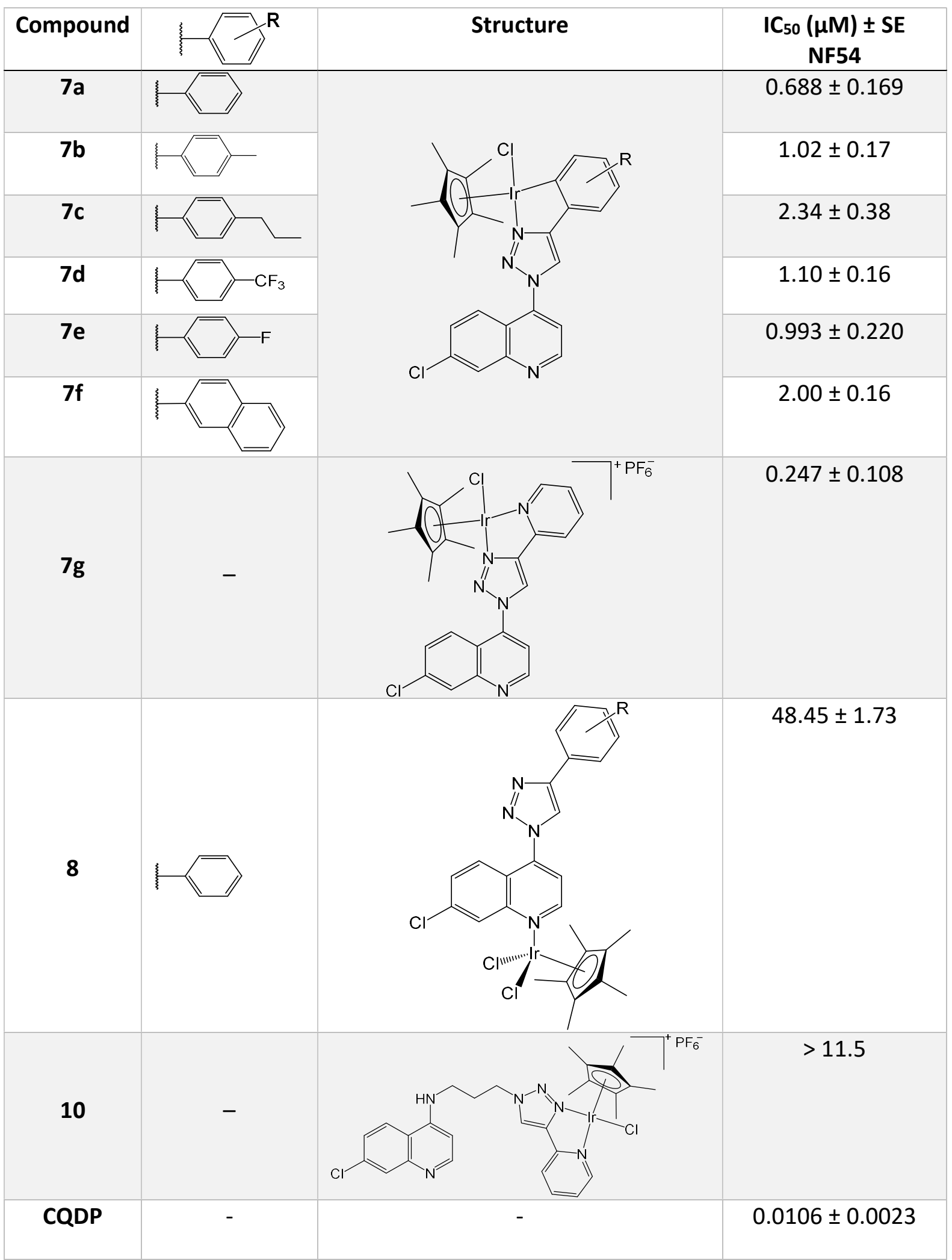




\subsubsection{Antiplasmodial evaluation against the chloroquine-resistant (CQR) K1 strain}

Since ligands 6a-e and Ir(III) complexes 7a-g exhibited good antiplasmodial activity against the CQS NF54 strain of $P$. falciparum, they were also tested for activity against the CQR K1 strain. Complex $\mathbf{1 0}$ was also tested against this strain to determine whether it might be more active in the resistant strain compared to the sensitive strain. The results are presented in Table 4.3.

Table 4.3: In vitro antiplasmodial activity of ligands 6a-e and $\operatorname{Ir}(I I I)$ half-sandwich complexes 7a-g and 10 against the CQS NF54 and CQR K1 strains of $P$. falciparum.

\begin{tabular}{|c|c|c|c|}
\hline Compound & $\mathrm{IC}_{50}(\mu \mathrm{M}) \pm \mathrm{SE}$ NF54 & $I C_{50}(\mu M) \pm S E K 1$ & $\begin{array}{c}\text { Resistance Index } \\
(\text { (RI) }\end{array}$ \\
\hline $6 a$ & $0.190 \pm 0.063$ & $0.335 \pm 0.102$ & 1.8 \\
\hline $6 b$ & $0.324 \pm 0.057$ & $0.846 \pm 0.087$ & 2.6 \\
\hline $6 c$ & $0.200 \pm 0.003$ & $0.245 \pm 0.015$ & 1.2 \\
\hline $6 d$ & $1.35 \pm 0.37$ & $1.23 \pm 0.10$ & 0.9 \\
\hline $6 e$ & $10.71 \pm 0.38$ & $11.82 \pm 1.34$ & 1.1 \\
\hline $7 a$ & $0.688 \pm 0.169$ & $1.06 \pm 0.16$ & 1.5 \\
\hline $7 b$ & $1.02 \pm 0.17$ & $2.22 \pm 0.18$ & 2.2 \\
\hline 7c & $2.34 \pm 0.38$ & $3.06 \pm 0.22$ & 1.3 \\
\hline $7 d$ & $1.10 \pm 0.16$ & $2.59 \pm 0.45$ & 2.4 \\
\hline $7 e$ & $0.993 \pm 0.220$ & $1.01 \pm 0.20$ & 1.0 \\
\hline $7 f$ & $2.00 \pm 0.16$ & $1.40 \pm 0.16$ & 0.7 \\
\hline $7 g$ & $0.247 \pm 0.108$ & $0.646 \pm 0.063$ & 2.6 \\
\hline 10 & $>11.5$ & $7.00 \pm 3.24$ & n.d. ${ }^{b}$ \\
\hline CQDP & $0.0106 \pm 0.0023$ & $0.134 \pm 0.041$ & 12.6 \\
\hline
\end{tabular}

The inhibitory data for these compounds tested against the K1 strain somewhat resembles the trend observed for the NF54 strain. Again, the cationic complex 7g exhibits the best activity of all the $\operatorname{Ir}(\mathrm{III})$ complexes $7 \mathrm{a}-\mathrm{g}$ with an $\mathrm{IC}_{50}$ value of $0.646 \mu \mathrm{M}$. Unlike with the CQS 
NF54 strain however, the unsubstituted compounds $6 \mathbf{a}$ and $7 \mathbf{a}$ are not the most active of the ligands (6a-e) and neutral complexes (7a-f) respectively in the CQR K1 strain. The most active of these series in the K1 strain were compounds $6 c$ and $7 e$, both of which have a fluoride substituent, which could mean that increased lipophilicity is required for activity in the resistant strain.

In order to draw conclusions about the difference in activity of the compounds across the two strains, the resistance index (RI) value is calculated. The resistance index is useful in the analysis of compounds as potential drug candidates and is defined as the quotient of the $\mathrm{IC}_{50}$ value obtained in the resistant strain and the $\mathrm{IC}_{50}$ value obtained in the sensitive strain. $A$ smaller RI value (i.e. 1 or $<1$ ) is indicative of the compound being equally or more active in the resistant parasitic strain relative to the sensitive strain. In most cases, the RI values for compounds 6a-e and 7a-g were slightly greater than 1 with some even being greater than 2 . These values suggest that the compounds likely experience mild cross-resistance similar to that of chloroquine, however, not to the extent of chloroquine, which has an RI value of 12.6. Since there is a slight decrease in activity for most compounds in the resistant strain, it suggests that these compounds may mildly encounter the same issue as CQ does, with decreased accumulation of the drug in the resistant strain compared to the sensitive strain. This is as a result of mutations in a gene encoding for the $P$. falciparum chloroquine-resistant transporter $(P f C R T)$ - a protein located in the membrane of the digestive vacuole. ${ }^{1,14}$ The mutation allows for some of the $\mathrm{CQ}$ to be expelled from the digestive vacuole in the case of the CQ-resistant strains. Since there are structural similarities between the compounds discussed here and chloroquine, these compounds may experience a similar fate in the resistant strain to some extent.

\subsection{In vitro cytotoxicity studies}

Since some compounds were found to have good antiplasmodial activity against various strains of $P$. falciparum, it was important to screen them further for cytotoxicity against a healthy, mammalian cell-line as well to determine their selectivity towards the parasitic cells. With the use of metal complexes in medicine, the issue of toxicity brought about by the metal is often a concern. For this reason, five of the most active metal complexes, namely $7 \mathbf{a}, \mathbf{7 b}$, 
7d, $\mathbf{7 e}$ and $\mathbf{7 g}$, were tested for cytotoxicity against the mammalian Chinese Hamster Ovarian $(\mathrm{CHO})$ cell line using the colorimetric 3-(4,5-dimethylthiazol-2-yl)-2,5diphenyltetrazoliumbromide (MTT) assay. The results of this assay are summarised in Table 4.4.

Table 4.4: $I C_{50}$ values obtained for selected $\operatorname{Ir}(I I I)$ complexes $(\mathbf{7 a}, 7 \mathbf{b}, 7 \mathrm{~d}, 7 \mathrm{e}$ and $\mathbf{7 g})$ against the Chinese Hamster Ovarian (CHO) cell line.

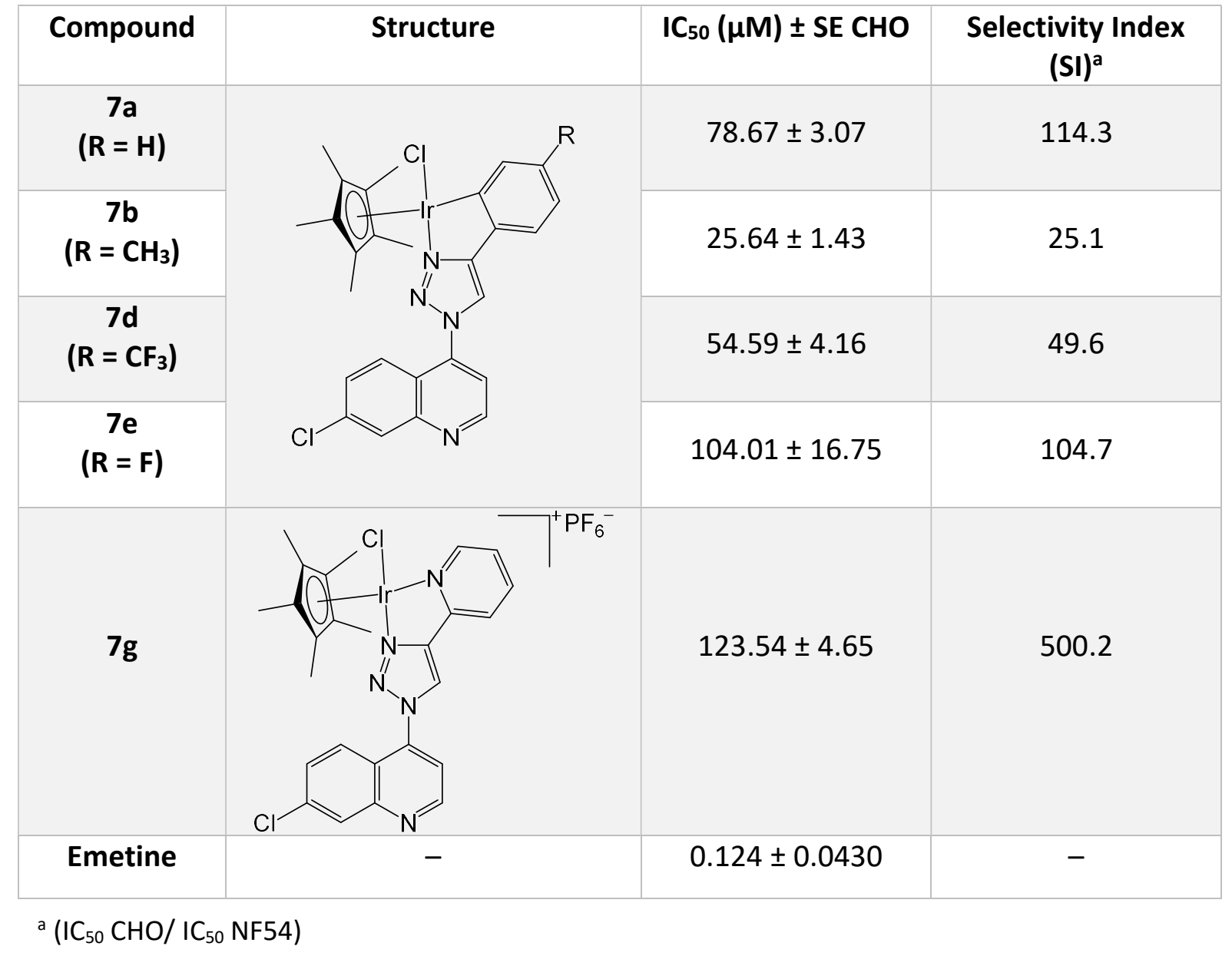

The results in Table 4.4 show that all five of the tested compounds are not cytotoxic compared to the control, Emetine. Emetine is a natural product alkaloid, the medicinal use of which has been discouraged due to its known toxicity and is therefore used as the standard control in this assay. ${ }^{26}$ Compound $\mathbf{7 b}$ was determined to be the most cytotoxic compared to the other $\operatorname{Ir}(\mathrm{III})$ complexes, with an $\mathrm{IC}_{50}$ value of $25.64 \mu \mathrm{M}$, while cationic complex $7 \mathrm{~g}$ is the least cytotoxic, with an $\mathrm{IC}_{50}$ value of $123.54 \mu \mathrm{M}$.

The selectivity index (SI) value for each of the five compounds was also calculated. This value is defined as the quotient of the $\mathrm{IC}_{50}$ value obtained in the $\mathrm{CHO}$ cell-line and the $\mathrm{IC}_{50}$ value 
obtained in the NF54 P. falciparum strain. This value is useful in determining the selectivity of a compound towards a particular cell type, with a large value indicating selectivity towards the parasitic cells as opposed to the healthy, $\mathrm{CHO}$ cells. From the calculated $\mathrm{SI}$ values displayed in Table 4.4, all five $\operatorname{Ir}(\mathrm{III})$ complexes display far greater selectivity towards the parasitic cells, with cationic complex $\mathbf{7 g}$ being 500 times more selective towards the parasite than the healthy cell-line. Even the least selective complex $\mathbf{7 b}$ is over 25 times more selective towards parasitic cells, showing that all the synthesised complexes will likely not cause damage to healthy cells.

\subsection{In vitro speed-of-action study}

One of the current challenges in the drug-discovery process is the narrowing-down of antiplasmodial drug hits to a handful of potential drug candidates. One of the ideal criteria for new drug candidates is that they are fast-acting, thereby providing a rapid relief of symptoms for the infected patient. ${ }^{27,28}$ This is also to ensure that very few parasites survive after drug exposure, thereby lowering the occurrence of mutations which could lead to the development of new drug resistance mechanisms. ${ }^{27,28}$

In order to evaluate the speed-of-action of the synthesised $\operatorname{Ir}(\mathrm{III})$ complexes with the greatest antiplasmodial activity $(\mathbf{7 a}, \mathbf{7 e}$ and $\mathbf{7 g}$ ), an assay experiment was performed following a modified method of the "IC $\mathrm{C}_{50}$ speed assay" previously described by Le Manach et al. ${ }^{29} \mathrm{~A}$ schematic representation of this assay is shown in Figure 4.3. This assay was performed using

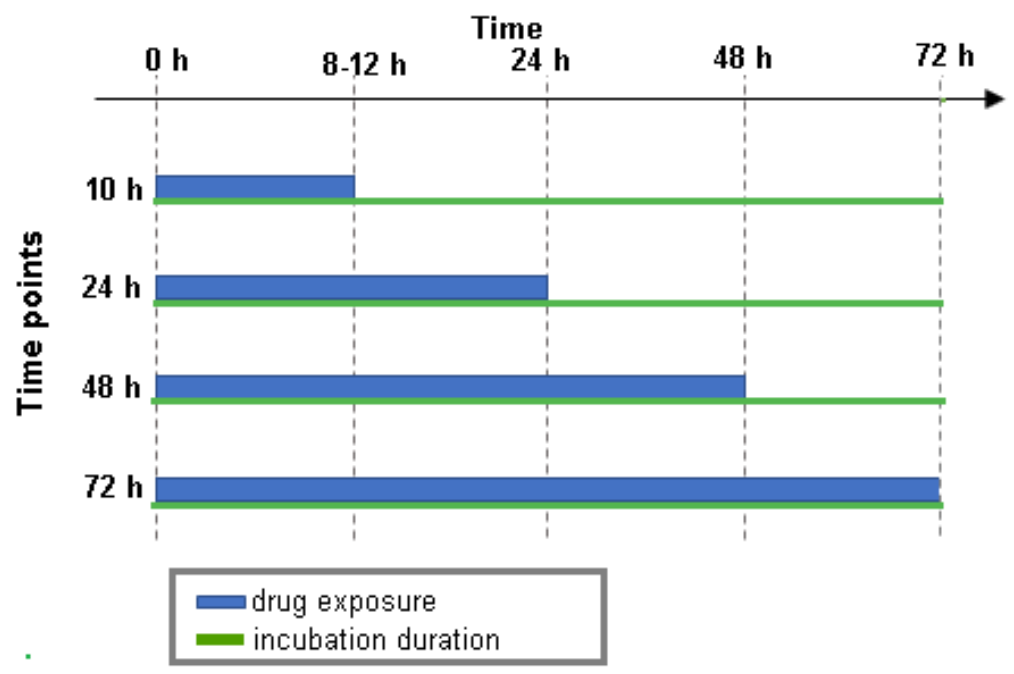

Figure 4.3: Schematic representation of the in vitro speed-of-action assay. 
synchronized ring cultures of the chloroquine-sensitive NF54 strain in order to determine whether compounds $\mathbf{7 a}, 7 \mathrm{e}$ and $\mathbf{7 g}$ are either fast- or slow-acting. Known antimalarial agents, chloroquine (CQ), ferroquine (FQ) and artemisinin (ART) were used as the controls in this experiment. The compounds and controls were added at time zero and were thereafter exposed to the parasites for 10, 24 and $48 \mathrm{~h}$, after which the drugs were removed, as depicted in Figure 4.3. Each drug exposure time-point of 10, 24, 48 and $72 \mathrm{~h}$ was represented by a 96-well plate, therefore, four plates, each with a final incubation time of $72 \mathrm{~h}$, were used. Parasite survival after drug exposure was measured using a SYBR Green flow cytometry-based method. SYBR Green is a nucleic acid stain which only stains viable parasites as the host erythrocytes lack nuclei.

The results of this speed of action experiment are summarised in Figure 4.4. The IC $\mathrm{C}_{50}$ values determined at the 10, 24 and $48 \mathrm{~h}$ time-points are represented as a ratio relative to the $72 \mathrm{~h}$ time-point. The dotted line at a ratio of 1.0 therefore represents the baseline $I C_{50}$ ratio at $72 \mathrm{~h}$ (i.e. $I \mathrm{I}_{50} 72 \mathrm{~h} / \mathrm{IC} \mathrm{C}_{50} 72 \mathrm{~h}=1.0$ ). Compounds which have an $\mathrm{IC}_{50}$ ratio (relative to $72 \mathrm{~h}$ ) of 1 or less than 1 early on in the incubation period are described as "fast-acting" while those with ratios greater than 1 are described as "slow-acting." The results in Figure 4.4 show that the

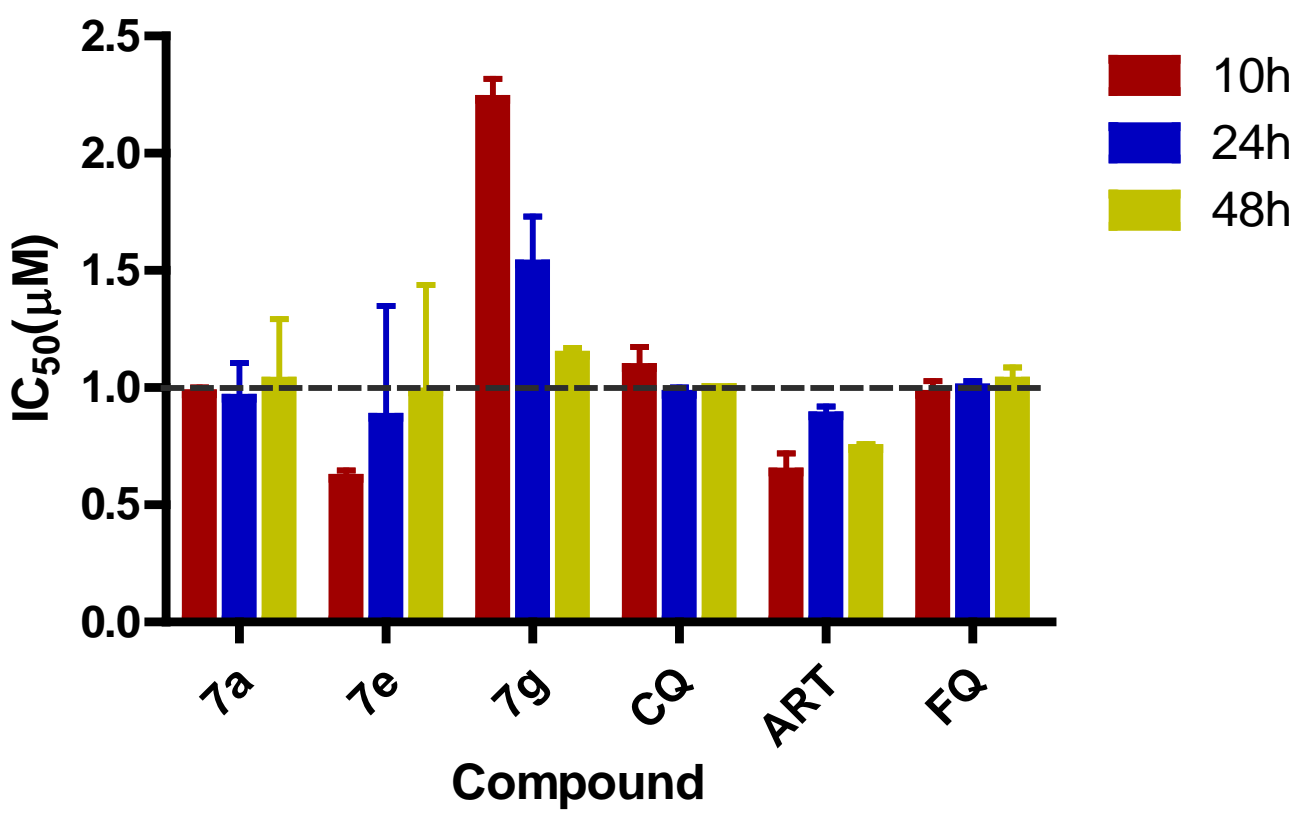

Figure 4.4: $I C_{50}$ speed assay profiles of $7 \mathbf{a}, 7 \mathrm{e}$, and $7 \mathrm{~g}$, as well as controls, $C Q, A R T$ and $F Q$. The mean $\mathrm{IC}_{50}$ values at each time point are presented as ratios relative to the $\mathrm{IC}_{50}$ value of the standard 72-hour assay. The dotted line indicates the baseline $\mathrm{IC}_{50}$ ratio at $72 \mathrm{~h}$. 
time it takes for the controls, CQ, ART and FQ to exert their maximum killing effect is within $24 \mathrm{~h}$, where the $\mathrm{IC}_{50}$ values are similar to those of the standard $72 \mathrm{~h}$ assay. The respective $\mathrm{IC}_{50} 24 \mathrm{~h} / \mathrm{IC}_{50} 72 \mathrm{~h}$ ratios of $0.9,0.8$ and 1.0 for these compounds are indicative of these drugs being fast-acting compounds, which has been observed in previous experiments. ${ }^{29}$ Similarly, compounds $7 \mathrm{a}$ and $7 \mathrm{e}$ also have their onset of action within $24 \mathrm{~h}$, with their respective $\mathrm{IC}_{50} 24 \mathrm{~h} / \mathrm{IC} \mathrm{C}_{50} 72 \mathrm{~h}$ ratios being 0.9 and 0.8 respectively. It can therefore be concluded that $\operatorname{Ir}(\mathrm{III})$ complexes $7 \mathrm{a}$ and $7 \mathrm{~T}$ are likely fast-acting compounds. In contrast to this, the $\mathrm{IC}_{50}$ ratio of $7 \mathrm{~g}$ at $10 \mathrm{~h}$ is 2.3 -fold higher than the respective $\mathrm{IC}_{50}$ value at the $72 \mathrm{~h}$ time point. The $\mathrm{IC}_{50} 24 \mathrm{~h} / \mathrm{IC}_{50} 72 \mathrm{~h}$ ratio only reaches 1.2 after $48 \mathrm{~h}$ of drug exposure, therefore, $7 \mathrm{~g}$ demonstrates the characteristics of a slow-acting compound. This result complements the RI values calculated for these complexes (Table 4.3) where the fast-acting complexes $7 \mathbf{a}$ and $7 \mathbf{e}$ have low RI values of 1.5 and 1.0 respectively while the slow-acting complex $7 \mathrm{~g}$ has a much higher RI value of 2.6. This supports the observation that slower-acting compounds are far more likely to promote the development of drug-resistance mechanisms within the parasite. ${ }^{27,28}$

\section{$4.5 \quad \beta$-Haematin inhibition studies}

Like chloroquine, the target for many aminoquinoline-based compounds is the erythrocytic stage of the life cycle of $P$. falciparum and, more specifically, the formation of haemozoin..$^{9,10,30}$ Upon entering the digestive vacuole of the parasite, these compounds bind to haematin, the toxic product of host haemoglobin degradation, thereby preventing its conversion into the crystalline haemozoin..$^{9,10,30}$ This inhibition of the parasite's innate detoxification mechanism leads to the build-up of free haematin and thus the death of the parasite..$^{9,10,30}$ The ability of a compound to inhibit haemozoin formation can be evaluated using the Nonidet P-40 (NP-40) detergent-mediated $\beta$-haematin inhibition assay, with $\beta$-haematin being the synthetic form of haemozoin. ${ }^{31}$ Research suggests that the formation of haemozoin is not a spontaneous process, with crystallisation solely occurring in the presence of neutral lipids found within the parasite's digestive vacuole. ${ }^{32,33}$ Since the presence of these lipids is vital for the formation of haemozoin, these lipids are mimicked by the neutral detergent, NP-40, in this assay, thereby mediating $\beta$-haematin formation. Two organic 
compounds, $\mathbf{6}$ a and $\mathbf{6 d}$, a neutral $\operatorname{Ir}(\mathrm{III})$ complex, $\mathbf{7 d}$, and two cationic $\operatorname{Ir}(\mathrm{III})$ complexes, $\mathbf{7 g}$ and 10, were tested for their ability to inhibit $\beta$-haematin formation, the results of which are shown in Figure 4.5. The compounds were all screened in triplicate up to a concentration of $1000 \mu \mathrm{M}$ and the amount of synthetic haemozoin formed was quantified using the colorimetric pyridine ferrochrome method published by Egan et al. ${ }^{34}$ This method allows for the amount of synthetic haemozoin formed to be measured, since pyridine is only capable of complexing to free haem and not $\beta$-haematin. Figure 4.5, therefore, shows the dose-response

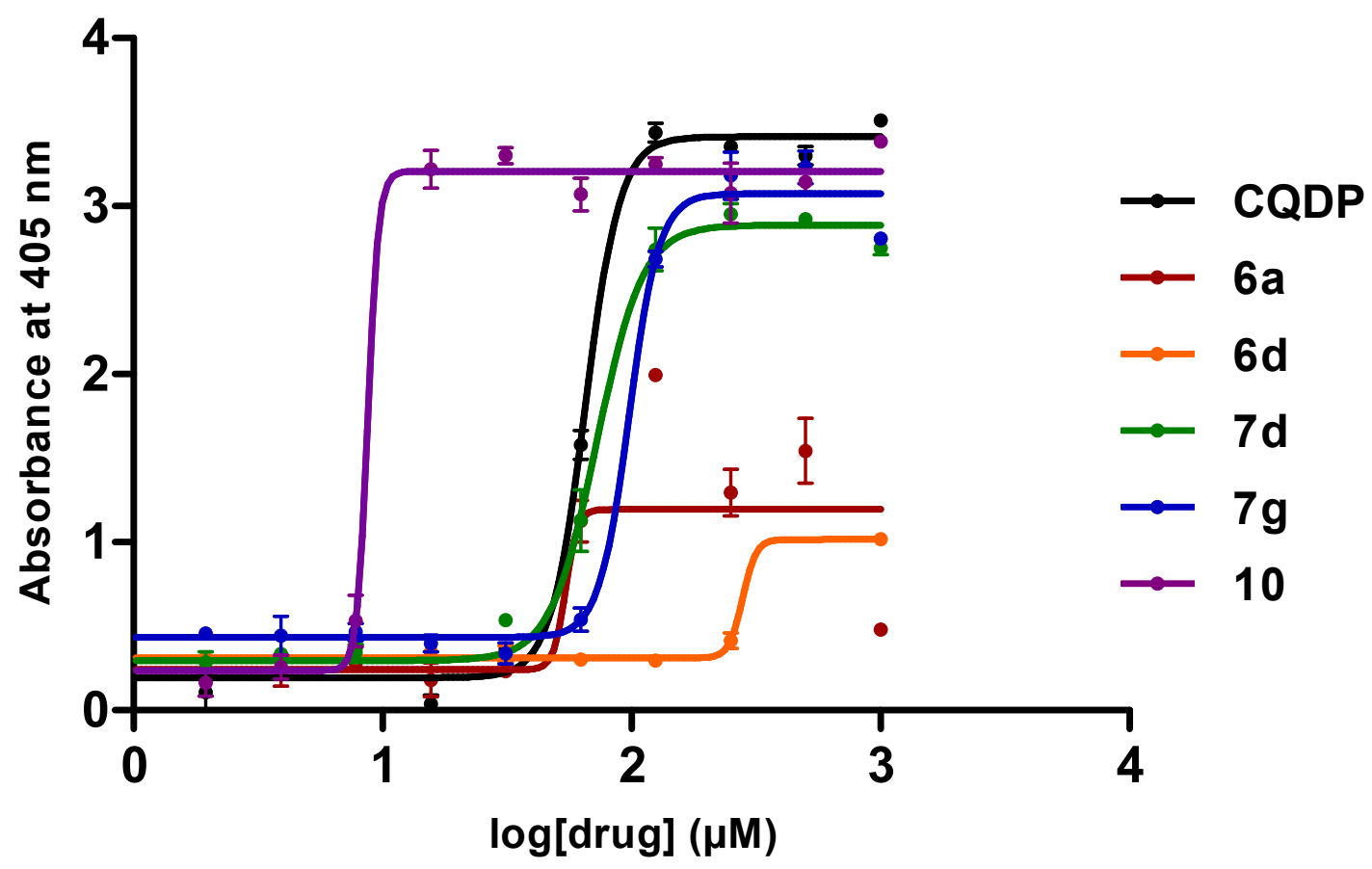

Figure 4.5: Dose-response curves obtained for compounds $\mathbf{6 a}, \mathbf{6 d}, \mathbf{7 d}, \mathbf{7 g}$, and $\mathbf{1 0}$, as well as CQDP, using the NP-40 detergent-mediated $\beta$-haematin inhibition assay.

curves of the tested compounds, representing the relationship between the absorbance of the haematin-pyridine complex formed with increasing drug concentration.

All of the compounds tested were found to inhibit $\beta$-haematin formation, indicated by the characteristic sigmoidal curve for each, however, their $\mathrm{IC}_{50}$ values differed drastically. These $I C_{50}$ values are represented graphically in Figure 4.6. In general, the activity of most of the compounds was lower than or comparable to chloroquine itself, which has an $\mathrm{IC}_{50}$ value of $65.3 \mu \mathrm{M}$. Organic compound $6 \mathrm{a}$ has an $\mathrm{IC}_{50}$ value of $61.4 \mu \mathrm{M}$, but it surprisingly loses activity at concentrations higher than $250 \mu \mathrm{M}$, as seen by the curve for $6 \mathbf{a}$ in Figure 4.5. Organic 
compound $6 \mathrm{~d}$ exhibited the worst activity with a very high IC 50 value of $274 \mu \mathrm{M}$, however, upon coordination of this compound to the metal fragment to form $\operatorname{Ir}(\mathrm{III})$ complex 10, the activity improves considerably. The $\mathrm{IC}_{50}$ value of complex 10 is $9.65 \mu \mathrm{M}$, meaning that it is far more active than chloroquine itself. This was unexpected since complex $\mathbf{1 0}$ displayed the lowest antiplasmodial activity of all the complexes tested in both the sensitive and resistant strains of $P$. falciparum. Entry of complex $\mathbf{1 0}$ into the parasitic digestive vacuole, where the haemozoin crystallisation takes place, must therefore be somewhat limited, since it has very good cell-free $\beta$-haematin inhibitory activity but very poor antiplasmodial activity. This thus shows that incorporation of the metal fragment onto the organic ligands leads to an enhancement of the $\beta$-haematin inhibitory activity of the free ligands, likely due to the effect of increased lipophilicity. Moreover, since complex $\mathbf{1 0}$ has better $\beta$-haematin inhibitory activity than the other cationic complex, $7 \mathbf{g}\left(I C_{50}=102 \mu \mathrm{M}\right)$, this highlights the importance of having a secondary amine and aliphatic chain in the structure of the compound. These, in combination with the 7-chloroquinoline moiety, have been proven to be instrumental in forming a strong complex with haematin, therefore aiding in parasitic cell death. ${ }^{25}$ Since the results of this cell-free assay suggest that these compounds do inhibit the formation of $\beta$-haematin, they are likely candidates for the inhibition of haemozoin in the parasite.

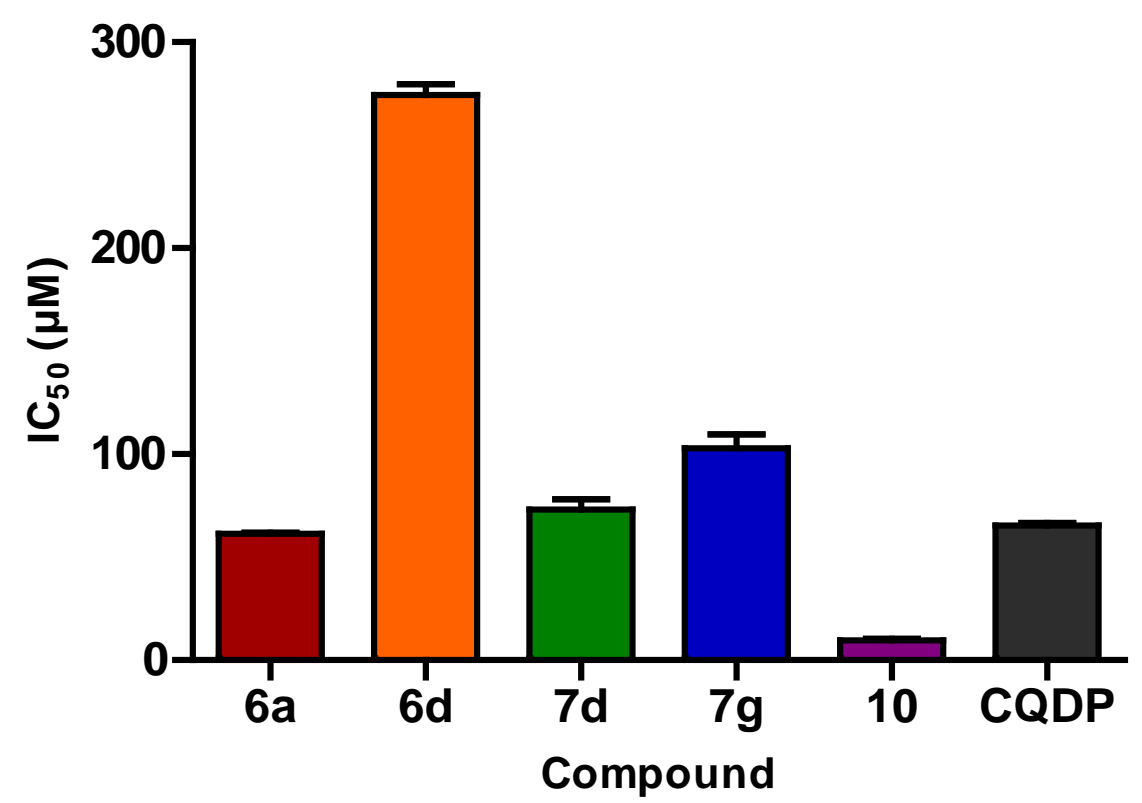

Figure 4.6: $I C_{50}$ values obtained from the $\beta$-haematin inhibition studies for compounds $6 \mathbf{a}, \mathbf{6 d}, \mathbf{7 d}, \mathbf{7 g}$, and 10 , as well as CQDP. 


\subsection{Preliminary transfer hydrogenation studies}

The coenzyme $\beta$-nicotinamide adenine dinucleotide $\left(N A D^{+}\right)$and its reduced form (1,4-NADH) play a vital role in cell metabolism and are required for many enzymatic reactions..$^{20,35}$ In recent years, it has been suggested that a disturbance in the intracellular $\mathrm{NAD}^{+} / \mathrm{NADH}$ ratio may affect the cellular redox status, thereby bringing about metabolic changes and possibly even cell death. ${ }^{20}$ It is for this reason that significant attention has been given to the use of organometallic complexes capable of regioselectively reducing $\mathrm{NAD}^{+}$to $1,4-\mathrm{NADH}$ under biological conditions. ${ }^{35}$ These types of reactions have been thoroughly studied in terms of anticancer applications, however, only just recently have they been applied to antimalarial therapy. ${ }^{36}$ In 2019, Stringer et al. tested two quinoline-based half-sandwich organoiridium and organorhodium complexes (Figure 4.7) in the presence of various concentrations of sodium formate $(0,5,10$ and $20 \mathrm{mM})$ against the CQ-resistant $\mathrm{K} 1$ strain of $P$. falciparum. ${ }^{36}$ While the organorhodium complex (complex 2, Figure 4.7) did not display any significant change in parasite viability, the organoiridium complex (complex 1, Figure 4.7) at $1000 \mathrm{ng} / \mathrm{mL}$ was found to exhibit a significant stepwise decrease in parasite viability with an increase in the concentration of sodium formate. ${ }^{36}$ The results of the in vitro formate assays for both complexes in this study are shown in the bar graph in Figure 4.7. Although only a preliminary study, it demonstrated that co-administration of metal-based complexes with a hydrogen source may be useful in targeting essential co-factors such as $\mathrm{NAD}^{+}$, thereby possibly overcoming resistance mechanisms within the parasite.

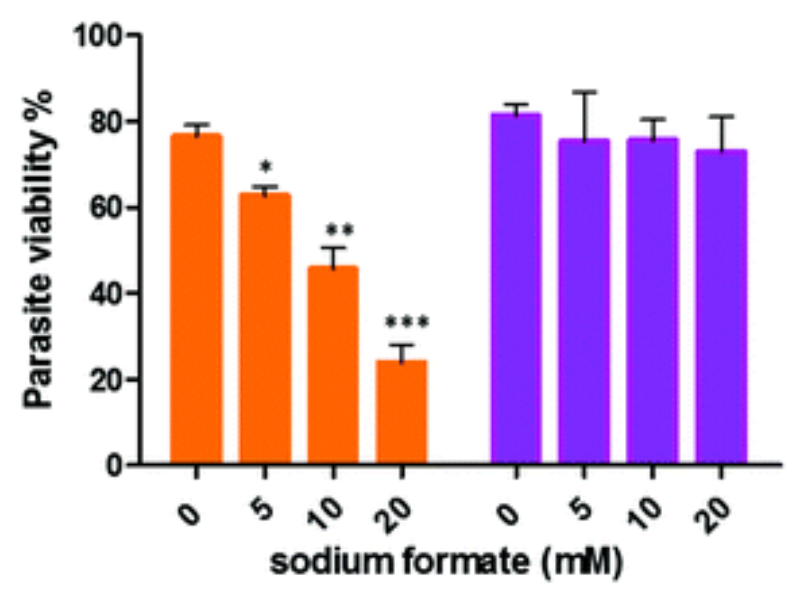

Complex 1

Complex 2

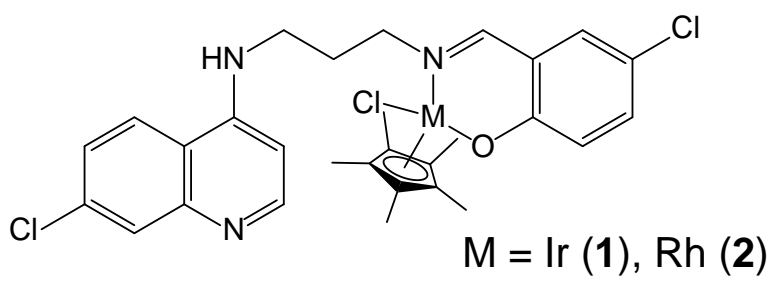

Figure 4.7. Parasite viability observed in the $\mathrm{K} 1$ strain when $1000 \mathrm{ng} / \mathrm{mL}$ concentrations of complexes 1 and $\mathbf{2}$ were incubated with various concentrations of sodium formate $(0,5,10$ and $20 \mathrm{mM})$. The structure of the complexes used in the study by Stringer et al. is also shown. ${ }^{36}$ 
4.6.1. Qualitative ${ }^{1} \mathrm{H}$ NMR spectroscopic studies for the conversion of $N A D^{+}$to $N A D H$ by complexes $7 \mathrm{a}$ and $7 \mathrm{~g}$

Thus far, no examples of iridium(III) 7-chloroquinoline-1,2,3-triazole half-sandwich complexes have been reported for transfer hydrogenation reactions. The complexes which displayed the best antiplasmodial activity, namely $\mathbf{7 a}$ and $\mathbf{7 g}$, were therefore tested for their ability to regioselectively catalyse the transfer hydrogenation reduction of $\mathrm{NAD}^{+}$to $\mathrm{NADH}$, using sodium formate as the hydrogen source. The proposed mechanism of the catalytic cycle for cyclometallated complex 7a can be seen in Figure 4.8 and is based on the mechanism previously reported by Lo et al. ${ }^{37}$ The complex is first believed to become solvated, forming cationic solvated complex $\mathbf{A}$. This then reacts with sodium formate, forming complex $\mathbf{B}$, which then undergoes a $\beta$-hydrogen elimination reaction to form the metal-hydride species $\mathbf{C}$ and liberating $\mathrm{CO}_{2}$ in the process. The oxygen of the amide functionality of $\mathrm{NAD}^{+}$then coordinates to the metal centre of $\mathbf{C}$, thereby facilitating the hydride transfer and forming transition state

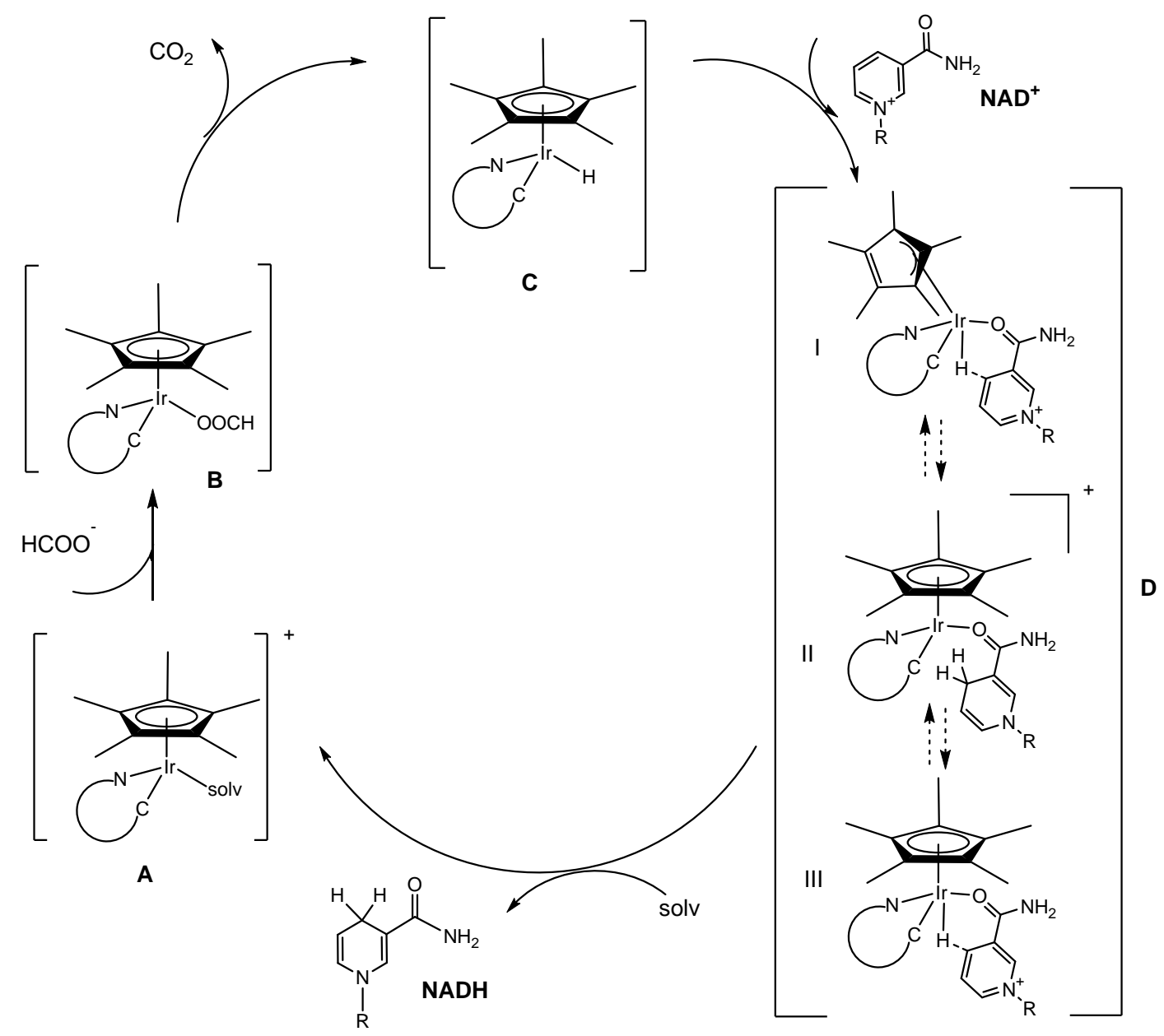

Figure 4.8: Proposed catalytic cycle for the regioselective reduction of $N A D^{+}$by $\operatorname{Ir}(I I I)$ complex $7 a .^{37}$ 
D. This allows for the regioselective hydride transfer at C-4 of NAD+, forming the 1,4-dihydro product, $\mathrm{NADH}$, and the solvated catalyst precursor, $\mathrm{A}$. The mechanism for the cationic complex, $7 \mathrm{~g}$, should follow the same catalytic cycle, as described by Lo et al. ${ }^{37}$

Qualitative tests by means of ${ }^{1} \mathrm{H}$ NMR spectroscopy were performed using complexes $7 \mathrm{a}$ and $7 \mathrm{~g}$ as catalyst precursors to test whether they are able to facilitate the hydride transfer reduction of $\mathrm{NAD}^{+}$to form NADH. To demonstrate this, a solution of the complex (7a or $\left.7 \mathbf{g}\right)$, $\mathrm{NAD}^{+}$and sodium formate was made in a mixture of MeOD and $\mathrm{D}_{2} \mathrm{O}$ and a ${ }^{1} \mathrm{H}$ NMR spectrum was recorded roughly 5 minutes after sample preparation and again after $4 \mathrm{~h}$, with incubation at $37^{\circ} \mathrm{C}$. If regioselective reduction of $\mathrm{NAD}^{+}$to $\mathrm{NADH}$ has occurred, changes in characteristic ${ }^{1} \mathrm{H}$ NMR spectral signals should be observed. The catalytic ${ }^{1} \mathrm{H}$ NMR spectroscopy experiments for complexes $7 \mathrm{a}$ and $\mathbf{7 g}$ are shown in Figure 4.9 and Figure 4.10 respectively.

In the ${ }^{1} \mathrm{H}$ NMR experiment for complex 7a (Figure 4.9), the spectrum at $\mathrm{t}=0 \mathrm{~h}$ shows predominantly the presence of $\mathrm{NAD}^{+}$, however, the presence of signals pertaining to 1,4-NADH are also observed at this time. This thus means that the catalytic reduction begins immediately once all the reactants are in solution. After $4 \mathrm{~h}$, the absence of characteristic

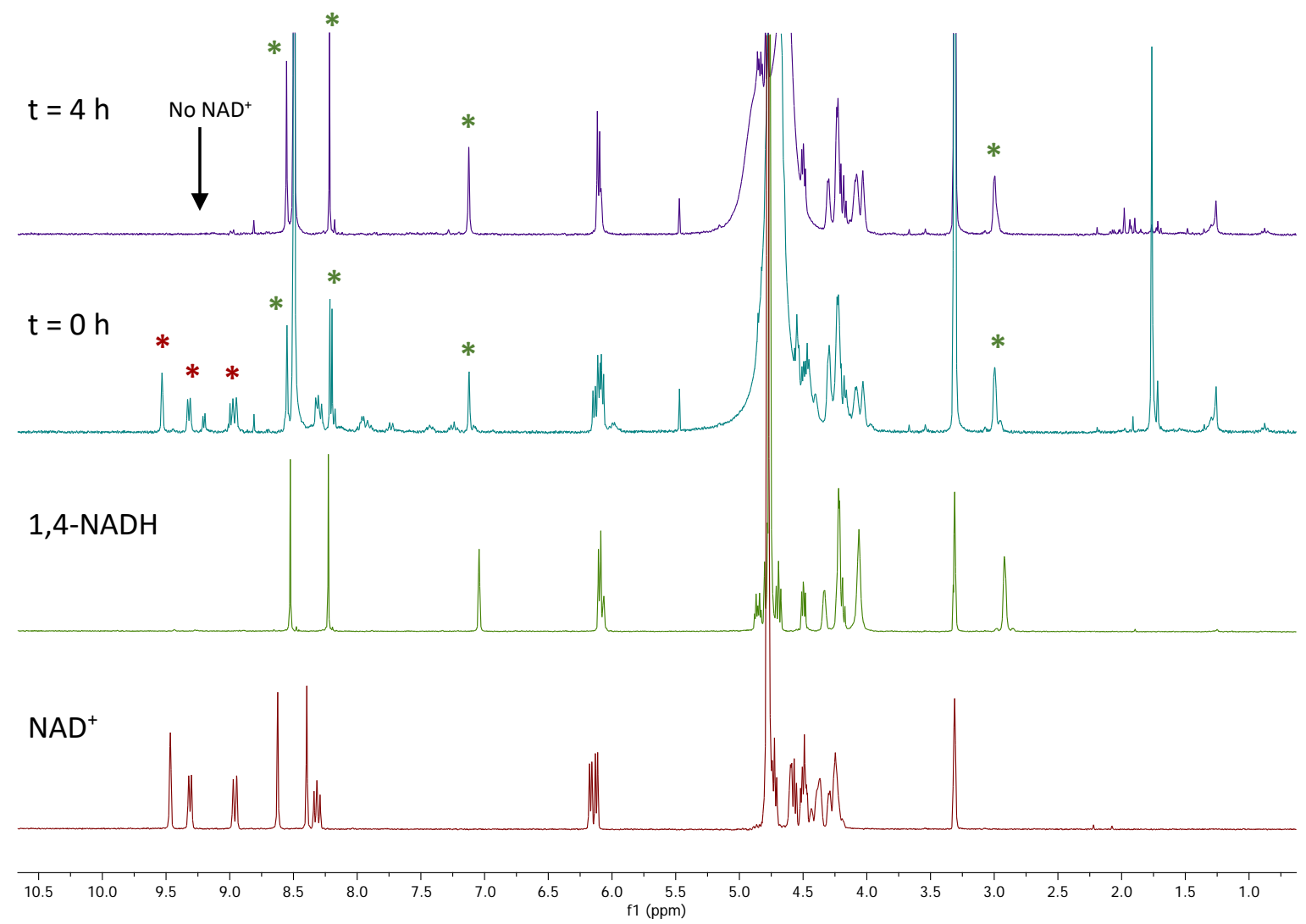

Figure 4.9: ${ }^{1} \mathrm{H} N M R$ spectra of a mixture of $\operatorname{Ir}(I I I)$ complex $7 \mathrm{a}, \mathrm{NAD}{ }^{+}$and sodium formate in $\mathrm{MeOD} / \mathrm{D}_{2} \mathrm{O}$ at $37^{\circ} \mathrm{C}$. Signals marked by $\left({ }^{*}\right)$ represent $\mathrm{NAD}^{+}$and $\left({ }^{*}\right)$ represent $1,4-\mathrm{NADH}$. 
$\mathrm{NAD}^{+}$signals indicated that no more $\mathrm{NAD}^{+}$was present in solution, with only signals characteristic of 1,4-NADH observed at this time interval. This means that neutral cyclometallated $\operatorname{Ir}(\mathrm{III})$ complex $7 \mathrm{a}$ is capable of catalysing the regioselective reduction of $\mathrm{NAD}^{+}$ to $1,4-N A D H$, using sodium formate as the hydrogen source.

Since cationic $\operatorname{Ir}(\mathrm{III})$ complex $\mathbf{7 g}$ exhibited the best antiplasmodial activity of all the tested complexes, the ${ }^{1} \mathrm{H}$ NMR experiment performed for $7 \mathrm{a}$ was repeated with $\mathbf{7 g}$. The same method was applied, with a spectrum being recorded 5 minutes after sample preparation and again after $4 \mathrm{~h}$ (Figure 4.10). Interestingly, unlike what was observed for the experiment with 7a, after $4 \mathrm{~h}$ there was still mostly NAD+ left in the solution. The ${ }^{1} \mathrm{H}$ NMR spectrum at $\mathrm{t}=4 \mathrm{~h}$ looks almost identical to that at $\mathrm{t}=0 \mathrm{~h}$. Very small signals corresponding to $\mathrm{NADH}$ are present at this time interval, meaning that the complex could be acting as a transfer hydrogenation catalyst, however, the reaction likely proceeds very slowly. In light of this, this complex was not used for further testing as it did not exhibit effective catalytic ability in reducing $\mathrm{NAD}^{+}$to $\mathrm{NADH}$.

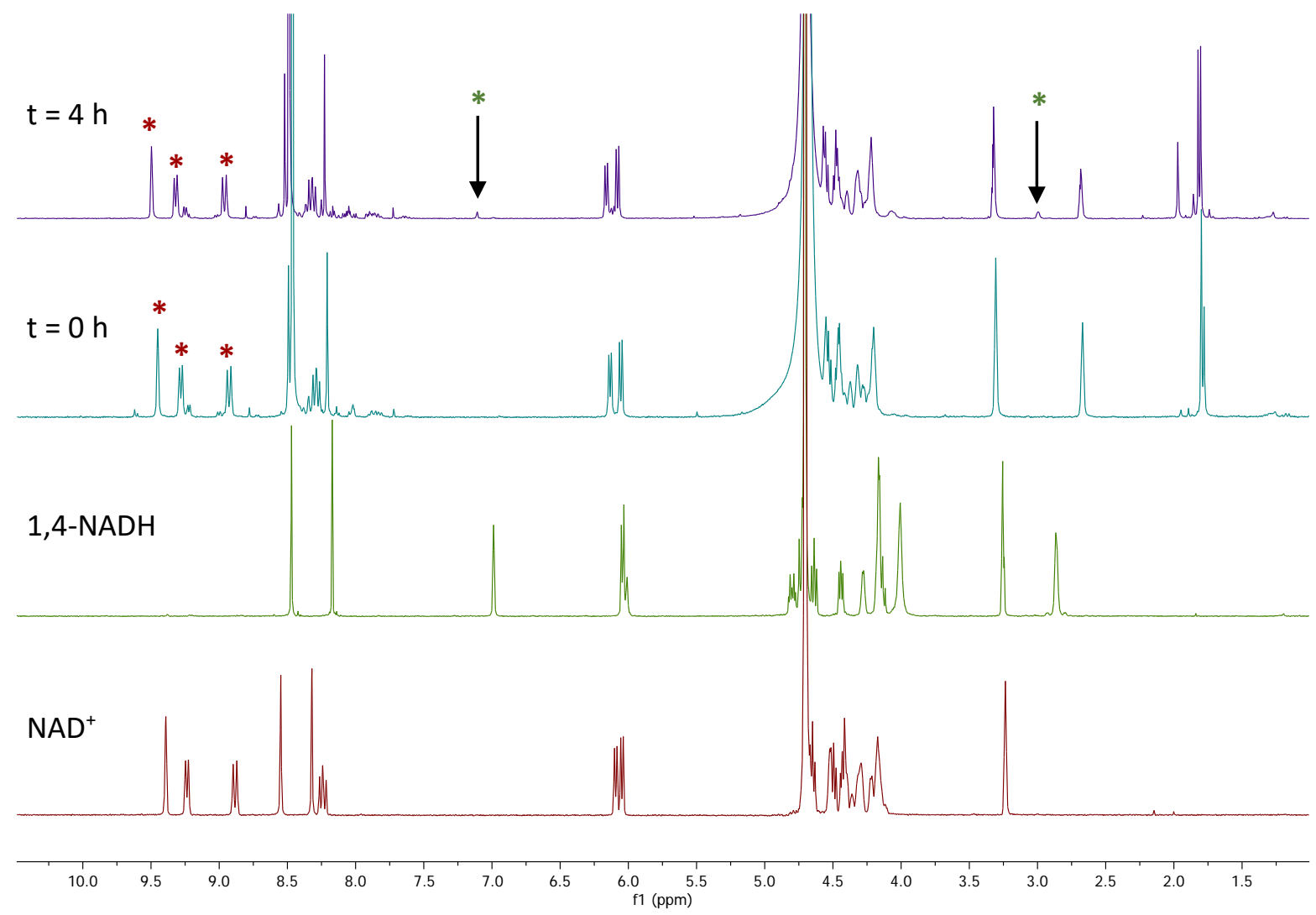

Figure 4.10: ${ }^{1} \mathrm{H}$ NMR spectra of a mixture of $\operatorname{Ir}(\mathrm{III})$ complex $7 \mathrm{~g}, \mathrm{NAD}{ }^{+}$and sodium formate in $\mathrm{MeOD} / \mathrm{D}_{2} \mathrm{O}$ at $37^{\circ} \mathrm{C}$. Signals marked by $\left({ }^{*}\right)$ represent $\mathrm{NAD}^{+}$and $\left({ }^{*}\right)$ represent $1,4-\mathrm{NADH}$. 


\subsubsection{Cell-free assay to detect the conversion of $\mathrm{NAD}^{+}$to $\mathrm{NADH}$ by complexes $7 \mathrm{a}$ and $7 \mathrm{e}$}

In order to verify further the ability of the Ir(III) 7-chloroquinoline-1,2,3-triazole complexes to catalyse the reduction of $\mathrm{NAD}^{+}$to $\mathrm{NADH}$, a cell-free assay, modified from the pLDH assay ${ }^{38}$, was performed. ${ }^{36}$ The principle behind the pLDH assay is shown in Figure 4.11. ${ }^{23}$ Parasite lactate dehydrogenase ( $\mathrm{pLDH}$ ) is an enzyme found within the parasite which catalyses the interconversion of pyruvate to lactate and, in so doing, converting cofactor NAD ${ }^{+}$to NADH and back. ${ }^{23,38}$ The pLDH assay makes use of this intracellular catalytic process specifically to detect the pLDH enzyme, thereby allowing conclusions to be drawn as to the parasite viability since the pLDH enzyme is only effective in live parasites. Makler et al. developed the Malstat ${ }^{\mathrm{TM}}$ method for the detection of parasite viability in 1993 and this method is still followed today. ${ }^{23,39}$ This method for the pLDH assay makes use of the fact that pLDH is able utilise the 3-acetyl pyridine analogue of $\mathrm{NAD}^{+}\left(\mathrm{APAD}^{+}\right)$while human lactate dehydrogenase (hLDH) enzymes do not readily use this analogue, therefore allowing the assay to detect pLDH activity over hLDH activity. ${ }^{39,40}$ In parasite-infected, lysed red blood cells, the pLDH enzyme oxidises lactate to pyruvate, reducing $\mathrm{APAD}^{+}$(found within the Malstat ${ }^{\mathrm{TM}}$ reagent) to APADH in the process. The yellow-coloured tetrazolium dye (in the form of nitroblue tetrazolium (NBT)) is added thereafter, which is reduced by the APADH to the dark blue formazan in the presence of the electron acceptor, phenazine ethosulfate (Figure 4.11).

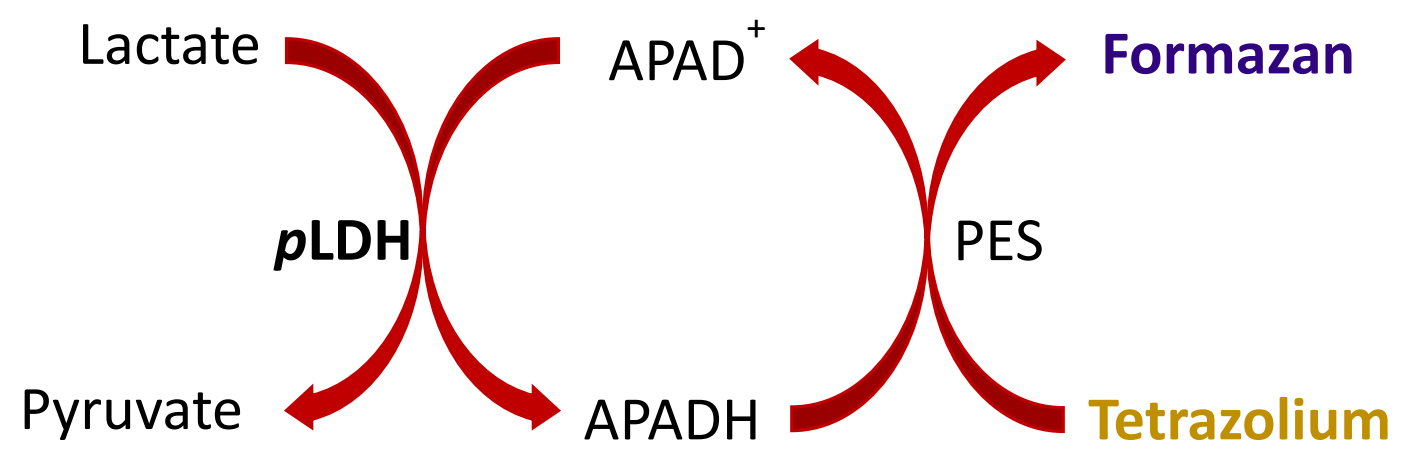

Figure 4.11: Principle of the pLDH Malstat ${ }^{\mathrm{TM}}$ assay for the detection of parasite viability. ${ }^{23}$

In order to monitor the transfer hydrogenation catalytic activity of neutral cyclometallated complexes 7a and 7e, a cell-free experiment, modified from the pLDH method, was used (Figure 4.11). This modified method was first described by Stringer et al. for detecting the cellfree catalytic ability of $\mathrm{N}, \mathrm{O}$-chelating quinoline-based half-sandwich rhodium and iridium 
complexes. ${ }^{36}$ Following this method, different concentrations of complexes 7a and 7e were incubated with $\mathrm{NAD}^{+}$and sodium formate at $37^{\circ} \mathrm{C}$ and $\mathrm{pH} 7.4$ for $6 \mathrm{~h}$. If the complexes are able to facilitate the reduction of $\mathrm{NAD}^{+}$to $\mathrm{NADH}$ in the presence of sodium formate, the NADH should reduce the nitroblue tetrazolium (NBT) to formazan, as shown in Figure $4.12 .{ }^{36}$ This

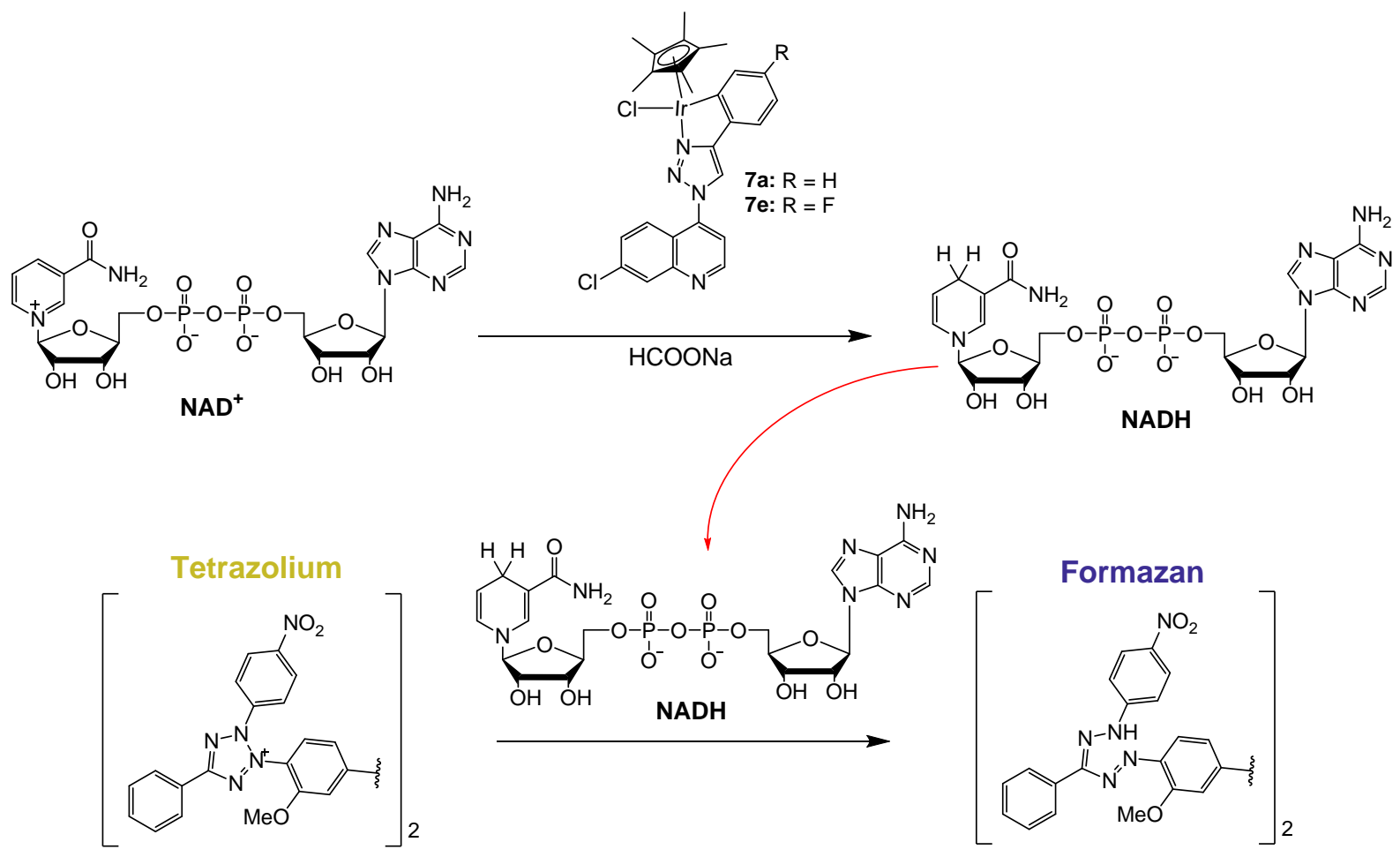

Figure 4.12: Principle used to detect transfer hydrogenation activity of complexes $\mathbf{7 a}$ and $\mathbf{7 g}{ }^{36}$

process is analogous to the reduction of the yellow tetrazolium salt to the dark blue formazan compound by APADH in the Malstat ${ }^{\mathrm{TM}}$ assay. The absorbance at $600 \mathrm{~nm}$ is then taken and is proportional to the amount of formazan present, therefore providing a means of detecting the transfer hydrogenation catalytic ability of the complexes. The results of this cell-free assay experiment are shown in Figure 4.13. As seen in Figure 4.13a, the experiment was performed in a 96-well plate in which 10 concentrations of each complex were plated in triplicate and two negative controls were included in the first two columns (column 1 = DMSO only; column $2=\mathrm{NAD}^{+}$only). Upon addition of the NBT reagent, the wells containing the higher concentrations of the complexes changed from yellow to blue and the change in absorbance with increasing complex concentration was plotted, as shown in Figure 4.13b. These results show that, as the concentration of the complex increases, the absorbance also increases and this is indicative of a greater concentration of NADH in solution. Although this is an indirect 
method of detecting coenzyme conversion, the results show that complexes $7 \mathbf{a}$ and $7 \mathbf{e}$, in the presence of sodium formate, can act as transfer hydrogenation catalysts, facilitating the reduction of $\mathrm{NAD}^{+}$to $\mathrm{NADH}$ in a cell-free environment. While complex 7e displays slightly better catalytic activity than complex $\mathbf{7 a}$, both demonstrate a positive correlation between the concentration of the complex and the amount of formazan formed.
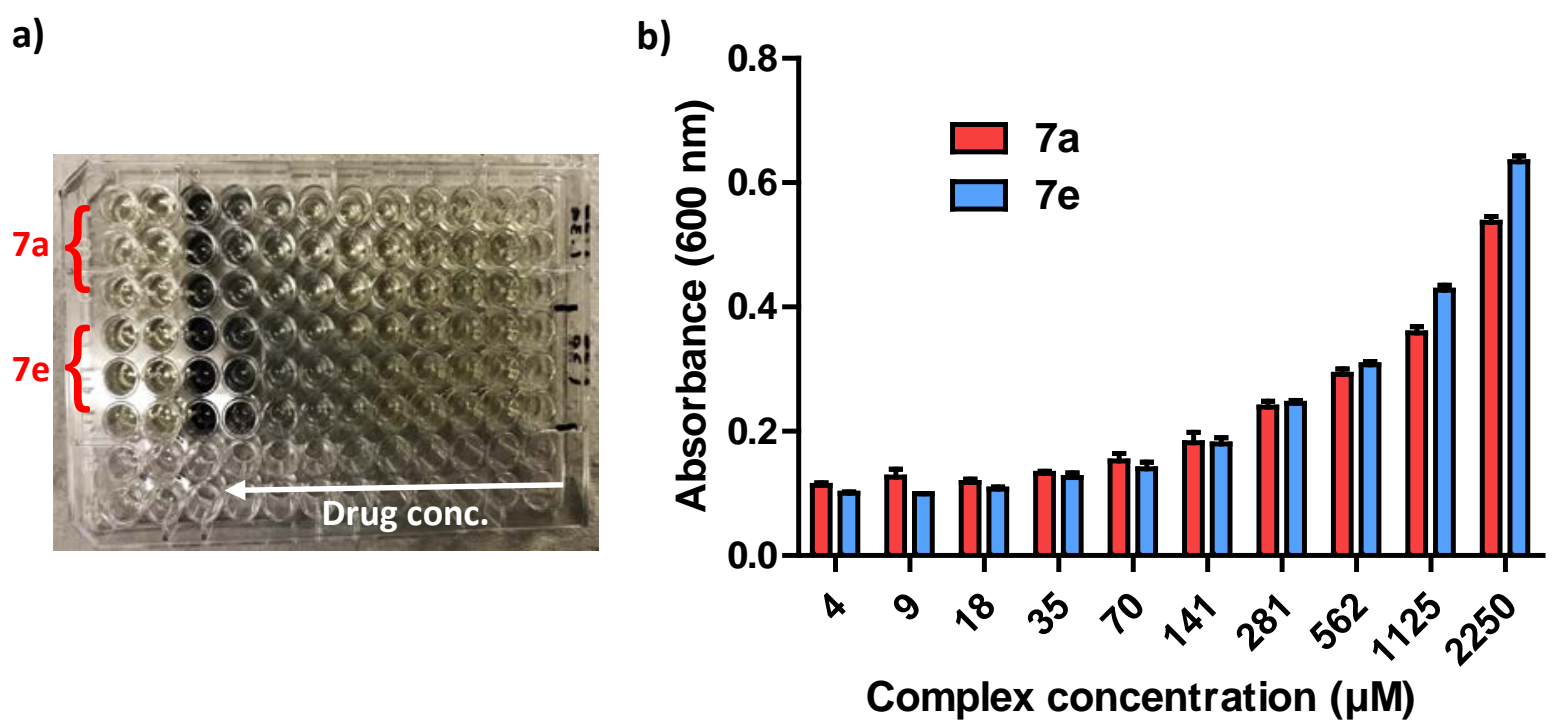

Figure 4.13: Results of the cell-free transfer hydrogenation experiment for complexes $7 a$ and $7 e$. (a) Plate set-up showing the presence of dark blue formazan at higher drug concentrations; (b) Absorbance values determined for increasing concentrations of the complexes $7 \mathbf{a}$ and $7 \mathbf{e}$.

The preliminary transfer hydrogenation experiments described in this section showed that $\operatorname{Ir}\left(\right.$ III) complexes $7 \mathrm{a}$ and $7 \mathrm{e}$ are capable of catalysing the reduction of $\mathrm{NAD}^{+}$to $\mathrm{NADH}$ in the presence of sodium formate in a cell-free environment. Future in vitro experiments should therefore be performed with these complexes to determine whether they retain their catalytic activity within various strains of $P$. falciparum. Although the groundwork for the in vitro formate assay has been laid by Stringer et al. in this regard ${ }^{36}$, many more tests using a variety of different metal-based compounds need to be performed in order to test the reproducibility of this method. Stringer et al. were able to show, however, that metalmediated transfer hydrogenation reactions could potentially be achieved within the malaria parasite ${ }^{36}$, paving the way for future experiments of this kind. 


\subsection{Summary}

Two series of 7-chloroquinoline-1,2,3-triazole ligands, $\mathbf{2 a - h}$ and $\mathbf{6 a - e}$, as well as the Ir(III) halfsandwich complexes $\mathbf{7 a - g}, \mathbf{8}$ and $\mathbf{1 0}$ were evaluated in vitro for their antiplasmodial activity against the NF54 CQS strain of $P$. falciparum. The ligand series containing the propyl chain linker (6a-e) displayed superior activity to those with the triazole directly bonded to the quinoline moiety (2a-h). Upon metal complexation with iridium, the activity of selected ligands is significantly enhanced, with some complexes being over one hundred times more active than their respective ligands. Cationic complex $7 \mathrm{~g}$ displayed the best activity of all the complexes with an $\mathrm{IC}_{50}$ value of $0.247 \mu \mathrm{M}$ while complex $7 \mathrm{a}$ was the most active of the neutral, cyclometallated complexes, having an $\mathrm{IC}_{50}$ value of $0.688 \mu \mathrm{M}$. Surprisingly, the cationic complex 10, which contains a propyl linker in its scaffold, exhibited the lowest antiplasmodial activity of all the synthesised complexes. Ligands 6a-e and complexes 7a-g and $\mathbf{1 0}$ were, thereafter, tested for their antiplasmodial activity against the K1 CQR strain of $P$. falciparum. For most of these compounds, their activity is lower in the resistant strain, however, their calculated RI values suggest that they likely experience cross-resistance but not to the extent of chloroquine. Compounds $\mathbf{7 a}, \mathbf{7 b}, \mathbf{7 d}, \mathbf{7 e}$ and $\mathbf{7 g}$ were tested against the healthy $\mathrm{CHO}$ cell line and were found not to be cytotoxic. They were also determined to be more selective towards parasitic cells, with complex $\mathbf{7 g}$ being almost 500 times more selective towards the parasite than healthy cells. An "IC 50 speed assay" using the CQS NF54 strain found complexes $7 \mathrm{a}$ and $7 \mathrm{e}$ to be fast-acting compounds, which reach their lowest $\mathrm{IC}_{50}$ values within $24 \mathrm{~h}$, while cationic complex $7 \mathrm{~g}$ was determined to be slow-acting, only reaching its lowest $\mathrm{IC}_{50}$ value after $48 \mathrm{~h}$. To gain insight into the possible mechanisms of action of these compounds, a $\beta$-haematin inhibition assay was performed on selected ligands (6a and $\mathbf{6 d}$ ) and complexes (7d, $7 \mathrm{~g}$ and 10), since 7-chloroquinoline-containing compounds are known to inhibit the formation of haemozoin within the parasite. All five of the tested compounds were found to inhibit $\beta$-haematin formation to some extent but were, in general, poorer $\beta$-haematin inhibitors than chloroquine itself. Interestingly, complex 10, which has the lowest antiplasmodial activity, exhibited far greater $\beta$-haematin inhibitory activity than chloroquine. Its $I_{50}$ value of $9.65 \mu \mathrm{M}$ is also 28 -times lower than that of its respective ligand, $6 \mathrm{~d}(274 \mu \mathrm{M})$, indicating that the inclusion of a metal fragment could improve complexation of the compound to haematin. Finally, the most active complexes $7 \mathrm{a}, \mathbf{7 e}$ and $\mathbf{7 g}$ were evaluated for 
their ability to facilitate transfer hydrogenation, by reducing $\beta$-nicotinamide adenine dinucleotide $\left(\mathrm{NAD}^{+}\right)$to $\mathrm{NADH}$ in the presence of the hydrogen source, sodium formate. Through ${ }^{1} \mathrm{H}$ NMR spectroscopy experiments and a cell-free assay modified from the pLDH assay, it was found that complexes $\mathbf{7 a}$ and $\mathbf{7 e}$ are capable of acting as transfer hydrogenation catalysts while cationic complex $\mathbf{7 g}$ is not, showing no reduction of $\mathrm{NAD}^{+}$to $\mathrm{NADH}$ over $4 \mathrm{~h}$. This preliminary study into the catalytic potential of active antiplasmodial complexes shows great promise, and future testing of these compounds as transfer hydrogenation catalysts in vitro could lead to the discovery of a novel mechanism of action, particularly in drug-resistant parasitic strains.

\subsection{References}

1 P. G. Bray, R. E. Martin, L. Tilley, S. A. Ward, K. Kirk and D. A. Fidock, Mol. Microbiol., $2005,56,323-333$.

2 A. Ecker, A. M. Lehane, J. Clain and D. A. Fidock, Trends Parasitol., 2012, 28, 504-514.

3 D. A. Fidock, T. Nomura, A. K. Talley, R. A. Cooper, S. M. Dzekunov, M. T. Ferdig, L. M. B. Ursos, A. bir Singh Sidhu, B. Naudé, K. W. Deitsch, X. Su, J. C. Wootton, P. D. Roepe and T. E. Wellems, Mol. Cell, 2000, 6, 861-871.

4 T. Hirao and T. Moriuchi, Eds., Advances in Bioorganometallic Chemistry, Elsevier, 1st edn., 2019.

5 C. Biot, G. Glorian, L. A. Maciejewski, J. S. Brocard, O. Domarle, G. Blampain, P. Millet, A. J. Georges, H. Abessolo, D. Dive and J. Lebibi, J. Med. Chem., 1997, 40, 3715-3718.

6 F. Dubar, T. J. Egan, B. Pradines, D. Kuter, K. K. Ncokazi, D. Forge, J.-F. Paul, C. Pierrot, H. Kalamou, J. Khalife, E. Buisine, C. Rogier, H. Vezin, I. Forfar, C. Slomianny, X. Trivelli, S. Kapishnikov, L. Leiserowitz, D. Dive and C. Biot, ACS Chem. Biol., 2011, 6, 275-287.

7 F. Dubar, J. Khalife, J. Brocard, D. Dive and C. Biot, Molecules, 2008, 13, 2900-2907.

8 C. Biot, W. Castro, C. Y. Botté and M. Navarro, Dalton Trans., 2012, 41, 6335-6349.

9 P. F. Salas, C. Herrmann and C. Orvig, Chem. Rev., 2013, 113, 3450-3492.

10 M. Navarro, W. Castro and C. Biot, Organometallics, 2012, 31, 5715-5727. 
11 T. J. Egan, E. Hempelmann and W. W. Mavuso, J. Inorg. Biochem., 1999, 73, 101-107.

12 T. J. Egan, R. Hunter, C. H. Kaschula, H. M. Marques, A. Misplon and J. Walden, J. Med. Chem., 2000, 43, 283-291.

13 A. Martínez, C. S. K. Rajapakse, D. Jalloh, C. Dautriche and R. A. Sánchez-Delgado, J. Biol. Inorg. Chem., 2009, 14, 863-871.

14 A. Martínez, C. S. K. Rajapakse, B. Naoulou, Y. Kopkalli, L. Davenport and R. A. SánchezDelgado, J. Biol. Inorg. Chem., 2008, 13, 703-712.

15 J. J. Soldevila-Barreda and N. Metzler-Nolte, Chem. Rev., 2019, 119, 829-869.

16 P. K. Sasmal, C. N. Streu and E. Meggers, Chem. Commun., 2013, 49, 1581-1587.

17 K. D. Mjos and C. Orvig, Chem. Rev., 2014, 114, 4540-4563.

18 Z. Yu and J. A. Cowan, Chem. Eur. J., 2017, 23, 14113-14127.

19 S. Betanzos-Lara, Z. Liu, A. Habtemariam, A. M. Pizarro, B. Qamar and P. J. Sadler, Angew. Chem. Int. Ed., 2012, 51, 3897-3900.

20 J. J. Soldevila-Barreda, P. C. A. Bruijnincx, A. Habtemariam, G. J. Clarkson, R. J. Deeth and P. J. Sadler, Organometallics, 2012, 31, 5958-5967.

21 J. J. Soldevila-Barreda, I. Romero-Canelón, A. Habtemariam and P. J. Sadler, Nat. Commun., 2015, 6, 6582.

22 Z. Liu, I. Romero-Canelón, B. Qamar, J. M. Hearn, A. Habtemariam, N. P. E. Barry, A. M. Pizarro, G. J. Clarkson and P. J. Sadler, Angew. Chem. Int. Ed., 2014, 53, 3941-3946.

23 M. T. Makler and D. J. Hinrichs, Am. J. Trop. Med. Hyg., 1993, 48, 205-210.

24 G. R. Pereira, G. C. Brandão, L. M. Arantes, H. A. De Oliveira, R. C. De Paula, M. F. A. Do Nascimento, F. M. Dos Santos, R. K. Da Rocha, J. C. D. Lopes and A. B. De Oliveira, Eur. J. Med. Chem., 2014, 73, 295-309.

25 T. J. Egan, R. Hunter, C. H. Kaschula, H. M. Marques, A. Misplon and J. Walden, J. Med. Chem., 2000, 43, 283-291.

26 E. S. Akinboye, Open Nat. Prod. J., 2011, 4, 8-15.

27 J. N. Burrows, D. Leroy, J. Lotharius and D. Waterson, Future Med. Chem., 2011, 3, 
1401-1412.

28 J. N. Burrows, R. Hooft van Huijsduijnen, J. J. Möhrle, C. Oeuvray and T. N. Wells, Malar. J., 2013, 12, 187.

29 C. Le Manach, C. Scheurer, S. Sax, S. Schleiferböck, D. Cabrera, Y. Younis, T. Paquet, L. Street, P. Smith, X. C. Ding, D. Waterson, M. J. Witty, D. Leroy, K. Chibale and S. Wittlin, Malar. J., 2013, 12, 424.

30 M. Foley and L. Tilley, Clin. Pharmacol. Ther., 1998, 79, 55-87.

31 R. D. Sandlin, M. D. Carter, P. J. Lee, J. M. Auschwitz, S. E. Leed, J. D. Johnson and D. W. Wright, Antimicrob. Agents Chemother., 2011, 55, 3363-3369.

32 A. N. Hoang, R. D. Sandlin, A. Omar, T. J. Egan and D. W. Wright, Biochemistry, 2010, 49, 10107-10116.

33 A. N. Hoang, K. K. Ncokazi, K. A. de Villiers, D. W. Wright and T. J. Egan, Dalton Trans., 2010, 39, 1235-1244.

34 K. K. Ncokazi and T. J. Egan, Anal. Biochem., 2005, 338, 306-319.

35 Y. K. Yan, M. Melchart, A. Habtemariam, A. F. A. Peacock and P. J. Sadler, J. Biol. Inorg. Chem., 2006, 11, 483-488.

36 T. Stringer, D. R. Melis and G. S. Smith, Dalton Trans., 2019, 48, 13143-13148.

37 H. C. Lo, C. Leiva, O. Buriez, J. B. Kerr, M. M. Olmstead and R. H. Fish, Inorg. Chem., $2001,40,6705-6716$.

38 R. C. Piper, J. A. Williams, M. T. Makler, B. L. Gibbins, D. J. Hinrichs, J. M. Ries and J. E. Bancroft, Am. J. Trop. Med. Hyg., 1993, 48, 739-741.

39 S. Houzé, L. Wentworth, P. Chiodini, A. Hunt-Cooke, R. Piper, M. Makler and J. Lebras, Am. J. Trop. Med. Hyg., 1999, 60, 109-118.

40 C. F. Markwalter, K. M. Davis and D. W. Wright, Anal. Biochem., 2016, 493, 30-34. 


\section{Chapter 5}

\section{Conclusions and future outlook}

\subsection{Overall summary and conclusions}

The primary aim of this project was to synthesise various 7-chloroquinoline-1,2,3-triazolebased ligands and their corresponding $\operatorname{Ir}(\mathrm{III})$ half-sandwich complexes to be tested as antiplasmodial agents. The first series of ligands $(2 \mathrm{a}-\mathrm{h})$ and complexes $(\mathbf{7 a - g}, \mathbf{8})$ had the triazole ring directly bonded to position-4 of the quinoline system while the second series complex (10) and ligands (6a-e) included an aminopropyl chain linker between the two entities. Coordination of select ligands using $\left[\operatorname{IrCl}(\mu-\mathrm{Cl})\left(\mathrm{Cp}^{*}\right)\right]_{2}$ yielded six neutral, cyclometallated $(\mathbf{7 a - f})$ and two cationic, $\mathrm{N}, \mathrm{N}$-chelated $(\mathbf{7 g}, \mathbf{1 0})$ iridium complexes. All of the compounds were fully characterised using an array of spectroscopic $\left({ }^{1} \mathrm{H},{ }^{13} \mathrm{C}\left\{{ }^{1} \mathrm{H}\right\},{ }^{19} \mathrm{~F}\left\{{ }^{1} \mathrm{H}\right\}\right.$, ${ }^{31} \mathrm{P}\left\{{ }^{1} \mathrm{H}\right\}$ NMR and FT-IR spectroscopy) and analytical (mass spectrometry and melting point analysis) techniques.

The ligands in both series (2a-h and 6a-e) were prepared by $\mathrm{Cu}(\mathrm{I})$-catalysed azide-alkyne cycloaddition "click" reactions and were isolated in moderate to good yields. The aromatic alkynes used in these reactions had side groups which varied according to their electronwithdrawing or electron-donating capacities. Ligands $2 a-f$ were then reacted with $\left[\mathrm{IrCl}(\mu-\mathrm{Cl})\left(\mathrm{Cp}^{*}\right)\right]_{2}$, undergoing $\mathrm{C}-\mathrm{H}$ activation to form cyclometallated complexes $7 \mathrm{a}-\mathrm{f}$. The synthesis of the cyclometallated complexes revealed a surprising result - the ligands first coordinate to the metal in a monodentate-fashion via the quinoline nitrogen. Complex $\mathbf{8}$, the monodentate complex of this type formed with ligand $\mathbf{2 a}$, was isolated and fully characterised. With continued heating over time, the metal detaches from the quinoline nitrogen and then coordinates to nitrogen-3 on the triazole, thereafter undergoing $\mathrm{C}-\mathrm{H}$ activation to form the cyclometallated products, 7a-f. Computational analysis of the reaction of ligand $2 \mathrm{a}$ with $\left[\mathrm{IrCl}(\mu-\mathrm{Cl})\left(C p^{*}\right)\right]_{2}$ revealed that the fastest-formed monodentate-type complex $\mathbf{8}$ is the kinetic product, which is formed at room temperature. At a temperature of $65{ }^{\circ} \mathrm{C}$, the cyclometallated complex $7 \mathrm{a}$, which is the thermodynamic product, is formed. The structures and nature of metal-coordination of these complexes ( $\mathbf{7 a}$ and $\mathbf{8})$ were confirmed 
using single-crystal X-ray diffraction, which also corroborated the pseudo-tetrahedral geometry about the metal centre for both complexes. Cyclometallation using ligands 6a-c was attempted multiple times, however, these reactions were unsuccessful. The pyridylcontaining ligands $\mathbf{2} \mathbf{g}$ and $\mathbf{6} \mathbf{d}$ were complexed using $\left[\operatorname{IrCl}(\mu-\mathrm{Cl})\left(\mathrm{Cp}^{*}\right)\right]_{2}$ via a bridge-splitting reaction to afford the respective $N, N$-chelated $\operatorname{Ir}(I I I)$ cationic complexes, $\mathbf{7 g}$ and $\mathbf{1 0}$.

All synthesised compounds were screened in vitro for their potential antiplasmodial activity against the chloroquine-sensitive NF54 strain of $P$. falciparum. Ligands 2 a-h exhibited low antiplasmodial activity while ligands 6 a-e displayed excellent activity, with submicromolar $\mathrm{IC}_{50}$ values. This is likely due to the presence of the secondary amine and propyl chain linker in the structures of these compounds, both of which aid in accumulation of the drug within the parasite. Upon coordination of ligands $\mathbf{2 a - g}$ with iridium to form complexes $7 \mathbf{a}-\mathrm{g}$, the antiplasmodial activity is significantly enhanced, with some complexes being over one hundred times more active than their respective ligands. Cationic complex $\mathbf{7 g}$ displayed the best antiplasmodial activity and monodentate complex 8 interestingly displayed very poor activity, indicating that the location of metal coordination is important. The complexes were further tested for their antiplasmodial activity against the chloroquine-resistant K1 strain of P. falciparum. The results of these experiments revealed that, in general, the complexes had decreased activity compared to that in the sensitive strain. The calculated RI values suggest that they likely experience mild cross-resistance, however, not to the same extent of chloroquine. Surprisingly, cationic complex $\mathbf{1 0}$ of the second series exhibited the worst antiplasmodial activity of all the tested complexes in both parasitic strains. A likely reason for this is the inability of this larger complex to permeate the parasitic membrane, although further tests need to be conducted to verify this hypothesis. Furthermore, selected active complexes $(\mathbf{7 a}, \mathbf{7 b}, \mathbf{7 d}, \mathbf{7 e}$ and $\mathbf{7 g})$ were tested against the healthy, mammalian Chinese Hamster Ovarian cell line. These were all found not to be cytotoxic and determined to be more selective towards the parasite than the healthy cells.

An "IC 50 speed assay" was carried out using the three most active complexes, $7 \mathbf{a}, 7 \mathbf{e}$ and $\mathbf{7 g}$, against the chloroquine-sensitive NF54 strain. The cyclometallated complexes 7a and 7e were found to be fast-acting compounds which reach their lowest $I C_{50}$ values within $24 \mathrm{~h}$, while the cationic complex $\mathbf{7 g}$ was determined to be slow-acting, only reaching its lowest $\mathrm{IC}_{50}$ value after $48 \mathrm{~h}$. Since the controls CQ and FQ are fast-acting compounds, it can be assumed from 
these results that the cyclometallated complexes $7 \mathbf{a}$ and $7 \mathrm{7e}$ likely have a similar mode of action to the controls within the parasite, while the slow-acting, cationic complex $7 \mathrm{~g}$ does not. To gain insight into a potential mechanism of action of these compounds, selected ligands and complexes were tested for their ability to inhibit the formation of $\beta$-haematin (the synthetic form of haemozoin), since one of the targets of 7-chloroquinoline-containing compounds is haemozoin. Two organic compounds, $\mathbf{6 a}$ and $\mathbf{6 d}$, a neutral $\operatorname{Ir}(\mathrm{III})$ complex, $\mathbf{7 d}$, and two cationic $\operatorname{Ir}(\mathrm{III})$ complexes, $\mathbf{7 g}$ and $\mathbf{1 0}$, were all found to inhibit the formation of $\beta$-haematin, some to a greater extent than others. All, except complex 10, were less effective $\beta$-haematin inhibitors than chloroquine itself. Complex 10, the aminopropyl-containing cationic complex which displayed the lowest antiplasmodial activity, interestingly exhibited far greater $\beta$-haematin inhibitory activity $\left(I_{50} 9.65 \mu \mathrm{M}\right)$ than chloroquine $\left(I C_{50} 65.3 \mu \mathrm{M}\right)$. The likely reasons for this impressive activity are the combined effects of the secondary amine and aliphatic chain, the 7-chloroquinoline entity and the metal fragment in the structure of the complex, all of which are instrumental in parasitic digestive vacuole accumulation and in the formation of a strong complex with haematin.

Finally, the three most active complexes $7 \mathrm{a}, 7 \mathrm{e}$ and $\mathbf{7 g}$ were evaluated for their ability to facilitate transfer hydrogenation, by reducing $\beta$-nicotinamide adenine dinucleotide $\left(N A D^{+}\right)$to $\mathrm{NADH}$ in the presence of the hydrogen source, sodium formate. Through preliminary ${ }^{1} \mathrm{H}$ NMR experiments and a cell-free assay adapted from the pLDH assay, it was found that neutral complexes $7 a$ and $7 e$ may be capable of acting as transfer hydrogenation catalysts. Conversely, cationic complex $\mathbf{7 g}$ is not an effective transfer hydrogenation catalyst as it showed no regioselective reduction of $\mathrm{NAD}^{+}$to $\mathrm{NADH}$ over $4 \mathrm{~h}$. Although transfer hydrogenation using complex $7 \mathrm{~g}$ as a catalyst may be occurring very slowly, it can be assumed that this complex likely acts with a different mechanism of action which confers excellent antiplasmodial activity within the parasite.

\subsection{Future Outlook}

Based on the results of this study, the 7-chloroquinoline-1,2,3-triazole complexes exhibit promising antiplasmodial activity. Selected complexes also displayed great potential in their ability to catalyse the hydride transfer reduction of $\mathrm{NAD}^{+}$to $\mathrm{NADH}$. Further mechanistic and 
catalytic studies could thus be made in order to gain insight into the mechanism(s) of action of these compounds within the parasite. Several structural modifications could also be made in order to improve the solubility and efficacy of the compounds.

\subsubsection{Further mechanistic studies}

While the compounds tested did display the ability to $\beta$-haematin inhibition, they generally did not have the same inhibitory activity as CQ. This implies that these compounds must have other possible modes of action which confer good antiplasmodial activity. Since the $\beta$-haematin inhibition assay is a cell-free experiment, haem fractionation studies could be performed with these compounds in vitro, thereby determining whether the compounds do indeed inhibit haemozoin formation within the parasite. ${ }^{1}$ The ability of a compound to produce ROS and thus kill by oxidative stress could be determined by incubating the compound with an antioxidant like $N$-acetylcysteine (NAC). ${ }^{2}$ The use of this antioxidant would lower the antiplasmodial activity of the compounds if they work by means of oxidative damage, thus providing insight into whether ROS formation is a possible mode of action. This oxidative stress could also be detected by means of flow cytometry using a fluorescent oxidative stress sensor in combination with a nucleic acid-binding dye to distinguish infected red blood cells. ${ }^{3}$ In order to visualise where these compounds localise within the parasite, a fluorescent tag could be incorporated onto the compound scaffold and could be tracked using confocal microscopy. Finally, in addition to the speed-of-action studies, stage specificity assays could be formed with these compounds to provide information about which stage of the asexual life cycle these compounds target. ${ }^{4}$

\subsubsection{Further catalytic studies}

Since selected compounds exhibited a good ability to catalyse the hydride transfer reduction of $\mathrm{NAD}^{+}$to $\mathrm{NADH}$ in a cell-free environment, the next step would be to determine whether activity holds within the parasite. In vitro tests should be performed with these complexes in the presence of increasing concentrations of sodium formate in both CQS and CQR strains of P. falciparum. ${ }^{5}$ If there is a decrease in parasite viability with increasing formate concentrations, this will indicate that intracellular catalysis is indeed taking place. 
Furthermore, the amount of $\mathrm{NAD}^{+} / \mathrm{NADH}$ can be determined using $\mathrm{NAD}^{+} / \mathrm{NADH}$ ratio test kits and possible cellular localisation tests could also be performed in this regard.

\subsubsection{Structural modifications}

Although the biological results of the compounds indicate promising antiplasmodial activity, this activity was not comparable to that of $\mathrm{CQ}$. In order to extend the activity into the nanomolar range, further modification of the 7-chloroquinoline-1,2,3-triazole compounds needs to be made in order to improve the solubility and efficacy of the compounds. Figure 5.1 below highlights some of these suggested structural modifications.

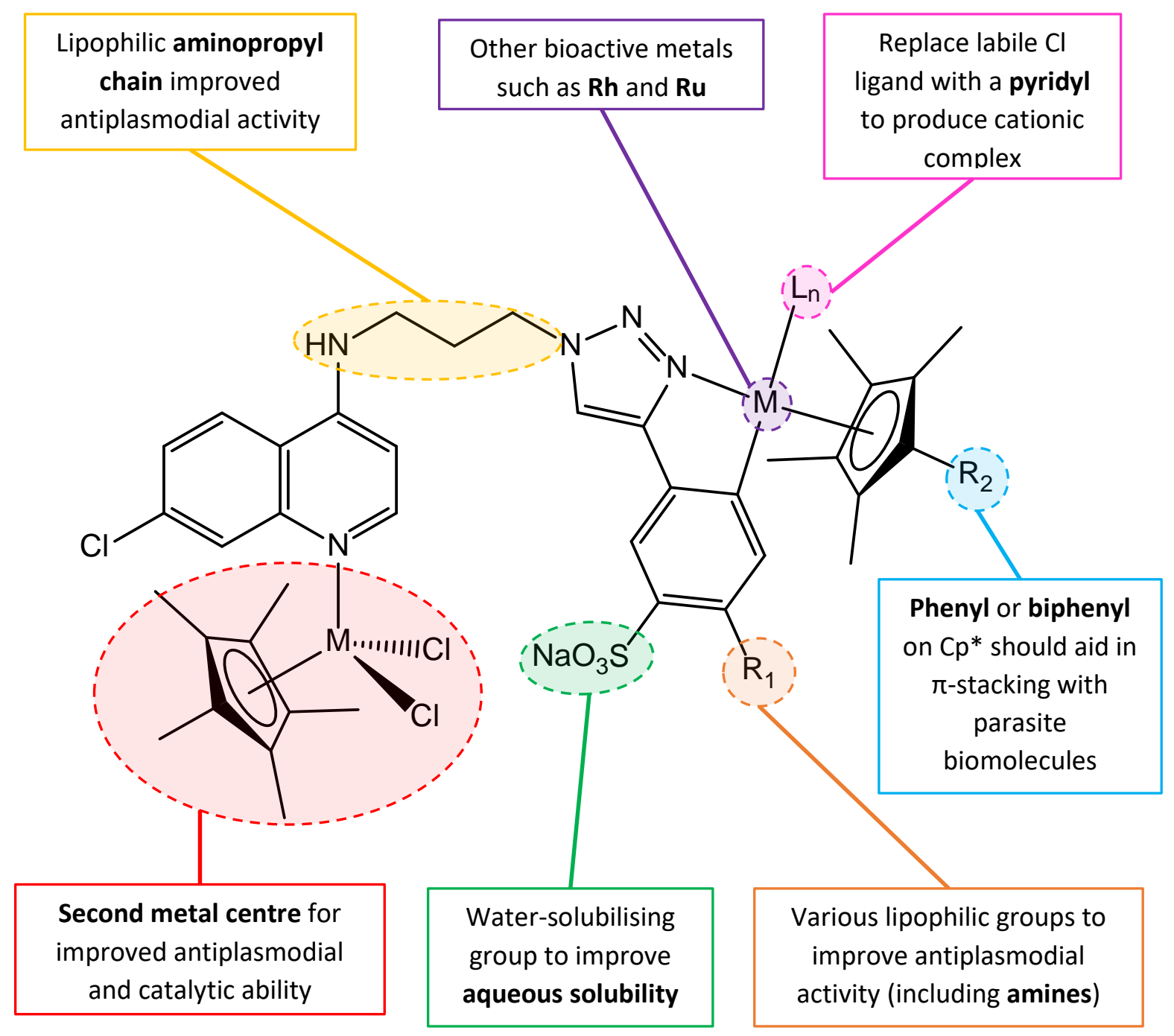

Figure 5.1: Suggested structural modifications for the compounds in this study. 
Due to its ability to inhibit $\beta$-haematin formation, the aminoquinoline motif should still be considered when designing antimalarial compounds. Similarly, the triazole entity should also be kept since it proved useful in acting as an anchor for metal coordination and for introducing aromatic functional groups through simple click chemistry. Owing to the impressive increase in activity upon inclusion of the lipophilic aminopropyl linker, this should also be considered in the design of active drugs. Effort should be made towards the cyclometallation of ligands of this type, as this could improve the antiplasmodial activity into the nanomolar range.

Suggested functional groups on the phenyl ring attached to position- 4 of the triazole include various lipophilic entities as well as groups containing amines, which have been proven to aid in $\mathrm{pH}$ trapping and thus accumulation of the drug within the parasitic digestive vacuole. Since the solubility of the neutral compounds in the water-based biological media was an issue in this study, the inclusion of a group like $\mathrm{NaSO}_{3}{ }^{-}$on this phenyl ring could improve aqueous solubility.

In terms of the metal and its ligands, other bioactive metals such as $\mathrm{Rh}(\mathrm{III})$ and $\mathrm{Ru}$ (II) can be used for complexation, as these metals have shown great efficacy within antimalarial compounds, as well as for transfer hydrogenation catalysis. Since the coordination of the metal to the quinoline nitrogen happened so readily, complexes could be made which include two metal centres - one via cyclometallation and one through quinoline-nitrogen coordination. Since the cationic complex $\mathbf{7 g}$ displayed the best antiplasmodial activity, the labile chloride ligand could be replaced with a pyridyl group to form a cationic complex. Lastly, in order to improve the $\pi$-stacking capability of these complexes and thus their antiplasmodial activity, the $\mathrm{Cp}^{*}$ ligand could be functionalised with a phenyl or biphenyl group as shown in Figure 5.1.

\subsection{References}

1 J. M. Combrinck, K. Y. Fong, L. Gibhard, P. J. Smith, D. W. Wright and T. J. Egan, Malar. J., 2015, 14, 253.

2 P. Arreesrisom, A. M. Dondorp, S. Looareesuwan and R. Udomsangpetch, Parasitol. Int., 2007, 56, 221-226. 
3 Y. Fu, L. Tilley, S. Kenny and N. Klonis, Cytom. A., 2010, 77A, 253-263.

4 G. Subramanian, A. Sadeer, K. Mukherjee, T. Kojima, P. Tripathi, R. Naidu, S. W. Tay, J. H. Pang, S. A. Pullarkat and R. Chandramohanadas, Dalton Trans., 2019, 48, 1108-1117.

5 T. Stringer, D. R. Melis and G. S. Smith, Dalton Trans., 2019, 48, 13143-13148. 


\section{Chapter 6}

\section{Experimental}

\subsection{General Details}

\subsubsection{Chemicals and General Methods}

All reagents and solvents were purchased from commercial sources (Sigma-Aldrich, Merck and KIMIX) and were used without further purification. Iridium(III) trichloride trihydrate was purchased from Heraeus SA. The iridium $\mathrm{Cp}^{*} \operatorname{dimer}[\operatorname{IrCp} *(\mu-\mathrm{Cl}) \mathrm{Cl}]_{2}$ was synthesised following a literature method. ${ }^{1}$ All solvents were of analytical grade, with some dried over molecular sieves. All reactions were carried out under an inert argon atmosphere using standard Schlenk line techniques unless otherwise stated. Reactions were monitored by thin-layer chromatography (TLC) using aluminium-backed Merck precoated silica-gel $60 \mathrm{~F}_{254}$ plates and compounds were visualised by ultraviolet light at $254 \mathrm{~nm}$. Column chromatography was conducted using $60 \AA ̊$ silica gel (70-230 mesh).

\subsubsection{Spectroscopic and Analytical Techniques}

Nuclear magnetic resonance (NMR) spectra were recorded on a Bruker XR600 $\mathrm{MHz}$ spectrometer $\left({ }^{1} \mathrm{H}\right.$ at $599.95 \mathrm{MHz}$ and ${ }^{13} \mathrm{C}\left\{{ }^{1} \mathrm{H}\right\}$ at $\left.151.0 \mathrm{MHz}\right)$, a Bruker Topspin $\mathrm{GmbH}\left({ }^{1} \mathrm{H}\right.$ at 400.22 MHz, ${ }^{13} \mathrm{C}\left\{{ }^{1} \mathrm{H}\right\}$ at $100.65 \mathrm{MHz},{ }^{19} \mathrm{~F}\left\{{ }^{1} \mathrm{H}\right\}$ at $376.58 \mathrm{MHz}$ and ${ }^{31} \mathrm{P}\left\{{ }^{1} \mathrm{H}\right\}$ at $162.01 \mathrm{MHz}$ ) or a Varian Mercury $300\left({ }^{1} \mathrm{H}\right.$ at $\left.300.08 \mathrm{MHz}\right)$ spectrometer. These were equipped with a Bruker Biospin $\mathrm{GmbH}$ casing and sample injector at $30^{\circ} \mathrm{C}$ and tetramethylsilane (TMS) was used as the internal standard.

Infrared (IR) spectroscopy was performed on a Perkin-Elmer Spectrum 100 FT-IR spectrometer using Attenuated Total Reflectance (ATR) with vibrations measured in units of $\mathrm{cm}^{-1}$.

Purity was determined using an analytical Agilant HPLC 1260 equipped with an Agilent infinity diode array detector (DAD) 1260 UV-Vis detector, with an absorption wavelength range of 
$210-640 \mathrm{~nm}$. The compounds were eluted using a mixture of solvent $\mathrm{A}\left(10 \mathrm{mM} \mathrm{NH} \mathrm{H}_{4} \mathrm{OAc} / \mathrm{H}_{2} \mathrm{O}\right)$ and solvent $\mathrm{B}\left(10 \mathrm{mM} \mathrm{NH} \mathrm{m}_{4} \mathrm{OAc} / \mathrm{MeOH}\right)$ at a flow rate of $0.9 \mathrm{~mL} \cdot \mathrm{min}^{-1}$. The gradient elution conditions were as follows: $10 \%$ solvent $B$ between 0 and $1 \mathrm{~min}, 10-95 \%$ solvent $B$ between 1 and $3 \mathrm{~min}, 95 \%$ solvent B between 3 and $5 \mathrm{~min}$. High resolution (HR) electrospray ionisation mass spectrometry (ESI-MS) was performed on a Waters Synapt G2 QTOF mass spectrometer with data recorded using the positive mode.

Melting points were obtained using a Büchi Melting Point Apparatus B-540 and are uncorrected.

\subsection{Synthesis of azide precursor (1)}

\subsubsection{4-Azido-7-chloroquinoline ${ }^{2}$ (1)}<smiles>Nc1ccnc2cc(Cl)ccc12</smiles>

4,7-Dichloroquinoline $(1.00 \mathrm{~g}, 5.05 \mathrm{mmol}$ ) was dissolved in anhydrous DMF (5.00 $\mathrm{mL})$. To this, $\mathrm{NaN}_{3}(0.657 \mathrm{~g}, 10.1 \mathrm{mmol})$ was added in one portion and the resulting mixture was stirred at $65{ }^{\circ} \mathrm{C}$ for $5 \mathrm{~h}$ and then left to stir at room temperature overnight. The completion of the reaction was determined by TLC. Ethyl acetate $(100 \mathrm{~mL})$ was then added and the reaction mixture was filtered to remove excess $\mathrm{NaN}_{3}$. The resulting filtrate was washed with water $(5 \times 30.0 \mathrm{~mL})$ and brine $(3 \times 20.0 \mathrm{~mL})$ and dried over anhydrous $\mathrm{Na}_{2} \mathrm{SO}_{4}$. The solvent was then removed using the rotary evaporator and toluene was used to aid in the evaporation of any excess DMF. The resulting product residue was then recrystallised using minimal DCM and hexane to yield the final product, 1, as pale yellow, needle-like crystals. Yield: $0.723 \mathrm{~g}(70.0 \%)$. ${ }^{1} \mathrm{H}$ NMR (300 MHz, CDCl 3$): \delta(p p m)=8.82(1 \mathrm{H}, \mathrm{d}, J=4.94 \mathrm{~Hz}, \mathrm{H}-2) ; 8.06(1 \mathrm{H}, \mathrm{d}, J=2.03 \mathrm{~Hz}$, $\mathrm{H}-8) ; 8.00(1 \mathrm{H}, \mathrm{d}, J=8.94 \mathrm{~Hz}, \mathrm{H}-5) ; 7.48(1 \mathrm{H}, \mathrm{dd}, J=2.08,8.94 \mathrm{~Hz}, \mathrm{H}-6) ; 7.13(1 \mathrm{H}, \mathrm{d}$, $J=4.94 \mathrm{~Hz}, \mathrm{H}-3) .{ }^{13} \mathrm{C}\left\{{ }^{1} \mathrm{H}\right\}$ NMR (101 MHz, $\left.\mathrm{CDCl}_{3}\right): \delta(\mathrm{ppm})=108.87$ (C-3), $120.17(\mathrm{C}-10), 123.92$ (C-6), 127.76 (C-8), 128.42 (C-5), 136.78 (C-7), 146.56 (C-4), 149.83 (C-9), 151.45 (C-2). 
IR (ATR): $\left(v_{\max } / \mathrm{cm}^{-1}\right) 2124(\mathrm{~N}=\mathrm{N}=\mathrm{N}), 1609(\mathrm{Ar} \mathrm{C}=\mathrm{N})$. Melting point: $118.0-118.8{ }^{\circ} \mathrm{C}$ (lit. $\left.115.0^{\circ} \mathrm{C}\right)$.

\subsection{Synthesis of 7-chloro-4-(1H-1,2,3-triazol-1-yl)quinoline ligands (2a-2h)}

\subsubsection{General method}

4-Azido-7-chloroquinoline (1) and a commercial alkyne were dissolved in either DCM or $t$ - $\mathrm{BuOH}(2.00 \mathrm{~mL})$. A freshly prepared solution of sodium ascorbate (0.6 eq.) and $\mathrm{CuSO}_{4} .5 \mathrm{H}_{2} \mathrm{O}$ (0.3 eq.) in water $(2.00 \mathrm{~mL})$ was then added to the reaction mixture. This was allowed to stir at $30^{\circ} \mathrm{C}$ for $2-72 \mathrm{~h}$ and stopped when the reaction was completed, as shown by TLC analysis. DCM $(30.0 \mathrm{~mL})$ was then added to the reaction mixture, which was then washed with a saturated $\mathrm{NH}_{4} \mathrm{Cl}$ solution $\left(3 \times 30.0 \mathrm{~mL}\right.$ ) to remove $\mathrm{Cu}^{2+}$ ions and subsequently washed with water $(3 \times 30.0 \mathrm{~mL})$. The solution was then dried using anhydrous $\mathrm{Na}_{2} \mathrm{SO}_{4}$, filtered and the solvent was thereafter removed from the filtrate. Purification was achieved via recrystallization from hot $\mathrm{MeOH}$ to yield the pure desired solid product.

\subsubsection{7-Chloro-4-(4-phenyl-1H-1,2,3-triazol-1-yl)quinoline ${ }^{3}$ (2a)}

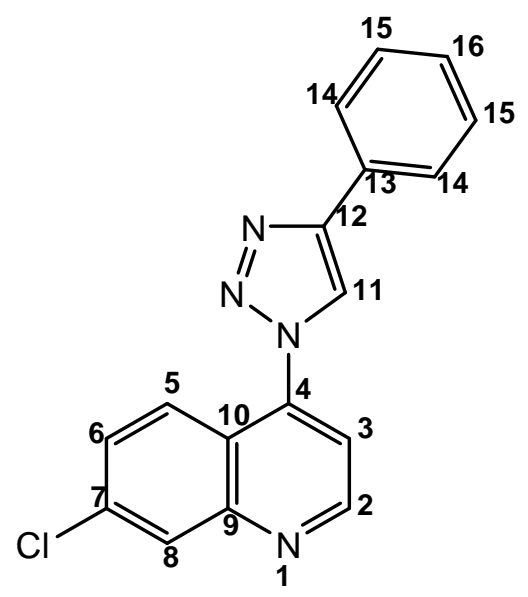

To a solution of $1(0.244 \mathrm{~g}, 1.19 \mathrm{mmol})$ and phenylacetylene $(0.144 \mathrm{~mL}, 1.31 \mathrm{mmol})$ in DCM $(2.00 \mathrm{~mL})$, a solution of sodium ascorbate and $\mathrm{CuSO}_{2} .5 \mathrm{H}_{2} \mathrm{O}$ in water $(2.00 \mathrm{~mL})$ was added and the reaction mixture was left to stir for $2 \mathrm{~h}$ at $30^{\circ} \mathrm{C}$. The product, $2 \mathrm{a}$, was isolated as a white powder. Yield: $0.305 \mathrm{~g}(83.3 \%) .{ }^{1} \mathrm{H}$ NMR $\left(400 \mathrm{MHz}, \mathrm{CDCl}_{3}\right): \delta(\mathrm{ppm})=9.08(1 \mathrm{H}, \mathrm{d}, J=4.62 \mathrm{~Hz}$, $\mathrm{H}-2) ; 8.27(1 \mathrm{H}, \mathrm{d}, J=2.08 \mathrm{~Hz}, \mathrm{H}-8) ; 8.23(1 \mathrm{H}, \mathrm{s}, \mathrm{H}-11) ; 8.07(1 \mathrm{H}, \mathrm{d}, J=9.08 \mathrm{~Hz}, \mathrm{H}-5) ; 7.94-7.97$ 
$(2 \mathrm{H}, \mathrm{m}, \mathrm{H}-14) ; 7.62(1 \mathrm{H}, \mathrm{dd}, J=2.12,9.08 \mathrm{~Hz}, \mathrm{H}-6) ; 7.55(1 \mathrm{H}, \mathrm{d}, J=4.62 \mathrm{~Hz}, \mathrm{H}-3) ; 7.47-7.52(2 \mathrm{H}$, m, H-15); 7.39-7.44 (1H, m, H-16). ${ }^{13} \mathrm{C}\left\{{ }^{1} \mathrm{H}\right\}$ NMR (101 MHz, $\left.\mathrm{CDCl}_{3}\right): \delta(\mathrm{ppm})=151.56(\mathrm{C}-2)$, 150.48 (C-9), 148.76 (C-12), 141.20 (C-7), 137.16 (C-4), 129.75 (C-13), 129.65 (C-6), 129.25 (C-15), 129.23 (C-8), 129.08 (C-16), 126.19 (C-14), 124.82 (C-5), 121.28 (C-11), 120.89 (C-10), 116.10 (C-3). IR (ATR): $\left(v_{\max } / \mathrm{cm}^{-1}\right)$ 1608, 1560 (Ar C=N). Melting point: $156.3-158.7^{\circ} \mathrm{C}$ (lit. $\left.148.5-149.2^{\circ} \mathrm{C}\right)$. Purity: $95.2 \%$ by LC ( $\left.t_{R} 2.59 \mathrm{~min}\right)$.

\subsubsection{7-Chloro-4-(4-p-tolyl-1H-1,2,3-triazol-1-yl)quinoline 3 (2b)}

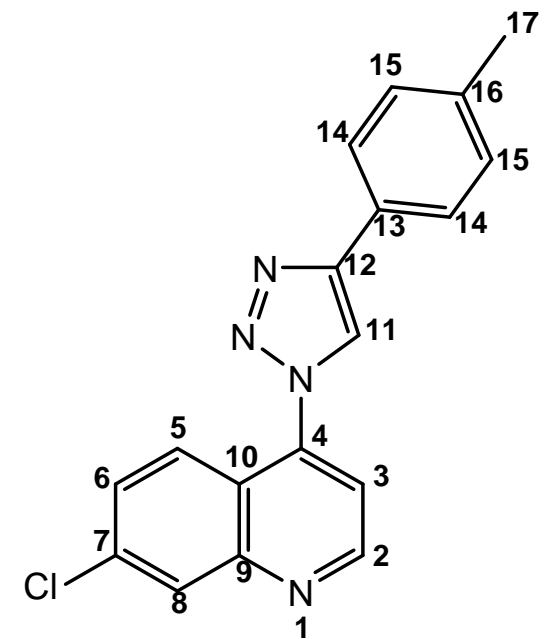

To a solution of $1(0.301 \mathrm{~g}, 1.47 \mathrm{mmol})$ and 4-ethynyltoluene $(0.187 \mathrm{~mL}, 1.47 \mathrm{mmol})$ in DCM $(2.00 \mathrm{~mL})$, a solution of sodium ascorbate and $\mathrm{CuSO}_{2} .5 \mathrm{H}_{2} \mathrm{O}$ in water $(2.00 \mathrm{~mL})$ was added and the reaction mixture was left to stir for $2 \mathrm{~h}$ at $30{ }^{\circ} \mathrm{C}$. The product, $\mathbf{2 b}$, was isolated as paleyellow crystals. Yield: $0.338 \mathrm{~g}(80.0 \%) .{ }^{1} \mathrm{H}$ NMR $\left(400 \mathrm{MHz}, \mathrm{CDCl}_{3}\right): \delta(p p m)=9.07(1 \mathrm{H}, \mathrm{d}$, $J=4.64 \mathrm{~Hz}, \mathrm{H}-2) ; 8.26(1 \mathrm{H}, \mathrm{d}, J=2.05 \mathrm{~Hz}, \mathrm{H}-8) ; 8.19(1 \mathrm{H}, \mathrm{s}, \mathrm{H}-11) ; 8.08(1 \mathrm{H}, \mathrm{d}, J=9.08 \mathrm{~Hz}$, $\mathrm{H}-5) ; 7.83(2 \mathrm{H}, \mathrm{d}, J=8.14 \mathrm{~Hz}, \mathrm{H}-14) ; 7.61(1 \mathrm{H}, \mathrm{dd}, J=2.11,9.09 \mathrm{~Hz}, \mathrm{H}-6) ; 7.55(1 \mathrm{H}, \mathrm{d}, J=4.64$ $\mathrm{Hz}, \mathrm{H}-3) ; 7.30(2 \mathrm{H}, \mathrm{d}, J=7.91 \mathrm{~Hz}, \mathrm{H}-15) ; 2.42\left(3 \mathrm{H}, \mathrm{s}, \mathrm{H}-17 .{ }^{13} \mathrm{C}\left\{{ }^{1} \mathrm{H}\right\}\right.$ NMR (101 MHz, CDCl 3 ): $\delta(\mathrm{ppm})=151.38(\mathrm{C}-2), 150.31$ (C-9), 148.68 (C-12), 141.08 (C-7), 138. 90 (C-13), 136.97 (C-4), 129.76 (C-15), 129.44 (C-6), 129.02 (C-8), 126.75 (C-16), 125.93 (C-14), 124.73 (C-5), 120.74 (C-11), 115.89 (C-3), 21.32 (C-17). IR (ATR): $\left(v_{\max } / \mathrm{cm}^{-1}\right)$ 2915, 2858, 1612, 1595, 1559 (Ar C=N). Melting point: $168.1-169.4^{\circ} \mathrm{C}$ (lit. $163.9-165.7^{\circ} \mathrm{C}$ ). Purity: $95.7 \%$ by LC ( $\mathrm{t}_{\mathrm{R}} 2.66 \mathrm{~min}$ ). 


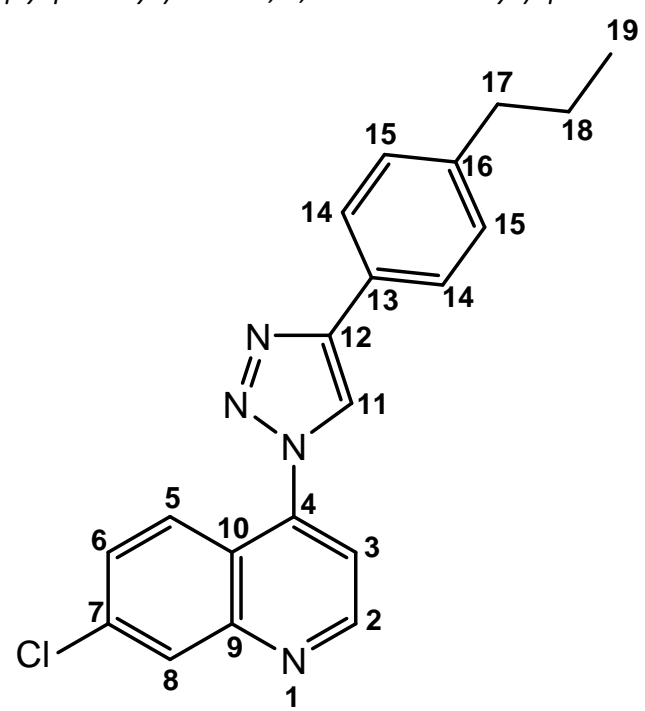

To a solution of $1(0.200 \mathrm{~g}, 0.977 \mathrm{mmol})$ and 1-eth-1-ynyl-4-propylbenzene (0.155 mL, 0.977 $\mathrm{mmol})$ in DCM $(2.00 \mathrm{~mL})$, a solution of sodium ascorbate and $\mathrm{CuSO}_{2} .5 \mathrm{H}_{2} \mathrm{O}$ in water $(2.00 \mathrm{~mL})$ was added and the reaction mixture was left to stir for $19 \mathrm{~h}$ at $30^{\circ} \mathrm{C}$. The product, $2 \mathrm{c}$, was isolated as beige crystals. Yield: $0.0805 \mathrm{~g},(23.4 \%) .{ }^{1} \mathrm{H}$ NMR $\left(400 \mathrm{MHz}, \mathrm{CDCl}_{3}\right): \delta(p p m)=9.09$ $(1 \mathrm{H}, \mathrm{br} d, J=5.71 \mathrm{~Hz}, \mathrm{H}-2) ; 8.26(1 \mathrm{H}, \mathrm{d}, J=1.90 \mathrm{~Hz}, \mathrm{H}-8) ; 8.20(1 \mathrm{H}, \mathrm{s}, \mathrm{H}-11) ; 8.08(1 \mathrm{H}, \mathrm{d}$, $J=9.08 \mathrm{~Hz}, \mathrm{H}-5) ; 7.86(2 \mathrm{H}, \mathrm{d}, J=8.21 \mathrm{~Hz}, \mathrm{H}-14) ; 7.61(1 \mathrm{H}, \mathrm{dd}, J=1.98,9.09 \mathrm{~Hz}, \mathrm{H}-6) ; 7.56(1 \mathrm{H}$, $\mathrm{d}, J=4.51 \mathrm{~Hz}, \mathrm{H}-3) ; 7.31(2 \mathrm{H}, \mathrm{d}, J=8.24 \mathrm{~Hz}, \mathrm{H}-15) ; 2.66(2 \mathrm{H}, \mathrm{t}, \mathrm{H}-17) ; 1.76-1.64(2 \mathrm{H}, \mathrm{m}, \mathrm{H}-18)$; $0.98(3 \mathrm{H}, \mathrm{t}, \mathrm{H}-19) ;{ }^{13} \mathrm{C}\left\{{ }^{1} \mathrm{H}\right\}$ NMR (101 MHz, CDCl 3$): \delta(\mathrm{ppm})=151.55$ (C-2), 150.65 (C-9), 148.94 (C-12),143.88 (C-7), 141.18 (C-13), 137.09 (C-4), 129.61 (C-6), 129.35 (C-8,15), 127.12 (C-16), 126.09 (C-14), 124.90 (C-5), 120.93 (C-10), 120.85 (C-11), 116.56 (C-3), 38.02 (C-17), 24.56 (C-18), 13.91 (C-19). IR (ATR): $\left(v_{\max } / \mathrm{cm}^{-1}\right)$ 2961, 2930, 2859, 1609, 1595, 1559 (Ar C=N). Melting point: $138.5-139.5^{\circ} \mathrm{C}$. Purity: $99.3 \%$ by LC ( $\left.t_{R} 2.78 \mathrm{~min}\right)$. 


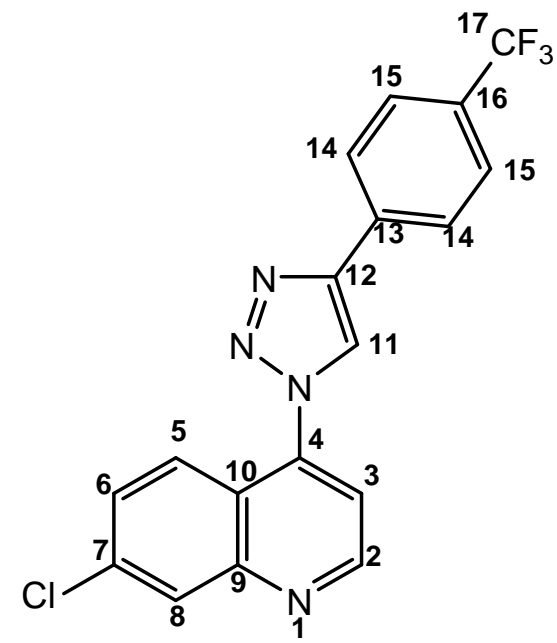

To a solution of $1(0.200 \mathrm{~g}, 0.977 \mathrm{mmol})$ and 1-ethynyl-4-(trifluoromethyl)benzene $(0.206 \mathrm{~mL}$, $1.46 \mathrm{mmol})$ in $\mathrm{DCM}(2.00 \mathrm{~mL})$, a solution of sodium ascorbate and $\mathrm{CuSO}_{2} .5 \mathrm{H}_{2} \mathrm{O}$ in water $(2.00 \mathrm{~mL})$ was added and the reaction mixture was left to stir for $20 \mathrm{~h}$ at $30^{\circ} \mathrm{C}$. The product, 2d, was isolated as a yellow crystalline solid. Yield: $0.235 \mathrm{~g}(64.2 \%) .{ }^{1} \mathrm{H}$ NMR (400 MHz, $\left.\mathrm{CDCl}_{3}\right)$ : $\delta(\mathrm{ppm})=9.09(1 \mathrm{H}, \mathrm{d}, J=4.10 \mathrm{~Hz}, \mathrm{H}-2) ; 8.32(1 \mathrm{H}, \mathrm{s}, \mathrm{H}-11) ; 8.27(1 \mathrm{H}, \mathrm{d}, J=1.98 \mathrm{~Hz}, \mathrm{H}-8) ; 8.07$ $(2 \mathrm{H}, \mathrm{d}, J=8.05 \mathrm{~Hz}, \mathrm{H}-14) ; 8.03(1 \mathrm{H}, \mathrm{d}, J=9.08 \mathrm{~Hz}, \mathrm{H}-5) ; 7.75(2 \mathrm{H}, \mathrm{d}, J=8.19 \mathrm{~Hz}, \mathrm{H}-15) ; 7.62$ $(1 \mathrm{H}, \mathrm{dd}, J=2.02,9.08 \mathrm{~Hz}, \mathrm{H}-6) ; 7.56(1 \mathrm{H}, \mathrm{d}, J=4.60 \mathrm{~Hz}, \mathrm{H}-3) .{ }^{13} \mathrm{C}\left\{{ }^{1} \mathrm{H}\right\} \mathrm{NMR}\left(101 \mathrm{MHz}, \mathrm{CDCl}_{3}\right)$ : $\delta(\mathrm{ppm})=151.54$ (C-2), 150.49 (C-9), 147.36 (C-12), 140.95 (C-7), 137.29 (C-13), 133.20 (C-4), $131.00\left(q,{ }^{2} J_{C-F}=32.7 \mathrm{~Hz}, \mathrm{C}-16\right), 129.80$ (C-6), 129.31 (C-8), 126.36 (C-14), 126.11 (br q, $\left.{ }^{3} J_{C-F}=3.6 \mathrm{~Hz}, \mathrm{C}-15\right), 124.60(\mathrm{C}-5), 124.33\left(q,{ }^{1} J_{\mathrm{C}-\mathrm{F}}=272.1 \mathrm{~Hz}, \mathrm{C}-17\right), 122.10$ (C-11), 116.18 (C-3). ${ }^{19} \mathrm{~F}\left\{{ }^{1} \mathrm{H}\right\}$ NMR (377 MHz, $\left.\mathrm{CDCl}_{3}\right): \delta(\mathrm{ppm})=-62.73$ (s). IR (ATR): $\left(v_{\max } / \mathrm{cm}^{-1}\right)$ 1623, 1610, 1592, 1560 (Ar C=N), 1324 (C-F stretch). Melting point: $181.3-182.7^{\circ} \mathrm{C}$. Purity: $99.2 \%$ by LC $\left(t_{R} 2.72 \mathrm{~min}\right)$. 


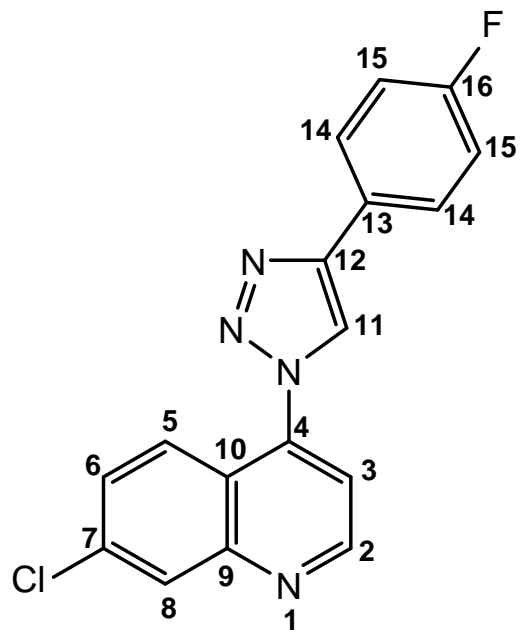

To a solution of $1(0.300 \mathrm{~g}, 1.47 \mathrm{mmol})$ and 1-ethynyl-4-fluorobenzene $(0.283 \mathrm{~mL}, 2.36 \mathrm{mmol})$ in DCM $(2.00 \mathrm{~mL})$, a solution of sodium ascorbate and $\mathrm{CuSO}_{2} .5 \mathrm{H}_{2} \mathrm{O}$ in water $(2.00 \mathrm{~mL})$ was added and the reaction mixture was left to stir for $15 \mathrm{~h}$ at $30^{\circ} \mathrm{C}$. The product, $2 \mathrm{e}$, was isolated as a bright yellow powder. Yield: $0.296 \mathrm{~g}(62.3 \%) .{ }^{1} \mathrm{H}$ NMR (400 MHz, $\left.\mathrm{CDCl}_{3}\right): \delta(\mathrm{ppm})=9.10$ $(1 \mathrm{H}, \mathrm{br} d, J=4.36 \mathrm{~Hz}, \mathrm{H}-2) ; 8.27(1 \mathrm{H}, \mathrm{d}, J=2.05 \mathrm{~Hz}, \mathrm{H}-8) ; 8.19(1 \mathrm{H}, \mathrm{s}, \mathrm{H}-11) ; 8.06(1 \mathrm{H}, \mathrm{d}$, $J=9.08 \mathrm{~Hz}, \mathrm{H}-5) ; 7.96-7.91(2 \mathrm{H}, \mathrm{m}, \mathrm{H}-14) ; 7.62(1 \mathrm{H}, \mathrm{dd}, J=2.08,9.08 \mathrm{~Hz}, \mathrm{H}-6) ; 7.55(1 \mathrm{H}, \mathrm{d}$, $J=4.60 \mathrm{~Hz}, \mathrm{H}-3) ; 7.26-7.30(2 \mathrm{H}, \mathrm{m}, \mathrm{H}-15) ;{ }^{13} \mathrm{C}\left\{{ }^{1} \mathrm{H}\right\}$ NMR $\left(101 \mathrm{MHz}, \mathrm{CDCl}_{3}\right): \delta(p p m)=163.14$ (d, ${ }^{1} J_{C-F}=248.7 \mathrm{~Hz}, C-16$ ) , 151.53 (C-2), 150.51 (C-9), 147.90 (C-12), 141.12 (C-7), 137.21 (C-4), 129.70 (C-6), 129.27 (C-8), $127.83\left(\mathrm{~d},{ }^{3} J_{C-F}=8.23 \mathrm{~Hz}, \mathrm{C}-14\right), 125.82\left(\mathrm{~d},{ }^{4} J_{C-F}=2.88 \mathrm{~Hz}\right.$, C-13), 124.75 (C-5), 121.03 (C-11), 120.88 (C-10), 116.33 (d, ${ }^{2} J_{C-F}=21.91 \mathrm{~Hz}, C-15$ ), 116.11 (C-3); ${ }^{19} \mathrm{~F}\left\{{ }^{1} \mathrm{H}\right\}$ NMR (377 MHz, $\left.\mathrm{CDCl}_{3}\right): \delta$ (ppm) $=-112.20$ (s). IR (ATR): $\left(v_{\mathrm{max}} / \mathrm{cm}^{-1}\right)$ 1609, 1592, 1561 (Ar C=N). Melting point: $173.4-175.0^{\circ} \mathrm{C}$ (lit. $\left.165.1-168.5^{\circ} \mathrm{C}\right)$. Purity: $99.2 \%$ by LC $\left(t_{R} 2.62\right.$ $\min$ ). 


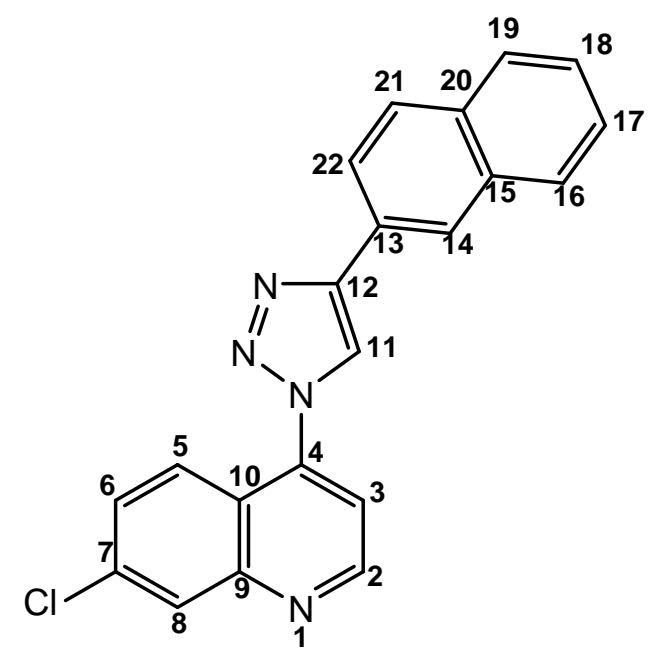

To a solution of $1(0.200 \mathrm{~g}, 0.977 \mathrm{mmol})$ and 2-ethynylnaphthalene $(0.149 \mathrm{~g}, 0.977 \mathrm{mmol})$ in $\operatorname{DCM}(2.00 \mathrm{~mL})$, a solution of sodium ascorbate and $\mathrm{CuSO}_{2} .5 \mathrm{H}_{2} \mathrm{O}$ in water $(2.00 \mathrm{~mL})$ was added and the reaction mixture was left to stir for $3 \mathrm{~h}$ at $30^{\circ} \mathrm{C}$. The product, $\mathbf{2 f}$, was isolated as a beige powder. Yield: $0.273 \mathrm{~g}(78.3 \%) .{ }^{1} \mathrm{H}$ NMR (400 $\left.\mathrm{MHz} \mathrm{CDCl}_{3}\right): \delta(\mathrm{ppm})=9.12(1 \mathrm{H}, \mathrm{br}$, $J=2.85 \mathrm{~Hz}, \mathrm{H}-2) ; 8.48(1 \mathrm{H}, \mathrm{d}, J=0.63 \mathrm{~Hz}, \mathrm{H}-14) ; 8.34(1 \mathrm{H}, \mathrm{s}, \mathrm{H}-11) ; 8.28(1 \mathrm{H}, \mathrm{d}, J=1.92 \mathrm{~Hz}$, $\mathrm{H}-8)$; $8.11(1 \mathrm{H}, \mathrm{d}, J=9.08 \mathrm{~Hz}, \mathrm{H}-5)$; $8.03(1 \mathrm{H}, \mathrm{dd}, J=1.69,8.51 \mathrm{~Hz}, \mathrm{H}-22) ; 7.97(1 \mathrm{H}, \mathrm{s}, \mathrm{H}-21)$; $7.88(1 \mathrm{H}, \mathrm{m}, \mathrm{H}-19) ; 7.88(1 \mathrm{H}, \mathrm{m}, \mathrm{H}-16) ; 7.63(1 \mathrm{H}, \mathrm{dd}, J=1.98,9.09 \mathrm{~Hz}, \mathrm{H}-6) ; 7.59(1 \mathrm{H}, \mathrm{d}$, $J=4.56 \mathrm{~Hz}, \mathrm{H}-3) ; 7.57-7.50(2 \mathrm{H}, \mathrm{m}, \mathrm{H}-17,18) .{ }^{13} \mathrm{C}\left\{{ }^{1} \mathrm{H}\right\}$ NMR $\left(101 \mathrm{MHz}, \mathrm{CDCl}_{3}\right): \delta(\mathrm{ppm})=151.48$ (C-2), 150.38 (C-9), 147.36 (C-12), 141.02 (C-7), 137.02 (C-13), 133.56 (C-4), 133.52 (C-20), 130.80 (C-10), 129.69 (C-6), 129.28 (C-5), 129.09 (C-21), 128.47 (C-19), 128.03 (C-16), 127.04 (C-15), 126.90 (C-17), 126.76 (C-18), 125.24 (C-14), 124.85 (C-5), 123.91 (C-22), 121.55 (C-11), 116.20 (C-3). IR (ATR): $\left(v_{\max } / \mathrm{cm}^{-1}\right)$ 1613, 1592, 1558 (Ar C=N). Melting point: 189.5-191.4 ${ }^{\circ} \mathrm{C}$. Purity: $99.1 \%$ by LC ( $\left.t_{R} 2.74 \mathrm{~min}\right)$. 


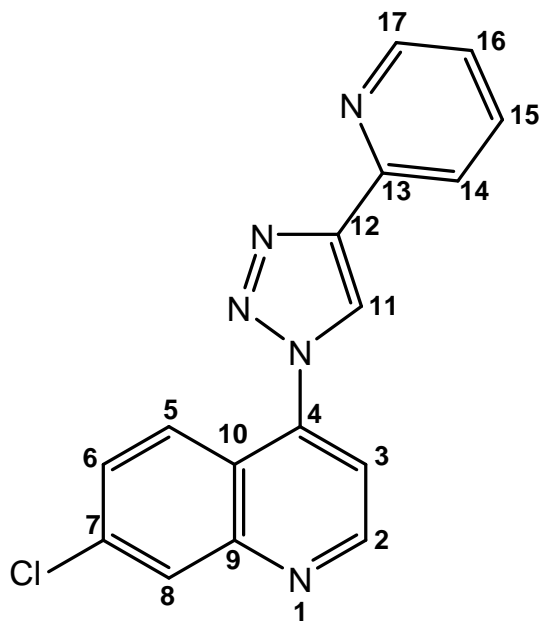

To a solution of $1(0.200 \mathrm{~g}, 0.977 \mathrm{mmol})$ and 2-ethynylpyridine $(0.109 \mathrm{~mL}, 1.08 \mathrm{mmol})$ in $t$ - $\mathrm{BuOH}(2.00 \mathrm{~mL})$, a solution of sodium ascorbate and $\mathrm{CuSO}_{2} .5 \mathrm{H}_{2} \mathrm{O}$ in water $(2.00 \mathrm{~mL})$ was added and the reaction mixture was left to stir for $3 \mathrm{~d}$ at $45^{\circ} \mathrm{C}$. The product, $2 \mathrm{~g}$, was isolated as a grey powder. Yield: $0.128 \mathrm{~g}(42.5 \%) .{ }^{1} \mathrm{H}$ NMR (400 MHz, DMSO- $\left.\boldsymbol{d}_{6}\right): \delta(\mathrm{ppm})=9.29(1 \mathrm{H}$, s, H-11); $9.18(1 \mathrm{H}, \mathrm{d}, J=4.66 \mathrm{~Hz}, \mathrm{H}-2)$; $8.69-8.67(1 \mathrm{H}, \mathrm{m}, \mathrm{H}-17) ; 8.30(1 \mathrm{H}, \mathrm{d}, J=2.06 \mathrm{~Hz}, \mathrm{H}-8)$; $8.19(1 \mathrm{H}, \mathrm{dt}, J=1.08,1.08,7.91 \mathrm{~Hz}, \mathrm{H}-14) ; 8.09(1 \mathrm{H}, \mathrm{d}, J=9.11 \mathrm{~Hz}, \mathrm{H}-5) ; 8.00(1 \mathrm{H}, \mathrm{td}, J=1.81$, 7.83, $7.87 \mathrm{~Hz}, \mathrm{H}-15) ; 7.96(1 \mathrm{H}, \mathrm{d}, J=4.62 \mathrm{~Hz}, \mathrm{H}-3) ; 7.80(1 \mathrm{H}, \mathrm{dd}, J=2.20,9.10 \mathrm{~Hz}, \mathrm{H}-6) ; 7.44$ $(1 \mathrm{H}, \mathrm{ddd}, J=1.19,4.82,7.57 \mathrm{~Hz}, \mathrm{H}-16) .{ }^{13} \mathrm{C}\left\{{ }^{1} \mathrm{H}\right\}$ NMR $\left(101 \mathrm{MHz}, \mathrm{CDCl}_{3}\right): \delta(p p m)=152.28$ (C-2), 149.73 (C-17), 149.34 (C-13), 149.12 (C-10), 147.86 (C-12), 140.33 (C-8), 137.34 (C-15), 135.33 (C-4), 128.94 (C-7), 128.03 (C-9), 125.48 (C-6), 125.34 (C-11), 123.47 (C-16), 120.36 (C-5), 119.95 (C-14), 117.19 (C-3). IR (ATR): $\left(v_{\mathrm{max}} / \mathrm{cm}^{-1}\right) 1606(\mathrm{C}=\mathrm{N})_{\text {pyridyl, }} 1567$ (C=N) quinoline. Melting point: $153.8-155.1^{\circ} \mathrm{C}$. Purity: $98.7 \%$ by $L C\left(t_{R} 2.51 \mathrm{~min}\right)$. 


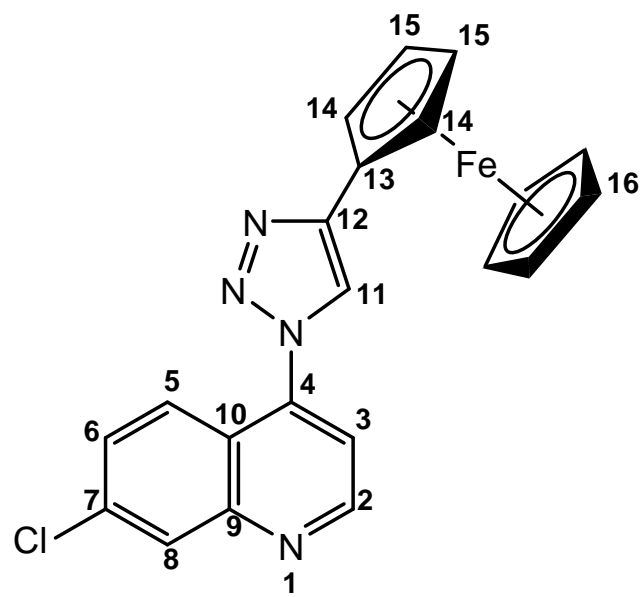

To a solution of $1(0.100 \mathrm{~g}, 0.489 \mathrm{mmol})$ and ethynylferrocene $(0.103 \mathrm{~g}, 0.489 \mathrm{mmol})$ in DCM $(2.00 \mathrm{~mL})$, a solution of sodium ascorbate and $\mathrm{CuSO}_{2} .5 \mathrm{H}_{2} \mathrm{O}$ in water $(2.00 \mathrm{~mL})$ was added and the reaction mixture was left to stir for $20 \mathrm{~h}$ at $30{ }^{\circ} \mathrm{C}$. The product, $\mathbf{2 h}$, was isolated as an orange powder. Yield: $0.142 \mathrm{~g}(70.2 \%) .{ }^{1} \mathbf{H}$ NMR (400 MHz, $\left.\mathrm{CDCl}_{3}\right): \delta(\mathrm{ppm})=9.07(1 \mathrm{H}, \mathrm{d}$, $J=2.04 \mathrm{~Hz}, \mathrm{H}-2) ; 8.25(1 \mathrm{H}, \mathrm{d}, J=1.51 \mathrm{~Hz}, \mathrm{H}-8) ; 8.09(1 \mathrm{H}, \mathrm{d}, J=9.00 \mathrm{~Hz}, \mathrm{H}-5) ; 7.89(1 \mathrm{H}, \mathrm{s}$, $\mathrm{H}-11) ; 7.62(1 \mathrm{H}, \mathrm{dd}, J=1.40,8.92 \mathrm{~Hz}, \mathrm{H}-6) ; 7.53(1 \mathrm{H}, \mathrm{d}, J=2.81 \mathrm{~Hz}, \mathrm{H}-3)$; $4.83(2 \mathrm{H}, \mathrm{br} \mathrm{s}, \mathrm{H}-14)$; $4.40\left(2 \mathrm{H}\right.$, br s, H-15); $4.16(5 \mathrm{H}, \mathrm{s}, \mathrm{H}-16) .{ }^{13} \mathrm{C}\left\{{ }^{1} \mathrm{H}\right\}$ NMR (101 MHz, $\left.\mathrm{CDCl}_{3}\right): \delta(p p m)=151.57$ (C-2), 150.51 (C-9), 148.26 (C-12), 141.12 (C-7), 137.06 (d, C-4, C-13), 129.57 (C-6), 128.96 (C-8), 124.79 (C-5), 120.60 (C-10), 120.16 (C-11), 115.70 (C-3), 71.45-70.98 (m, C-16), 70.61-70.20 (m, C-15), 68.26-67.92 (m, C-14). IR (ATR): $\left(v_{\max } / \mathrm{cm}^{-1}\right)$ 1611, 1591, 1558 (Ar C=N). Melting point: $203.0-204.6^{\circ} \mathrm{C}$. MS (HR-ESI, $\left.\mathrm{m} / \mathrm{z}\right)$ : $414.0333\left(60 \%,[\mathrm{M}]^{+}\right)$, calculated 414.0335.

\subsection{Synthesis of 7-chloro-4-aminoquinoline precursors (3-5)}

\subsubsection{3-((7-Chloroquinolin-4-yl)amino)propan-1-ol ${ }^{4}$ (3)}<smiles>OCCCNc1ccnc2cc(Cl)ccc12</smiles>

A mixture of 4,7-dichloroquinoline $(3.00 \mathrm{~g}, 15.2 \mathrm{mmol})$ and 2-aminopropan-1-ol $(8.20 \mathrm{~mL}$, $106 \mathrm{mmol}$ ) was heated slowly without stirring at $80^{\circ} \mathrm{C}$ for 1 hour until all the solid had melted. 
The resulting solution was then refluxed at $130{ }^{\circ} \mathrm{C}$ for $17 \mathrm{~h}$ with stirring until completion of the reaction, as determined by TLC analysis. Once the reaction mixture was cooled to room temperature, it was transferred to ice-cold water $(50 \mathrm{~mL})$ and stirred for 10 minutes, resulting in the precipitation of the product. This was recovered by filtration, washed with cold water and dried, yielding 3 as a beige powder. Yield: $3.51 \mathrm{~g}(97.8 \%) .{ }^{1} \mathbf{H}$ NMR (400 MHz, DMSO-d $\boldsymbol{d}_{6}$ ): $\delta(p p m)=8.39(1 \mathrm{H}, \mathrm{d}, J=5.40 \mathrm{~Hz}, \mathrm{H}-2) ; 8.24(1 \mathrm{H}, \mathrm{d}, J=9.04 \mathrm{~Hz}, \mathrm{H}-5) ; 7.77(1 \mathrm{H}, \mathrm{d}, J=2.22 \mathrm{~Hz}$, $\mathrm{H}-8) ; 7.43(1 \mathrm{H}, \mathrm{dd}, J=2.26,8.98 \mathrm{~Hz}, \mathrm{H}-6) ; 7.26(1 \mathrm{H}, \mathrm{br} \mathrm{t}, J=5.13 \mathrm{~Hz}, \mathrm{H}-11) ; 6.47(1 \mathrm{H}, \mathrm{d}$, $J=5.46 \mathrm{~Hz}, \mathrm{H}-3)$; $4.57(1 \mathrm{H}, \mathrm{br} \mathrm{s}, \mathrm{H}-15) ; 3.55(2 \mathrm{H}, \mathrm{t}, \mathrm{J}=4.57 \mathrm{~Hz}, \mathrm{H}-12) ; 3.36-3.31(2 \mathrm{H}, \mathrm{m}, \mathrm{H}-14)$; $1.82(2 \mathrm{H}, \mathrm{p}, \mathrm{H}-13) .{ }^{13} \mathrm{C}\left\{{ }^{1} \mathrm{H}\right\}$ NMR (101 MHz, DMSO-d $): \delta(\mathrm{ppm})=151.85$ (C-2), 150.09 (C-4), 149.03 (C-9), 133.26 (C-7), 127.43 (C-8), 123.92 (C-6), 123.90 (C-5), 117.41 (C-10), 98.54 (C-3), 58.56 (C-14), 40.07 (C-12), 31.03 (C-13). IR (ATR): $\left(v_{\max } / \mathrm{cm}^{-1}\right) 3479(\mathrm{O}-\mathrm{H}), 3308\left(2^{\circ} \mathrm{N}-\mathrm{H}\right), 2967$, $2883,1697,1586$ (Ar C=N). Melting point: $151.0-152.7^{\circ} \mathrm{C}$ (lit. $130.0-133.0^{\circ} \mathrm{C}$ ).

\subsubsection{3-((7-Chloroquinolin-4-yl)amino)propyl methanesulfonate ${ }^{4}$ (4)}

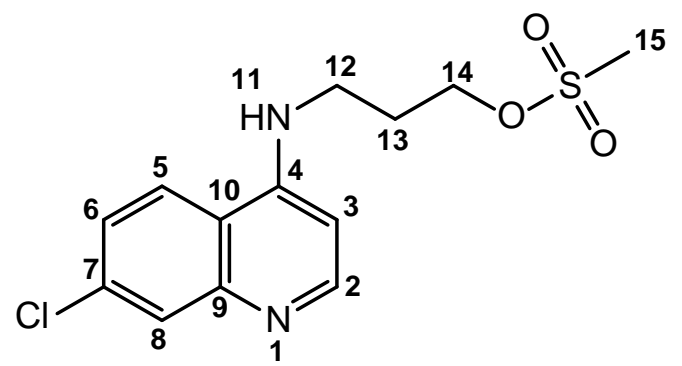

To a solution of $3(0.500 \mathrm{~g}, 2.11 \mathrm{mmol})$ in dry THF $(15.0 \mathrm{~mL})$ under argon, $\mathrm{Et}_{3} \mathrm{~N}(0.890 \mathrm{~mL}$, $6.34 \mathrm{mmol}$ ) was added and the reaction vessel was placed into an ice bath and cooled to $0{ }^{\circ} \mathrm{C}$. Methanesulfonyl chloride $(0.250 \mathrm{~mL}, 3.17 \mathrm{mmol})$ was then added to the cold reaction mixture and this was allowed to stir overnight, allowing the temperature to increase to room temperature. A saturated $\mathrm{NaHCO}_{3}$ solution $(20.0 \mathrm{~mL})$ was then added to the reaction mixture to quench unreacted $\mathrm{MsCl}$ and the THF was removed using a rotary evaporator. The aqueous layer was then extracted using $\mathrm{Et}_{2} \mathrm{O}(12 \times 50.0 \mathrm{~mL})$ until TLC analysis showed no more product in the organic layer. The solvent was then removed, yielding 4 as a beige solid. Yield: $0.285 \mathrm{~g}$ (42.9\%). ${ }^{1} \mathrm{H}$ NMR (400 MHz, DMSO-d $\left.d_{6}\right): \delta(p p m)=8.42(1 \mathrm{H}, \mathrm{d}, J=5.40 \mathrm{~Hz}, \mathrm{H}-2) ; 8.26(1 \mathrm{H}, \mathrm{d}$, $J=9.03 \mathrm{~Hz}, \mathrm{H}-5) ; 7.79(1 \mathrm{H}, \mathrm{d}, J=2.12 \mathrm{~Hz}, \mathrm{H}-8) ; 7.46(1 \mathrm{H}, \mathrm{dd}, J=2.04,8.97 \mathrm{~Hz}, \mathrm{H}-6) ; 7.33(1 \mathrm{H}$, brt $J=5.03 \mathrm{~Hz}, \mathrm{H}-11) ; 6.51(1 \mathrm{H}, \mathrm{d}, J=5.45 \mathrm{~Hz}, \mathrm{H}-3) ; 4.35(2 \mathrm{H}, \mathrm{t}, J=6.21 \mathrm{~Hz}, \mathrm{H}-12) ; 3.48-3.27$ 
(2H, m, H-14); 3.18 (3H, s, H-15); 2.08 (2H, p, H-13). ${ }^{13} \mathrm{C}\left\{{ }^{1} \mathrm{H}\right\}$ NMR (101 MHz, DMSO-d 6 ): $\delta(\mathrm{ppm})=151.38$ (C-2), 150.32 (C-4), 148.36 (C-9), 133.69 (C-7), 126.95 (C-8), 124.27 (C-6), 124.10 (C-5), 117.34 (C-10), 98.73 (C-3), 68.30 (C-14), 39.26 (C-12), 36.63 (C-15), 27.51 (C-13). IR (ATR): $\left(v_{\max } / \mathrm{cm}^{-1}\right) 3231\left(2^{\circ} \mathrm{N}-\mathrm{H}\right), 2968,2923,2851,1609,1574$ (Ar C=N). Melting point: $125.8-127.4^{\circ} \mathrm{C}$ (lit. $124.0-126.0^{\circ} \mathrm{C}$ ).

\subsubsection{N-(3-Azidopropyl)-7-chloroquinolin-4-amine ${ }^{4}$ (5)}

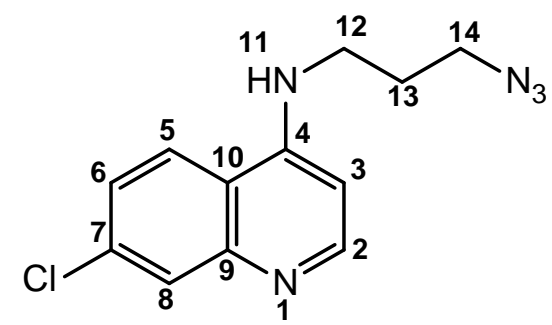

Compound 4 (0.285 g, $1.06 \mathrm{mmol})$ was dissolved in anhydrous DMF $(5.00 \mathrm{~mL})$. To this, $\mathrm{NaN}_{3}$ $\left(0.139 \mathrm{~g}, 2.13 \mathrm{mmol}\right.$ ) was added in one portion and the resulting mixture was stirred at $65{ }^{\circ} \mathrm{C}$ for $15 \mathrm{~h}$. The completion of the reaction was determined by TLC. Ethyl acetate $(100 \mathrm{~mL})$ was then added and the reaction mixture was filtered to remove excess $\mathrm{NaN}_{3}$. The resulting filtrate was washed with water $(5 \times 30 \mathrm{~mL})$ and brine $(3 \times 20 \mathrm{~mL})$ and dried over anhydrous $\mathrm{Na}_{2} \mathrm{SO}_{4}$. The solvent was then removed using the rotary evaporator and the resulting product residue was then recrystallised using minimal DCM and cold hexane to yield the final product, 5, as a fluffy, white powder. Yield: $0.152 \mathrm{~g}(45.2 \%) .{ }^{1} \mathrm{H}$ NMR (400 MHz, DMSO- $\left.\boldsymbol{d}_{6}\right): \delta(\mathrm{ppm})=8.41$ $(1 \mathrm{H}, \mathrm{d}, J=5.40 \mathrm{~Hz}, \mathrm{H}-2) ; 8.26(1 \mathrm{H}, \mathrm{d}, J=9.05 \mathrm{~Hz}, \mathrm{H}-5) ; 7.79(1 \mathrm{H}, \mathrm{d}, J=2.23 \mathrm{~Hz}, \mathrm{H}-8) ; 7.45(1 \mathrm{H}$, $\mathrm{dd}, J=2.19,8.99 \mathrm{~Hz}, \mathrm{H}-6) ; 7.29(1 \mathrm{H}, \mathrm{brt}, J=5.22 \mathrm{~Hz}, \mathrm{H}-11) ; 6.49(1 \mathrm{H}, \mathrm{d}, J=5.44 \mathrm{~Hz}, \mathrm{H}-3) ; 3.49$ $(2 \mathrm{H}, \mathrm{t}, J=6.74 \mathrm{~Hz}, \mathrm{H}-12) ; 3.51-3.31(2 \mathrm{H}, \mathrm{m}, \mathrm{H}-14) ; 1.92(2 \mathrm{H}, \mathrm{p}, \mathrm{H}-13) .{ }^{13} \mathrm{C}\left\{{ }^{1} \mathrm{H}\right\}$ NMR (101 MHz, DMSO-d $\left.\boldsymbol{d}_{6}\right): \delta(\mathrm{ppm})=151.88$ (C-2), 149.95 (C-4), 149.02 (C-9), 133.33 (C-7), 127.44 (C-8), 124.00 (C-5,6), 117.44 (C-10), 98.64 (C-3), 48.53 (C-14), 40.07 (C-12), 27.07 (C-13). IR (ATR): $\left(v_{\max } / \mathrm{cm}^{-1}\right) 3240\left(2^{\circ} \mathrm{N}-\mathrm{H}\right), 2957,2946,2872,2106(\mathrm{~N}=\mathrm{N}=\mathrm{N}), 1613,1576$ ( $\left.\operatorname{Ar} \mathrm{C}=\mathrm{N}\right)$. Melting point: $152.2-153.9^{\circ} \mathrm{C}$ (lit. $145.0-147.0^{\circ} \mathrm{C}$ ). 


\subsection{Synthesis of 7-chloro- $N-(3-(1 H-1,2,3-t$ triazol-1-yl)propyl)quinolin-4-amine ligands (6a-6e)}

\subsubsection{General method}

$\mathrm{N}$-(3-azidopropyl)-7-chloroquinolin-4-amine (5) and a commercial alkyne were dissolved in $t$ - $\mathrm{BuOH}(3.00 \mathrm{~mL})$. A freshly prepared solution of sodium ascorbate (0.6 eq.) and $\mathrm{CuSO}_{4} .5 \mathrm{H}_{2} \mathrm{O}$ ( 0.3 eq.) in water $(3.00 \mathrm{~mL}$ ) was then added to the reaction mixture. This was allowed to stir at $40{ }^{\circ} \mathrm{C}$ for $24-48 \mathrm{~h}$ and stopped when the reaction was complete, as shown by TLC analysis. The solvent was removed and the resulting residue was loaded onto silica and purified by column chromatography (100\% EtOAC with TEA). Pentane was then added to the eluted product, forming a precipitate which was then filtered via suction filtration to afford the pure solid compound.

\subsubsection{7-Chloro-N-(3-(4-phenyl-1H-1,2,3-triazol-1-yl)propyl)quinolin-4-amine ${ }^{5}$ (6a)}

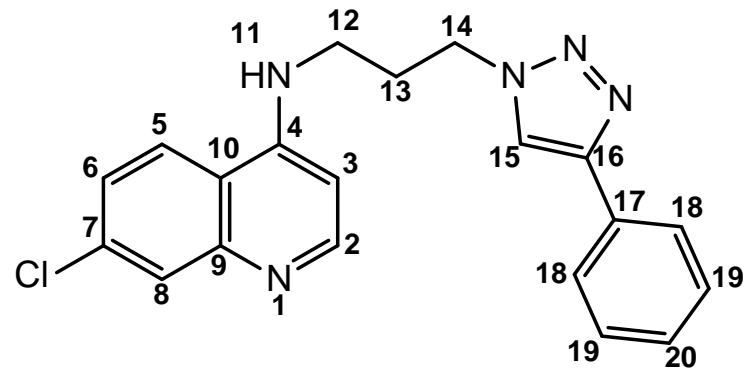

To a solution of $5(0.140 \mathrm{~g}, 0.535 \mathrm{mmol})$ and phenylacetylene $(0.118 \mathrm{~mL}, 1.07 \mathrm{mmol})$ in $t$ - $\mathrm{BuOH}(3.00 \mathrm{~mL})$, a solution of sodium ascorbate and $\mathrm{CuSO}_{2} .5 \mathrm{H}_{2} \mathrm{O}$ in water $(3.00 \mathrm{~mL})$ was added and the reaction mixture was left to stir for $24 \mathrm{~h}$ at $40{ }^{\circ} \mathrm{C}$. The product, $6 \mathrm{a}$, was isolated as a beige powder. Yield: $0.165 \mathrm{~g}(58.4 \%) .{ }^{1} \mathrm{H}$ NMR (400 MHz, DMSO-d $\left.\boldsymbol{d}_{6}\right): \delta(\mathrm{ppm})=8.59(1 \mathrm{H}$, s, H-15); $8.40(1 \mathrm{H}, \mathrm{d}, J=5.37 \mathrm{~Hz}, \mathrm{H}-2) ; 8.26(1 \mathrm{H}, \mathrm{d}, J=9.03 \mathrm{~Hz}, \mathrm{H}-5) ; 7.84-7.82(2 \mathrm{H}, \mathrm{m}, \mathrm{H}-18)$; $7.79(1 \mathrm{H}, \mathrm{d}, \mathrm{J}=2.17 \mathrm{~Hz}, \mathrm{H}-8)$; 7.50-7.39 (3H, m, H-6,19); 7.35-7.29 (2H, m, H-11,20); 6.48 (1H, d, $J=5.42 \mathrm{~Hz}, \mathrm{H}-3) ; 4.56(2 \mathrm{H}, \mathrm{t}, J=6.95 \mathrm{~Hz}, \mathrm{H}-14) ; 3.36(2 \mathrm{H}, \mathrm{q}, \mathrm{H}-12) ; 2.30(2 \mathrm{H}, \mathrm{p}, \mathrm{H}-13)$. ${ }^{13} \mathrm{C}\left\{{ }^{1} \mathrm{H}\right\}$ NMR (101 MHz, DMSO- $\left.\boldsymbol{d}_{6}\right): \delta(\mathrm{ppm})=151.85$ (C-2), 149.89 (C-4), 149.01 (C-9), 146.26 (C-16), 133.33 (C-7), 130.77 (C-17), 128.77 (C-18), 127.70 (C-20), 127.45 (C-8), 125.06 (C-19), 124.01 (C-6), 123.98 (C-5), 121.39 (C-15), 117.44 (C-10), 98.70 (C-3), 47.52 (C-14), 40.10 
(C-12), 28.31 (C-13). IR (ATR): $\left(v_{\max } / \mathrm{cm}^{-1}\right) 3324\left(2^{\circ} \mathrm{N}-\mathrm{H}\right), 2977,2945,2892,1611,1580$ (Ar C=N). Melting point: $>228^{\circ} \mathrm{C}$ dec. with melt (lit. $>250{ }^{\circ} \mathrm{C} \mathrm{dec}$.). Purity: $98.9 \%$ by LC ( $t_{R}$ $2.25 \mathrm{~min})$.

6.5.3 7-Chloro-N-(3-(4-(p-tolyl)-1H-1,2,3-triazol-1-yl)propyl)quinolin-4-amine (6b)<smiles>Clc1ccc(-c2cn(CCCNc3ccnc4cc(Cl)ccc34)nn2)cc1</smiles>

To a solution of $5(0.101 \mathrm{~g}, 0.386 \mathrm{mmol})$ and 4-ethynyltoluene $(0.0980 \mathrm{~mL}, 0.772 \mathrm{mmol})$ in $t$ - $\mathrm{BuOH}(3.00 \mathrm{~mL})$, a solution of sodium ascorbate and $\mathrm{CuSO}_{2} .5 \mathrm{H}_{2} \mathrm{O}$ in water $(3.00 \mathrm{~mL})$ was added and the reaction mixture was left to stir for $24 \mathrm{~h}$ at $40{ }^{\circ} \mathrm{C}$. The product, $6 \mathrm{~b}$, was isolated as a white crystalline powder. Yield: $0.0835 \mathrm{~g}(64.0 \%) .{ }^{1} \mathbf{H}$ NMR (400 MHz, DMSO- $\boldsymbol{d}_{6}$ ): $\delta$ (ppm) $=8.54(1 \mathrm{H}, \mathrm{s}, \mathrm{H}-15) ; 8.40(1 \mathrm{H}, \mathrm{d}, J=0.53 \mathrm{~Hz}, \mathrm{H}-2) ; 8.26(1 \mathrm{H}, \mathrm{d}, J=9.05 \mathrm{~Hz}, \mathrm{H}-5) ; 7.79(1 \mathrm{H}, \mathrm{d}$, $J=1.87 \mathrm{~Hz}, \mathrm{H}-8) ; 7.72-7.70(2 \mathrm{H}, \mathrm{m}, \mathrm{H}-18) ; 7.45(1 \mathrm{H}, \mathrm{dd}, J=2.10,8.98 \mathrm{~Hz}, \mathrm{H}-6) ; 7.35(1 \mathrm{H}, \mathrm{t}$, $J=5.26 \mathrm{~Hz}, \mathrm{H}-11) ; 7.25-7.23(2 \mathrm{H}, \mathrm{m}, \mathrm{H}-19) ; 6.48(1 \mathrm{H}, \mathrm{d}, J=5.35 \mathrm{~Hz}, \mathrm{H}-3) ; 4.55(2 \mathrm{H}, \mathrm{t}$, $J=6.97 \mathrm{~Hz}, \mathrm{H}-14) ; 3.35(2 \mathrm{H}, \mathrm{q}, \mathrm{H}-12) ; 2.33(3 \mathrm{H}, \mathrm{s}, \mathrm{H}-21) ; 2.29(2 \mathrm{H}, \mathrm{p}, \mathrm{H}-13) .{ }^{13} \mathrm{C}\left\{{ }^{1} \mathrm{H}\right\}$ NMR $(101 \mathrm{MHz}$, DMSO-d $): \delta(\mathrm{ppm})=151.83(\mathrm{C}-2), 149.96$ (C-4), 148.99 (C-9), 146.37 (C-16), 137.05 (C-17), 133.51 (C-7), 129.37 (C-19), 128.03 (C-20), 127.44 (C-8), 125.03 (C-19), 124.10 (C-6), 124.06 (C-5), 121.04 (C-15), 117.48 (C-10), 98.76 (C-3), 47.51 (C-14), 39.52 (C-12), 28.34 (C-13), 20.78 (C-21). IR (ATR): $\left(v_{\max } / \mathrm{cm}^{-1}\right) 3325\left(2^{\circ} \mathrm{N}-\mathrm{H}\right), 2977,2949,2892,1609,1581$ (Ar $\mathrm{C}=\mathrm{N})$. Melting point: $>240^{\circ} \mathrm{C}$ dec. with melt. Purity: $99.2 \%$ by LC $\left(t_{R} 2.33 \mathrm{~min}\right)$. 


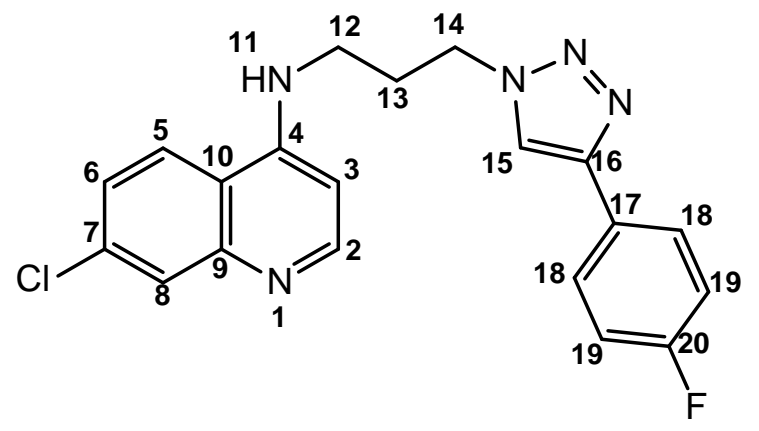

To a solution of $5(0.103 \mathrm{~g}, 0.535 \mathrm{mmol})$ and 1-ethynyl-4-fluorobenzene $(0.0944 \mathrm{~g}$, $0.786 \mathrm{mmol})$ in $t-\mathrm{BuOH}(3.00 \mathrm{~mL})$, a solution of sodium ascorbate and $\mathrm{CuSO}_{2} .5 \mathrm{H}_{2} \mathrm{O}$ in water $(3.00 \mathrm{~mL})$ was added and the reaction mixture was left to stir for $42 \mathrm{~h}$ at $40{ }^{\circ} \mathrm{C}$. The product, 6c, was isolated as a pale-yellow powder. Yield: $0.165 \mathrm{~g}$ (64.3\%). ${ }^{1} \mathbf{H}$ NMR (400 $\mathbf{~ M H z}$, DMSO- $\left.d_{6}\right): \delta(p p m)=8.58(1 \mathrm{H}, \mathrm{s}, \mathrm{H}-15) ; 8.39(1 \mathrm{H}, \mathrm{d}, J=5.36 \mathrm{~Hz}, \mathrm{H}-2) ; 8.25(1 \mathrm{H}, \mathrm{d}, J=9.04 \mathrm{~Hz}$, $\mathrm{H}-5)$; 7.87-7.78 (2H, m, H-18); $7.78(1 \mathrm{H}, \mathrm{d}, J=2.22 \mathrm{~Hz}, \mathrm{H}-8) ; 7.44(1 \mathrm{H}, \mathrm{dd}, J=2.26,8.98 \mathrm{~Hz}$, $\mathrm{H}-6)$; $7.35(1 \mathrm{H}, \mathrm{t}, J=5.25 \mathrm{~Hz}, \mathrm{H}-11)$; 7.30-7.26 (2H, m, H-19); $6.47(1 \mathrm{H}, \mathrm{d}, J=5.44 \mathrm{~Hz}, \mathrm{H}-3)$; $4.56(2 \mathrm{H}, \mathrm{t}, J=6.97 \mathrm{~Hz}, \mathrm{H}-14) ; 3.34(2 \mathrm{H}, \mathrm{q}, \mathrm{H}-12) ; 2.29(2 \mathrm{H}, \mathrm{p}, \mathrm{H}-13) .{ }^{13} \mathrm{C}\left\{{ }^{1} \mathrm{H}\right\}$ NMR (101 MHz, DMSO- $\left.d_{6}\right): \delta(p p m)=162.54$ (C-20), 160.92 (C-17), 151.87 (C-2), 149.98 (C-4), 148.98 (C-9), 145.46 (C-16), 133.43 (C-7), 127.44 (C-8), 127.11 (d, C-18), 124.12 (C-6), 124.06 (C-5), 121.40 (C-15), 117.47 (C-10), 115.88 (d, C-19), 98.76 (C-3), 47.62 (C-14), 39.52 (C-12), 28.33 (C-13). ${ }^{19} \mathrm{~F}\left\{{ }^{1} \mathrm{H}\right\}$ NMR (377 MHz, DMSO- $\left.\boldsymbol{d}_{6}\right): \delta(\mathrm{ppm})=-114.24$ (s). IR (ATR): $\left(v_{\max } / \mathrm{cm}^{-1}\right) 3337\left(2^{\circ} \mathrm{N}-\mathrm{H}\right)$, 2956, 2949, 2892, 1609, 1580 ( $\mathrm{Ar} \mathrm{C}=\mathrm{N}), 1227$ (C-F). Melting point: 230.0-232.9 ${ }^{\circ} \mathrm{C}$. Purity: $99.0 \%$ by LC ( $\left.t_{R} 2.27 \mathrm{~min}\right)$.

\subsubsection{7-Chloro-N-(3-(4-(pyridin-2-yl)-1H-1,2,3-triazol-1-yl)propyl)quinolin-4-amine (6d)}

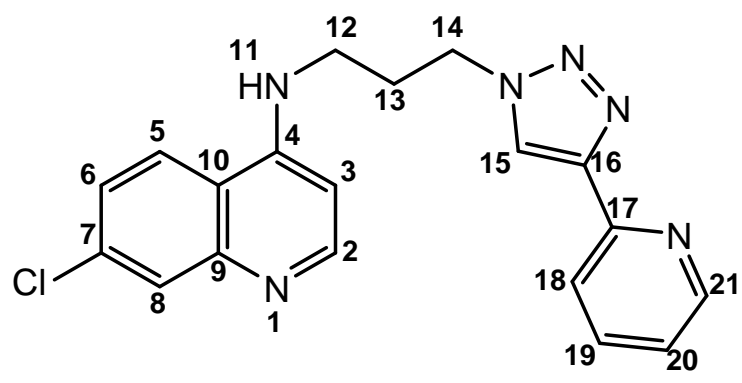

To a solution of $5(0.145 \mathrm{~g}, 0.554 \mathrm{mmol})$ and 2-ethynylpyridine $(0.0671 \mathrm{~mL}, 0.665 \mathrm{mmol})$ in $t$ - $\mathrm{BuOH}(3.00 \mathrm{~mL})$, a solution of sodium ascorbate and $\mathrm{CuSO}_{2} .5 \mathrm{H}_{2} \mathrm{O}$ in water $(3.00 \mathrm{~mL})$ was 
added and the reaction mixture was left to stir for $48 \mathrm{~h}$ at $40^{\circ} \mathrm{C}$. The product, $6 \mathrm{~d}$, was isolated as a beige powder. Yield: (0.116 g, 57.3\%). ${ }^{1} \mathrm{H}$ NMR (400 MHz, DMSO- $\left.\boldsymbol{d}_{6}\right): \delta(\mathrm{ppm})=8.67(1 \mathrm{H}$, s, H-15); 8.60-8.58 (1H, m, H-21); $8.39(1 \mathrm{H}, \mathrm{d}, J=5.40 \mathrm{~Hz}, \mathrm{H}-2) ; 8.25(1 \mathrm{H}, \mathrm{d}, J=9.05 \mathrm{~Hz}, \mathrm{H}-5)$; 8.03-8.01 (1H, m, H-18); $7.88(1 \mathrm{H}, \mathrm{td}, J=1.77,7.72,7.81 \mathrm{~Hz}, \mathrm{H}-19) ; 7.78(1 \mathrm{H}, \mathrm{d}, J=2.20 \mathrm{~Hz}$, $\mathrm{H}-8) ; 7.43(1 \mathrm{H}, \mathrm{dd}, \mathrm{J}=2.23,8.99 \mathrm{~Hz}, \mathrm{H}-6) ; 7.33(2 \mathrm{H}, \mathrm{ddd}, J=1.10,4.89,7.35 \mathrm{~Hz}, \mathrm{H}-11,20) ; 6.47$ $(1 \mathrm{H}, \mathrm{d}, J=5.46 \mathrm{~Hz}, \mathrm{H}-3) ; 4.59(2 \mathrm{H}, \mathrm{t}, J=6.88 \mathrm{~Hz}, \mathrm{H}-14) ; 3.36(2 \mathrm{H}, \mathrm{q}, \mathrm{H}-12) ; 2.30(2 \mathrm{H}, \mathrm{p}, \mathrm{H}-13)$. ${ }^{13} \mathrm{C}\left\{{ }^{1} \mathrm{H}\right\}$ NMR (101 MHz, DMSO-d $\left.\mathbf{d}_{6}\right): \delta(\mathrm{ppm})=151.76$ (C-2), 149.99 (C-4), $149.96(\mathrm{C}-21), 149.48$ (C-17), 148.88 (C-9), 147.20 (C-16), 137.05 (C-19), 133.34 (C-7), 127.34 (C-8), 124.03 (2C, C-5,6), 123.37 (C-15), 122.82 (C-20), 119.32 (C-18), 117.43 (C-10), 98.70 (C-3), 47.52 (C-14), 40.10 (C-12), 28.31 (C-13). IR (ATR): $\left(v_{\max } / \mathrm{cm}^{-1}\right) 3357$ ( $\left.2^{\circ} \mathrm{N}-\mathrm{H}\right), 2950,2895,1605$ (C=N) pyridyl, $1580(\mathrm{C}=\mathrm{N})_{\text {quinoline. }}$ Melting point: $183.5-185.2{ }^{\circ} \mathrm{C}$. Purity: $99.9 \%$ by $L C\left(t_{R} 2.04 \mathrm{~min}\right)$.

6.5.6 7-Chloro-N-(3-(4-(ferrocenyl)-1H-1,2,3-triazol-1-yl)propyl)quinolin-4-amine (6e)

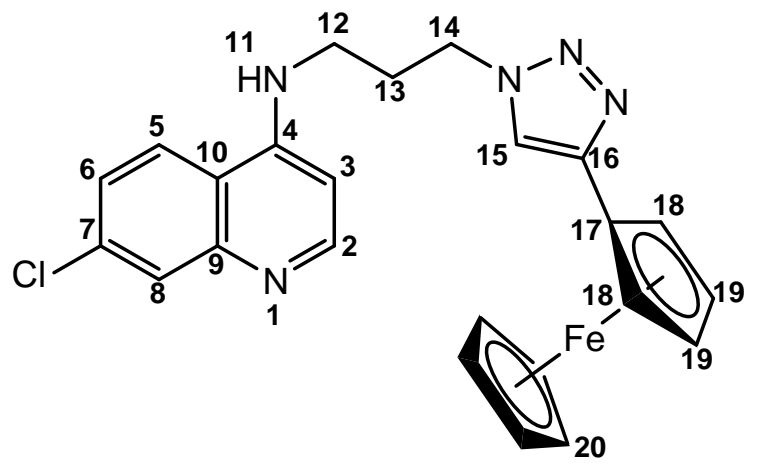

To a solution of $5(0.145 \mathrm{~g}, 0.554 \mathrm{mmol})$ and ethynylferrocene $(0.128 \mathrm{~g}, 0.609 \mathrm{mmol})$ in $t$ - $\mathrm{BuOH}(3.00 \mathrm{~mL})$, a solution of sodium ascorbate and $\mathrm{CuSO}_{2} .5 \mathrm{H}_{2} \mathrm{O}$ in water $(3.00 \mathrm{~mL})$ was added and the reaction mixture was left to stir for $27 \mathrm{~h}$ at $40^{\circ} \mathrm{C}$. The product, $6 \mathrm{e}$, was isolated as a yellow powder. Yield: $0.165 \mathrm{~g}(70.3 \%) .{ }^{1} \mathrm{H}$ NMR (400 MHz, DMSO- $\left.\boldsymbol{d}_{6}\right): \delta(p p m)=8.40(1 \mathrm{H}$, d, $J=5.35 \mathrm{~Hz}, \mathrm{H}-2) ; 8.28(1 \mathrm{H}, \mathrm{d}, J=9.06 \mathrm{~Hz}, \mathrm{H}-5) ; 8.20(1 \mathrm{H}, \mathrm{s}, \mathrm{H}-15) ; 7.79(1 \mathrm{H}, \mathrm{d}, J=2.22 \mathrm{~Hz}$, $\mathrm{H}-8) ; 7.46(1 \mathrm{H}, \mathrm{dd}, J=2.24,9.00 \mathrm{~Hz}, \mathrm{H}-6) ; 7.33(1 \mathrm{H}, \mathrm{t}, J=4.95 \mathrm{~Hz}, \mathrm{H}-11) ; 6.45(1 \mathrm{H}, \mathrm{d}$, $J=5.44 \mathrm{~Hz}, \mathrm{H}-3) ; 4.70(2 \mathrm{H}, \mathrm{t}, J=1.84 \mathrm{~Hz}, \mathrm{H}-18) ; 4.51(2 \mathrm{H}, \mathrm{t}, J=6.96 \mathrm{~Hz}, \mathrm{H}-14) ; 4.30(2 \mathrm{H}, \mathrm{t}$, $J=1.83 \mathrm{~Hz}, \mathrm{H}-19) ; 4.03(5 \mathrm{H}, \mathrm{s}, \mathrm{H}-20) ; 3.32(2 \mathrm{H}, \mathrm{q}, \mathrm{H}-12) ; 2.27(2 \mathrm{H}, \mathrm{p}, \mathrm{H}-13) .{ }^{13} \mathrm{C}\left\{{ }^{1} \mathrm{H}\right\}$ NMR (101 MHz, DMSO-d $\left.\boldsymbol{d}_{6}\right): \delta$ (ppm) = 151.83 (C-2), 149.91 (C-4), 149.01 (C-9), 145.17 (C-16), 133.34 (C-7), 127.45 (C-8), 124.03 (C-6), 124.00 (C-5), 120.55 (C-15), 117.44 (C-10), 98.62 (C-3), 76.03 (C-17), 69.12 (C-20), 68.10 (C-19), 66.23 (C-18), 47.27 (C-14), 39.52 (C-12), 28.35 (C-13). 
IR (ATR): $\left(v_{\max } / \mathrm{cm}^{-1}\right) 3296\left(2^{\circ} \mathrm{N}-\mathrm{H}\right), 3120,3084,2949,2924,1613,1575,1564$ (Ar C=N). Melting point: $173.9-175.4{ }^{\circ} \mathrm{C}$. MS (HR-ESI, m/z): $472.0997\left(100 \%,[\mathrm{M}+\mathrm{H}]^{+}\right)$, calculated 472.0986 .

\subsection{Synthesis of cyclometallated Ir(III) half-sandwich complexes (7a-7f)}

\subsubsection{General method}

A solution of the desired ligand (1 eq.), $[\operatorname{IrCp} *(\mu-\mathrm{Cl}) \mathrm{Cl}]_{2}(0.7$ eq.) and $\mathrm{NaOAc}(2$ eq.) was made in anhydrous ACN (20.0 mL). The reaction mixture was refluxed under argon at $65-75^{\circ} \mathrm{C}$ for 48-72 $\mathrm{h}$ and then left to stir at room temperature for a further $72 \mathrm{~h}$, after which a yellow precipitate formed. This precipitate was filtered and washed with ACN. The resulting yellow powder was dissolved in DCM and filtered through Celite ${ }^{\mathrm{TM}}$ to remove any excess NaOAc. The solvent was then reduced and $\mathrm{Et}_{2} \mathrm{O}$ was added to produce a yellow precipitate, which was then filtered and dried.

\subsubsection{Ir(III) triazole-phenyl complex (7a)}

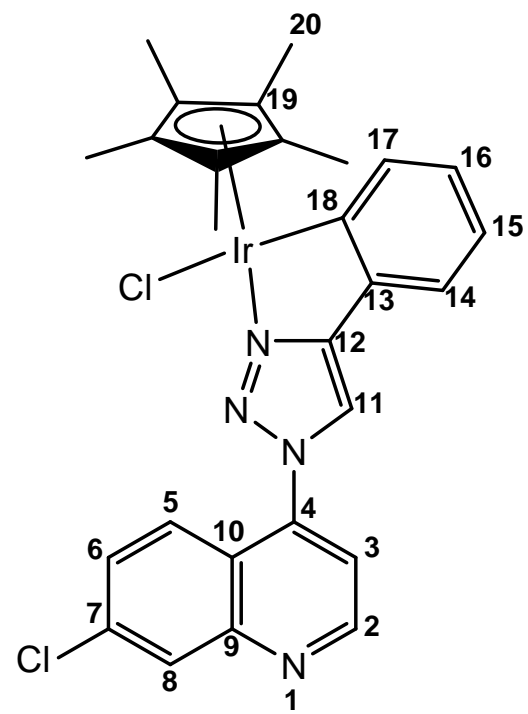

A solution of $2 \mathrm{a}(0.100 \mathrm{~g}, 0.326 \mathrm{mmol}),[\mathrm{IrCp} *(\mu-\mathrm{Cl}) \mathrm{Cl}]_{2}(0.182 \mathrm{~g}, 0.229 \mathrm{mmol})$ and $\mathrm{NaOAc}$ $(0.0535 \mathrm{~g}, 0.652 \mathrm{mmol})$ was made in anhydrous $\mathrm{ACN}(20.0 \mathrm{~mL})$ and refluxed under nitrogen for 72 h. Complex 7a was isolated as a yellow solid. Yield: $0.128 \mathrm{~g}(58.9 \%) .{ }^{1} \mathbf{H}$ NMR 
(400 MHz, CDCl 3$): \delta(p p m)=9.06(1 \mathrm{H}, \mathrm{d}, J=4.62 \mathrm{~Hz}, \mathrm{H}-2) ; 8.27(1 \mathrm{H}, \mathrm{d}, J=1.80 \mathrm{~Hz}, \mathrm{H}-8)$; 8.14-8.16 (2H, m, H-5,11); $7.79(1 \mathrm{H}, \mathrm{d}, J=7.55, \mathrm{H}-14)$; 7.65 (1H, dd, J = 1.97, $9.11 \mathrm{~Hz}, \mathrm{H}-6)$; $7.50(1 \mathrm{H}, \mathrm{d}, J=4.63 \mathrm{~Hz}, \mathrm{H}-3) ; 7.44(1 \mathrm{H}, \mathrm{d}, J=7.42 \mathrm{~Hz}, \mathrm{H}-17) ; 7.06(1 \mathrm{H}, \mathrm{t}, J=7.24 \mathrm{~Hz}, \mathrm{H}-15)$; $6.88(1 \mathrm{H}, \mathrm{t}, J=7.33 \mathrm{~Hz}, \mathrm{H}-16) ; 1.81(15 \mathrm{H}, \mathrm{s}, \mathrm{H}-20) .{ }^{13} \mathrm{C}\left\{{ }^{1} \mathrm{H}\right\}$ NMR (101 MHz, CDCl 3 ): 159.74 (C-12), 158.61 (C-18), 151.70 (C-2), 150.44 (C-9), 140.59 (C-7), 137.13 (C-4), 136.23 (C-14), 134.75 (C-13), 129.74 (br s, 2C, C-6,15), 129.29 (C-8), 124.77 (C-5), 122.72 (C-16), 122.27 (C-17), 120.28 (C-10), 118.66 (C-11), 116.02 (C-3), 89.00 (C-19), 9.25 (C-20). IR (ATR): $\left(v_{\max } / \mathrm{cm}^{-1}\right)$ 1611, 1586, $1560(\mathrm{Ar} \mathrm{C}=\mathrm{N})$. Melting point: $>280{ }^{\circ} \mathrm{C}$ dec. MS (HR-ESI, $\left.\mathrm{m} / \mathrm{z}\right)$ : $633.1409\left(100 \%,[\mathrm{M}-\mathrm{Cl}]^{+}\right)$, calculated 633.1397.

6.6.3 Ir(III) triazole-p-tolyl complex (7b)

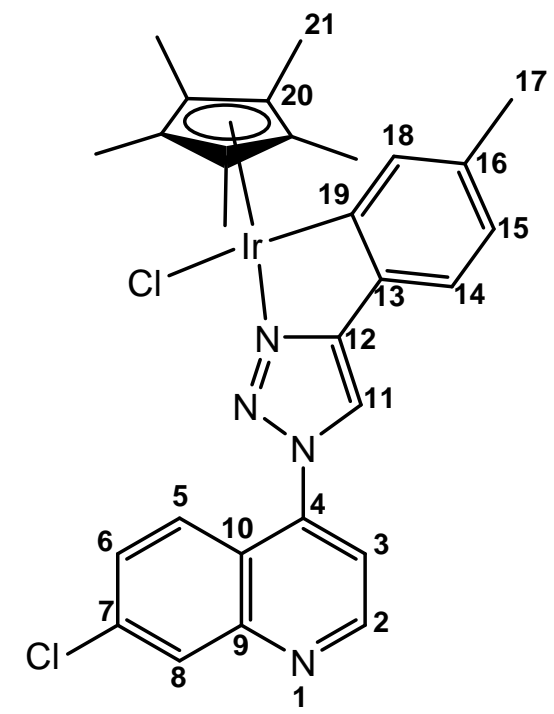

A solution of $\mathbf{2 b}(0.0700 \mathrm{~g}, 0.218 \mathrm{mmol}),[\operatorname{IrCp} *(\mu-\mathrm{Cl}) \mathrm{Cl}]_{2}(0.122 \mathrm{~g}, 0.153 \mathrm{mmol})$ and $\mathrm{NaOAC}$ $(0.0358 \mathrm{~g}, 0.436 \mathrm{mmol})$ was made in anhydrous $\mathrm{ACN}(20.0 \mathrm{~mL})$ and refluxed under nitrogen for $48 \mathrm{~h}$. Complex $\mathbf{7 b}$ was isolated as a yellow solid. Yield: $0.0481 \mathrm{~g}$, (32.3\%). ${ }^{\mathbf{H}} \mathbf{H} \mathbf{~ N M R}$ (400 MHz, $\left.\mathrm{CDCl}_{3}\right): \delta(\mathrm{ppm})=9.05(1 \mathrm{H}, \mathrm{d}, J=4.64 \mathrm{~Hz}, \mathrm{H}-2) ; 8.27(1 \mathrm{H}, \mathrm{d}, J=1.74 \mathrm{~Hz}, \mathrm{H}-8) ; 8.18$ $(1 \mathrm{H}, \mathrm{d}, J=9.12 \mathrm{~Hz}, \mathrm{H}-5) ; 8.10(1 \mathrm{H}, \mathrm{s}, \mathrm{H}-11) ; 7.65(1 \mathrm{H}, \mathrm{dd}, J=2.05,9.11 \mathrm{~Hz}, \mathrm{H}-6) ; 7.60(1 \mathrm{H}, \mathrm{s}$, $\mathrm{H}-18) ; 7.50(1 \mathrm{H}, \mathrm{d}, J=4.65 \mathrm{~Hz}, \mathrm{H}-3) ; 7.34(1 \mathrm{H}, \mathrm{d}, J=7.58 \mathrm{~Hz}, \mathrm{H}-14) ; 6.69(1 \mathrm{H}, \mathrm{d}, J=7.45 \mathrm{~Hz}$, $\mathrm{H}-15) ; 2.30$ (3H, s, H-17); 1.81 (15H, s, H-21). ${ }^{13} \mathrm{C}\left\{{ }^{1} \mathrm{H}\right\}$ NMR (101 MHz, CDCl $)$ : 159.68 (C-12), 158.64 (C-19), 151.67 (C-2), 150.46 (C-9), 140.65 (C-16), 139.29 (C-7), 137.11 (C-4), 136.98 (C-18), 132.01 (C-13), 129.70 (C-6), 129.27 (C-8), 124.88 (C-5), 123.74 (C-15), 121.98 (C-14), 
120.27 (C-10), 118.12 (C-11), 115.92 (C-3), 88.89 (C-20), 21.92 (C-17), 9.25 (C-21); IR (ATR): $\left(v_{\max } / \mathrm{cm}^{-1}\right)$ 1609, 1591, 1560 (Ar C=N). Melting point: $\left.>290^{\circ} \mathrm{C} \mathrm{dec.} \mathrm{MS} \mathrm{(HR-ESI,} \mathrm{m} / \mathrm{z}\right)$ : $647.1555\left(100 \%,[\mathrm{M}-\mathrm{Cl}]^{+}\right)$, calculated 647.1554 .

6.6.4 Ir(III) triazole-propylphenyl complex (7c)

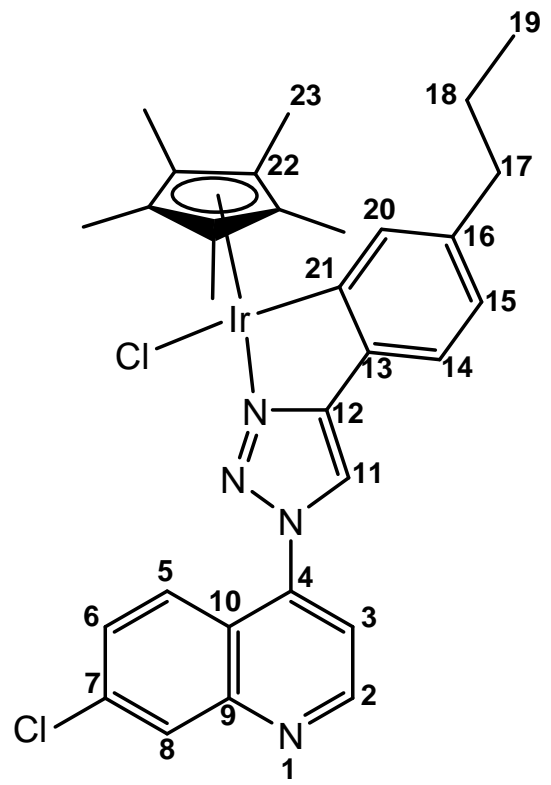

A solution of $2 \mathrm{c}(0.0510 \mathrm{~g}, 0.146 \mathrm{mmol}),[\mathrm{IrCp} *(\mu-\mathrm{Cl}) \mathrm{Cl}]_{2}(0.0815 \mathrm{~g}, 0.102 \mathrm{mmol})$ and $\mathrm{NaOAc}$ $(0.0359 \mathrm{~g}, 0.438 \mathrm{mmol})$ was made in anhydrous $\mathrm{ACN}(10.0 \mathrm{~mL})$ and refluxed under argon for 72 h. Complex 7c was isolated as a yellow solid. Yield: $0.0618 \mathrm{~g}$ (85.2\%). ${ }^{\mathbf{1}} \mathbf{H}$ NMR (400 MHz, $\left.\mathrm{CDCl}_{3}\right): \delta(\mathrm{ppm})=9.05(1 \mathrm{H}, \mathrm{d}, J=4.64 \mathrm{~Hz}, \mathrm{H}-2) ; 8.27(1 \mathrm{H}, \mathrm{d}, J=1.74 \mathrm{~Hz}, \mathrm{H}-8) ; 8.18$ $(1 \mathrm{H}, \mathrm{d}, J=9.12 \mathrm{~Hz}, \mathrm{H}-5) ; 8.10(1 \mathrm{H}, \mathrm{s}, \mathrm{H}-11) ; 7.65(1 \mathrm{H}, \mathrm{dd}, J=2.05,9.11 \mathrm{~Hz}, \mathrm{H}-6) ; 7.60(1 \mathrm{H}, \mathrm{s}$, $\mathrm{H}-20) ; 7.50(1 \mathrm{H}, \mathrm{d}, J=4.65 \mathrm{~Hz}, \mathrm{H}-3) ; 7.34(1 \mathrm{H}, \mathrm{d}, J=7.58 \mathrm{~Hz}, \mathrm{H}-14) ; 6.69(1 \mathrm{H}, \mathrm{d}, J=7.45 \mathrm{~Hz}$, $\mathrm{H}-15) ; 2.30(3 \mathrm{H}, \mathrm{s}, \mathrm{H}-17) ; 1.81(15 \mathrm{H}, \mathrm{s}, \mathrm{H}-21) ;{ }^{13} \mathrm{C}\left\{{ }^{1} \mathrm{H}\right\}$ NMR (101 MHz, CDCl 3 ): 159.59 (C-12), 158.69 (C-21), 151.66 (C-2), 150.42 (C-9), 143.98 (C-16), 140.68 (C-7), 137.12 (C-4), 136.45 (C-20), 132.24 (C-13), 129.71 (C-6), 129.24 (C-8), 124.88 (C-5), 123.17 (C-15), 122.00 (C-14), 120.31 (C-10), 118.16 (C-11), 115.96 (C-3), 88.90 (C-22), 38.56 (C-17) , 24.81 (C-18), 14.17 (C-19), 9.23 (C-23). IR (ATR): $\left(v_{\max } / \mathrm{cm}^{-1}\right)$ 2869, 2925, 2954, 1607, 1594, 1561 (Ar C=N). Melting point: > $283^{\circ} \mathrm{C}$ dec. MS (HR-ESI, m/z): 753.1960 (100\%, [M-Cl+DMSO] $\left.{ }^{+}\right)$, calculated 753.2005. 


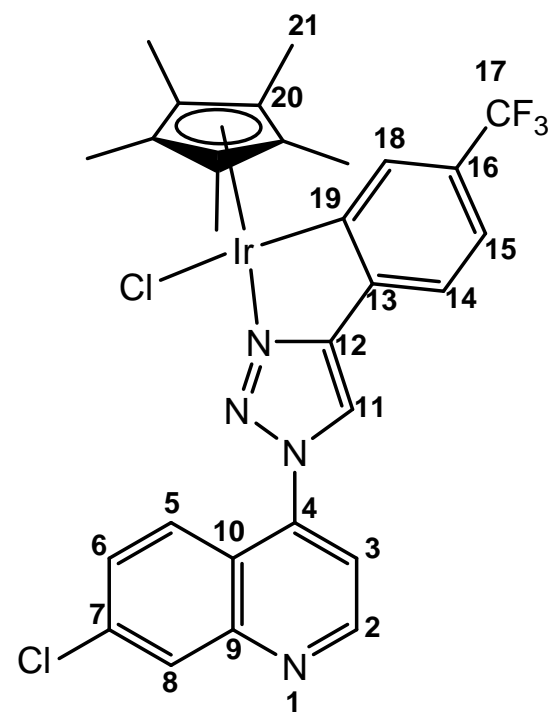

A solution of $2 \mathrm{~d}(0.050 \mathrm{~g}, 0.133 \mathrm{mmol}),[\operatorname{IrCp} *(\mu-\mathrm{Cl}) \mathrm{Cl}]_{2}(0.0744 \mathrm{~g}, 0.0934 \mathrm{mmol})$ and $\mathrm{NaOAC}$ $(0.0328 \mathrm{~g}, 0.400 \mathrm{mmol})$ was made in anhydrous $\mathrm{ACN}(10.0 \mathrm{~mL})$ and refluxed at $75{ }^{\circ} \mathrm{C}$ under argon for 72 h. Complex 7d was isolated as a yellow solid. Yield: $0.0121 \mathrm{~g}(12.3 \%) .{ }^{1} \mathbf{H}$ NMR $\left(400 \mathrm{MHz}, \mathrm{CDCl}_{3}\right): \delta(\mathrm{ppm})=9.09(1 \mathrm{H}, \mathrm{d}, J=4.65 \mathrm{~Hz}, \mathrm{H}-2), 8.29(1 \mathrm{H}, \mathrm{d}, J=2.02 \mathrm{~Hz}, \mathrm{H}-8), 8.22$ $(1 \mathrm{H}, \mathrm{s}, \mathrm{H}-11), 8.05(1 \mathrm{H}, \mathrm{d}, J=9.30 \mathrm{~Hz}, \mathrm{H}-5), 8.04(1 \mathrm{H}, \mathrm{s}, \mathrm{H}-18), 7.66(1 \mathrm{H}, \mathrm{dd}, J=2.09,9.11 \mathrm{~Hz}$, $\mathrm{H}-6)$, 7.51-7.58 (2H, m, H-3, 14), $7.20(1 \mathrm{H}, \mathrm{dd}, J=0.90,7.91 \mathrm{~Hz}, \mathrm{H}-15), 1.81(15 \mathrm{H}, \mathrm{s}, \mathrm{H}-21)$; ${ }^{13} \mathrm{C}\left\{{ }^{1} \mathrm{H}\right\}$ NMR (101 MHz, CDCl ${ }_{3}$ ): 160.21 (C-12), 157.68 (C-19), 151.57 (C-2), 150.57 (C-9), 140.61 (C-13), 138.27 (C-7), 137.48 (C-4), 132.60 (br q, ${ }^{3} \mathrm{C}_{\mathrm{C}-\mathrm{F}}=3.45 \mathrm{~Hz}, \mathrm{C}-18$ ), 130.62 (q, $\left.{ }^{2} J_{C-F}=30.75 \mathrm{~Hz}, \mathrm{C}-16\right), 130.10$ (C-6), 129.49 (C-8), 124.68 (q, $\left.{ }^{1} \mathrm{~J}_{\mathrm{C}-\mathrm{F}}=273.14 \mathrm{~Hz}, \mathrm{C}-17\right), 124.33$ (C-5), 122.00 (C-11), 120.41 (C-10), 119.79 (br q, $\left.{ }^{3} \mathrm{~J}_{\mathrm{C}-\mathrm{F}}=3.58 \mathrm{~Hz}, \mathrm{C}-15\right), 119.63$ (C-14), 116.21 (C-3), 89.45 (C-20), 30.28 (C-, 9.20 (C-21). ${ }^{19} \mathrm{~F}\left\{{ }^{1} \mathrm{H}\right\}$ NMR (377 MHz, CDCl 3 ): $\delta(p p m)=$ -62.13 (s). IR (ATR): $\left(v_{\max } / \mathrm{cm}^{-1}\right)$ 1618, 1606, 1595, 1560 (Ar C=N), 1314 (C-F stretch). Melting point: > $280^{\circ} \mathrm{C}$ dec. MS (HR-ESI, m/z): $779.1396\left(100 \%,[M-C l+D M S O]^{+}\right)$, calculated 779.1410. 


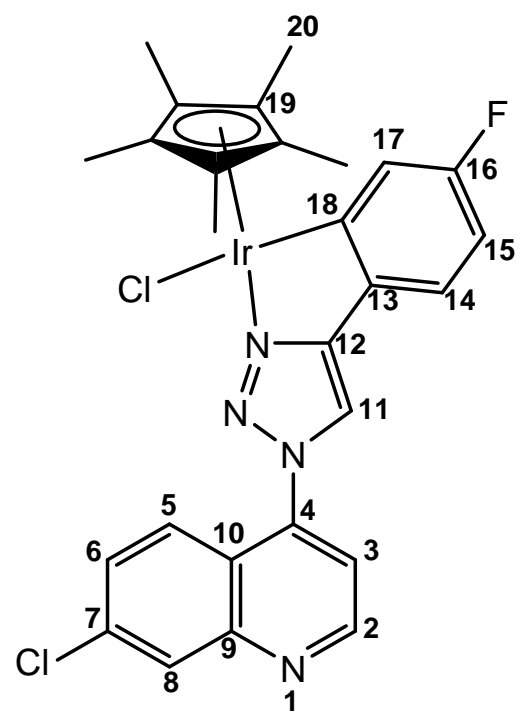

A solution of $2 \mathrm{e}(0.0762 \mathrm{~g}, 0.235 \mathrm{mmol}),[\operatorname{IrCp} *(\mu-\mathrm{Cl}) \mathrm{Cl}]_{2}(0.131 \mathrm{~g}, 0.164 \mathrm{mmol})$ and $\mathrm{NaOAC}$ $(0.0578 \mathrm{~g}, 0.704 \mathrm{mmol})$ was made in anhydrous ACN $(15.0 \mathrm{~mL})$ and refluxed at $65{ }^{\circ} \mathrm{C}$ under argon for $72 \mathrm{~h}$. Complex $7 \mathrm{e}$ was isolated as a yellow solid. Yield: $0.0336 \mathrm{~g}$ (29.8\%). ${ }^{\mathbf{H}} \mathbf{H}$ NMR $\left(400 \mathrm{MHz}, \mathrm{CDCl}_{3}\right): \delta(\mathrm{ppm})=9.08(1 \mathrm{H}, \mathrm{d}, J=4.65 \mathrm{~Hz}, \mathrm{H}-2), 8.28(1 \mathrm{H}, \mathrm{d}, J=2.07 \mathrm{~Hz}, \mathrm{H}-8), 8.10$ $(1 \mathrm{H}, \mathrm{d}, J=9.30 \mathrm{~Hz}, \mathrm{H}-5), 8.09(1 \mathrm{H}, \mathrm{s}, \mathrm{H}-11), 7.65(1 \mathrm{H}, \mathrm{dd}, J=2.12,9.12 \mathrm{~Hz}, \mathrm{H}-6), 7.52(1 \mathrm{H}, \mathrm{d}$, $J=4.65 \mathrm{~Hz}, \mathrm{H}-3), 7.52-7.43(2 \mathrm{H}, \mathrm{m}, \mathrm{H}-14,17), 6.63(1 \mathrm{H}, \mathrm{td}, J=2.36,8.64,8.80 \mathrm{~Hz}, \mathrm{H}-15), 1.81$ (15H, s, H-21). ${ }^{13} \mathrm{C}\left\{{ }^{1} \mathrm{H}\right\}$ NMR (101 MHz, CDCl $): 163.15$ (d, $\left.{ }^{1} J_{\mathrm{C}-\mathrm{F}}=251.43 \mathrm{~Hz}, \mathrm{C}-16\right), 162.86$ (d, $\left.{ }^{3} J_{C-F}=4.89 \mathrm{~Hz}, C-18\right), 157.81$ (C-12), 151.63 (C-2), 150.56 (C-9), 140.60 (C-7), 137.27 (C-13), 130.98 (C-4), 129.86 (C-6), 129.43 (C-8), 124.61 (C-5), 123.49 (d, ${ }^{3} \mathrm{~J}_{\mathrm{C}-\mathrm{F}}=8.68 \mathrm{~Hz}, \mathrm{C}-14$ ), 122.36 (d, $\left.{ }^{2} \mathrm{~J}_{\mathrm{C}-\mathrm{F}}=17.83 \mathrm{~Hz}, \mathrm{C}-17\right), 120.31$ (C-10), 118.34 (C-11), 116.01 (C-3), 109.77 (d, ${ }^{2} \mathrm{~J}_{\mathrm{C}-\mathrm{F}}=23.34$ $\mathrm{Hz}, \mathrm{C}-15), 89.22$ (C-19), 9.20 (C-20). ${ }^{19} \mathrm{~F}\left\{{ }^{1} \mathrm{H}\right\}$ NMR (377 MHz, CDCl $): \delta(\mathrm{ppm})=-112.15$ (s). IR (ATR): $\left(v_{\max } / \mathrm{cm}^{-1}\right) 1615,1590,1560$ (Ar C=N). Melting point: $>283^{\circ} \mathrm{C}$ dec. MS (HR-ESI, $m / z): 729.1418\left(100 \%,[\mathrm{M}-\mathrm{Cl}+\mathrm{DMSO}]^{+}\right)$, calculated 729.1442. 


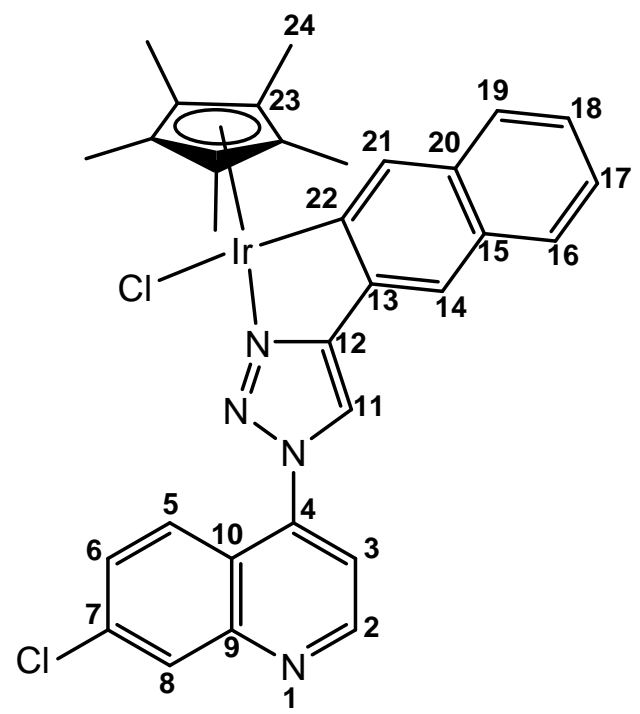

A solution of $2 \mathrm{f}(0.050 \mathrm{~g}, 0.140 \mathrm{mmol}),[\mathrm{IrCp} *(\mu-\mathrm{Cl}) \mathrm{Cl}]_{2}(0.0781 \mathrm{~g}, 0.0980 \mathrm{mmol})$ and $\mathrm{NaOAC}$ $(0.0345 \mathrm{~g}, 0.420 \mathrm{mmol})$ was made in anhydrous $\mathrm{ACN}(10.0 \mathrm{~mL})$ and refluxed at $75{ }^{\circ} \mathrm{C}$ under argon for 72 h. Complex $7 f$ was isolated as a yellow solid. Yield: $0.0100 \mathrm{~g}(9.9 \%) .{ }^{1} \mathbf{H}$ NMR $\left(400 \mathrm{MHz} \mathrm{CDCl}_{3}\right): \delta(\mathrm{ppm})=8.87(1 \mathrm{H}, \mathrm{d}, J=4.63 \mathrm{~Hz}, \mathrm{H}-2) ; 8.34(1 \mathrm{H}, \mathrm{s}, \mathrm{H}-11) ; 8.26(1 \mathrm{H}, \mathrm{d}$, $J=2.03 \mathrm{~Hz}) ; 8.16-8.13(2 \mathrm{H}, \mathrm{m}, \mathrm{H}-5,14) ; 8.14(1 \mathrm{H}, \mathrm{s}, \mathrm{H}-21) ; 7.73(1 \mathrm{H}, \mathrm{d}, J=8.43 \mathrm{~Hz}, \mathrm{H}-6)$; 7.74-7.61 (2H, m, H-16,19); $7.45(1 \mathrm{H}, \mathrm{d}, \mathrm{J}=4.69 \mathrm{~Hz}, \mathrm{H}-3)$; 7.37-7.32 (1H, m, H-17); 7.22-7.16 (1H, m, H-18); 1.85 (15H, s, H-24). IR (ATR): $\left(v_{\max } / \mathrm{cm}^{-1}\right)$ 3084, 2918, 1612, 1595, 1560 (Ar C=N). Melting point: $>280^{\circ} \mathrm{C}$ dec. MS (HR-ESI, $\left.m / z\right): 761.1661\left(100 \%,[M-C l+D M S O]^{+}\right)$, calculated 761.1693. 


\subsection{Synthesis of neutral monodentate $\operatorname{Ir}(I I I)$ half-sandwich complex (8)}

\subsubsection{Ir(III) monodentate triazole-phenyl complex (8)}

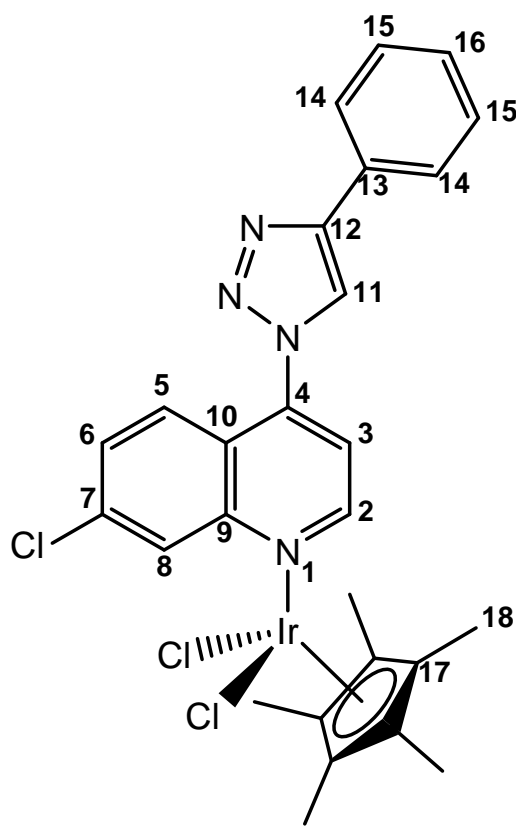

A solution of ligand $2 \mathrm{a}(0.0500 \mathrm{~g}, 0.163 \mathrm{mmol})$ and $[\operatorname{IrCp} *(\mu-\mathrm{Cl}) \mathrm{Cl}]_{2}(0.0649 \mathrm{~g}, 0.0815 \mathrm{mmol})$ was made in anhydrous $\mathrm{ACN}(10.0 \mathrm{~mL})$. The reaction mixture was stirred at room temperature under argon for $16 \mathrm{~h}$. A bright yellow precipitate formed, which was then filtered and washed with ACN, yielding complex 8 as a bright yellow powder. Yield: $0.0776 \mathrm{~g}$ (67.5 \%). ${ }^{1} \mathbf{H}$ NMR (300 MHz, $\left.\mathrm{CDCl}_{3}\right): \delta(\mathrm{ppm})=9.50(1 \mathrm{H}, \mathrm{br} \mathrm{s}, \mathrm{H}-2) ; 8.78(1 \mathrm{H}, \mathrm{br} \mathrm{s}, \mathrm{H}-8) ; 8.26(1 \mathrm{H}, \mathrm{s}, \mathrm{H}-11) ; 8.13$ $(1 \mathrm{H}, \mathrm{d}, J=9.09 \mathrm{~Hz}, \mathrm{H}-5) ; 7.98-7.95(2 \mathrm{H}, \mathrm{m}, \mathrm{H}-14) ; 7.63(1 \mathrm{H}, \mathrm{dd}, J=1.89,9.11 \mathrm{~Hz}, \mathrm{H}-6) ; 7.57$ $(1 \mathrm{H}, \mathrm{d}, J=5.13 \mathrm{~Hz}, \mathrm{H}-3) ; 7.53-7.48(2 \mathrm{H}, \mathrm{m}, \mathrm{H}-15)$; 7.45-7.40 (1H, m, H-16); $1.58(15 \mathrm{H}, \mathrm{s}, \mathrm{H}-18)$. ${ }^{13} \mathrm{C}\left\{{ }^{1} \mathrm{H}\right\}$ NMR (101 MHz, CDCl 3 ): $\delta(p p m)=154.48(\mathrm{C}-2), 149.67(\mathrm{C}-9), 148.77$ (C-12), 141.85 (C-7), 137.63 (C-4), 130.15 (C-8), 129.84 (C-6), 129.39 (C-13), 129.09 (C-15), 128.99 (C-16), 126.11 (C-14), 125.15 (C-5), 121.34 (C-11), 120.41 (C-10), 116.30 (C-3), 86.40 (C-17), 9.11 (C-18). IR (ATR): $\left(v_{\max } / \mathrm{cm}^{-1}\right) 1611,1560(\mathrm{C}=\mathrm{N})_{\text {quinoline. }}$ Melting point: $>235^{\circ} \mathrm{C}$ dec with melt.

\subsection{Synthesis of cationic $\operatorname{Ir}(I I))$ half-sandwich complexes $(7 g, 10)$}

\subsubsection{General method}

To a solution of the desired ligand (1 eq.) in DCM/EtOH $(1: 1,10 \mathrm{~mL})$, a solution of $[\operatorname{lrCp} *(\mu-\mathrm{Cl}) \mathrm{Cl}]_{2}$ (0.5 eq.) in $\mathrm{DCM} / \mathrm{EtOH}(1: 1,10 \mathrm{~mL})$ was added dropwise and the reaction 
mixture was left to stir at room temperature overnight under argon. After 20-23 $\mathrm{h}$, TLC analysis confirmed that there was no ligand left in the mixture. The resulting mixture was filtered through Celite ${ }^{\mathrm{TM}}$ and washed with minimal $\mathrm{DCM} / \mathrm{EtOH}$ mixture. $\mathrm{NH}_{4} \mathrm{PF}_{6}$ (4 eq.) was added to the solution, which was allowed to stir at room temperature under argon for $90 \mathrm{~min}$. The solvent was, thereafter, reduced to approximately $5.00 \mathrm{~mL}$, cooled rapidly in an ice bath and then put into the fridge for $2 \mathrm{~h}$. The precipitate was filtered, washed with cold EtOH and dried, yielding the desired product.

\subsubsection{Ir(III) N,N-chelated 7-chloroquinoline-triazole complex (7g)}

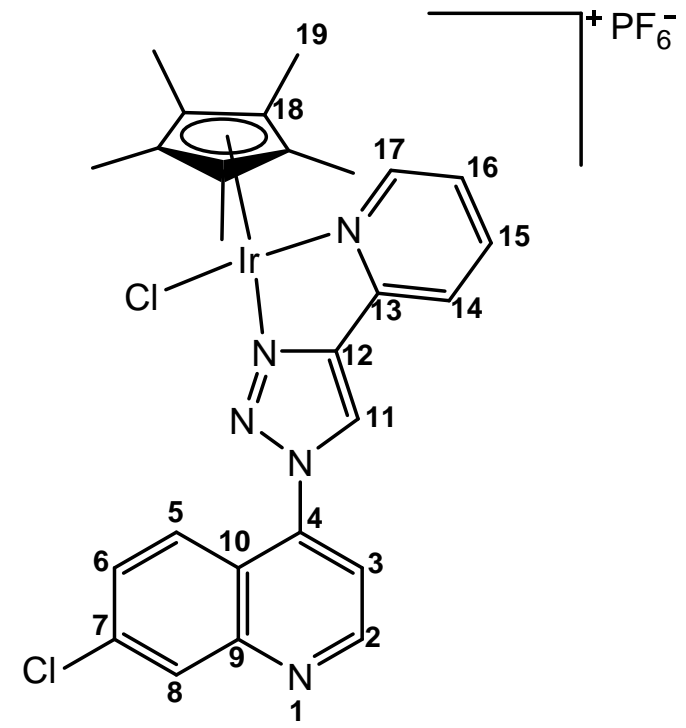

To a solution of $2 \mathrm{~g}(0.0300 \mathrm{~g}, 0.0975 \mathrm{mmol})$ in DCM/EtOH $(1: 1,10 \mathrm{~mL})$, a solution of $[\operatorname{IrCp} *(\mu-\mathrm{Cl}) \mathrm{Cl}]_{2}(0.0388 \mathrm{~g}, 0.0487 \mathrm{mmol})$ in DCM/EtOH $(1: 1,10 \mathrm{~mL})$ was added dropwise and the reaction mixture was left to stir at room temperature for $20 \mathrm{~h}$. $\mathrm{NH}_{4} \mathrm{PF}_{6}(0.0640 \mathrm{~g}$, $0.390 \mathrm{mmol}$ ) was added to the solution, yielding $7 \mathrm{~g}$ as a pale yellow solid. Yield: $0.0627 \mathrm{~g}$ (78.9\%). ${ }^{1}$ H NMR (400 MHz, DMSO-d $\left.d_{6}\right): \delta(p p m)=9.99(1 \mathrm{H}, \mathrm{s}, \mathrm{H}-11), 9.31(1 \mathrm{H}, \mathrm{d}, J=4.64 \mathrm{~Hz}$, H-2), $9.03(1 \mathrm{H}, \mathrm{d}, J=5.47 \mathrm{~Hz}, \mathrm{H}-17), 8.45(1 \mathrm{H}, \mathrm{d}, J=7.80 \mathrm{~Hz}, \mathrm{H}-14), 8.41(1 \mathrm{H}, \mathrm{d}, J=2.08 \mathrm{~Hz}$, $\mathrm{H}-8), 8.34-8.40(1 \mathrm{H}, \mathrm{m}, \mathrm{H}-15), 8.14(1 \mathrm{H}, \mathrm{d}, J=4.64 \mathrm{~Hz}, \mathrm{H}-3), 8.02(1 \mathrm{H}, \mathrm{d}, J=9.04 \mathrm{~Hz}, \mathrm{H}-5), 7.93$ $(1 \mathrm{H}, \mathrm{dd}, J=2.13,9.10 \mathrm{~Hz}, \mathrm{H}-6), 7.82(1 \mathrm{H}, \mathrm{ddd}, J=1.52,5.73,7.42 \mathrm{~Hz}, \mathrm{H}-16), 1.76(15 \mathrm{H}, \mathrm{s}$, $\mathrm{H}-19$ ); ${ }^{13} \mathrm{C}\left\{{ }^{1} \mathrm{H}\right\}$ NMR (101 MHz, DMSO-d $\left.\boldsymbol{d}_{6}\right): 152.47$ (C-2), 152.36 (C-17), 149.35 (C-9), 148.22 (C-13), 147.51 (C-12), 140.81 (C-15), 139.44 (C-7), 135.91 (C-4), 129.59 (C-6), 128.47 (C-11), 128.41 (C-8), 127.76 (C-16), 124.37 (C-5), 122.53 (C-14), 119.89 (C-10), 118.08 (C-3), 89.26 
(C-18), 8.34 (C-19). ${ }^{19} \mathrm{~F}\left\{{ }^{1} \mathrm{H}\right\}$ NMR (377 MHz, DMSO- $\left.d_{6}\right): \delta(p p m)=-70.19\left(\mathrm{~d},{ }^{1} \mathrm{~J}_{P-F}=-711.15 \mathrm{~Hz}\right)$. ${ }^{31} \mathrm{P}\left\{{ }^{1} \mathrm{H}\right\}$ NMR (162 MHz, DMSO- $\left.\boldsymbol{d}_{6}\right): \delta(\mathrm{ppm})=-144.17$ (sept., ${ }^{1} \mathrm{~J}_{F-P}=-711.19 \mathrm{~Hz}$ ). IR (ATR): $\left(v_{\max } / \mathrm{cm}^{-1}\right)$ 3470, 3145, 1630, 1614, 1594 (Ar C=N), 825 (P-F stretch). Melting point: 249.5-251.2 ${ }^{\circ} \mathrm{C}$ dec. MS (HR-ESI, $\left.m / z\right): 670.1107\left(100 \%,\left[M-P F_{6}\right]^{+}\right)$, calculated 670.1116.

\subsubsection{Ir(III) N,N-chelated 7-chloroquinoline-4-aminotriazole complex (10)}

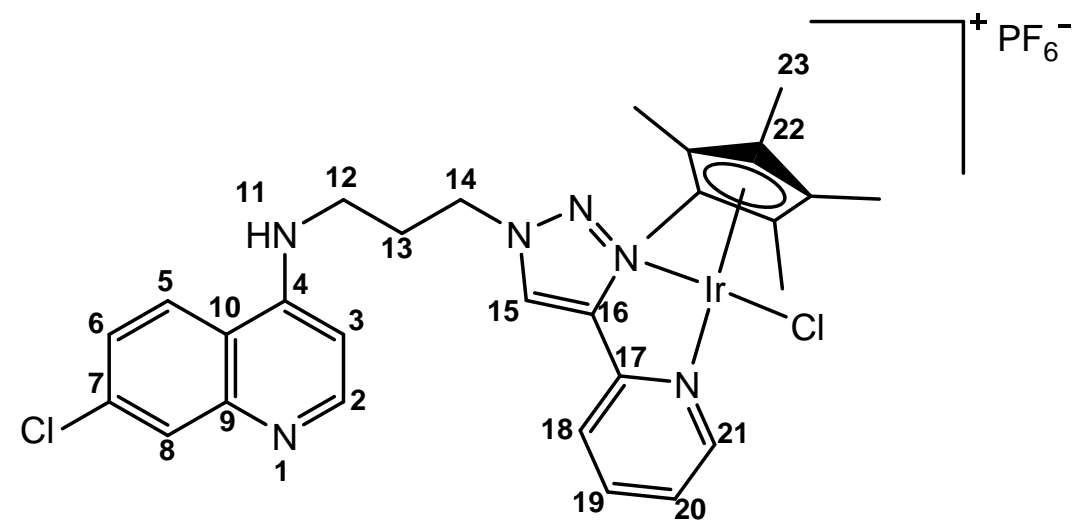

To a solution of $6 \mathrm{~g}(0.0500 \mathrm{~g}, 0.137 \mathrm{mmol})$ in DCM/EtOH $(1: 1,10 \mathrm{~mL})$, a solution of $[\operatorname{IrCp} *(\mu-\mathrm{Cl}) \mathrm{Cl}]_{2}(0.0546 \mathrm{~g}, 0.0685 \mathrm{mmol})$ in DCM/EtOH $(1: 1,10 \mathrm{~mL})$ was added dropwise and the reaction mixture was left to stir at room temperature for $23 \mathrm{~h}$. $\mathrm{NH}_{4} \mathrm{PF}_{6}(0.0893 \mathrm{~g}$, $0.548 \mathrm{mmol}$ ) was added to the solution, yielding 10 as a pale yellow solid. Yield: $0.0295 \mathrm{~g}$ (24.7\%). ${ }^{1}$ H NMR (400 MHz, DMSO-d $\left.)_{6}\right): \delta(p p m)=9.33(1 \mathrm{H}, \mathrm{s}, \mathrm{H}-15), 9.23$ (1H, br t, H-11); 8.93 $(1 \mathrm{H}, \mathrm{d}, J=5.60 \mathrm{~Hz}, \mathrm{H}-21) ; 8.57(1 \mathrm{H}, \mathrm{d}, J=6.92 \mathrm{~Hz}, \mathrm{H}-2) ; 8.53(1 \mathrm{H}, \mathrm{d}, J=9.15 \mathrm{~Hz}, \mathrm{H}-5) ; 8.31-8.27$ $(2 \mathrm{H}, \mathrm{m}, \mathrm{H}-18,19) ; 7.94(1 \mathrm{H}, \mathrm{d}, \mathrm{J}=2.09 \mathrm{~Hz}, \mathrm{H}-8) ; 7.76(1 \mathrm{H}, \mathrm{dd}, \mathrm{J}=2.08,9.07 \mathrm{~Hz}, \mathrm{H}-6) ; 7.72(1 \mathrm{H}$, ddd, $J=1.89,5.73,7.37 \mathrm{~Hz}, \mathrm{H}-20) ; 6.86(1 \mathrm{H}, \mathrm{d}, J=7.03 \mathrm{~Hz}, \mathrm{H}-3) ; 4.90-4.83(2 \mathrm{H}, \mathrm{m}, \mathrm{H}-14)$; 3.70-3.62 (2H, m, H-12); 2.50-2.38 (2H, m, H-13); $1.68(15 \mathrm{H}, \mathrm{s}, \mathrm{H}-23) .{ }^{13} \mathrm{C}\left\{{ }^{1} \mathrm{H}\right\}$ NMR (101 MHz,

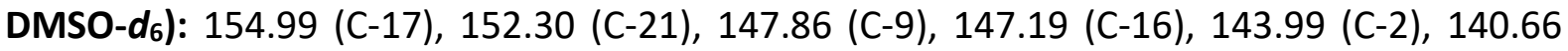
(C-19), 139.33 (C-7), 137.70 (C-4), 127.31 (C-20), 126.75 (C-6), 126.36 (C-15), 125.50 (C-5), 122.10 (C-18), 119.88 (C-8), 115.66 (C-10), 98.73 (C-3), 88.78 (C-22), 49.94 (C-14), 40.32 (C-12), 27.63 (C-13), 8.30 (C-23). ${ }^{19} \mathrm{~F}\left\{{ }^{1} \mathrm{H}\right\}$ NMR (377 MHz, DMSO- $\left.d_{6}\right): \delta(p p m)=-70.21(\mathrm{~d}$, $\left.{ }^{1} J_{P-F}=-711.11 \mathrm{~Hz}\right) .{ }^{31} \mathrm{P}\left\{{ }^{1} \mathrm{H}\right\}$ NMR $\left(162 \mathrm{MHz}\right.$, DMSO-d $\left.\boldsymbol{d}_{6}\right): \delta$ (ppm) = -144.18 (sept., $\left.{ }^{1} J_{F-P}=-711.15 \mathrm{~Hz}\right)$. IR (ATR): $\left(v_{\max } / \mathrm{cm}^{-1}\right) 3631\left(2^{\circ} \mathrm{N}-\mathrm{H}\right), 1615(\mathrm{C}=\mathrm{N})_{\text {pyridyl, }} 1590(\mathrm{C}=\mathrm{N})_{\text {quinoline, }} 828$ (P-F stretch). Melting point: $>200{ }^{\circ} \mathrm{C}$ dec. MS (HR-ESI, m/z): $727.1658\left(100 \%,\left[M-P F_{6}\right]^{+}\right)$, calculated 727.1694. 


\subsection{X-ray Crystallography Method}

Suitable single crystals of complexes $\mathbf{7 a}$ and $\mathbf{8}$ were grown from the slow diffusion of diethyl ether into a concentrated dichloromethane solution. Single-crystal X-ray diffraction data were collected on a Bruker KAPPA APEX II DUO diffractometer using graphite-monochromated Mo-K $\alpha$ radiation $(\chi=0.71073 \AA$ ). Data collection was carried out at $173(2) \mathrm{K}$. The temperature was controlled by an Oxford Cryostream cooling system (Oxford Cryostat). Cell refinement and data reduction were performed using the program SAINT ${ }^{6}$. The data were scaled and absorption correction performed using SADABS ${ }^{7}$.

The structure was solved by direct methods using SHELXS- $97^{7}$ and refined by full-matrix leastsquares methods based on $\mathrm{F}^{2}$ using SHELXL-2018 ${ }^{7}$ and using the graphics interface program X-Seed..$^{8,9}$ The programs X-Seed and POV-Ray were used to prepare molecular graphic images.

All non-hydrogen atoms were refined anisotropically. All hydrogen atoms were placed in idealised positions and refined in riding models with $U_{\text {iso }}$ assigned 1.2 or 1.5 times $U_{\text {eq }}$ of their parent atoms and the bond distances were constrained to 0.95 and $0.98 \AA$.

\subsection{Biological methods}

\subsubsection{In vitro antiplasmodial assay}

The test samples were tested in triplicate on one or two separate occasions against the chloroquine-sensitive (NF54) and chloroquine-resistant (K1) strains of $P$. falciparum. Continuous in vitro cultures of asexual erythrocyte stages of $P$. falciparum were maintained using a modified method of Trager and Jensen. ${ }^{10}$ Quantitative assessment of antiplasmodial activity in vitro was determined via the parasite lactate dehydrogenase assay using a modified method described by Makler. ${ }^{11}$ The test samples were prepared to a $20 \mathrm{mg} / \mathrm{mL}$ or a $2 \mathrm{mg} / \mathrm{mL}$ stock solution in $100 \%$ DMSO. Samples were tested as a suspension if not completely dissolved. Stock solutions were stored at $-20^{\circ} \mathrm{C}$. Further dilutions were prepared on the day of the experiment. Chloroquine (CQ) was used as the reference drug in all experiments. A full dose-response was performed for all compounds to determine the concentration inhibiting $50 \%$ of parasite growth ( $\mathrm{IC}_{50}$ value). Test samples were tested at a starting concentration of 
$10 \mu \mathrm{g} / \mathrm{mL}$ or $100 \mu \mathrm{g} / \mathrm{mL}$, which was then serially diluted 2-fold in complete medium to give 10 concentrations, with the lowest concentration being $0.02 \mu \mathrm{g} / \mathrm{mL}$ or $0.2 \mu \mathrm{g} / \mathrm{mL}$ respectively. The same dilution technique was used for all samples. The $\mathrm{IC}_{50}$ values were obtained using a non-linear dose response curve fitting analysis via Graph Pad Prism v.5.0 software.

\subsubsection{Cytotoxicity assay}

Compounds were tested for in vitro cytotoxicity against the mammalian, Chinese Hamster Ovarian (CHO) cell-line using the MTT (3-(4,5-dimethylthiazol-2-yl)-2,5diphenyltetrazoliumbromide) assay. The MTT assay is used as a colorimetric assay for cellular growth and survival and compares well with other available assays. The $\mathrm{CHO}$ cell line was cultured in sterile flasks containing 10\% foetal calf serum, 45\% DMEM and 45\% HAMS F-12 medium in an environment of $5 \% \mathrm{CO}_{2}$ at $37{ }^{\circ} \mathrm{C}$. The cell monolayers were detached with trypsin then resuspended with $5 \mathrm{~mL}$ culture medium. The number of cells were counted with crystal violet dye on a counting chamber to achieve a concentration of $10^{5} \mathrm{cells} / \mathrm{mL}$. Cells were distributed in flat-bottomed 96 -well plates and incubated at $37^{\circ} \mathrm{C}$ for $24 \mathrm{~h}$ for attachment.

The test samples were tested in triplicate on one occasion. The test samples were prepared to a $2 \mathrm{mg} / \mathrm{mL}$ stock solution in $10 \% \mathrm{MeOH}$ or $10 \%$ DMSO and were tested as a suspension if not completely dissolved. Test compounds were stored at $-20^{\circ} \mathrm{C}$ until use. Emetine was used as the reference drug in all experiments. The initial concentration of emetine was $100 \mu \mathrm{g} / \mathrm{mL}$, which was serially diluted in complete medium with 10-fold dilutions to give 6 concentrations, the lowest being $0.001 \mu \mathrm{g} / \mathrm{mL}$. The same dilution technique was applied to all the test samples. The highest concentration of solvent to which the cells were exposed had no measurable effect on cell viability. After $48 \mathrm{~h}$, an aliquot of $25 \mu \mathrm{L} \mathrm{MTT}$ was added to each well and plates were incubated at $37^{\circ} \mathrm{C}$ for $4 \mathrm{~h}$. Dimethyl sulfoxide (DMSO) was used to dissolve the MTT crystals. The plates were read at $570 \mathrm{~nm}$ with a Modulus ${ }^{\mathrm{TM}}$ microplate fluorometer. The $\mathrm{IC}_{50}$ values were obtained from plotting non-linear dose-response curves using Graph Pad Prism v.5.0 software. 


\subsubsection{In vitro speed of action assay}

A modified IC 50 speed assay was followed in order to categorize $\operatorname{Ir}(I I I)$ complexes $7 a, 7 e$ and $7 \mathrm{~g}$ as either slow-acting or fast-acting compounds. ${ }^{12} \mathrm{~A}$ synchronized, chloroquine-sensitive (NF54) strain of $P$. falciparum in ring phase at $2 \%$ haematocrit with $2 \%$ parasitemia was used to conduct this experiment. Four 96-well plates were set up as described in section 6.10.1 for one biological replicate. A diagram of the set-up for each 96-well plate is shown in Figure 6.1. The highest testing concentrations for $7 \mathrm{a}$ and $7 \mathrm{~g}$ (column 2; Figure 6.1) was $5000 \mathrm{ng} / \mathrm{mL}$ and $10000 \mathrm{ng} / \mathrm{mL}$ for 7e (column 7; Figure 6.1). Chloroquine (CQ), artemisinin (ART) and ferroquine (FQ) were used as the controls. The blank (column 1, Figure 6.1) contained $100 \mu \mathrm{L}$ complete medium and $100 \mu \mathrm{L} 2 \%$ haematocrit. A serial dilution was performed from column 2 to 6 and from column 7 to 12 . Columns 2 and 7 had the highest concentration of drugs while the lowest concentrations were in columns 6 and 12. Each plate represented a drug exposure time-point of $10,24,48$ or $72 \mathrm{~h}$. At each time-point, the corresponding plate was removed and the antimalarial compounds and controls were aspirated. Fresh complete medium $(200 \mu \mathrm{L})$ was, thereafter, added to each well. All four plates were incubated at $37^{\circ} \mathrm{C}$ for a total of $72 \mathrm{~h}$.

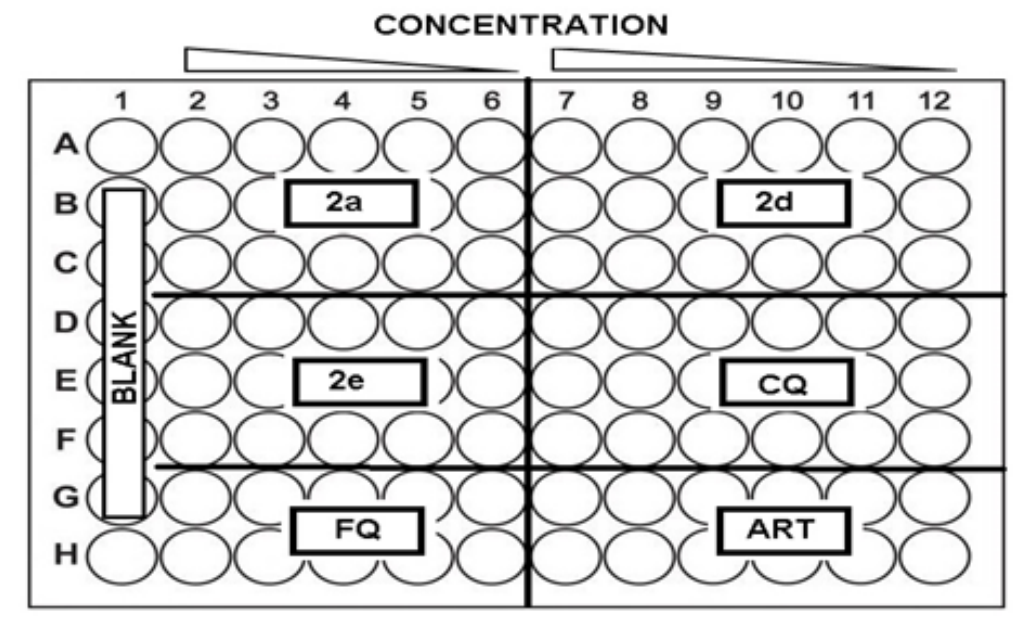

Figure 6.1. Diagram of the plate set-up foreach 96 -well plate used in the $I C_{50}$ speed assay, with a total volume of $200 \mu \mathrm{L}$ in each well.

After $72 \mathrm{~h}$, the parasite viability was assessed using a SYBR-green flow cytometry-based method. All the plates were removed, resuspended and the contents of each transferred to separate round-bottom plates, which were then centrifuged at $750 \mathrm{rpm}$ for $5 \mathrm{~min}$. The 
complete medium was then aspirated and the parasites were washed twice with $100 \mu \mathrm{L}$ filtered PBS. A SYBR-green solution was made up by adding $1.00 \mu \mathrm{L}$ SYBR-green into $10.0 \mathrm{~mL}$ of filtered PBS and, thereafter, $100 \mu \mathrm{L}$ of this SYBR-green solution was added to each plate. The plates were then covered with foil and incubated at $37^{\circ} \mathrm{C}$ for 1 hour. After incubation, a BD CSampler ${ }^{\mathrm{TM}}$ Plus Flow Cytometer was used to run these plates, with each well being run for 10 seconds on medium flow rate with one agitation every 12 wells in a cycle. The $I C_{50}$ values obtained from each plate were then calculated as ratios relative to the $\mathrm{IC}_{50}$ value at $72 \mathrm{~h}$. The following formula, with $72 \mathrm{~h}$ being the baseline $\mathrm{IC}_{50}$ value for each drug, was used:

$$
\mathrm{IC}_{50} \text { of } 10 \text { or } 24 \text { or } 48 \mathrm{~h} / \mathrm{IC}_{50} \text { of } 72 \mathrm{~h}=\mathrm{IC}_{50} \text { relative to } 72 \mathrm{~h}
$$

\subsection{4 $\beta$-Haematin inhibition assay}

The $\beta$-haematin formation assay was modified from the method described by Sandlin et al. ${ }^{13}$ The test compounds were prepared as $10 \mathrm{mM}$ stock solutions in DMSO. The compounds were delivered to a 96-well plate in triplicate and were tested at a starting concentration of $1000 \mu \mathrm{M}$, where the lowest drug concentration was $1 \mu \mathrm{M}$. The stock solution was serially diluted to give 11 concentrations in the 96-well flat-bottom assay plate. NP-40 detergent was then added to mediate the formation of $\beta$-haematin (30.55 $\mu \mathrm{M}$, final concentration). A $25 \mathrm{mM}$ stock solution of haematin was prepared by dissolving hemin (16.3 $\mathrm{mg}$ ) in DMSO (1.00 mL). A $178 \mu \mathrm{L}$ aliquot of haematin stock was suspended in $20 \mathrm{~mL}$ of a $2 \mathrm{M}$ acetate buffer, $\mathrm{pH}$ 4.7. The haematin suspension was then added to the plate to give a final haematin concentration of $100 \mu \mathrm{M}$. The plate was then incubated for $16 \mathrm{~h}$ at $37^{\circ} \mathrm{C}$. The compounds were analysed using the pyridine-ferrochrome method developed by Ncokazi and Egan. ${ }^{14}$ $32 \mu \mathrm{L}$ of a solution of $50 \%$ pyridine, $20 \%$ acetone, $20 \%$ water, and $10 \% 2 \mathrm{M}$ HEPES buffer $(\mathrm{pH}$ 7.4) was added to each well. To this, $60 \mu \mathrm{L}$ acetone was then added to each well and mixed. The UV-Vis absorbance of the resulting complex was measured at $405 \mathrm{~nm}$ on a SpectraMax $340 \mathrm{PC}$ plate reader. The $\mathrm{IC}_{50}$ values were obtained using a non-linear doseresponse curve fitting analysis via Graph Pad Prism v.5.0 software. 


\subsection{Transfer hydrogenation methods}

\subsubsection{Method for qualitative ${ }^{1} H$ NMR spectroscopy study}

Approximately $6.00 \mathrm{mg}$ of the complex, $20.0 \mathrm{mg}$ of $\mathrm{NAD}^{+}$and $40.0 \mathrm{mg}$ of sodium formate were weighed. The $\mathrm{NAD}^{+}$was dissolved in $600 \mu \mathrm{L}$ of $\mathrm{D}_{2} \mathrm{O}$ and the sodium formate in $600 \mu \mathrm{L}$ of MeOD, with sonication to aid in dissolving. The complex was then suspended in a mixture of $100 \mu \mathrm{L}$ of the sodium formate solution and $300 \mu \mathrm{L}$ of the $\mathrm{NAD}^{+}$solution. To this, $300 \mu \mathrm{L}$ of MeOD was added. The suspension was then mixed well and any solid matter that remained was filtered off. The solution was then added to an NMR tube. The ${ }^{1} \mathrm{H}$ NMR spectrum was recorded prior to incubation at $37^{\circ} \mathrm{C}$. The tube was then incubated at $37^{\circ} \mathrm{C}$ and the spectra recorded at various time intervals thereafter.

\subsubsection{Method for cell-free assay to detect transfer hydrogenation of $N A D^{+}$to $N A D H$}

Solutions were made up as follows:

- A $50.0 \mathrm{~mL}$ solution containing $\mathrm{NAD}^{+}$at $\mathrm{pH} 7.4$ was prepared as follows: Sodium formate $(0.310 \mathrm{~g}, 4.56 \mathrm{mmol})$, trizma base $(0.330 \mathrm{~g}, 2.72 \mathrm{mmol})$ and $\mathrm{NAD}^{+}(5.50 \mathrm{mg}$, $0.00829 \mathrm{mmol}$ ) were dissolved in $25.0 \mathrm{~mL}$ of distilled water. The $\mathrm{pH}$ was then adjusted to 7.4 using $\mathrm{HCl}$. The volume was made up to $50.0 \mathrm{~mL}$ with distilled water.

- The tetrazolium solution (NBT) was made up using nitroblue tetrazolium (NBT) ( $80.0 \mathrm{mg}, 0.0978 \mathrm{mmol}$ ) and phenazine ethosulfate $(4.00 \mathrm{mg}, 0.0120 \mathrm{mmol})$ in $50.0 \mathrm{~mL}$ distilled water.

\section{Plate set-up:}

$6 \mathrm{mM}$ Stocks of each complex were prepared in DMSO (to $1.00 \mathrm{~mL}$ ). In a 96-well plate (labelled plate 1), $200 \mu \mathrm{L}$ of the drug solution was added to column 3 in triplicate. $100 \mu \mathrm{L}$ of DMSO was added to each well from column 4 to column 12 . The compounds were serially diluted giving 10 concentrations. $75.0 \mu \mathrm{L}$ of the solution from each well was transferred into a second 96-well plate (labelled plate 2) into the corresponding well (eg. $75.0 \mu \mathrm{L} \mathrm{C1}$ of plate 1 into C1 of plate 2 etc). $100 \mu \mathrm{L}$ of the $\mathrm{NAD}^{+}$solution was then added to each well. In column $1,75.0 \mu \mathrm{L}$ DMSO and $100 \mu \mathrm{LAD}^{+}$solution were added to each well only. In column 2, $175 \mu \mathrm{L}$ DMSO 
was added to each well only. The plate was read at $600 \mathrm{~nm}$ to account for the absorbance of the compounds (pre-read). The plate was then covered with a foil plate cover to prevent evaporation and was incubated for $6-8 \mathrm{~h}$ at $37^{\circ} \mathrm{C}$. After this time, $25.0 \mu \mathrm{L}$ of the NBT solution was added and the plate incubated for a further $24 \mathrm{~h}$ to aid plate developing. After this time, the absorbance was read at $600 \mathrm{~nm}$ again, the data from the pre-read accounted for and the data plotted using Graph Pad Prism v.5.0 at the various concentrations ( $2250 \mu \mathrm{M}$ to $4 \mu \mathrm{M}$ ).

\subsection{References}

1 J. W. Kang, K. Moseley and P. M. Maitiis, J. Am. Chem. Soc., 1969, 91, 5970-5977.

2 E. M. Guantai, K. Ncokazi, T. J. Egan, J. Gut, P. J. Rosenthal, P. J. Smith and K. Chibale, Bioorg. Med. Chem., 2010, 18, 8243-8256.

3 G. R. Pereira, G. C. Brandão, L. M. Arantes, H. A. De Oliveira, R. C. De Paula, M. F. A. Do Nascimento, F. M. Dos Santos, R. K. Da Rocha, J. C. D. Lopes and A. B. De Oliveira, Eur. J. Med. Chem., 2014, 73, 295-309.

4 K. Starčević, D. Pešić, A. Toplak, G. Landek, S. Alihodžić, E. Herreros, S. Ferrer, R. Spaventi and M. Perić, Eur. J. Med. Chem., 2012, 49, 365-378.

5 G. M. Fisher, R. P. Tanpure, A. Douchez, K. T. Andrews and S. A. Poulsen, Chem. Biol. Drug Des., 2014, 84, 462-472.

$6 \quad$ SAINT Version 7.60a, Bruker AXS Inc., Madison, WI, USA, 2006.

7 G. M. Sheldrick, SHELXS-97, SHELXL-2014 and SADABS version 2.05, University of Göttingen, Germany, 2004.

8 L. J. Barbour, J. Supramol. Chem., 2001, 1, 189-191.

9 J. L. Atwood and L. J. Barbour, Cryst. Growth Des., 2003, 3, 3-8.

10 W. Trager and J. Jensen, Science, 1976, 193, 673-675.

11 M. T. Makler and D. J. Hinrichs, Am. J. Trop. Med. Hyg., 1993, 48, 205-210. 
12 C. Le Manach, C. Scheurer, S. Sax, S. Schleiferböck, D. Cabrera, Y. Younis, T. Paquet, L. Street, P. Smith, X. C. Ding, D. Waterson, M. J. Witty, D. Leroy, K. Chibale and S. Wittlin, Malar. J., 2013, 12, 424.

13 R. D. Sandlin, M. D. Carter, P. J. Lee, J. M. Auschwitz, S. E. Leed, J. D. Johnson and D. W. Wright, Antimicrob. Agents Chemother., 2011, 55, 3363-3369.

14 K. K. Ncokazi and T. J. Egan, Anal. Biochem., 2005, 338, 306-319. 